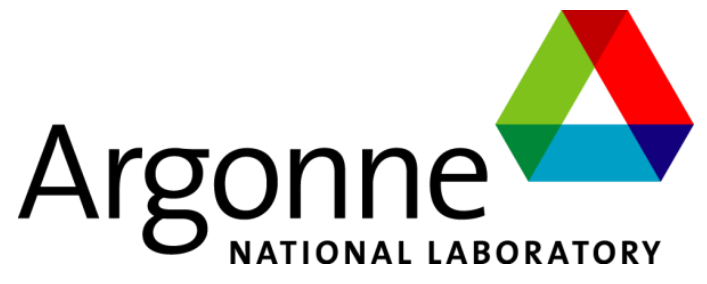

ANL-21/20

NATIONAL LABORATORY

\title{
Computational Analysis of Hydraulic Capacity of Ohio DOT Catch Basins On-Grade and in Sag Locations
}

Nuclear Science and Engineering Division 


\section{About Argonne National Laboratory}

Argonne is a U.S. Department of Energy laboratory managed by UChicago Argonne, LLC under contract DE-AC02-06CH11357. The Laboratory's main facility is outside Chicago, at 9700 South Cass Avenue, Argonne, Illinois 60439. For information about Argonne and its pioneering science and technology programs, see www.anl.gov.

\section{DOCUMENT AVAILABILITY}

Online Access: U.S. Department of Energy (DOE) reports produced after 1991 and a growing number of pre-1991 documents are available free at OSTI.GOV

(http://www.osti.gov/), a service of the U.S. Dept. of Energy's Office of Scientific and

Technical Information

Reports not in digital format may be purchased by the public from the National Technical Information Service (NTIS):

U.S. Department of Commerce

National Technical Information Service

5301 Shawnee Rd

Alexandra, VA 22312

www.ntis.gov

Phone: (800) 553-NTIS (6847) or (703) 605-6000

Fax: (703) 605-6900

Email: orders@ntis.gov

Reports not in digital format are available to DOE and DOE contractors from the Office of Scientific and Technical Information (OSTI):

U.S. Department of Energy

Office of Scientific and Technical Information

P.O. Box 62

Oak Ridge, TN 37831-0062

www.osti.gov

Phone: (865) 576-8401

Fax: (865) 576-5728

Email: reports@osti.gov

Disclaimer

This report was prepared as an account of work sponsored by an agency of the United States Government. Neither the United States Government nor any agency thereof, nor UChicago Argonne, LLC, nor any of their employees or officers, makes any warranty, express or implied, or assumes any legal liability or responsibility for the accuracy, completeness, or usefulness of any information, apparatus, product, or process disclosed, or represents that its use would not infringe privately owned rights. Reference herein to any specific commercial product, process, or service by trade name, trademark, manufacturer, or otherwise, does not necessarily constitute or imply its endorsement, recommendation, or favoring by the United States Government or any agency thereof. The views and opinions of document authors expressed herein do not necessarily state or reflect those of the United States Government or any agency thereof, Argonne National Laboratory, or UChicago Argonne, LLC. 


\section{Computational Analysis of Hydraulic Capacity of Ohio DOT Catch Basins On-Grade and in Sag Locations}

prepared by:

M.A. Sitek, S.A. Lottes

Nuclear Science and Engineering Division, Argonne National Laboratory

J. Syar

Office of Hydraulic Engineering, Ohio Department of Transportation

April 2021 
Table of Contents

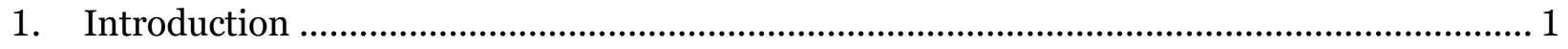

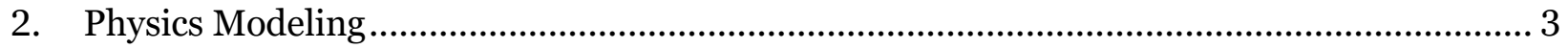

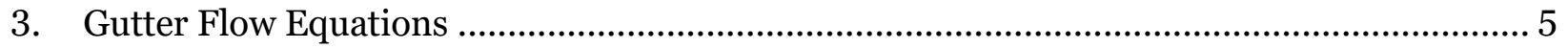

4. Hydraulic Efficiency of Inlets According to HEC 22 and ODOT Equations ......................... 9

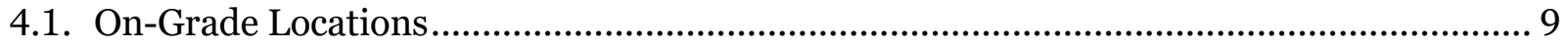

4.1.1. Interception Capacity of Grate Inlets on Continuous Grade According to HEC 22. 9

4.1.2. Interception Capacity of Grate Inlets on Continuous Grade According to ODOT . 11

4.1.3. Interception Capacity of Curb-Opening Inlets on Continuous Grade According to

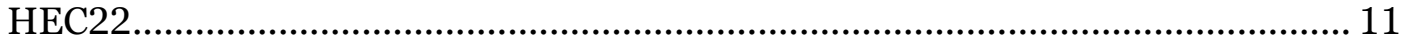

4.1.4. Interception Capacity of Curb-Opening Inlets on Continuous Grade According to

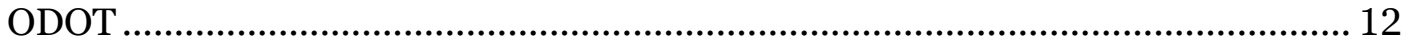

4.1.5. Interception Capacity of Combination Inlets on Continuous Grade According to

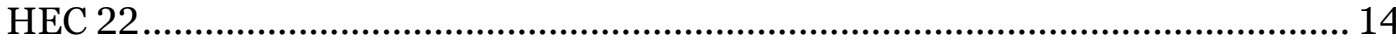

4.1.6. Interception Capacity of Combination Inlets on Continuous Grade According to

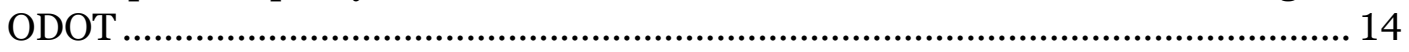

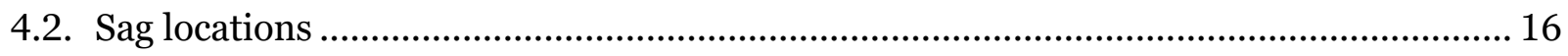

4.2.1. Interception Capacity of Grate Inlets in Sag Locations According to HEC 22 ...... 16

4.2.2. Interception Capacity of Grate Inlets in Sag Locations According to ODOT ......... 17

4.2.3. Interception Capacity of Curb-Opening Inlets in Sag Locations According to HEC

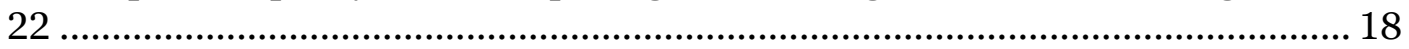

4.2.4. Interception Capacity of Curb-Opening Inlets in Sag Locations According to ODOT

4.2.5. Interception Capacity of Combination Inlets in Sag Locations According to ODOT

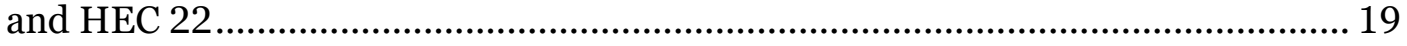

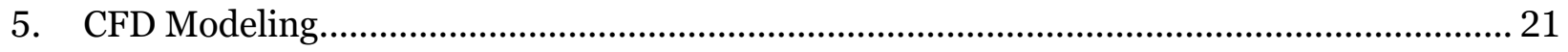

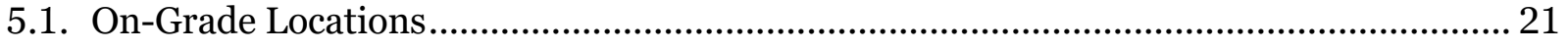

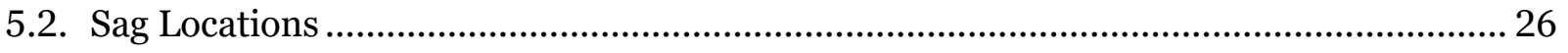

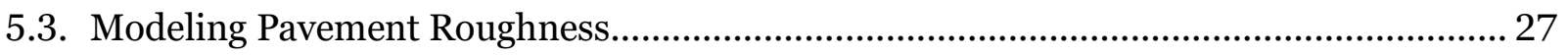

5.4. Inlet Clogging in On-Grade Locations .................................................................. 30

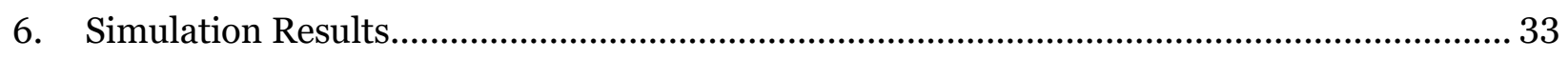

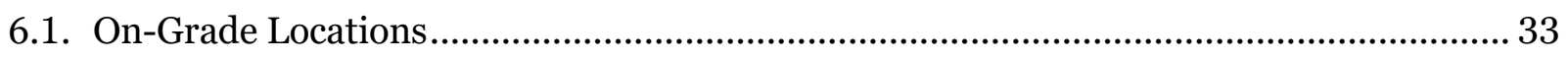

6.1.1. Influence of Pavement Roughness Model ........................................................ 33

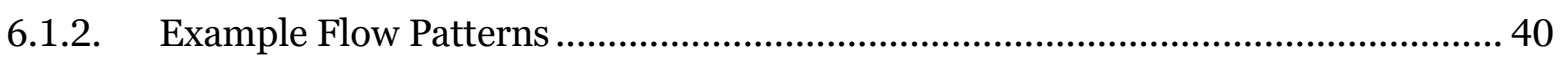

6.1.3. CB 3A Catch Basin Efficiency................................................................... 41

Computational Analysis of Hydraulic Capacity of Ohio DOT Catch Basins On-Grade and in Sag Locations

Page I 
6.1.4. Influence of Clogging on the Catch Basin Efficiency in On-Grade Locations ........ 65

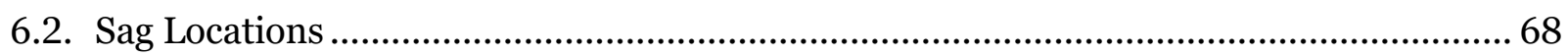

6.2.1. Curb Opening and Grate Contribution to Hydraulic Capacity of Catch Basin CB 3 69

6.2.2. No Contribution of Curb Opening to Hydraulic Capacity of Catch Basin CB 3 ..... 74

6.2.3. No Contribution of Grate to Hydraulic Capacity of Catch Basin CB 3 ................. 77

6.2.4. Influence of Clogging on Hydraulic Capacity of Inlets in Sag locations ................. 80

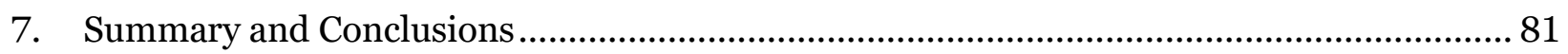

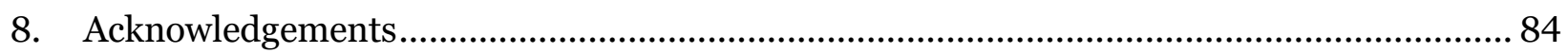

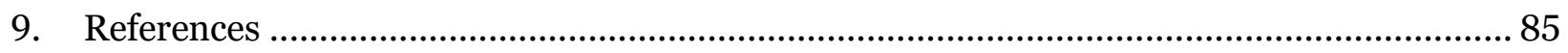

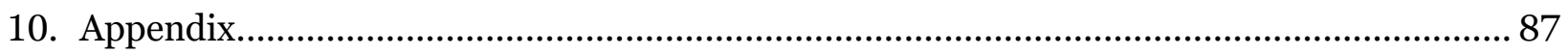


List of Figures

Figure 2.1 Plan view of the CB 3A catch basin with a diagonal grate.

Figure 2.2 Cross-section through the CB 3A catch basin with a diagonal grate for a 2-ft-wide curb and gutter configuration.............................................................................................. 3

Figure 2.3 Curve vane ("V") grate............................................................................. 4

Figure 3.1: Triangular cross section of road and gutter with uniform cross slope showing infinitesimal section of area used to integrate Manning's equation to obtain discharge.............. 5

Figure 3.2: Right-angled trapezoid subsection of road cross-section with constant cross slope $\boldsymbol{S} \boldsymbol{x}$.

Figure 3.3 Cross-section through a composite gutter. ....................................................... 7

Figure 4.1 Sketches of the (a) front and (b) side view of a curb opening inlet.......................... 13

Figure 4.2 Gutter flow according to ODOT design manual. ................................................... 15

Figure 4.3 Definition of depth in orifice flow condition according to HEC 22......................... 17

Figure 4.4 Definition of depth for curb opening inlets with horizontal throat in sump conditions

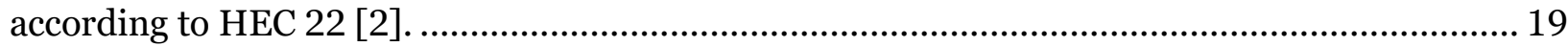

Figure 5.1 Axisymmetric view of an example CFD model of a thin strip of the road cross-section for a 8 -foot spread...................................................................................................... 22

Figure 5.2 Velocity profile obtained from a CFD model of a thin strip of the road cross-section for a 8 -foot spread............................................................................................................ 22

Figure 5.3 Perspective view of the model with boundary conditions marked with different colors: grey - wall b.c., red - velocity inlet b.c., orange - pressure outlet b.c., blue - symmetry b.c. The top surface of the domain (not shown here) has assigned a pressure outlet b.c., and a close-up of the porous layer (grey)............................................................................................................. 23

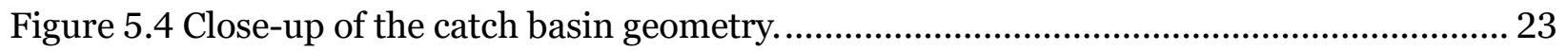

Figure 5.5 Discretization of the domain in the vicinity of the catch basin................................ 24

Figure 5.6 Planes used to monitor flow into the grate........................................................ 25

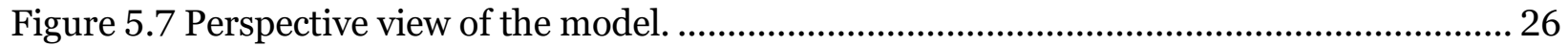

Figure 5.8 Discretization of the computational domain shown on planes across the model. Close up of the transition of cell size around the vanes of the grate .................................................. 27

Figure 5.9 Prediction of roughness height from Manning coefficient by Colebrook-White and

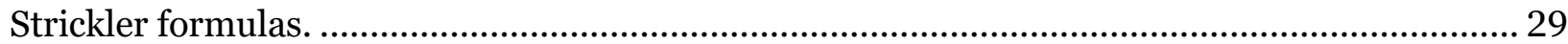


Figure 5.10 Representation of a surface profile with a porous medium, (a) surface profile, (b) approximation of the aggregate with spheres, (c) computational model.................................. 30

Figure 5.11 Geometry of the models with $0,10,30$, and $50 \%$ clogging of the grate................... 32

Figure 5.12 Model with entirely blocked curb opening.......................................................... 32

Figure 6.1 Pooling spread on a pavement for a 2-ft-wide composite curb and gutter with a longitudinal grade of $0.0025 \mathrm{ft} / \mathrm{ft}$, at a flow rate of $0.187 \mathrm{cfs}$.

Figure 6.2 Top view of the model with a 4-mm-thick, porous layer with water surface colored with elevation. Water flow on a 2-ft-wide composite curb and gutter with a $0.0025 \mathrm{ft} / \mathrm{ft}$ longitudinal grade.

Figure 6.3 Pooling spread on a pavement for a 2-ft-wide composite curb and gutter with a longitudinal grade of $0.08 \mathrm{ft} / \mathrm{ft}$, at a flow rate of $4.6 \mathrm{cfs}$.

Figure 6.4 Top view of the model with a 4-mm-thick, porous layer with water surface colored with elevation. Water flow on a 2-ft-wide composite curb and gutter with a longitudinal grade of $0.08 \mathrm{ft} / \mathrm{ft}$, at a flow rate of $4.6 \mathrm{cfs}$.

Figure 6.5 Flow intercepted by the grate and window for various models of the pavement surface for a 2-foot composite curb and gutter with $0.0025 \mathrm{ft} / \mathrm{ft}$ longitudinal grade with $2 \mathrm{ft}$ spread. ... 39

Figure 6.6 Flow intercepted by the grate and window for various models of the pavement surface for a 2-foot composite curb and gutter with $0.08 \mathrm{ft} / \mathrm{ft}$ longitudinal grade with $8 \mathrm{ft}$ spread......... 39

Figure 6.7 Water flow on a 2-foot composite curb and gutter with $0.08 \mathrm{ft} / \mathrm{ft}$ longitudinal grade. Pool spread is $10 \mathrm{ft}$.

Figure 6.8 Water flow on a road with an 8 -foot shoulder with $0.0025 \mathrm{ft} / \mathrm{ft}$ longitudinal grade. Pool spread is $10 \mathrm{ft}$.

Figure 6.9 Water flow on a road with an 8-foot shoulder with $0.08 \mathrm{ft} / \mathrm{ft}$ longitudinal grade. Pool spread is $10 \mathrm{ft}$.

Figure 6.10 Catch basin efficiency as a function of spread and longitudinal grade for (a) a 2-ftwide curb and gutter, (b) a 4-ft-wide shoulder, (c) an 8-ft-wide shoulder. Note: the range of pool spread was reversed for better readability of the chart.

Figure 6.11 Front flow interception as a function of spread and longitudinal grade for (a) a 2-ftwide curb and gutter, (b) a 4-ft-wide shoulder, (c) an 8-ft-wide shoulder. Note: the range of pool spread was reversed for better readability of the chart.

Figure 6.12 Side flow interception in function of spread and longitudinal grade for (a) $2 \mathrm{ft}$ curb and gutter, (b) $4 \mathrm{ft}$ shoulder, (c) $8 \mathrm{ft}$ shoulder. 50

Figure 6.13 Bypass flow as a function of spread and longitudinal grade for (a) a 2-ft-wide curb and gutter, (b) a 4-ft-wide shoulder, (c) an 8-ft-wide shoulder. 53

Figure 6.14 Side flow into CB 3A catch basin vs. longitudinal profile grade for a road with (a) 2ft-wide composite curb and gutter, (b) 4-ft-wide shoulder, (c) 8-ft-wide shoulder.................... 56

Computational Analysis of Hydraulic Capacity of Ohio DOT Catch Basins On-Grade and in Sag Locations 
Figure 6.15 "Grate flow" into CB 3A catch basin vs. longitudinal profile grade for a road with (a) a 2-ft-wide composite curb and gutter, (b) a 4-ft-wide shoulder, (c) an 8-ft-wide shoulder....... 58

Figure 6.16 Bypass flow vs. longitudinal grade for a road with (a) a 2-ft-wide composite curb and gutter, (b) a 4-ft-wide shoulder, (c) an 8-ft-wide shoulder.

Figure 6.17 Efficiency of CB3A catch basin vs. longitudinal grade for a road with (a) 2-ft-wide composite curb and gutter, (b) 4-ft-wide shoulder, (c) 8-ft-wide shoulder.

Figure 6.18 Comparison of CB3A efficiency obtained with CFD and ODOT design calculations. Dashed lines show a $\pm 10 \%$ difference, and dotted lines show a $\pm 20 \%$ difference (legend: $2 \mathrm{ftC} \& \mathrm{G}$ stands for a road with a 2-ft-wide composite curb and gutter, 4ftShoulder - a road with a 4-ftwide shoulder, $8 \mathrm{ftShoulder} \mathrm{-} \mathrm{a} \mathrm{road} \mathrm{with} \mathrm{an} \mathrm{8-ft-wide} \mathrm{shoulder).}$

Figure 6.19 Efficiency vs. flow rate with varying longitudinal grade, and road geometry.

Figure 6.20 Flow patterns above a combination inlet for varying percentage of blocked area of the grate.

Figure 6.21 Flow pattern above a combination inlet with a blocked curb opening.

Figure 6.22 Flow interception by the grate (blue), window (orange), and total (grey) as a function of the percentage of clogged area of the grate. Efficiency of the catch basin with curb opening open (black solid line) and curb opening blocked (grey dashed line).

Figure 6.23 Combination inlet. Depth of the ponding water vs. discharge in sump conditions (Dinit - initial water depth measured from the lowest point in the gutter, Wdom - domain width from the roadside edge of grate)

Figure 6.24 Change of discharge through a combination inlet and ponding water depth in time for a model with Dinit $=3 \mathrm{~m}$ and a bigger computational domain, Wdom $=3 \mathrm{~m}$.

Figure 6.25 Ratio of grate and curb opening contribution in the total intercepted flow for a model with a combination inlet.

Figure 6.26 Water surface elevation for a model with a combination inlet. Water depth at curb away from the inlet is equal $0.611 \mathrm{~m}(\sim 2 \mathrm{ft})$. Orifice flow condition for both grate and window. 72

Figure 6.27 Water surface elevation at 25.7 seconds of simulated time for a model with a combination inlet. Water depth at curb away from the inlet is equal $0.317 \mathrm{~m}(\sim 1 \mathrm{ft})$. 72

Figure 6.28 Views of the water surface elevation for a model with a combination inlet, (a) axisymmetric and (b) top view, at onset of weir flow condition for the grate. Water depth at curb away from the inlet is equal $0.237 \mathrm{~m}(\sim 9.3 \mathrm{in}) .$.

Figure 6.29 Change of discharge through a grate inlet and ponding water depth in time for a model with Dinit $=3 \mathrm{~m}$ and a bigger computational domain Wdom=3 $\mathrm{m}$.

Figure 6.30 Water surface elevation at 20 seconds of simulated time for a model with a grate inlet. Orifice flow condition over the grate. 
Figure 6.31 Water surface elevation at 25 seconds of simulated time for a model with a grate inlet. Transition flow condition over the grate.

Figure 6.32 Water surface elevation at 28.5 seconds of simulated time for a model with a grate inlet, (a) top view, (b) side view. Onset of weir flow condition over the grate.

Figure 6.33 Water surface elevation at 30 seconds of simulated time for a model with a grate inlet. Weir flow condition over the grate.

Figure 6.34 Grate inlet without the curb opening contribution. Depth of the ponding water vs. discharge in sump conditions.

Figure 6.35 Discharge through the curb opening and ponding water depth vs. nondimensional simulated time, $\boldsymbol{\tau}=\mathrm{t} / \mathrm{t}(\mathrm{d}=3 \mathrm{in})$.

Figure 6.36 Snapshots of water surface elevation in a model with only curb opening unobstructed, initialized with $1 \mathrm{~m}(\sim 3.3 \mathrm{ft})$ of water depth, corresponding to $\tau=\sim 0.72$.

Figure 6.37 Snapshots of water surface elevation in a model with only curb opening unobstructed, initialized with $1 \mathrm{~m}(\sim 3.3 \mathrm{ft})$ of water depth, corresponding to $\tau=\sim 0.5$.

Figure 6.38 Snapshots of water surface elevation in a model with only curb opening unobstructed, initialized with $1 \mathrm{~m}(\sim 3.3 \mathrm{ft})$ of water depth, corresponding to $\tau=\sim 1$.

Figure 6.39 Curb opening inlet without the grate contribution. Depth of the ponding water vs. discharge in sump conditions.

Figure 6.40 Influence of clogging on discharge capacity. Water depth vs. discharge for a combination inlet (grate and curb opening), only curb opening, and only grate.

Figure 10.1 Two-foot-wide curb and gutter. Total, grate, window, and bypass discharge vs. longitudinal profile grade for flow spread: (a) $2 \mathrm{ft}$, (b) $4 \mathrm{ft}$, (c) $6 \mathrm{ft}$, (d) $8 \mathrm{ft}$, (e) $10 \mathrm{ft}$. 89

Figure 10.2 Four-foot-wide shoulder. Total, grate, window, and bypass discharge vs. longitudinal profile grade for flow spread: (a) $2 \mathrm{ft}$, (b) $4 \mathrm{ft}$, (c) $6 \mathrm{ft}$, (d) $8 \mathrm{ft}$, (e) $10 \mathrm{ft}$. 91

Figure 10.3 Eight-foot-wide shoulder. Total, grate, window, and bypass discharge vs. longitudinal profile grade for flow spread: (a) $2 \mathrm{ft}$, (b) $4 \mathrm{ft}$, (c) $6 \mathrm{ft}$, (d) $8 \mathrm{ft}$, (e) $10 \mathrm{ft}$. 92 
List of Tables

Table 6-1 Explanation of the Legend in Figure 6.1 and Figure 6.3...................................... 34

Table 10-1 Efficiency, Front, Side and Bypass Flow Rates for Catch Basin No. 3A in on-Grade

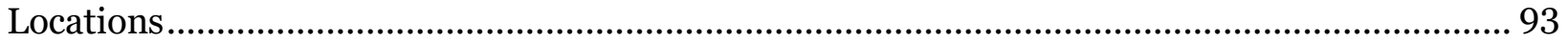

Table 10-2 Catch Basin No. 3 - Sump Hydraulic Capacity for Varying Ponding Depth. The type of flow was marked with a letter: (o) for orifice flow, (t) for transition flow, or (w) for weir flow.... 95 


\section{Nomenclature}

\begin{tabular}{|c|c|c|}
\hline Symbol & Description & Units \\
\hline$A$ & area & $\mathrm{m}^{2}\left(\mathrm{ft}^{2}\right)$ \\
\hline$A_{g}$ & projected open area of a grate & $\mathrm{m}^{2}\left(\mathrm{ft}^{2}\right)$ \\
\hline$a$ & gutter depression & $\mathrm{m}(\mathrm{ft})$ \\
\hline$C_{o}$ & discharge coefficient in orifice flow equation for grates & - \\
\hline$C_{w}$ & discharge coefficient in weir equation for grates & - \\
\hline$C_{w c}$ & discharge coefficient for curb opening in weir flow & - \\
\hline$D_{p}$ & mean particle diameter (aggregate size) & $\mathrm{m}(\mathrm{ft})$ \\
\hline$d$ & flow depth at an $(\mathrm{x}, \mathrm{y})$ point on the street & $\mathrm{m}(\mathrm{ft})$ \\
\hline$d_{0}$ & effective head at curb opening in orifice flow & $\mathrm{m}(\mathrm{ft})$ \\
\hline$d A$ & differential area of vertical section of water on street & $\mathrm{m}(\mathrm{ft})$ \\
\hline$d_{c}$ & flow depth at curb & $\mathrm{m}(\mathrm{ft})$ \\
\hline$d_{e}$ & flow depth at street side edge of grate & $\mathrm{m}(\mathrm{ft})$ \\
\hline$d_{g}$ & average depth over grate $=0.5\left(d_{c}+d_{e}\right)$ & $\mathrm{m}(\mathrm{ft})$ \\
\hline$d_{L}$ & flow depth at the left side of a water pool section & $\mathrm{m}(\mathrm{ft})$ \\
\hline$d_{w}$ & flow depth at gutter edge & $\mathrm{m}(\mathrm{ft})$ \\
\hline$d P$ & differential length of wetted perimeter & $\mathrm{m}(\mathrm{ft})$ \\
\hline$d_{R}$ & flow depth at the right side of a section & $\mathrm{m}(\mathrm{ft})$ \\
\hline$d x$ & differential distance in $\mathrm{x}$-direction & $\mathrm{m}(\mathrm{ft})$ \\
\hline$E$ & inlet efficiency & - \\
\hline$E_{o}$ & $\begin{array}{l}\text { ratio of flow in the depressed section to total gutter flow determined } \\
\text { by the gutter configuration upstream of the inlet }\end{array}$ & - \\
\hline$E_{C F D}$ & inlet efficiency determined via CFD & - \\
\hline$E_{H E C ~ 22}$ & inlet efficiency determined from HEC 22 equations & \\
\hline$E_{O D O T}$ & inlet efficiency determined from ODOT equations & - \\
\hline$e$ & ratio of flow intercepted by an inlet to design flow & - \\
\hline$F_{w}$ & Froude number & - \\
\hline$g$ & gravitational acceleration & $\mathrm{m} / \mathrm{s}^{2}\left(\mathrm{ft} / \mathrm{s}^{2}\right)$ \\
\hline$H$ & water depth at curb opening & $\mathrm{m}(\mathrm{ft})$ \\
\hline$h$ & height of curb opening & $\mathrm{m}(\mathrm{ft})$ \\
\hline$K_{u}$ & coefficient & $\mathrm{m}^{1 / 3} / \mathrm{ft}^{1 / 3}$ \\
\hline$k$ & unit conversion factor in Manning's equation, $(1 / 0.3048)^{1 / 3}$ & $\mathrm{~m}^{1 / 3} / \mathrm{ft}^{1 / 3}$ \\
\hline$k_{S}$ & surface roughness height & $\mathrm{m}(\mathrm{ft})$ \\
\hline$L$ & actual length of curb opening & $\mathrm{m}(\mathrm{ft})$ \\
\hline$L_{g r}$ & length of grate along the street & $\mathrm{m}(\mathrm{ft})$ \\
\hline$L_{T}$ & $\begin{array}{l}\text { length of curb opening inlet required to intercept } 100 \% \text { of gutter } \\
\text { flow }\end{array}$ & $\mathrm{m}(\mathrm{ft})$ \\
\hline$\dot{m}$ & mass flow rate & $\begin{array}{c}\mathrm{kg} / \mathrm{s} \\
(\mathrm{lbm} / \mathrm{s})\end{array}$ \\
\hline$n$ & Manning's coefficient & $\mathrm{s} / \mathrm{m}^{1 / 3}$ \\
\hline $\boldsymbol{n}$ & unit vector normal to a surface & \\
\hline$P$ & wetted perimeter or grate perimeter minus curb side & $\mathrm{m}(\mathrm{ft})$ \\
\hline$P_{i}$ & porous media inertial resistance coefficient & $\mathrm{Pa}-\mathrm{s}^{2} / \mathrm{m}^{3}$ \\
\hline$P_{v}$ & porous media viscous resistance coefficient & $\mathrm{Pa}-\mathrm{s} / \mathrm{m}^{2}$ \\
\hline$Q$ & discharge, or volume flow rate & $\mathrm{m}^{3} / \mathrm{s}\left(\mathrm{ft}^{3} / \mathrm{s}\right)$ \\
\hline
\end{tabular}

Computational Analysis of Hydraulic Capacity of Ohio DOT Catch Basins On-Grade and in Sag Locations 


\begin{tabular}{|c|c|c|}
\hline$Q_{A B C}$ & $\begin{array}{l}\text { volume flow through triangular section } \mathrm{ABC} \text { where } \mathrm{A}, \mathrm{B} \text {, and } \mathrm{C} \text { are } \\
\text { triangle vertices (cfs) }\end{array}$ & $\mathrm{m}^{3} / \mathrm{s}\left(\mathrm{ft}^{3} / \mathrm{s}\right)$ \\
\hline$Q_{b}$ & volume flow bypassing an inlet & $\mathrm{m}^{3} / \mathrm{s}\left(\mathrm{ft}^{3} / \mathrm{s}\right)$ \\
\hline$Q_{g r}$ & volume flow intercepted by grate & \\
\hline$Q_{i g}$ & volume flow intercepted by front edge of grate & $\mathrm{m}^{3} / \mathrm{s}\left(\mathrm{ft}^{3} / \mathrm{s}\right)$ \\
\hline$Q_{i w}$ & volume flow intercepted by curb opening & $\mathrm{m}^{3} / \mathrm{s}\left(\mathrm{ft}^{3} / \mathrm{s}\right)$ \\
\hline$Q_{i}$ & flow intercepted by an inlet & $\mathrm{m}^{3} / \mathrm{s}\left(\mathrm{ft}^{3} / \mathrm{s}\right)$ \\
\hline$Q_{S}$ & $\begin{array}{l}\text { volume flow capacity of the gutter section above the depressed sec- } \\
\text { tion, } \mathrm{m}^{3} / \mathrm{s}\left(\mathrm{ft}^{3} / \mathrm{s}\right)\end{array}$ & $\mathrm{m}^{3} / \mathrm{s}\left(\mathrm{ft}^{3} / \mathrm{s}\right)$ \\
\hline$Q_{\text {side }}$ & volume flow intercepted by roadside edge of grate & \\
\hline$Q_{w}$ & volume flow in depressed section of the gutter, $\mathrm{m}^{3} / \mathrm{s}\left(\mathrm{ft}^{3} / \mathrm{s}\right)$ & $\mathrm{m}^{3} / \mathrm{s}\left(\mathrm{ft}^{3} / \mathrm{s}\right)$ \\
\hline$R$ & hydraulic radius $=A / P$ & $\mathrm{~m}(\mathrm{ft})$ \\
\hline$S^{\prime}{ }_{w}$ & $\begin{array}{l}\text { cross slope of the gutter measured from the cross slope of the pave- } \\
\text { ment, } S_{x}\end{array}$ & $\mathrm{~m} / \mathrm{m}(\mathrm{ft} / \mathrm{ft})$ \\
\hline$S_{e}$ & equivalent cross slope & $\mathrm{m} / \mathrm{m}(\mathrm{ft} / \mathrm{ft})$ \\
\hline$S_{l}$ & slope along the flow direction & $\mathrm{m} / \mathrm{m}(\mathrm{ft} / \mathrm{ft})$ \\
\hline$S_{w}$ & gutter cross slope & $\mathrm{m} / \mathrm{m}(\mathrm{ft} / \mathrm{ft})$ \\
\hline$S_{x}$ & street cross slope & $\mathrm{m} / \mathrm{m}(\mathrm{ft} / \mathrm{ft})$ \\
\hline$T$ & spread & $\mathrm{m}(\mathrm{ft})$ \\
\hline V & mean flow velocity & $\mathrm{m} / \mathrm{s}(\mathrm{ft} / \mathrm{s})$ \\
\hline $\mathbf{v}$ & flow velocity vector at a point & $\mathrm{m} / \mathrm{s}(\mathrm{ft} / \mathrm{s})$ \\
\hline$v_{S}$ & superficial velocity of flow in porous media & $\mathrm{m} / \mathrm{s}(\mathrm{ft} / \mathrm{s})$ \\
\hline$W$ & width of gutter & $\mathrm{m}(\mathrm{ft})$ \\
\hline$W_{a}$ & width of local depression & $\mathrm{m}(\mathrm{ft})$ \\
\hline$W_{g r}$ & width of grate in cross-street direction & $\mathrm{m}(\mathrm{ft})$ \\
\hline$x$ & $\begin{array}{l}\text { variable distance from water spread edge, } x \in[0, T] \text {, or variable dis- } \\
\text { tance in } \mathrm{x} \text {-direction }\end{array}$ & $\mathrm{m}(\mathrm{ft})$ \\
\hline$x_{L}$ & $x$ position of left side of water pool section & $\mathrm{m}(\mathrm{ft})$ \\
\hline$x_{R}$ & $x$ position of right side of water pool section & $\mathrm{m}(\mathrm{ft})$ \\
\hline$\phi_{w}$ & water volume fraction & - \\
\hline$\mu$ & dynamic viscosity & $\begin{array}{c}\mathrm{Pa}-\mathrm{S} \\
\left(\mathrm{lbf}-\mathrm{s} / \mathrm{ft}^{2}\right)\end{array}$ \\
\hline$\rho_{w}$ & water density & $\begin{array}{l}\mathrm{kg} / \mathrm{m}^{3} \\
\left(\mathrm{lbm} / \mathrm{ft}^{3}\right)\end{array}$ \\
\hline$\chi$ & porosity of porous media (void volume fraction) & - \\
\hline
\end{tabular}

Computational Analysis of Hydraulic Capacity of Ohio DOT Catch Basins On-Grade and in Sag Locations 


\section{Introduction}

Stormwater runoff from streets and highways is typically captured by drainage structures strategically placed when roadways use curb or curb and gutter systems. These structures include catch basins with grates, inlets, or combination grates/inlets that collect and discharge storm water runoff to buried pipe conveyance systems. The performance of these drainage structures is measured in terms of hydraulic efficiency, which is defined as the percentage of flow captured by the basin as compared to the total flow draining to the structure. Understanding the performance of these drainage structures allows for a safe and economical design which prevents flooding along Ohio roadways.

The current hydraulic design methodology used to model Ohio Department of Transportation (ODOT) drainage structures is believed to have been developed in the mid to late 1970s and was based on the early Federal Highway Administration (FHWA) Hydraulic Engineering Circular 12 (HEC 12) [1]. It is not certain if any physical modelling for standard ODOT grates was performed in developing the methodology, if it was adopted from another DOT, or if it used estimates from known grates. Much of that institutional knowledge has been lost as many of the original design engineers have since left or retired from ODOT. There is a need to verify ODOT drainage structure capacities, which requires either hydraulic physical modelling or Computational Fluid Dynamics (CFD) modeling.

Recent climate trends have indicated an increase in rainfall intensity occurring in more frequent events. This trend was evident in the latest IDF curve updates applied by the Office of Hydraulic Engineering. The increased rainfall intensity impacts ODOT hydraulic design of drainage structures that convey runoff from the more frequent events (i.e., 2-year and 5-year events). This increase in intensity directly impacts the estimated amount of rainfall that is captured on the pavement surface and the drainage structures that use these more frequent events in their design. It is uncertain if this trend will worsen in the future, and it highlights the need for a thorough understanding of ODOT's drainage structure efficiency.

The FHWA Hydraulic Engineering Circular 22 "Urban Drainage Design Manual” (HEC 22) [2] is the present-day authoritative resource for urban hydraulic engineering for transportation facilities. HEC 22 includes empirically derived equations to calculate the hydraulic capacity of drainage structures for several FHWA standard grate configurations. The FHWA standard grate configurations have associated physical modelling that was used to develop the empirical design equations for the FHWA standard grates. HEC 22 indicates that, "With laboratory data, agencies could develop design curves for their standard grates ...”. ODOT uses several standard drainage structures to capture runoff which are detailed in the Office of Hydraulic Engineering Standard Constructed Drawings which are different from the FHWA standard grates.

In the past, one of the primary obstacles for evaluating the hydraulic performance of drainage structures was the need for expensive physical modeling in a hydraulics laboratory. However, with more recent advances in engineering software and computing power, CFD modeling can now be used to develop mathematical models at a fraction of the cost. The Federal Highway Administration currently offers CFD modeling to determine the efficiency of catch basins with varying physical properties and site conditions. By utilizing the capabilities offered by FHWA, this process is less expensive overall, especially if utilized through the Transportation Pooled Fund Program. The pooled fund study "High Performance Computational Fluid Dynamics Modeling Services for

Computational Analysis of Hydraulic Capacity of Ohio DOT Catch Basins On-Grade and in Sag Locations

Page | 1 
Highway Hydraulics" is intended for this exact purpose. Referenced by study number TPF-5(446) (previously TPF-5(279)), FHWA and Argonne National Laboratory have been providing successful CFD modeling for multiple DOTs since 2013. The most recent commitment is South Carolina testing multiple catch basins in a similar process to what ODOT needs [3].

A research study presented at the 2018 National Hydraulic Engineering Conference confirmed that the standard method outlined in the HEC 22 may need to be revised. This was discovered through a research project performed by the Texas Department of Transportation that utilized large scale physical modelling in a hydraulic flume. The results of the physical modeling were confirmed with CFD analysis [4].

Additionally, research through the American Society of Civil Engineers under the title "Hydraulic Efficiency of Grate and Curb Inlets for Urban Storm Drainage" [5] has concluded a similar finding. From the abstract of the ASCE study, "Collected test data on inlet efficiency were compared to previously published methods for the inlets and were found to deviate by as much as $45 \%$ and an average of $13 \%$ at typical design depths of $0.1-0.15 \mathrm{~m}$ ". Other factors also add to the need to evaluate the design methodologies.

A full-scale hydraulic flume study of the standard (at that time) parallel and directional ODOT grates for an ODOT No. 3 catch basin was performed by Sarikelle, S. and French, G.L. in 1976 for the City of Barberton, Ohio [6]. The parallel ODOT grate for the No. 3 catch basin was compared to a custom directional grate from the city and the directional grate used by ODOT. The study showed that the directional grates were less hydraulically efficient than the standard parallel grate and it recommended beveling of the lower edges of the directional grate. The ODOT standard parallel grate was discontinued in the May 1979 ODOT standard construction drawing and the recommended beveling was never implemented.

This research provides ODOT with a validated methodology for evaluating the efficiency of present-day grates and curb-opening inlets. Information obtained from the research will allow ODOT to provide safer and more efficient designs to benefit the users of drainage systems. Results will be applied to ODOT policy, design software, and institutional knowledge will be documented.

Computational Analysis of Hydraulic Capacity of Ohio DOT Catch Basins On-Grade and in Sag Locations 


\section{Physics Modeling}

The hydraulic efficiency in on-grade locations for Catch Basin CB 3A and discharge capabilities in sump conditions of catch basin CB 3 are analyzed in this study. Both are combination inlets, which can be used with a diagonal or a curved vane grate and a curb opening of the length of the grate. The window is considered a factor of safety against grate clogging and its capacity is not generally included in the determination of grate spacing. The difference between the catch basins is that $\mathrm{CB}$ $3 \mathrm{~A}$ is a single inlet and CB 3 a double inlet, employed to increase its discharge capacity in sag locations. A plan view of CB 3A is shown in Figure 2.1 and the cross-section of the catch basin for a 2-ft-wide curb and gutter is presented in Figure 2.2. Currently, a curved vane (or "V") grate shown in Figure 2.3 is used by ODOT engineers instead of the diagonal grate.

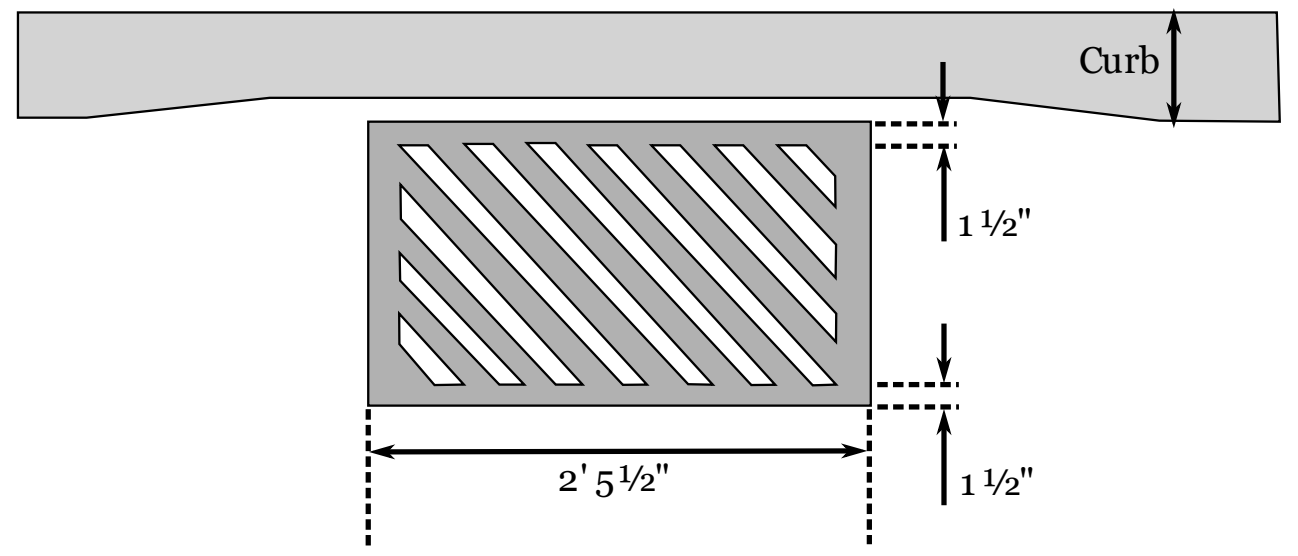

Figure 2.1 Plan view of the CB 3A catch basin with a diagonal grate.

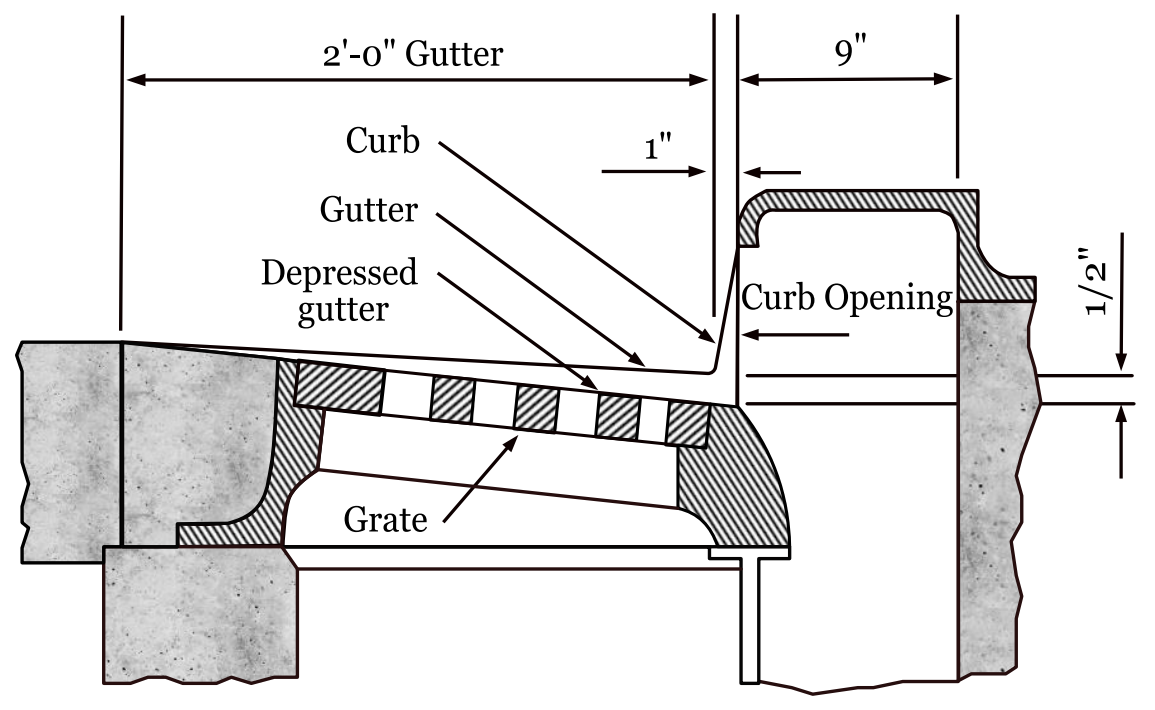

Figure 2.2 Cross-section through the CB 3A catch basin with a diagonal grate for a 2-ft-wide curb and gutter configuration. 


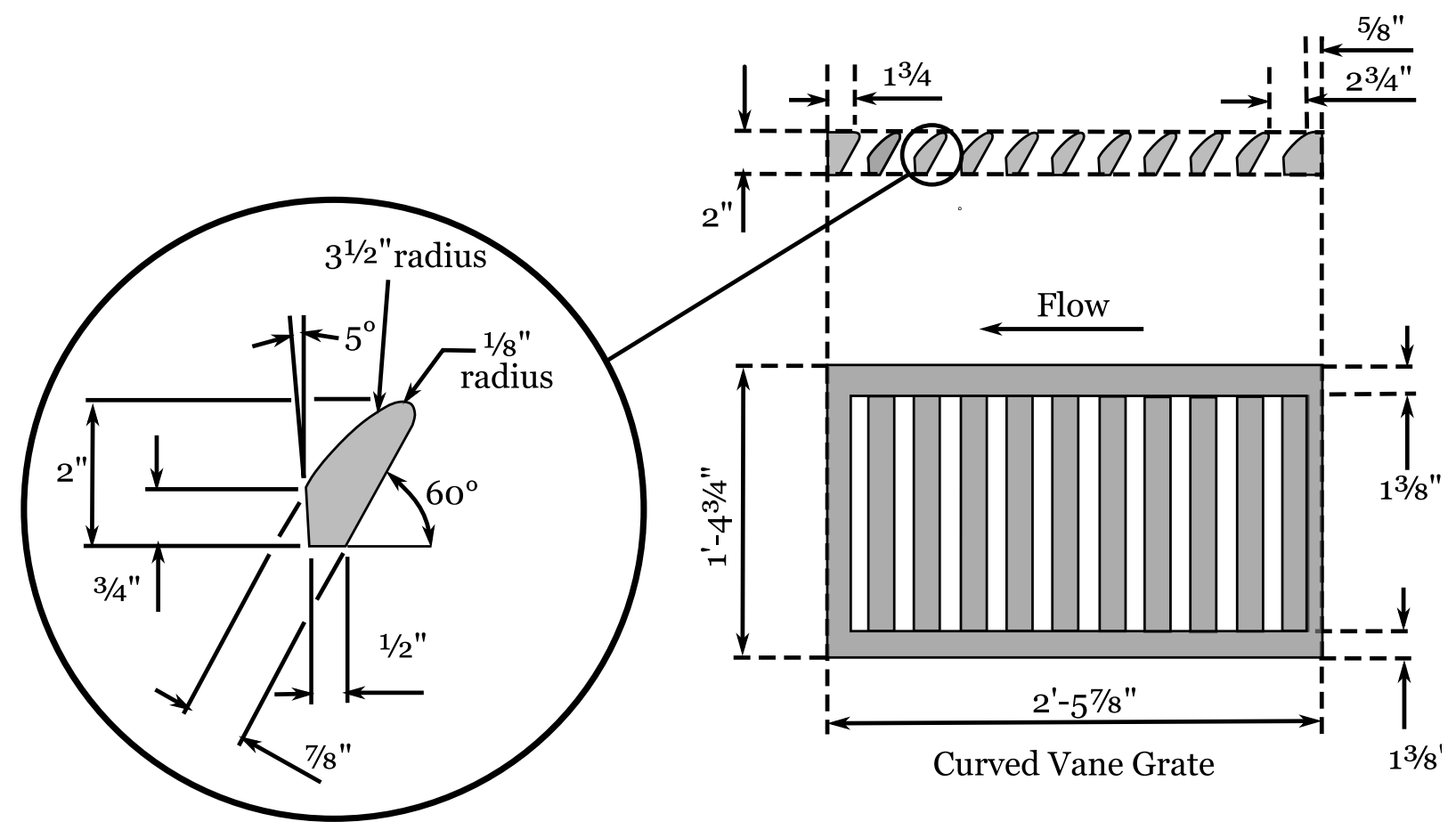

Figure 2.3 Curve vane ("V") grate.

The hydraulic efficiency of an inlet in an on-grade location is defined as the percentage of intercepted flow to the total flow. Three road cross-sections are considered in this study: a 2-ft-wide composite curb and gutter with an $8.33 \%$ cross slope, a 4 -ft-wide shoulder at $4.0 \%$ cross slope, and an 8 -ft-wide shoulder at $4.0 \%$ cross slope. In each case the road pavement cross slope is $1.6 \%$. The curb is 6-in-high, and Manning's n-value equals 0.015 for the road surfaces.

In the on-grade cases, the roadway longitudinal profile grades are as following: $0.25 \%, 0.5 \%, 1 \%$, $3 \%, 5 \%$, and $8 \%$. The frontal flow, side flow, and bypass flow is determined from the model for the pavement spreads of 2, 4, 6, 8, and 10 feet.

The hydraulic capacity of an inlet in sump conditions depends on the depth of ponding over the drain. The modeling encompasses a range of flow depths up to 18 inches and three scenarios are studied:

(1) full clogging of the window with all flow draining through the grate,

(2) full clogging of the grate with all flow draining through the window, and

(3) flow draining through fully open window and grate.

Computational Analysis of Hydraulic Capacity of Ohio DOT Catch Basins On-Grade and in Sag Locations 


\section{Gutter Flow Equations}

The mean flow velocity, $V$, in an open channel can be calculated from Manning's equation [2]:

$$
V=\frac{k}{n} R^{2 / 3} S_{l}^{1 / 2}
$$

where $n$ is the empirical roughness coefficient known as Manning's $n, R$ is the hydraulic radius defined as the flow area $A$, divided by the wetted perimeter $P, R=\frac{A}{P}, S_{l}$ is the channel slope along the flow direction, and $k$ is a unit conversion factor. Note that to yield velocity, Manning's $n$ must have units of $\left[\mathrm{T} / \mathrm{L}^{1 / 3}\right]$ or $\left(\mathrm{s} / \mathrm{ft}^{1 / 3}\right)$ or $\left(\mathrm{s} / \mathrm{m}^{1 / 3}\right)$. In metric units $k$ has a value of 1 . For English units, $1 \mathrm{~s} / \mathrm{m}^{1 / 3}=(1 / 0.3048)^{1 / 3} \mathrm{~s} / \mathrm{ft}^{1 / 3}$, which yields an exact value for $k$ in English units of $(1 / 0.3048)^{1 / 3}$ $\approx 1.48591857749626 \approx 1.4859 \approx 1.49$. In practice, $n$ values are empirical and determined by measurement, and therefore the best value of $k$ to use is the one that was used to determine the value of $n$. The Engineering Toolbox [7] website and USGS researchers [8] list a value for $k$ of 1.486 , other sources list values with varying numbers of digits. For numerical work, a good practice is to use values that are as accurate as possible and then round the result down to a number of digits that is justified by the uncertainty in the computation, which is usually two or three digits in engineering computations. In this case that would mean using the value of $k$ given in the source document for $n$, if it is present, and if not, using $k$ equal to 1.486 should be sufficient.

For a uniform triangular section of water spread across gutter and street with the same slope where the width is typically between one and two orders of magnitude greater than the depth, the hydraulic radius does not adequately characterize the flow because most of the flow occurs in the deeper portion close to the curb. In this case, the hydraulic radius gives too much weight to the effect of road roughness in the triangle tip where the depth drops to zero. The Manning equation does, however, characterize the local open channel flow velocity with engineering accuracy as the depth tends to zero. A relation between volume flow, road cross and longitudinal slopes, and Manning's $n$ can be obtained by integrating Manning's equation over an infinitesimally small width of triangular cross-section as shown in Figure 3.1 from the point of high elevation to point of the greatest depth at curb, $d_{c}$. The cross-section is oriented with the perspective of a driver on the road with the left side of the cross section on the crown or center side of the road and the right side of the subsection on the curb side of the road.

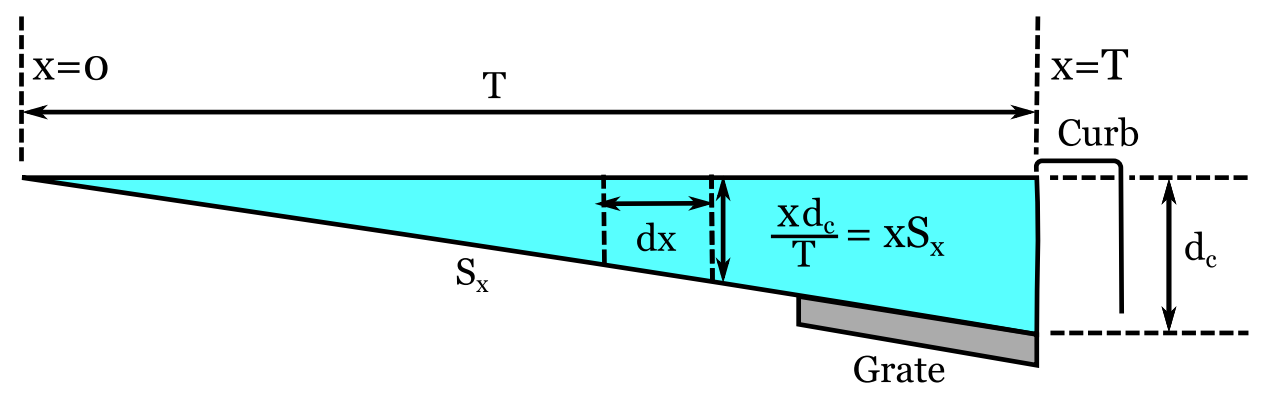

Figure 3.1: Triangular cross section of road and gutter with uniform cross slope showing infinitesimal section of area used to integrate Manning's equation to obtain discharge.

Computational Analysis of Hydraulic Capacity of Ohio DOT Catch Basins On-Grade and in Sag Locations 
The section of width $d x$ in Figure 3.1 has area $d A=S_{x} x d x$ and wetted perimeter $d P=d x$, giving a local hydraulic radius of $R=d A / d P=S_{x} x$, where $S_{x}$ is the cross slope and $x$ is the position variable across the road, $x \in[0, T]$, and $T$ is spread.

The total discharge through the triangular section may then be obtained by integrating flow through section $d x$ from $x=0$ to $x=T$ using the velocity from Manning's eq. (1):

$$
V=\frac{k}{n} R^{2 / 3} S_{l}^{1 / 2}=\frac{k}{n} S_{l}^{1 / 2}\left(S_{x} x\right)^{2 / 3},
$$

The total discharge through the triangular section may then be obtained by integrating flow through section $d x$ from $x=0$ to $x=T$ using the velocity from Manning's eq. (2) :

$$
Q=\int_{0}^{T} V S_{x} x d x=\frac{k}{n} S_{l}^{1 / 2} S_{x} \int_{0}^{T}\left(S_{x} x\right)^{2 / 3} x d x=\frac{3 k}{8 n} S_{l}^{1 / 2} S_{x}^{5 / 3} T^{8 / 3}
$$

Noting that spread $T=d_{c} / S_{x}$, and that the roughness of the curb is neglected, and the integral in the eq. (3) could run from $x=0$ up to any fraction of the spread where the depth is $d_{1}$, the equation can be rewritten for any triangular section up to depth $d$ as:

$$
Q=\frac{K_{u}}{n} S_{x}^{-1} S_{l}^{1 / 2} d^{8 / 3}
$$

where $K_{u}=3 k / 8$ equals 0.375 for metric units or 0.56 for English units. Note that HEC 22 and most references give the value of $K_{u}$ in metric units as 0.376 [2].

Manning's equation can also be integrated for any subsection of constant cross slope, $S_{x}$. In this case the integration is over a right-angled trapezoid from $x=x_{L}$ to $x=x_{R}$ as shown in Figure 3.2. Because the origin of the position coordinate system is arbitrary and may be chosen for convenience, define the position of the left side of the right trapezoid as $x_{L}=d_{L} / S_{x}$, then the water depth $d(x)$ at any position $x \in\left[x_{L}, x_{R}\right]$ within the trapezoid is the depth on the left plus the addition resulting from the slope, $d(x)=d_{L}+S_{x}\left(x-x_{L}\right)=d_{L}+S_{x}\left(x-d_{L} / S_{x}\right)=S_{x} x$, which simply reduces to the slope times the position, $d(x)=S_{x} x$, and is convenient for integration. Note that cross slopes to the left, $S_{x L}$, and right, $S_{x R}$, of the trapezoidal subsection of interest may be different from the cross slope, $S_{x}$, in the trapezoidal subsection.

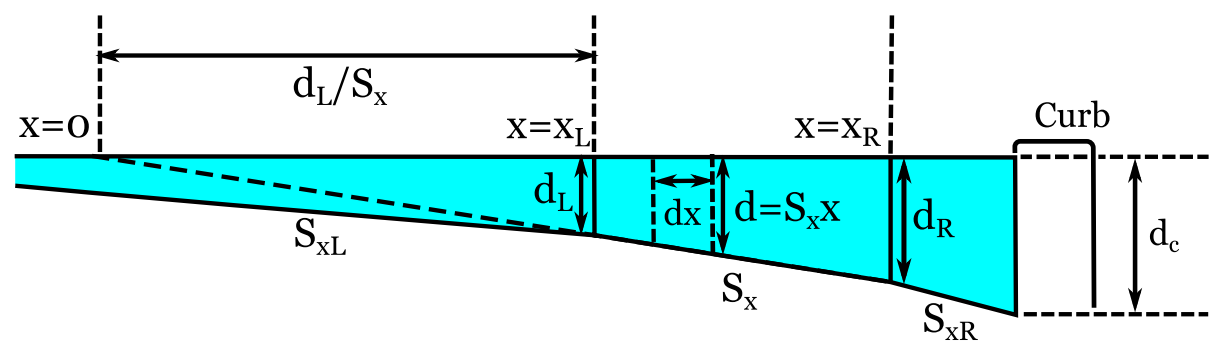

Figure 3.2: Right-angled trapezoid subsection of road cross-section with constant cross slope $S_{x}$.

A differential area at any position $x$ within the trapezoid has area $d A=S_{x} x d x$, the water depth at $x$ times the differential width $d x$, the wetted perimeter of the differential subsection is $d P=d x$, giving a local hydraulic radius of $R=d A / d P=S_{x} x$, which yields the same expression for local velocity at position $x$ as in eq. (2).

Computational Analysis of Hydraulic Capacity of Ohio DOT Catch Basins On-Grade and in Sag Locations

Page $\mid 6$ 
The discharge $Q$ for the trapezoid is:

$$
Q=\int_{x_{L}}^{x_{R}} V S_{x} x d x=\frac{k}{n} S_{l}^{\frac{1}{2}} S_{x}^{\frac{5}{3}} \int_{x_{L}}^{x_{R}} x^{\frac{5}{3}} d x=\frac{3 k}{8 n} S_{l}^{\frac{1}{2}} S_{x}^{\frac{5}{3}}\left(x_{R}^{\frac{8}{3}}-x_{L}^{\frac{8}{3}}\right)=\frac{3 k}{8 n} S_{l}^{\frac{1}{2}} S_{x}^{-1}\left(d_{R}^{\frac{8}{3}}-d_{L}^{\frac{8}{3}}\right)
$$

Eq. (5) is a generalization of eq. (4) that may be applied to any trapezoidal subsection of road cross-section with constant cross slope, $S_{x}$, to obtain the discharge $Q$ from the street cross and longitudinal slopes and the water depths on the left and right ends of the subsection. When that section happens to be at the left (high) end of the spread, then $d_{L}=0$ and eq. (4) is recovered.

To summarize, for any right trapezoidal section of road cross section with constant or nearly constant cross slope, the discharge, $Q$, is given by an integrated Manning's equation:

$$
Q=\frac{K_{u}}{n} S_{l}^{\frac{1}{2}} S_{x}^{-1}\left(d_{R}^{\frac{8}{3}}-d_{L}^{\frac{8}{3}}\right)
$$

where $K_{u}=3 k / 8$ equals 0.375 for metric units or 0.56 for English units, $S_{l}$ is the longitudinal slope, $S_{x}$ is the cross slope, $d_{R}$ is the water depth on the right side (the curb side) of the subsection and $d_{L}$ is the depth on the left side (the road crown side) of the subsection.

Using eq. (6), the discharge, $Q$, for an arbitrary contour of road cross section may be calculated by approximating it with a set of cords yielding a set of trapezoidal sections. Eq. (6) can be applied to each section and the set of discharges, $Q_{i}$, summed to give the total discharge. To obtain the discharge for a composite street with cross slope, $S_{x}$, and gutter with cross slope, $S_{w}$, apply eq. (6) to the gutter section and street section shown in Figure 3.3. The width of the gutter is $W, d_{c}$ is the water depth at the curb, $S_{w}$ is the gutter cross slope, $T_{s}$ is the spread from the street side edge of the gutter to the high point, $S_{x}$ is the street cross slope, and $d_{e}=d_{c}-S_{w} W=S_{x} T_{s}$ is the water depth at the street side edge of the gutter. The total discharge, $Q$, gutter discharge, $Q_{w}$, and street discharge, $Q_{s}$, are respectively:

$$
\begin{gathered}
Q=Q_{w}+Q_{s} \\
Q_{w}=\frac{K_{u}}{n} S_{l}^{\frac{1}{2}} S_{w}^{-1}\left(d_{c}^{\frac{8}{3}}-d_{e}^{\frac{8}{3}}\right), Q_{s}=\frac{K_{u}}{n} S_{l}^{\frac{1}{2}} S_{x}^{-1} d_{e}^{\frac{8}{3}}
\end{gathered}
$$

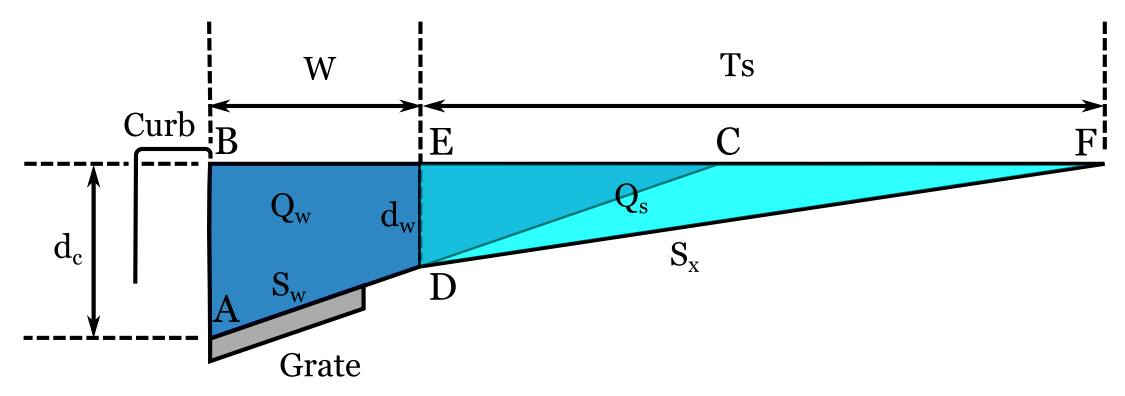

Figure 3.3 Cross-section through a composite gutter.

Computational Analysis of Hydraulic Capacity of Ohio DOT Catch Basins On-Grade and in Sag Locations 
Note that this result may also be obtained by applying the integrated Manning's equation for a triangular cross section of road, eq. (4) to triangles ABC, DEC, and DEF shown in Figure 3.3:

$$
\begin{gathered}
Q_{A B C}=\frac{K_{u}}{n} S_{l}^{\frac{1}{2}} S_{w}^{-1} d_{c}^{\frac{8}{3}}, \\
Q_{D E C}=\frac{K_{u}}{n} S_{l}^{\frac{1}{2}} S_{w}^{-1} d_{w}^{\frac{8}{3}}, \\
Q_{D E F}=\frac{K_{u}}{n} S_{l}^{\frac{1}{2}} S_{x}^{-1} d_{w}^{\frac{8}{3}},
\end{gathered}
$$

Because triangles $\mathrm{ABC}$ and DEF overlap in triangle DEC, the discharge calculated for DEC must be subtracted from the sum of the other two to avoid counting it twice. Line segment DC is not in contact with the road surface and therefore does not satisfy the conditions of the Manning equation for triangles $\mathrm{ABC}$ and $\mathrm{DEC}$, however, any error incurred in calculating flow through $\mathrm{ABC}$ is corrected when flow through DEC is subtracted off. The resulting discharge $Q$ is:

$$
\begin{gathered}
Q=Q_{A B C}-Q_{D E C}+Q_{D E F}, \\
Q=\frac{K_{u}}{n} S_{l}^{\frac{1}{2}}\left[S_{w}^{-1}\left(d_{c}^{\frac{8}{3}}-d_{w}^{\frac{8}{3}}\right)+S_{x}^{-1} d_{w}^{\frac{8}{3}}\right],
\end{gathered}
$$

This superposition of triangles to obtain the discharge for composite gutter flow is the procedure presented in "ODOT Drainage Manual, Part 1, Hydrology, Pavement Drainage and Storm Sewer Design" [9] and it matches the result obtained by integrating Manning's equation for the gutter and road way subsections and summing them in eq. (7).

For a given flow rate, the mean upstream flow velocity, $V$, can be back-calculated as:

$$
V={ }^{Q} / A
$$

where $A$ is the inlet area computed from the road geometry and spread, assuming a level water surface:

- for uniform gutter cross sections:

$$
A=0.5 S_{x} T^{2}
$$

- for composite gutter cross sections:

$$
A=0.5 S_{x}\left(T^{2}-W^{2}\right)+0.5 S_{w} W^{2} .
$$

Computational Analysis of Hydraulic Capacity of Ohio DOT Catch Basins On-Grade and in Sag Locations 


\section{Hydraulic Efficiency of Inlets According to HEC 22 and ODOT Equations}

Results of the CFD analysis were compared to results calculated using the HEC 22 equations [2], and ODOT in-house design equations [9]. Both design approaches are presented in this Section of the report.

\subsection{On-Grade Locations}

\subsubsection{Interception Capacity of Grate Inlets on Continuous Grade According to HEC 22}

The interception capacity of a selected set of bicycle-safe grates in on-grade locations was investigated by the Bureau of Reclamation for the Federal Highway Administration [10], [11]. These grates are: $\mathrm{P}-1^{7} / 8(\mathrm{P}-50)$ parallel bar grate, $\mathrm{P}-1^{7} / 8^{-4}(\mathrm{P}-50 \times 100)$ parallel bar grate with lateral rods, $\mathrm{P}-1^{1} / 8$ (P-30) parallel bar grate, curved vane grate with transverse bars, $45^{\circ}\left(45^{\circ}-60\right)$ tiltbar grate with transverse bars, $45^{\circ}\left(45^{\circ}\right.$ - 85) tilt-bar grate with transverse bars, $30^{\circ}\left(30^{\circ}\right.$ - 85) tiltbar grate with transverse bars, and a reticuline "honeycomb" pattern of lateral bars and longitudinal bearing bars. The test conditions were:

- grate dimensions: $2 \mathrm{ft}$ by $2 \mathrm{ft}$, and $2 \mathrm{ft}$ by $4 \mathrm{ft}$,

- longitudinal slopes: $0.5 \%-13 \%$,

- cross slopes: 1:96 - 1:16(1.04\% - 6.25\%),

- maximum gutter flow $5.6 \mathrm{cfs}$,

- Manning number: 0.016, 0.017.

In the first part of the study [10], the researchers performed 1800 hydraulic tests with a wide range of geometric and flow parameters that encompass many of real-life road conditions. Nevertheless, there are limitations. The tested pavement ( $2 \mathrm{ft}$ gutter and $6 \mathrm{ft}$ travel lane) had a uniform cross slope, and so no influence of a depressed gutter or local depression was accounted for, which influences the efficiency of the inlet. Even though the range of values of tested parameters is large, it does not cover all possible conditions, such as $0.25 \%$ cross slope considered in this study, flow rates greater than $5.6 \mathrm{cfs}$, or smoother pavement surfaces. Also, as stated in HEC 22, there is no data on interception for cases with low flow velocity in combination with a small spread, when most of or total flow is intercepted, although this does not introduce too much of an error.

In the second part of the study [11], additional hydraulic tests were performed on three grate designs: parallel bar grate with spacers, $\mathrm{P}-1^{1} / 8$, parallel bar grate with transverse rods, $\mathrm{P}-1^{7} / 8$, and curved vane grate. The test conditions were:

- $\quad$ dimensions: $3 \mathrm{ft}$ by $4 \mathrm{ft}, 3 \mathrm{ft}$ by $3 \mathrm{ft}, 1.25 \mathrm{ft}$ by $2.67 \mathrm{ft}$, and $1.25 \mathrm{ft}$ by $2 \mathrm{ft}$,

- cross slopes: 1:48 (2.08\%), 1:24 (4.17\%), 1:16 (6.25\%),

- longitudinal slopes: $0.5 \%-13 \%$,

- gutter flows: up to $5.6 \mathrm{cfs}$.

The experimental results were combined in HEC 22 in form of charts. Chart 5 for frontal flow interception is based on test results which show that grates intercept total frontal flow until a velocity is reached at which water begins to splash over the grate. At velocities greater than the

Computational Analysis of Hydraulic Capacity of Ohio DOT Catch Basins On-Grade and in Sag Locations 
splash-over velocity, grate efficiency in intercepting frontal flow is diminished. Grates also intercept a portion of the flow along the length of the grate (side flow). Chart 6 is provided to determine the side flow interception, which depends on the cross slope of the pavement, length of the grate, and flow velocity.

If the grate is of the width of the gutter, the ratio of frontal flow to total gutter flow for a uniform cross slope is calculated as:

$$
E_{o}=\frac{Q_{w}}{Q}=1-\left(1-\frac{W}{T}\right)^{2.67}
$$

If a grate of width smaller than the gutter width is considered, the frontal flow ratio must be adjusted:

$$
E_{o}^{\prime}=E_{o} \frac{A^{\prime} w}{A_{w}}
$$

where $E^{\prime}{ }_{o}$ is adjusted frontal flow area ratio, $A^{\prime}{ }_{w}$ is gutter flow area in a width equal to the grate width, and $A_{w}$ is the flow area in depressed gutter width.

The ratio of the intercepted frontal flow to total flow is expressed by:

$$
\begin{gathered}
V \leq V_{o}: R_{f}=1, \\
V>V_{o}: R_{f}=1-K_{u}\left(V-V_{o}\right),
\end{gathered}
$$

where $K_{u}$ is 0.295 for SI units and 0.09 for English units, $V$ (in m/s or ft/s) is gutter flow velocity, and $V_{o}$ gutter velocity at which splash-over occurs (in $\mathrm{m} / \mathrm{s}$ or $\mathrm{ft} / \mathrm{s}$ ). The splash-over velocity for a set of grates can be established depending on the grate length from Chart 5A for SI units or Chart 5B for English units.

The ratio of side flow to total gutter flow is:

$$
\frac{Q_{s}}{Q}=1-E_{o}
$$

The ratio of side flow to total flow that is intercepted by the grate is expressed by:

$$
R_{S}=\frac{1}{1+\frac{K_{u} V^{1.8}}{S_{x} L^{2.3}}}
$$

where $K_{u}$ is 0.0828 for SI units and 0.15 for English units. The ratio $R_{s}$ can be also established from Chart 6A for SI units or Chart 6B for English units based on the road cross slope and grate length.

The efficiency of a grate can be calculated as:

$$
E=R_{f} E_{o}+R_{s}\left(1-E_{o}\right) .
$$

and the intercepted flow is expressed by:

Computational Analysis of Hydraulic Capacity of Ohio DOT Catch Basins On-Grade and in Sag Locations 


$$
Q_{i}=E Q .
$$

\subsubsection{Interception Capacity of Grate Inlets on Continuous Grade According to ODOT}

A combination grate and curb-opening inlet is used for on-grade locations. The design equations for a combination inlet are presented in Section 4.1.6.

\subsubsection{Interception Capacity of Curb-Opening Inlets on Continuous Grade Accord- ing to HEC22}

The equations to calculate the interception capacity of curb-opening inlets are based on work of Bauer and Woo [12] and Izzard [13], [14].

Bauer and Woo performed a series of tests on curb-opening inlets with varying size and shape of the depressed area. Test conditions were as follows:

- weir flow conditions,

- approach gutter has a triangular shape,

- local depression width $2 \mathrm{ft}$, depression 2 in,

- cross slopes: $1.5 \%-6 \%$

- longitudinal slopes: $0.2 \%-6 \%$,

- Manning's roughness coefficient: 0.01 and 0.016 ,

- Width of flow spread: $5 \mathrm{ft}, 10 \mathrm{ft}$,

- Length of curb-opening inlet: $5 \mathrm{ft}$ to $35 \mathrm{ft}$.

Izzard in his paper [13] analyzed the original experimental data by Karaki and Haynie [15], and found that the interception ratios can be represented as dimensionless functions of a parameter $\frac{L}{F_{W} T}$ and cross-slope $S_{x}$. Based on his findings, the length $L_{T}$ of a curb opening required to intercept $100 \%$ of the gutter flow on a pavement section with uniform cross slope can be calculated as:

$$
L_{T}=1.65 F_{w} T,
$$

where $F_{w}$ is Froude number of flow depth at distance $W$ from curb face, $T$ is width of spread of uniform flow in street, which can be calculated as:

$$
F_{W}=\frac{0.262}{n}\left[S_{x}(T-W)\right]^{\frac{1}{6}} S^{\frac{1}{2}} \text {, and } T=\left(\frac{n Q}{0.56 S_{l}^{\frac{1}{2}}}\right)^{\frac{3}{8}} S_{x}^{\frac{5}{8}},
$$

which gives for English units (and the same rounding as used in HEC 22):

$$
L_{T}=0.6 Q^{0.44} S_{l}^{0.28}\left(\frac{1}{n S_{x}}\right)^{0.56},
$$

The equation in HEC 22 has the same form, but differs with the power values:

Computational Analysis of Hydraulic Capacity of Ohio DOT Catch Basins On-Grade and in Sag Locations 


$$
L_{T}=K_{u} Q^{0.42} S_{l}^{0.3}\left(\frac{1}{n S_{x}}\right)^{0.6}
$$

where $K_{u}$ equals 0.6 in English units or 0.817 in SI units, $Q$ is the gutter flow, $S_{l}$ is the pavement longitudinal slope, $S_{x}$ is the pavement cross slope.

Izzard in [13] distinguished two parts of the dimensionless graph of $\frac{Q_{i}}{Q}$ vs. $\frac{L}{F_{w} T}$ :

$$
\begin{gathered}
\text { if } \frac{L}{F_{w} T}<0.4 \text {, then } \frac{Q_{i}}{Q}=\frac{L}{L_{1}} \text {, where } L_{1}=2.79 W^{-\frac{1}{6}} S_{x}^{0.3} F_{w} T, \\
\text { and } \\
\text { if } 0.4<\frac{L}{F_{w} T}<1.65 \text {, then } \frac{Q_{i}}{Q}=\left(\frac{L}{L_{1}}\right)^{0.4} \text {, where } L_{3}=1.65 F_{w} T .
\end{gathered}
$$

In another publication [14], Izzard proposes a form of equation for curb-opening efficiency:

$$
E=\frac{Q_{i}}{Q}=1-\left(1-\frac{L}{L_{T}}\right)^{\frac{5}{2}}
$$

HEC 22 recommends calculating the efficiency of a curb opening with length $L<L_{T}$ as:

$$
E=1-\left(1-\frac{L}{L_{T}}\right)^{1.8}
$$

Although it was not stated explicitly in HEC 22, it seems that the power 1.8 was obtained from a best fit in the experimental data points which was also hypothesized by Muhammad [16].

For depressed curb-opening inlets or curb openings in depressed gutter sections, HEC 22 recommends finding the interception capacity from equations (23) and (26) by substituting $S_{x}$ with the equivalent cross slope $S_{e}$ where:

$$
S_{e}=S_{x}+S^{\prime}{ }_{w} E_{o}
$$

where $S^{\prime}{ }_{w}$ is the cross slope of the gutter measured from the cross slope of the pavement, $S_{x}, S^{\prime}{ }_{w}=$ $\frac{a}{W}$ or $S^{\prime}{ }_{w}=S_{w}-S_{x}, a$ is the gutter depression, $W$ is the local depression width, $E_{o}$ is the ratio of flow in the depressed section to total gutter flow determined by the gutter configuration upstream of the inlet:

$$
E_{o}=1-\left(1-\frac{W}{T}\right)^{2.67}
$$

\subsubsection{Interception Capacity of Curb-Opening Inlets on Continuous Grade Accord- ing to ODOT}

The ODOT design equations follow a study by C.F. Izzard[14]. Izzard's method is based on a theoretical analysis verified with experimental measurements at the time. The experiments covered the following test conditions:

Computational Analysis of Hydraulic Capacity of Ohio DOT Catch Basins On-Grade and in Sag Locations 
- inlets without local depression (not yet published at the time of release [14]):

○ approach gutter slope: $2^{1 / 2} 2^{\prime \prime}$ over $1^{\prime} 1^{1} / 8^{\prime \prime}$

$\circ$ inlet length: $2.23 \mathrm{ft}, 6 \mathrm{ft}, 10 \mathrm{ft}$

- longitudinal grades: $0.125 \%$ to $4 \%$,

- inlets with a local depression [17]:

○ approach gutter slope: 2" over 2',

○ depression depth $0.25 \mathrm{ft}$,

$\circ$ length of curb opening: $1 \mathrm{ft}-7 \mathrm{ft}$,

$\circ$ gutter grades: $0.5 \%-10 \%$,

- inlets with a local depression [18]:

○ approach gutter slope: 2" over 1'6"

○ depression depth $0.167 \mathrm{ft}$,

○ length of curb opening: $3 \mathrm{ft}, 8.92 \mathrm{ft}$,

○ longitudinal grades: $0.75 \%, 1 \%, 2 \%$

The front and side view of a curb opening inlet, as well as dimensions considered in the calculations of its interception capacity are shown in Figure 4.1.

(a)

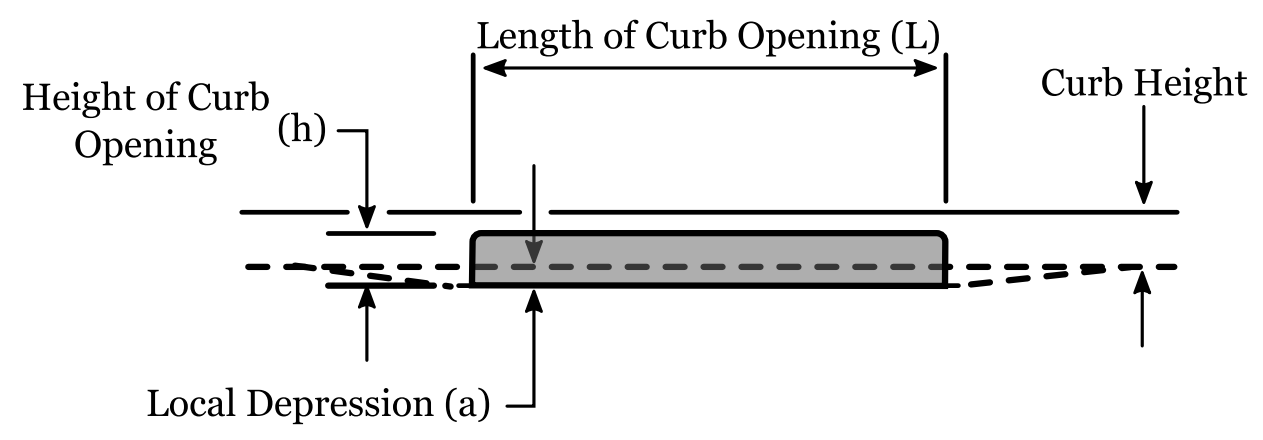

(b)

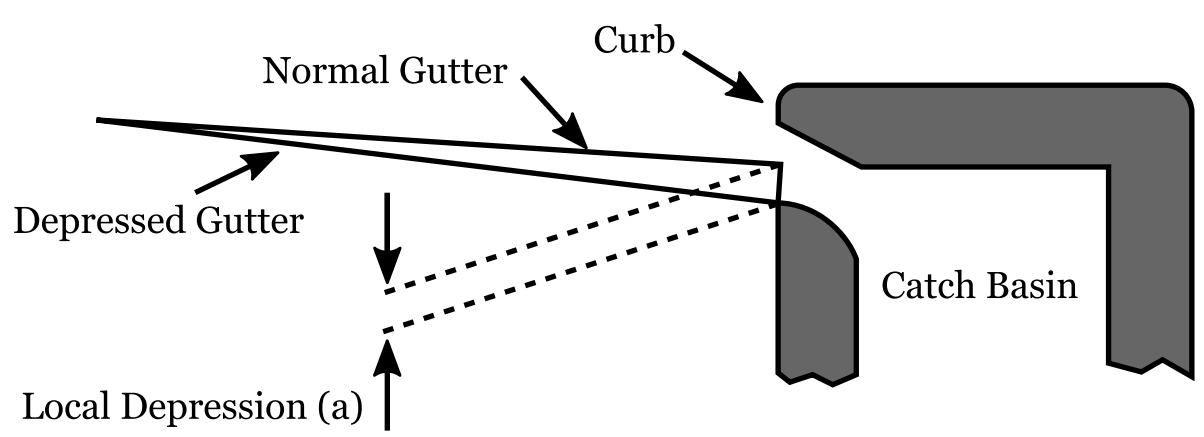

Figure 4.1 Sketches of the (a) front and (b) side view of a curb opening inlet.

For a curb-opening with length $L$ and height $h$, and a local depression $a$, the interception per foot of inlet opening for a window intercepting $100 \%$ of the design flow, is:

$$
\frac{Q}{L_{T}}=0.7\left(a+d_{c}\right)^{1.5}\left[1-\left(1-\frac{d_{c}}{a+d_{c}}\right)^{2.5}\right],
$$

where $Q$ is the design discharge [cfs], $a$ is the depression of the inlet lip below the normal gutter flow line [ft], and $d_{c}$ is the depth of flow in the approach gutter at the face of curb [ft].

Computational Analysis of Hydraulic Capacity of Ohio DOT Catch Basins On-Grade and in Sag Locations 
The length of curb opening required to intercept $100 \%$ of the gutter flow is calculated from the relationship between the ratio of the design discharge, $Q$, and the interception per foot of inlet opening given with eq. (29):

$$
L_{T}=\frac{Q}{\left(\frac{Q}{L_{T}}\right)}
$$

The ratio of the flow intercepted by the inlet, $Q_{i}$, to the design flow is:

$$
E=\frac{Q_{i}}{Q}=\frac{\left(\frac{a}{d_{c}}+1\right)^{2.5}-\left(\frac{a}{d_{c}}+1-\frac{L}{L_{T}}\right)^{2.5}}{\left(\frac{a}{d_{c}}+1\right)^{2.5}-\left(\frac{a}{d_{c}}\right)^{2.5}},
$$

where $L$ is the length of curb opening.

The amount of gutter flow intercepted by the curb opening is:

$$
Q_{i}=E Q
$$

and the bypass flow is:

$$
Q_{b}=Q-Q_{i}
$$

\subsubsection{Interception Capacity of Combination Inlets on Continuous Grade Accord- ing to HEC 22}

HEC 22 stated that the interception capacity of a combination inlet consisting of a curb opening and a grate placed side-by-side is only marginally greater than that of the grate alone. HEC 22 recommends computing the capacity by neglecting the curb opening. The curb opening is viewed as an improvement to the grate because it is more resistant to being clogged by debris, and therefore the grate-curb opening system functions closer to the design efficiency when the runoff water is carrying debris such as leaves.

\subsubsection{Interception Capacity of Combination Inlets on Continuous Grade Accord- ing to ODOT}

For a combination inlet, it is assumed that $100 \%$ of the frontal flow over the grate, $Q_{g r}$, is intercepted by the inlet, along with a portion of the side flow, $Q_{\text {side }}$, which coincides with the assumption made in HEC 22. Flow through the window is not considered in calculating efficiency in ongrade locations.

The amount of intercepted side flow depends on the depth of flow on the roadside edge of the grate, $d_{e}$, which is calculated as:

$$
d_{e}=d_{c}-W S_{x / w}
$$

Computational Analysis of Hydraulic Capacity of Ohio DOT Catch Basins On-Grade and in Sag Locations 
where $d_{c}$ is the depth of flow at the face of curb, $S_{x / w}$ is the pavement cross slope $S_{x}$ for a triangular gutter section or the gutter or paved shoulder cross slope $S_{w}$ for a composite gutter section, and $W$ is the width of the grate.

The flow past the side of the grate for a triangular gutter section with continuous cross slope, $S_{x}$, is:

$$
Q_{\text {side }}=\frac{K_{u}}{n S_{x}} d_{e}^{2.67} S_{l}^{0.5}
$$

where $K_{u}$ is 0.56 for English units ( 0.376 for metric units) and $S_{l}$ is the longitudinal slope, and the grate flow can be calculated as:

$$
Q_{g r}=Q-Q_{\text {side }}
$$

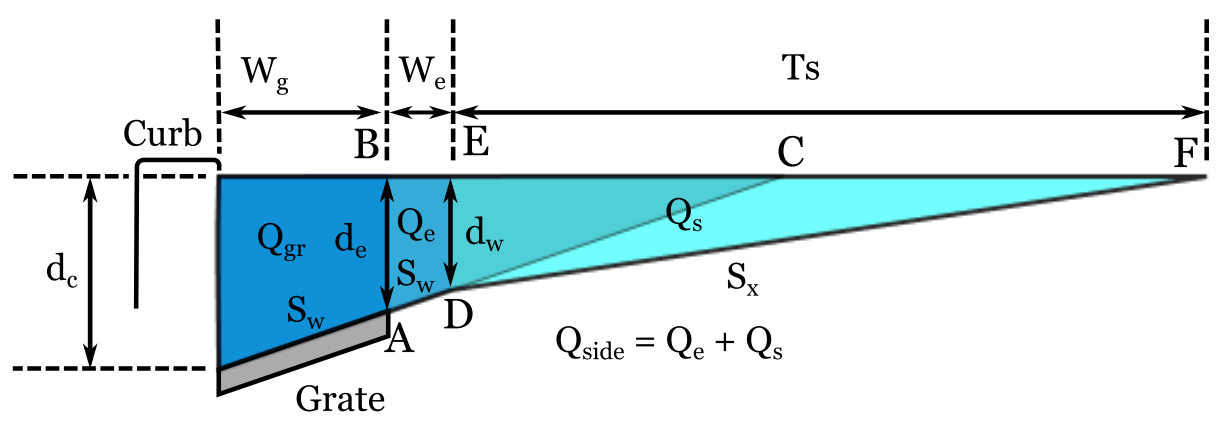

Figure 4.2 Gutter flow according to ODOT design manual.

Figure 4.2 shows flow over the grate, $Q_{g r}$, and flow past the side of the grate, $Q_{\text {side }}=Q_{e}+Q_{s}$, for a composite gutter section, where $Q_{e}$.is the flow between the street side edge of the grate and the edge of the gutter, and $Q_{s}$ is the flow on the street. The width of the gutter is $W=W_{g}+W_{e}$ were $W_{g}$ is the width of the grate, and $W_{e}$ is the width from the street side edge of the grate to the edge of the gutter. Further, $d_{e}$ is the water depth at the street side edge of the grate, and $d_{w}$ is the water depth at the edge of the gutter. Note that the labeling is different from that found in the ODOT design manual to help clarify nomenclature and make it consistent throughout this report. The total grate side flow for a composite street and gutter slope is calculated from overlapping triangles $\mathrm{ABC}, \mathrm{DEC}$, and $\mathrm{DEF}$ as follows:

$$
\begin{gathered}
Q_{\text {side }}=Q_{A B C}-Q_{D E C}+Q_{D E F} \\
Q_{A B C}=\frac{K_{u}}{n_{w} S_{w}} d_{e}^{2.67} S_{l}^{0.5}, \\
Q_{D E C}=\frac{K_{u}}{n_{w} s_{w}} d_{w}^{2.67} S_{l}^{0.5}, \\
Q_{D E F}=\frac{K_{u}}{n_{s} s_{x}} d_{w}^{2.67} S_{l}^{0.5}
\end{gathered}
$$

where $n_{w}$ is the Manning number for the gutter surface roughness, and $n_{s}$ is the Manning number for the street surface roughness.

Computational Analysis of Hydraulic Capacity of Ohio DOT Catch Basins On-Grade and in Sag Locations 
The portion of the gutter flow going over the grate is calculated as:

$$
Q_{g r}=Q-Q_{\text {side }}
$$

where $Q$ is the total street and gutter flow that may be computed from eq. (9), or $Q_{g r}$ may be computed directly from eq. (6) as flow in a trapezoidal section referring to Figure 4.2:

$$
Q_{g r}=\frac{K_{u}}{n_{w}} S_{l}^{\frac{1}{2}} S_{w}^{-1}\left(d_{c}^{\frac{8}{3}}-d_{e}^{\frac{8}{3}}\right)
$$

The amount of flow intercepted by the inlet over the outside edge of the grate, $Q_{\text {out }}$, is calculated using eq. (29) for a curb-opening inlet on a continuous grade and using $Q_{\text {side }}$ as the design flow. In these calculations the length of the grate is substituted for the length of curb opening. For the curb and gutter sections, it is assumed that the depression, $a$, which is the depth the grate is depressed below the edge of pavement or gutter at the roadside edge of the grate, is equal to zero. This assumption ignores a small portion of the flow near the road-side edge of the grate.

Total efficiency of the combination inlet is calculated as:

$$
E=\frac{Q_{\text {gr }}+Q_{\text {out }}}{Q} .
$$

\subsection{Sag locations}

Inlets in sag locations operate as weirs or orifices, depending on the ponding water depth, the area of the grate, and the open area fraction of the inlet. Between the two flow conditions there is also a stage where the flow transitions from orifice to weir flow when draining. The water depth at which the flow transitions from one type to another varies for different inlets and needs to be established experimentally, or with the use of CFD.

The design equations presented in HEC 22 and provided by ODOT for sump conditions for curb openings and grate inlets are presented in this section.

\subsubsection{Interception Capacity of Grate Inlets in Sag Locations According to HEC 22}

For grate inlets in sag locations HEC 22 states that: "A grate inlet in a sag location operates as a weir to depths dependent on the size of the grate and as an orifice at greater depths" [2].

The weir flow equation given in HEC 22 is as follows:

$$
Q=C_{w} P d_{g}^{1.5},
$$

where $C_{w}$ is a discharge coefficient, $C_{w}=1.66$ for SI units and 3.0 for English units, $P$ is the perimeter of the grate without the curb side, which is equal to the weir length, and $d_{g}$ is the average depth across the grate, calculated as (see Figure 4.3):

$$
d_{g}=0.5\left(d_{c}+d_{e}\right)
$$


The orifice flow equation given in HEC 22 is:

$$
Q=C_{o} A_{g} \sqrt{2 g d_{g}}
$$

where $C_{o}=0.67, A_{g}$ is the clear opening area of the grate, $g$ is gravitational acceleration $g=9.81 \mathrm{~m} / \mathrm{s}^{2}$ (or in English units $g=32.2 \mathrm{ft} / \mathrm{s}^{2}$ ).

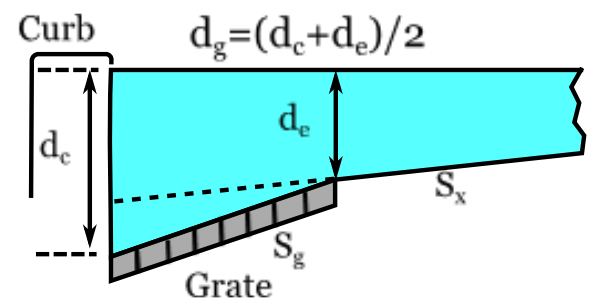

Figure 4.3 Definition of depth in orifice flow condition according to HEC 22.

To facilitate the design process, HEC 22 provides hydraulic engineers with Chart 9A and Chart 9B that plot the relations of the above equations for grates as functions of perimeter for the weir condition and open area for the orifice flow condition on a log-log scale, which yields straight lines. The transition stage is omitted from the chart, and it is recommended to draw a curve between the lines for the corresponding perimeter and area. The clear open area ratio, established in a laboratory setting [19], is also given for a set of grates.

\subsubsection{Interception Capacity of Grate Inlets in Sag Locations According to ODOT}

The design procedure adopted by ODOT also differentiates three types of flow, weir, transition, and orifice flow.

Weir flow is assumed to occur for ponding depth smaller than 0.4 feet and is derived from the general weir flow equation:

$$
Q=3.0 L_{g r} d_{e}^{1.5}+2 \int_{0}^{W_{g r}} 3.0\left(d_{e}+S_{x} x\right)^{1.5} d x
$$

where $d_{e}$ is the depth of ponding at the roadside edge of the grate [ft], $a$ is the depression at the face of curb [ft], $L_{g r}$ is the length of grate [ft], and $W_{g r}$ is the width of grate [ft] and the cross slope $S_{x}$ is calculated as:

$$
S_{x}=\frac{d_{c}-d_{e}}{W_{g r}}=\frac{a}{W_{g r}} .
$$

Substitution of eq. (45) into eq. (44) gives:

$$
\begin{aligned}
Q= & 3.0 L_{g r} d_{e}^{1.5}+6.0 \frac{W_{g r}}{a} \int_{0}^{W_{g r}}\left(d_{e}+\frac{a}{W_{g r}} x\right)^{1.5} \frac{a}{W_{g r}} d x= \\
& =3.0 L_{g r} d_{e}^{1.5}+\left.6.0 \frac{2}{5} \frac{W_{g r}}{a}\left[\left(d_{e}+\frac{a}{W_{g r}} x\right)^{2.5}\right]\right|_{0} ^{W_{g r}}=
\end{aligned}
$$

Computational Analysis of Hydraulic Capacity of Ohio DOT Catch Basins On-Grade and in Sag Locations 


$$
=3.0 L_{g r} d_{e}^{1.5}+2.4 \frac{W_{g r}}{a}\left[\left(d_{e}+a\right)^{2.5}-d_{e}^{2.5}\right] \text {. }
$$

The orifice flow equation applies for depths $d_{e} \geq 1.4^{\prime}$ and is as follows:

$$
d_{e} \geq 1.4^{\prime}: Q=5.37 A_{g} \sqrt{d_{e}+0.5 a},
$$

which corresponds to eq. (43).

It is assumed that when transition flow occurs for depths $0.4^{\prime} \leq d_{e} \leq 1.4^{\prime}$ a proportional transition between weir and orifice flow should be used.

\subsubsection{Interception Capacity of Curb-Opening Inlets in Sag Locations According to HEC 22}

The weir flow equation for a curb opening with a local depression according to Bauer and Woo [12] and repeated by Izzard [13] is:

$$
Q=1.7\left(L+1.8 W_{a}\right)(d+a)^{1.85}
$$

where $d=T S_{x}, a$ is the depth of depression, $W_{a}$ is the width of the local depression, $L$ is the length of the opening.

Bauer and Woo [12] considered only one depression width of $2 \mathrm{ft}$ and local depression depth $a=$ 2 in. They also noted that eq. (48) should not be used to compute discharge for water depths greater than $1 \mathrm{ft}$, because that was the limit of the experimental data. Because surface roughness does not influence the results, the equation can be used for any surface roughness.

In HEC 22 the equation is as follows:

$$
Q=C_{w c}(L+1.8 W) d_{c}^{1.5},
$$

where $C_{w c}=1.25$ (for SI units) or 2.3 (for English units), $L$ is length of curb opening (m or ft), $W$ is lateral width of local depression ( $\mathrm{m}$ or $\mathrm{ft}$ ), $d_{c}$ is depth at curb calculated as for a road with constant cross slope, $d_{c}=T S_{x}$ (m or $\mathrm{ft}$ ). The limitation on the use of this eq. is: $d_{c} \leq h+a, h$ is height of the curb opening ( $\mathrm{m}$ or $\mathrm{ft}$ ), $a$ is depth of depression ( $\mathrm{m}$ or $\mathrm{ft}$ ).

HEC 22 states that: "Curb-opening inlets operate as orifices at depths greater than approximately 1.4 times the opening height." The orifice flow equation is:

$$
Q=C_{o} h L \sqrt{2 g d_{o}}
$$

where $C_{o}=0.67$ is the orifice coefficient, $d_{o}$ is the effective head at the center of the orifice throat $d_{o}=H-0.5 h$, according to Figure 4.4.

Computational Analysis of Hydraulic Capacity of Ohio DOT Catch Basins On-Grade and in Sag Locations 


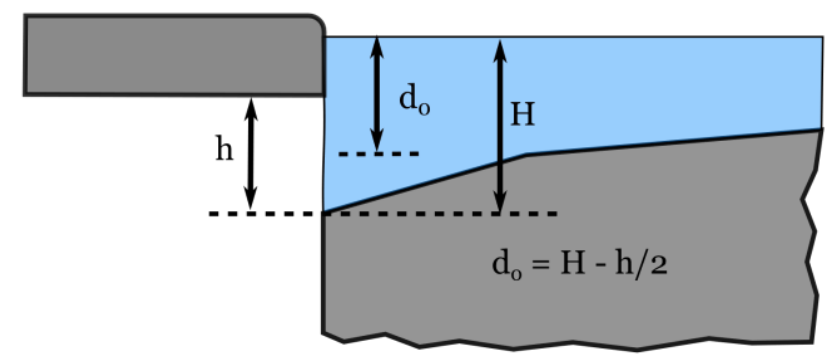

Figure 4.4 Definition of depth for curb opening inlets with horizontal throat in sump conditions according to HEC 22 [2].

\subsubsection{Interception Capacity of Curb-Opening Inlets in Sag Locations According to ODOT}

The engineers at ODOT use the following equation in the design of curb opening inlets. The discharge of a curb opening when it works as a weir is (English units):

$$
\frac{H}{h} \leq 1: Q=3.087 L H^{1.5}
$$

where $h$ is the height of the curb opening (ft), and $H$ is water depth at the opening entrance (ft), and $L$ is the curb opening length (ft).

The weir flow equation (51) is different from eq. (49) in a way that it does not include the influence of the local depression width on the flow.

The discharge for the orifice flow condition is calculated as (English units):

$$
\frac{H}{h} \geq 2: Q=5.62 h L \sqrt{H-0.5 h},
$$

The orifice flow equation differs from the one found in HEC 22. Equation (52) has a factor of 5.62, whereas in eq. (50) there is $C_{o} \sqrt{2 g}=0.67 \sqrt{2 \times 32.174}=5.37$. The source and derivation of eq. (52) is unknown to the authors, and the assumption is that a different value of the orifice coefficient, $C_{o}=0.7$, was used in [9].

It is assumed that transition between weir and orifice flows occurs at depths when the ratio of water depth to opening height is $1 \leq \frac{H}{h} \leq 2$. For those depths, a proportional transition is used.

The ODOT estimate is therefore more conservative than HEC 22 for depths in the range $1.4 \leq \frac{H}{h} \leq$ 2 , as a linear interpolation gives higher depths than the orifice flow equation.

\subsubsection{Interception Capacity of Combination Inlets in Sag Locations According to ODOT and HEC 22}

Both, HEC 22 and ODOT design procedures, assume that the weir flow discharge for combination inlets is characterized by the same equation as that used for a grate inlet, (41) or (46), respectively. The discharge in orifice flow is a sum of the flow rate through the grate and curb opening, i.e. equations (43) and (50), or (47) and (52), respectively. The ODOT procedure states that for depths between $0.4^{\prime} \leq d_{1} \leq 1.4^{\prime}$ a proportional transition is used, the same way as for grates. HEC 22

Computational Analysis of Hydraulic Capacity of Ohio DOT Catch Basins On-Grade and in Sag Locations 
does not specify the limits for transition flow, therefore the smaller discharge calculated from weir flow equation and orifice flow equation for a given water depth is selected, to obtain a more conservative result.

HEC 22 design recommendations are based on experiments performed by Burgi et al. [19] for a combination of a grate and a curb-opening inlet. The adopted test conditions were:

- grates tested: $\mathrm{P}-1^{1} / 8, \mathrm{P}-1^{7} / 8^{-} 4$, curved vane grate $\mathrm{CV}-3^{1} / 4^{-}-4^{1} / 4$,

- $\quad$ grate sizes: $3 \mathrm{ft}$ by $4 \mathrm{ft}, 3 \mathrm{ft}$ by $2 \mathrm{ft}, 2 \mathrm{ft}$ by $4 \mathrm{ft}, 2 \mathrm{ft}$ by $2 \mathrm{ft}, 1.25 \mathrm{ft}$ by $2.67 \mathrm{ft}, 1.25 \mathrm{ft}$ by $2 \mathrm{ft}$,

- longitudinal slope: $0.2 \%$,

- uniform gutter cross slopes: 1/48 - 1/16 (2.08\% - 6.25\%),

- maximum flow depth 10 in,

- Manning roughness factor: 0.016, 0.017 .

Computational Analysis of Hydraulic Capacity of Ohio DOT Catch Basins On-Grade and in Sag Locations 


\section{CFD Modeling}

The Unsteady Reynolds Averaged Navier-Stokes Solver with k-epsilon turbulence model was used in the CFD modeling. The Eulerian two-phase model with a gas phase, air, and liquid phase, water, combined with the Volume of Fluid (VOF) physics model was selected to model the water flow with a free surface and air above. Detailed information about the formulations and usage can be found in the STAR-CCM+ documentation [20].

Separate CFD models were developed for the two flow conditions that occur in the on-grade locations and sag locations. They differ in geometry, boundary conditions, and initial conditions. A description of the model for the on-grade locations can be found in Section 5.1 and for the sump conditions in Section 5.2.

A hexahedral mesh was used to discretize the continuum with cell size transitioning from a millimeter ( 0.04 inch) to represent the geometry of the vane bars in a grate, to a few centimeters ( $\sim 1$ inch) in the sections of the road away from the places of interest in the flow. The mesh size in the vertical direction is smaller than in-plane horizontal dimensions to resolve the water surface and vertical velocity profile more accurately while retaining a computationally efficient grid.

The influence of pavement roughness on the pool spread and efficiency of the catch basin was analyzed. A roughness height model [20] and a porous region model, developed by the authors, and presented in [21], as well as a smooth no-slip wall, were investigated in modeling the pavement surface. The details of these modeling approaches are presented in Section 5.3.

\subsection{On-Grade Locations}

The geometry of the CFD model built to analyze the interception of catch basins installed on a continuous grade covers a section of a road with a longer fraction of the road upstream and shorter fraction downstream of the catch basin because convection dominates the solutions and the downstream in these problems has only minor effects on the upstream conditions. The width of the road is assumed to be wider than the expected spread of the flow. The longitudinal slope is modeled by introducing a component of gravitational acceleration in the longitudinal direction along the travel lanes.

Simulations were initialized with the computational domain filled with air. Water was introduced to the computational domain through the vertical boundary across the road upstream of the catch basin at the upstream end of the model domain, which was assigned a velocity inlet boundary condition.

The inlet velocity profile is computed in a separate, CFD model of a $1 \mathrm{~cm}(\sim 0.5 \mathrm{inch})$ thick crosssection of a road. The shape of the model represents a cross-section through a body of water with spread (depth) and mass flow rate corresponding to each case from the case matrix. It is a singlephase model, with symmetry boundary condition on the top surface, representing the water surface, and cyclic boundary condition on the front and back surfaces. The cyclic boundary condition feeds the fluid leaving at the outlet boundary back into to upstream inlet boundary at the outlet velocity at each location. This additional model is run allowing the velocity distribution to evolve until a steady state is reached, and the velocity profile is fully developed.

Computational Analysis of Hydraulic Capacity of Ohio DOT Catch Basins On-Grade and in Sag Locations

Page | 21 
Figure 5.1 shows an axisymmetric view of the model of a thin strip of the road cross-section for an 8-foot spread and Figure 5.2 shows the velocity profile obtained from that CFD model. The resulting distribution of velocity magnitude is tabularized and imported in the main simulation as the inlet velocity. This procedure for determining inlet velocity distribution yields a distribution with velocities that are much higher than the mean of $V=Q / A$ in the zone where the water is the deepest and much lower that the mean where the water layer on the street is the thinnest, which is much more realistic than assuming a uniform velocity inlet at $V=Q / A$.

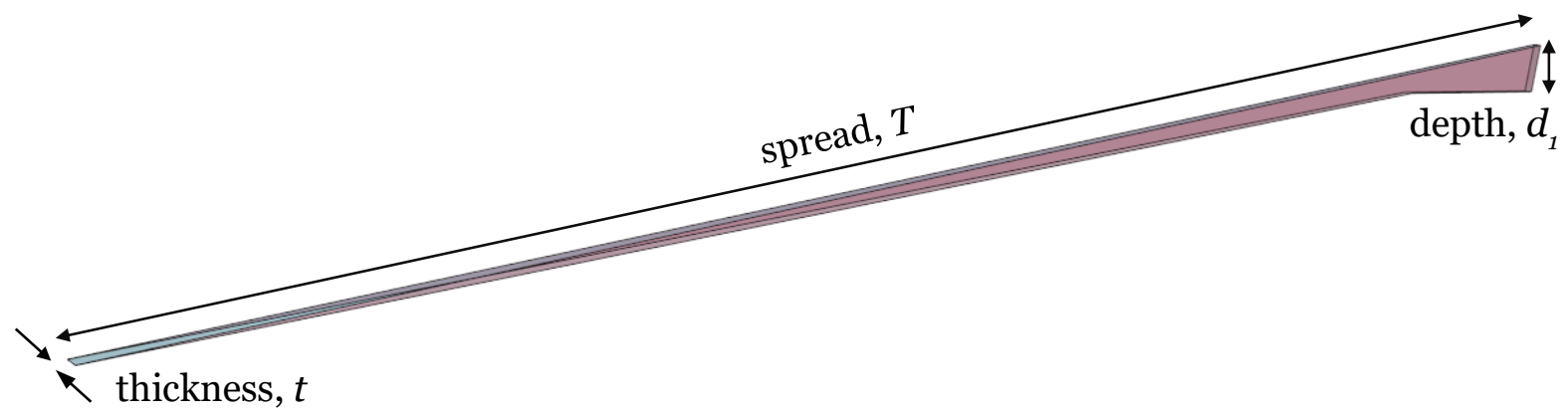

Figure 5.1 Axisymmetric view of an example CFD model of a thin strip of the road cross-section for a 8-foot spread.

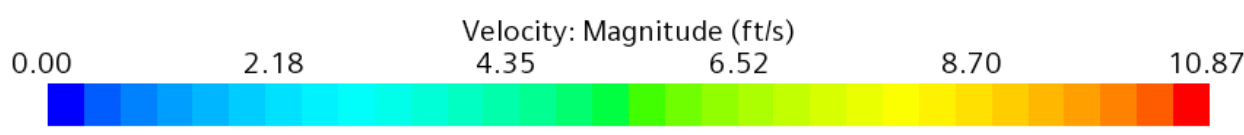

Figure 5.2 Velocity profile obtained from a CFD model of a thin strip of the road cross-section for a 8-foot spread.

Using a fully developed velocity profile at the inlet allowed a reduction of the length of the computational domain upstream of the drain and a saving of computational resources. The flow can leave the domain through the grate inlet or the window, or it can bypass the drain. These boundary surfaces were assigned a pressure outlet boundary condition, where the pressure is zero-gauge pressure at the boundary plus static pressure minus dynamic pressure within the water leaving through the boundary. A pressure outlet boundary condition was also defined on the top of the domain. This boundary is in the air above the water surface and is set to zero-gauge pressure. The surface representing the road median side boundary of the domain was assigned a symmetry boundary condition. The median side boundary is also in air only, and the symmetry boundary condition provides a free slip condition for any air flow that is present at that boundary, but no air can cross it. A perspective view of the computational model is presented in Figure 5.3, and a closeup view of the catch basin is presented in Figure 5.4.

The pavement was modeled in two ways, as a wall boundary condition with an assigned roughness height, or as an additional volume with properties of a porous medium and roughness height thickness, as shown in Figure 5.3. The details of the pavement modeling are presented in Section 5.3 .

Computational Analysis of Hydraulic Capacity of Ohio DOT Catch Basins On-Grade and in Sag Locations 
pressure outlet b.c.

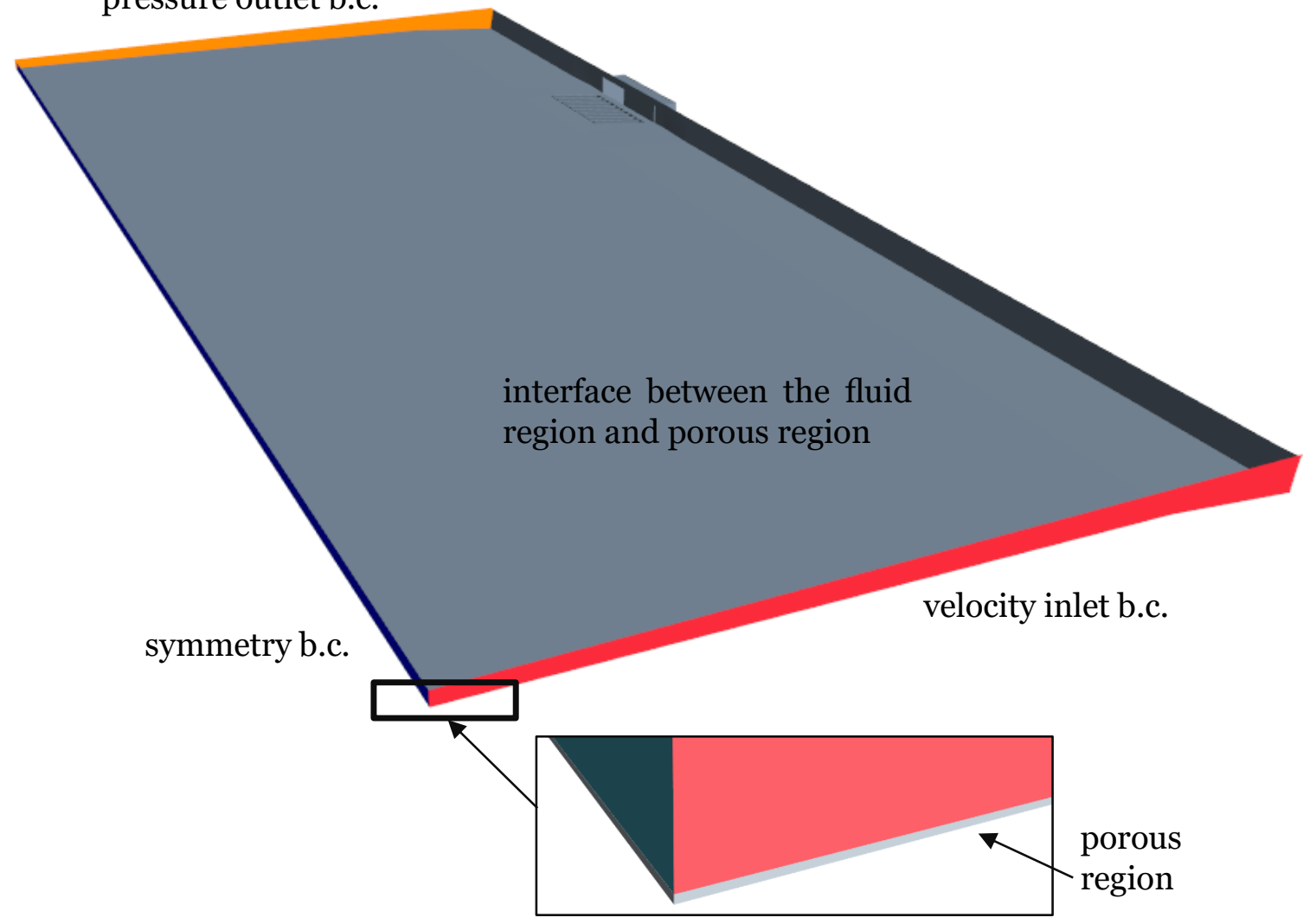

Figure 5.3 Perspective view of the model with boundary conditions marked with different colors: grey - wall b.c., red - velocity inlet b.c., orange - pressure outlet b.c., blue - symmetry b.c. The top surface of the domain (not shown here) has assigned a pressure outlet b.c., and a close-up of the porous layer (grey).

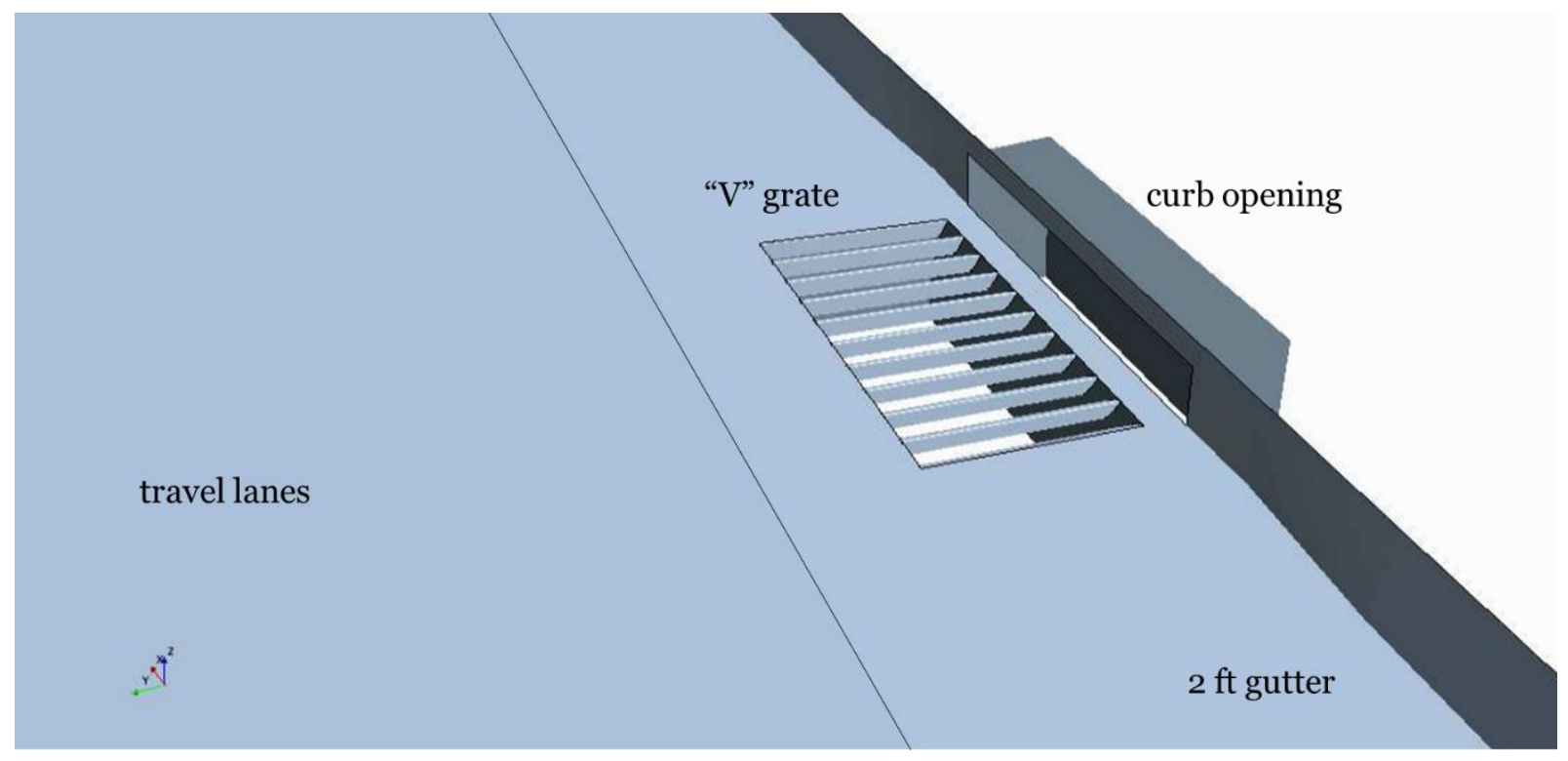

Figure 5.4 Close-up of the catch basin geometry.

Computational Analysis of Hydraulic Capacity of Ohio DOT Catch Basins On-Grade and in Sag Locations

Page | 23 
The trimmed cell mesher was used to discretize the computational domain with hexahedral cells. Also, the prism layer mesher was used to create a $1 \mathrm{~mm}$ (0.04 inch)-thick layer of cells in the vicinity of wall surfaces, road, grate, curb, and catch basin walls. The smallest cells were used around the grate, with a face size of $1 \mathrm{~mm}$ in length. Away from the grate, the cell face size varies in plane from $2 \mathrm{~cm}$ to $5 \mathrm{~cm}(\sim 1$ inch to $\sim 2 \mathrm{inch})$. In the part of the domain where water flow is expected, vertical cell thickness is decreased to $5 \mathrm{~mm}$. A porous region accounting for road roughness was meshed with 5 cells across the thickness of the layer. The discretization used in the model is presented on two plane sections in Figure 5.5. The width and length of the domain varied due to the flow spread, e.g., it was smaller for the 2-foot spread than for the 10-foot spread, to save on computational time. Therefore, the total number of computational cells in the mesh varied from a few million to approximately 20 million.

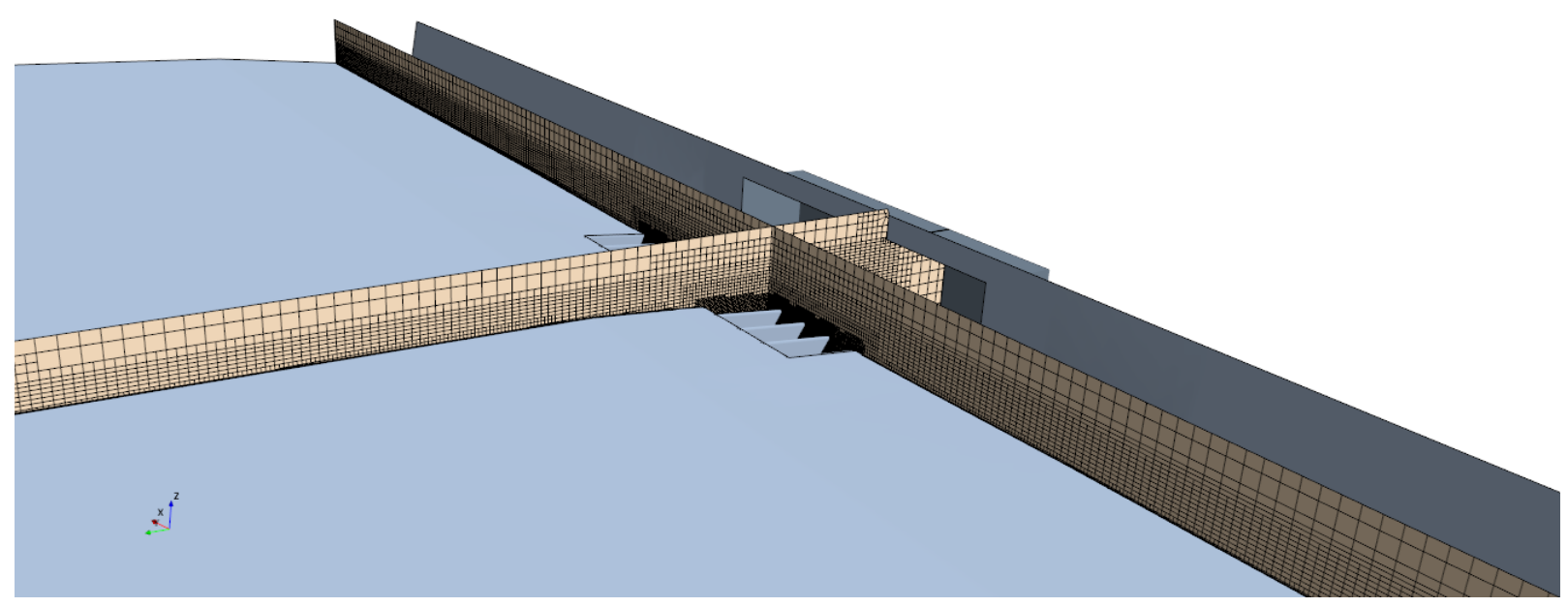

Figure 5.5 Discretization of the domain in the vicinity of the catch basin.

Each simulation, with varied longitudinal slope and discharge, was run using the unsteady solver until a steady state was reached. The solution determines the flow split between the grate, curb opening, and street outlets, which is a function of the resistance along the flow paths through the domain. The front, side, and bypass flow, as well the flow through the window and the grate, were recorded at the end of a simulation and the results were used to calculate the efficiency of the catch basin as a function of the geometry and flow conditions.

The time step was chosen according to the input parameters of the simulation; for the cases with faster moving water, it was decreased to better capture the details of the flow pattern above the grate. The simulated time, needed to obtain a converged solution, differs from case to case because it depends on the residence time of the flow in the domain, which in turn depends on the mean flow velocity. The computations were stopped when the mass rate of the inflowing and outflowing fluid was in balance. Note that there were three outlets: through the grate, through the curb opening, and bypass flow on the street. 


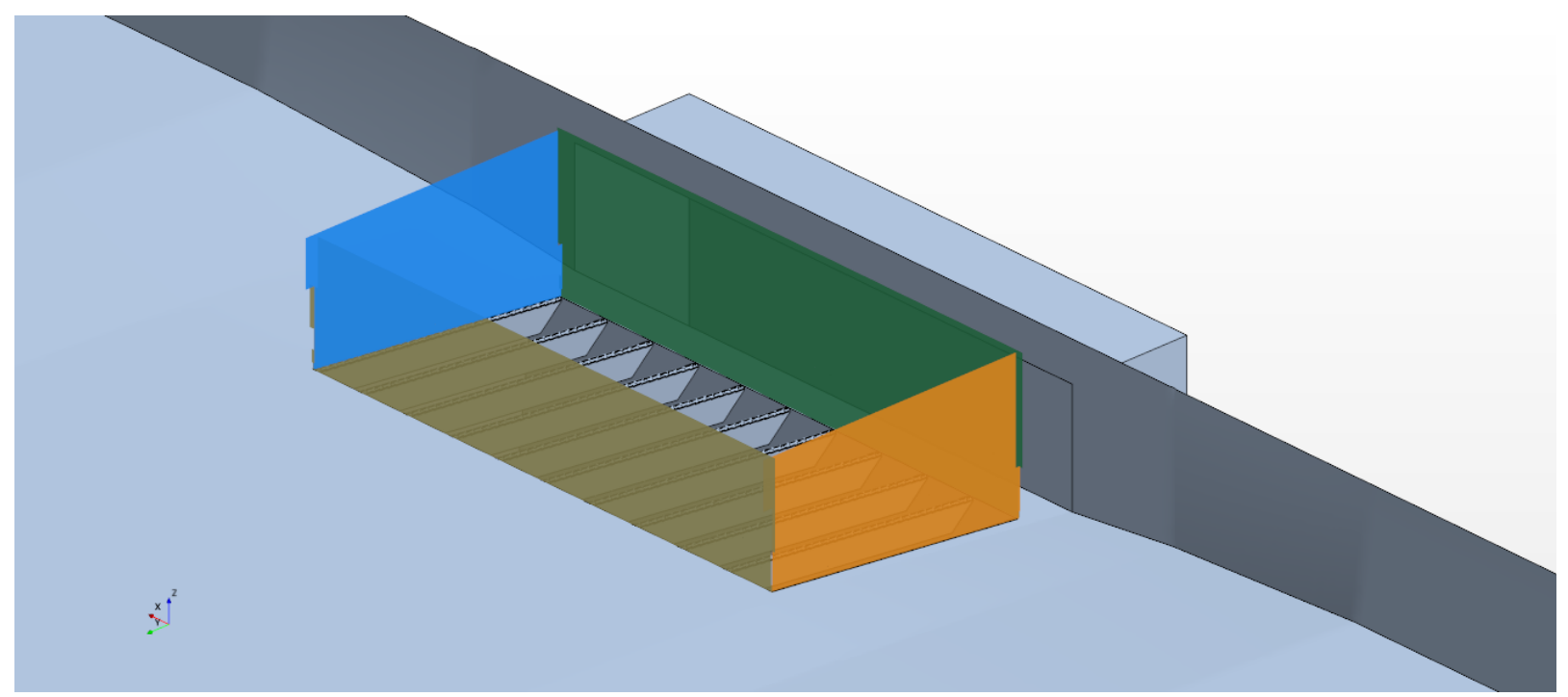

Figure 5.6 Planes used to monitor flow into the grate.

Section planes were also placed at the upstream front (orange), at the road side (yellow), at the downstream back side of the grate (blue), as well as at the curb side of the grate (green). The water mass flow was monitored on these planes for the purpose of calculating the ratios of the front and side flow to the total flow going through the grate.

The mass flow rate through a surface was computed as an integral over the surface:

$$
\dot{m}=\iint \rho_{w} \phi_{w} \mathbf{v} \cdot \mathbf{n} d A
$$

where $\rho_{w}$ is water density, $\phi_{w}$ is volume fraction of water, $\mathbf{v}$ is velocity vector, $\mathbf{n}$ is a unit vector normal to the surface, and $A$ is the area of the surface. The volume fraction factor is needed because the flow in computational cells near the water surface is also partly air and multiplying by the volume fraction of water excludes the flowing air mass. The water discharge through the surface area $A$ is:

$$
Q=\frac{\dot{m}}{\rho_{w}}
$$

The collected data was used to calculate the efficiency of the catch basin, $E_{C F D}$, as a ratio of the flow intercepted by the grate, $Q_{i g}$, and the curb opening, $Q_{i w}$, to total flow, $Q$ :

$$
E_{C F D}=\frac{Q_{i g}+Q_{i w}}{Q}
$$

as well as the bypass flow, $Q_{b}$, that is not intercepted by the inlet:

$$
Q_{b}=Q-Q_{i}, \quad Q_{i}=Q_{i g}+Q_{i w}
$$

Computational Analysis of Hydraulic Capacity of Ohio DOT Catch Basins On-Grade and in Sag Locations 


\subsection{Sag Locations}

The geometry of the computational model used to analyze the sump condition covers a section of a road upstream of the catch basin and half of the CB3 catch basin. Being a double catch basin with a symmetric geometry, it can be assumed that the flow through the inlet is also symmetric. This assumption makes it possible to use only half of the model and therefore decrease the resources needed to complete a simulation. The height of the domain is significantly greater than the one used in the study of on-grade conditions in order to capture the orifice flow conditions that occur at higher flow depths. A perspective view of the computational domain is presented in Figure 5.7.

A transient model was built, in which the domain is initially filled with water up to a depth sufficient to produce orifice flow conditions. During the simulation, the water drains through the grate and/or curb opening until all water leaves the domain. The discharge versus time and average water depth versus time data are recorded and as a final step, the data are combined to show the relationship between the discharge capacity and ponding depth.

Figure 5.8 shows the discretization of the computational domain on two representative planes crossing the model and a close-up of the mesh in the vicinity of the grate. A transition of cell size around the vanes of the grate was defined to better capture smaller details of the flow in that part of the model.

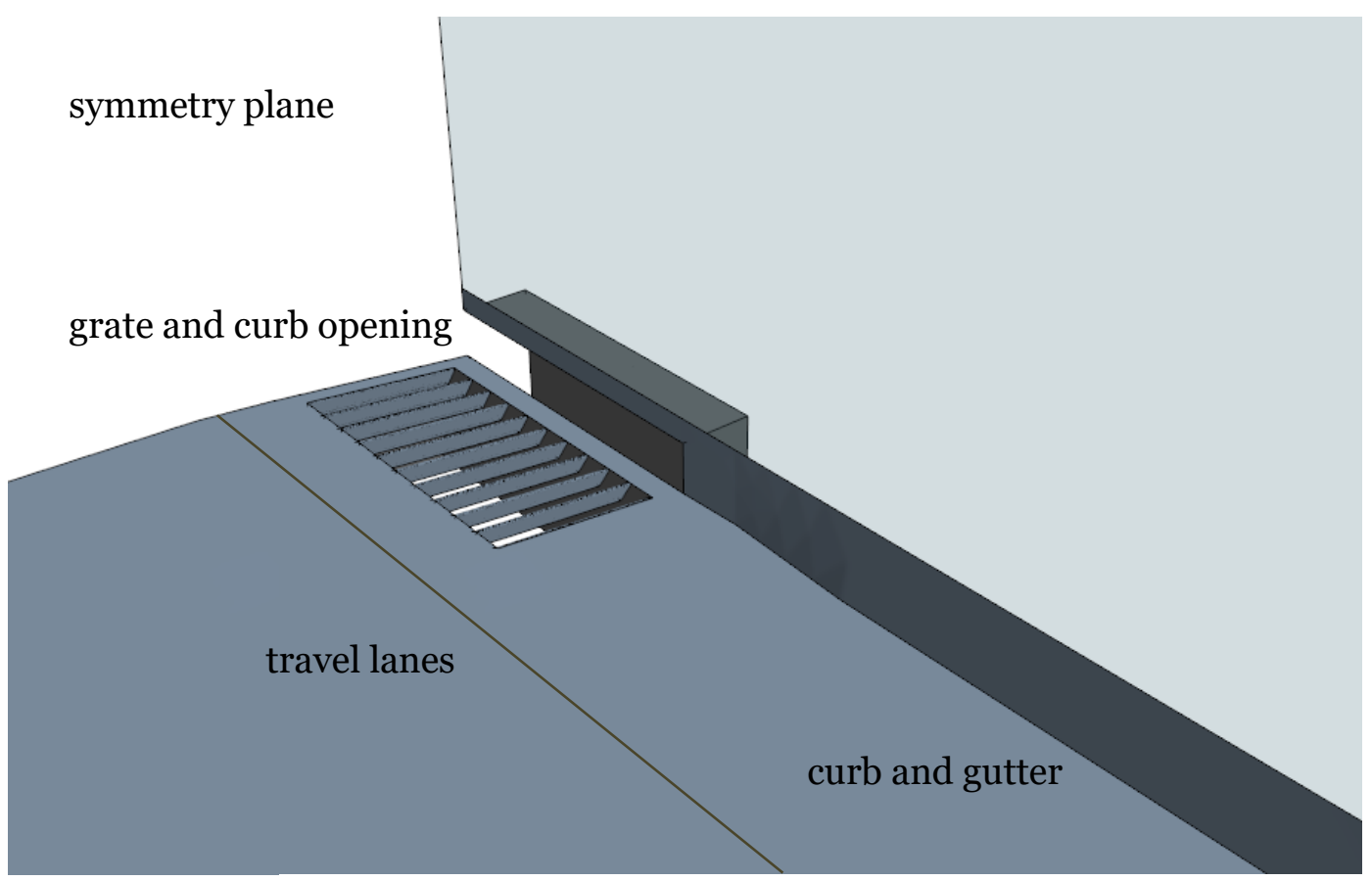

Figure 5.7 Perspective view of the model. 


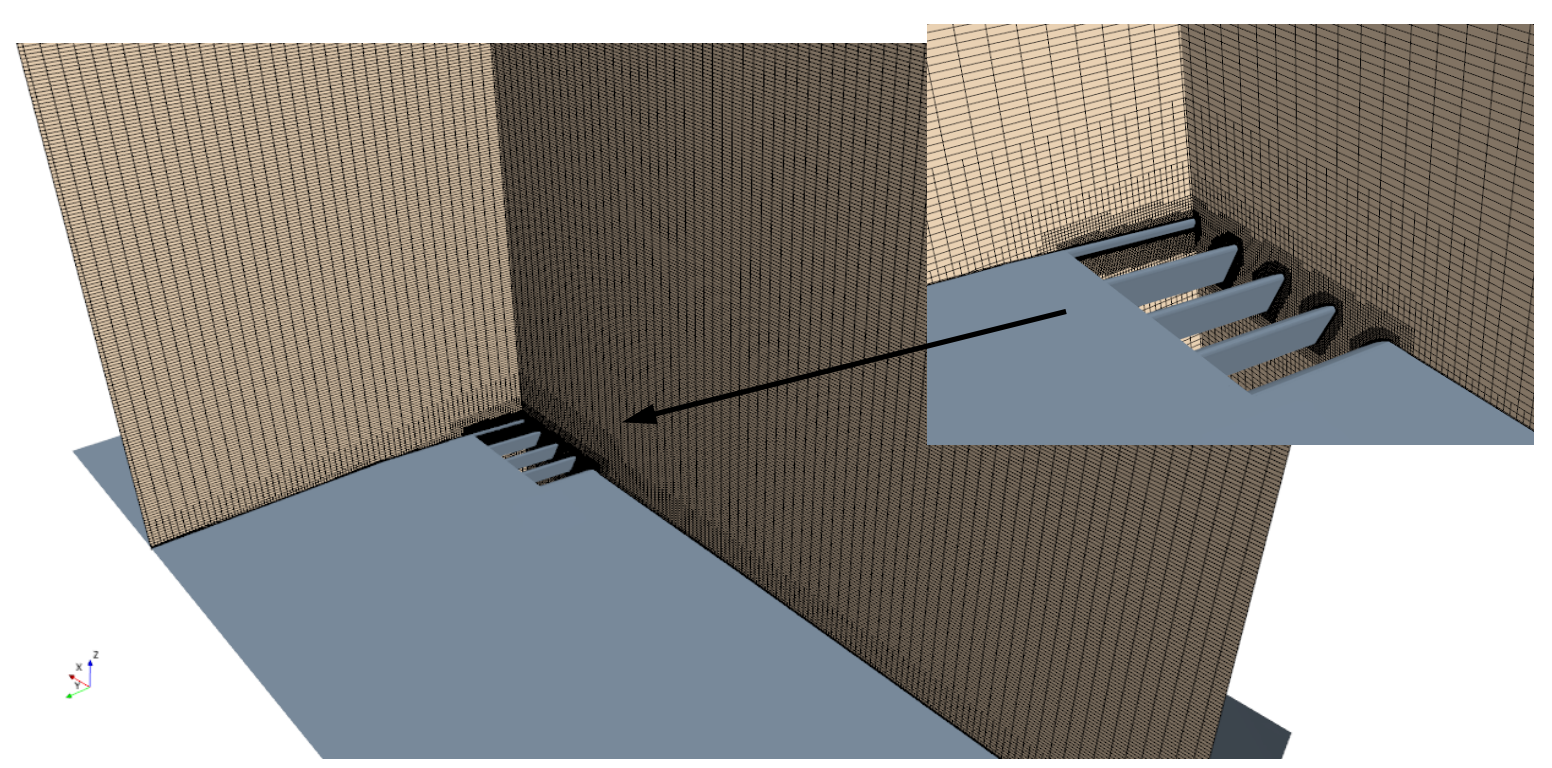

Figure 5.8 Discretization of the computational domain shown on planes across the model. Close up of the transition of cell size around the vanes of the grate.

\subsection{Modeling Pavement Roughness}

The pavement surface can be modeled in CFD in various ways, by including the effect of surface roughness or disregarding it. The simplest approach is to model the surface as smooth i.e., without roughness. Previous studies showed that this assumption gives good approximations of the flow for nearly smooth surfaces, when roughness height is up to a fraction of a millimeter [22]. This assumption is appropriate for concrete roads and other smooth surfaces but may not be sufficient for the range of textures of asphalt roads and similar road surfaces, which are usually significantly rougher than concrete.

Alternative methods for accounting for the roughness of asphalt roads were investigated in a previous study [22], where roughness of the pavement surface was represented in three ways: with a roughness coefficient or roughness height, with a meshed-out geometry of the surface, and with a porous region. In the current study, the roughness height approach and porous region model were considered. Meshing out the aggregate was not considered because doing it on a large section of pavement was deemed to be computationally too expensive.

In hydraulic engineering, the Manning roughness coefficient is often used to characterize roughness, and its values are derived from experiments or assumed from empirical tables. In most CFD software, STAR-CCM+ included, the user needs to specify a roughness height parameter, $k_{s}$, giving the equivalent sand-grain roughness height on a surface. In the version of the software used in this study, STAR-CCM+ v.16.02, roughness height can be greater than half of the first cell layer thickness.

Roughness height and Manning's roughness coefficient do not represent the same physical parameter and have different units ( $k_{s}$ has units of length and Manning's $n$ has units of time/length $\left.{ }^{1 / 3}\right)$. Nevertheless, they both characterize the effect of surface roughness on flow and relations between them were developed to allow determination of equivalent roughness height in

Computational Analysis of Hydraulic Capacity of Ohio DOT Catch Basins On-Grade and in Sag Locations 
CFD analysis from a given Manning coefficient value. One of these relations is Strickler's equation [23]:

$$
n=0.038 k_{s}^{1 / 6}, \text { or } k_{s}=\left(\frac{n}{0.038}\right)^{6}
$$

where $k_{s}$ is roughness height in meters and $n$ is the Manning coefficient. A unit conversion factor should be used to obtain roughness height in English units.

An alternative relationship between the Manning's roughness coefficient and roughness height can be derived from the rough, turbulent portion of the Colebrook-White relation for $k_{s}$ [23]:

$$
k_{s}=12.27 d\left(10^{\frac{d^{(1 / 6)}}{(-2.03) n \sqrt{8 g}}}\right)
$$

where $d$ is flow depth $[\mathrm{m}]$ and $g$ is gravitational acceleration $\left[\mathrm{m} / \mathrm{s}^{2}\right]$. A unit conversion factor should be used to obtain roughness height in English units.

Figure 5.9 presents the Strickler and Colebrook-White equivalent roughness height as a function of Manning's coefficient. For example, for Manning number of $0.015 \mathrm{~s} / \mathrm{m}^{1 / 3}$, Strickler's relation gives $k_{s}=3.78 \mathrm{~mm}$ (0.15 in), while McGahey's relation depends on the water depth and for water depth of $0.01 \mathrm{~m}$, gives $k_{s}=2.33 \mathrm{~mm}(0.1 \mathrm{in})$, for water depth of $0.05 \mathrm{~m}$, gives $k_{s}=3.45 \mathrm{~mm}$ ( $0.136 \mathrm{in})$, and for water depth of $0.1 \mathrm{~m}$, gives $k_{s}=3.66 \mathrm{~mm}(0.144 \mathrm{in})$. The use of a mean flow depth is assumed to be adequate for engineering purposes. 


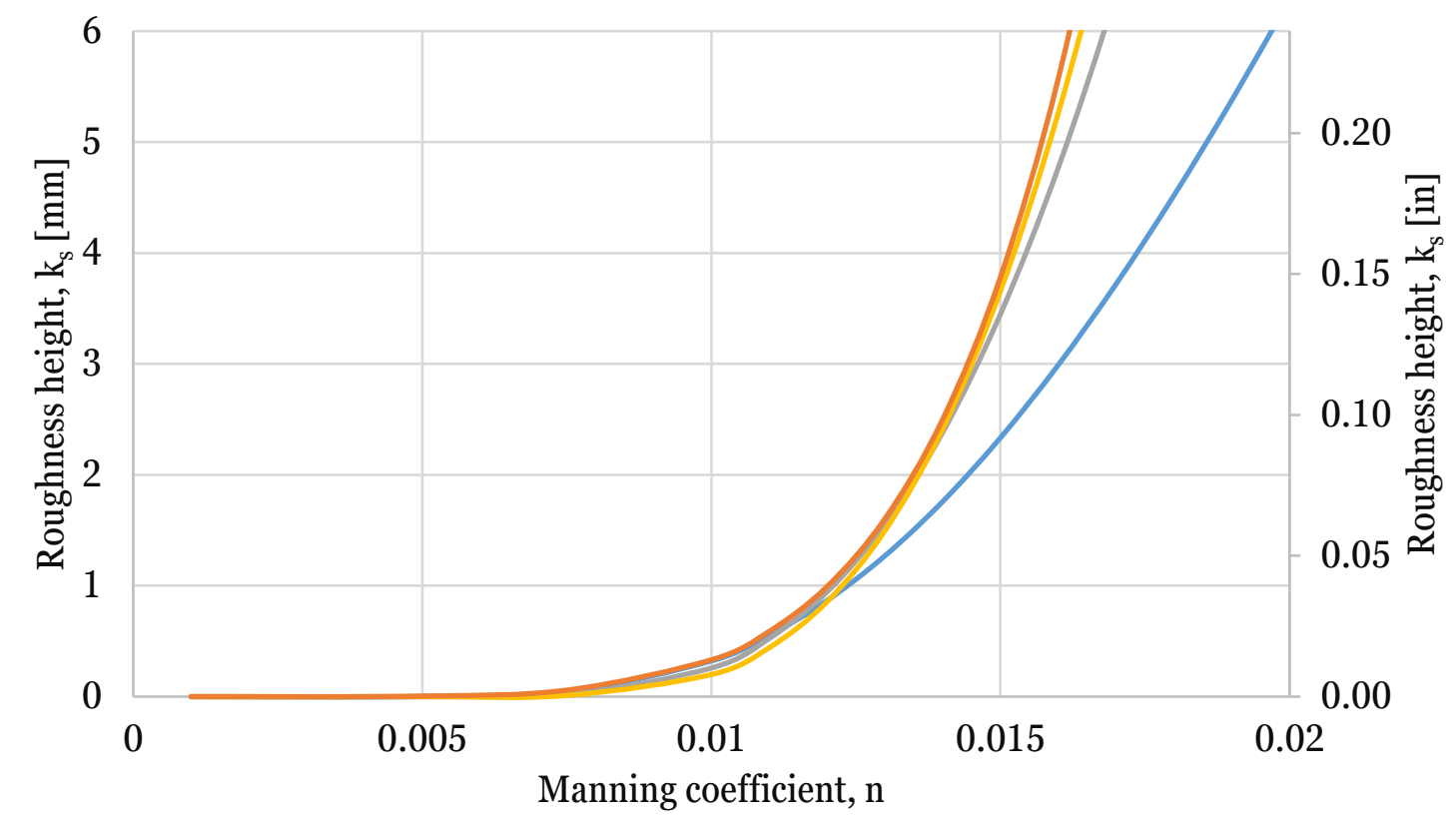

Colebrook-White, $\mathrm{d}=0.01 \mathrm{~m}$ (0.39in) —Colebrook-White, $\mathrm{d}=0.05 \mathrm{~m}$ (1.97in)

Colebrook-White, $\mathrm{d}=0.1 \mathrm{~m}$ (3.94in) — Strickler

Figure 5.9 Prediction of roughness height from Manning coefficient by Colebrook-White and Strickler formulas.

In another approach, the rough pavement surface was modeled as a packed bed of spheres with diameter equal to the aggregate size, assumed to be equal $13 \mathrm{~mm}$ and thickness of the roughness height, $k_{s}$. The average roughness height was estimated as $4 \mathrm{~mm}$. A sensitivity study was performed on a selected set of cases from the case matrix, to establish the influence of the porous media thickness ( $3 \mathrm{~mm}$ and $4 \mathrm{~mm}$ ).

A porous medium is characterized by three main parameters: porosity, porous inertial resistance, and porous viscous resistance. The resistance to flow within the porous media is related to the surface area per unit volume, which is determined from the aggregate size and porosity. Previous study by the authors [22] showed that the best fit to experimental measurements of water film thickness is obtained when porosity is equal 0.5.

The porous resistance was estimated from the Ergun relationship between pressure drop across a length, $L$, of a porous region and fluid velocity for a packed bed of spheres [20]:

$$
\begin{gathered}
-\frac{\mathrm{d} p}{L}=P_{v} v_{s}+P_{i}, v_{s}^{2}, \\
P_{v}=\frac{150 \mu(1-\chi)^{2}}{\chi^{3} D_{p}^{2}}, P_{i}=\frac{1.75 \rho(1-\chi)}{\chi^{3} D_{p}}
\end{gathered}
$$

where $P_{v}$ is the viscous term, $P_{i}$ is the inertial term, $\rho$ is fluid density, $\mu$ is fluid dynamic viscosity, $v_{S}$ is fluid superficial velocity through the medium, and $D_{p}$ is particle diameter (aggregate size). 
The bottom surface of the domain is a no-slip wall boundary. In the porous media model, the details of flow in the void space between solid asperities are not calculated and the flow solution represents a volume average that accounts for the presence of the surface texture without resolving the asperities in the surface. A sketch of a rough surface with a corresponding CFD two-region model is presented in Figure 5.10. The bottom region is a porous media region, and the region on top is a fluid region [20]. An internal interface joins the two regions within the same continuum.

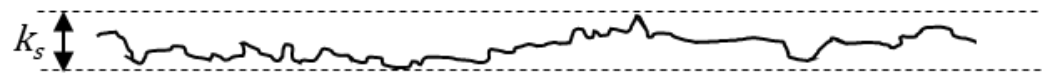

(b)

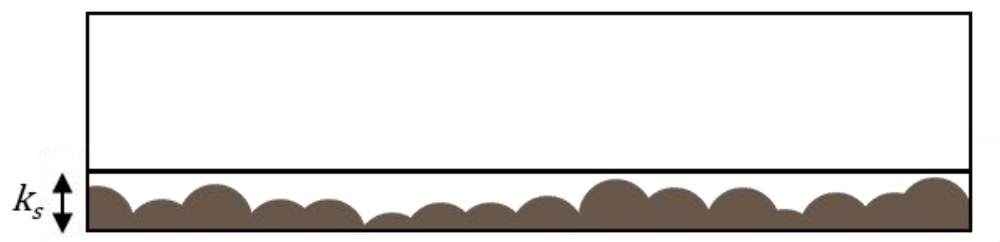

(c)

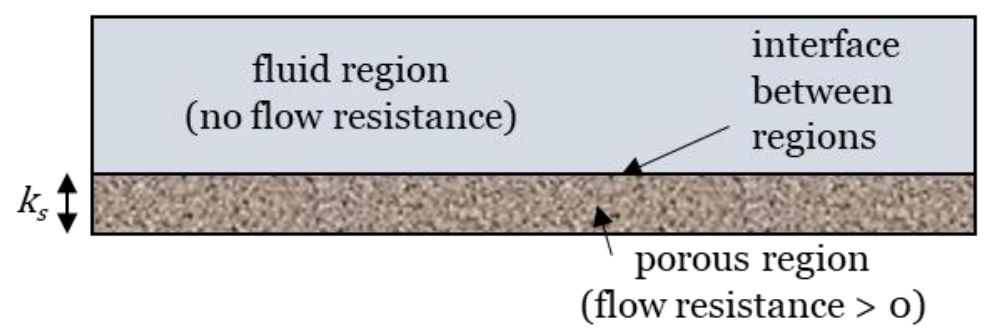

Figure 5.10 Representation of a surface profile with a porous medium, (a) surface profile, (b) approximation of the aggregate with spheres, (c) computational model.

\subsection{Inlet Clogging in On-Grade Locations}

Grate inlets can often become partially or fully clogged with debris if they are not properly maintained. Clogging leads to a decrease in the efficiency of a catch basin and may lead to an increase in pool spread and depth during rain events.

A limited computational analysis was performed to evaluate the influence of clogging on the inlet efficiency as well as the depth and spread of the pooling water based on a few scenarios. Clogging of the grate was modeled by blocking $10 \%, 30 \%$, and $50 \%$ of the upstream area of the grate, as depicted in Figure 5.11. This kind of model may represent a thin layer of fallen leaves or similar debris, which is one of the major problems in grate inlet maintenance.

An additional case was considered in which the entire curb opening is blocked, and the grate is fully operational, to evaluate the influence of curb opening on the efficiency of combination inlets in on-grade locations. The geometry of this model is presented in Figure 5.12. A similar analysis was performed for CB 3 catch basin in a sag location and the results are presented in Section 6.2. 


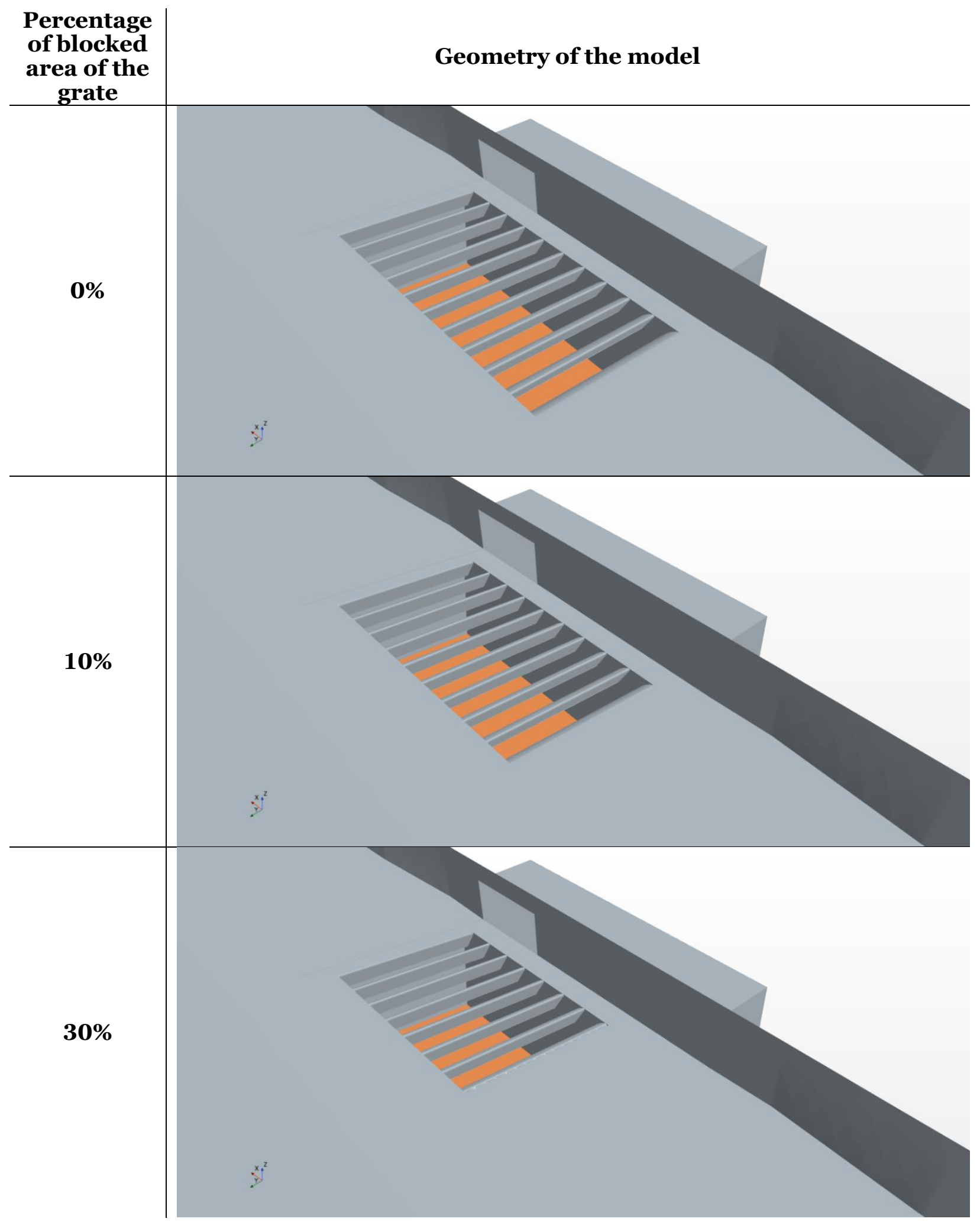

Computational Analysis of Hydraulic Capacity of Ohio DOT Catch Basins On-Grade and in Sag Locations 


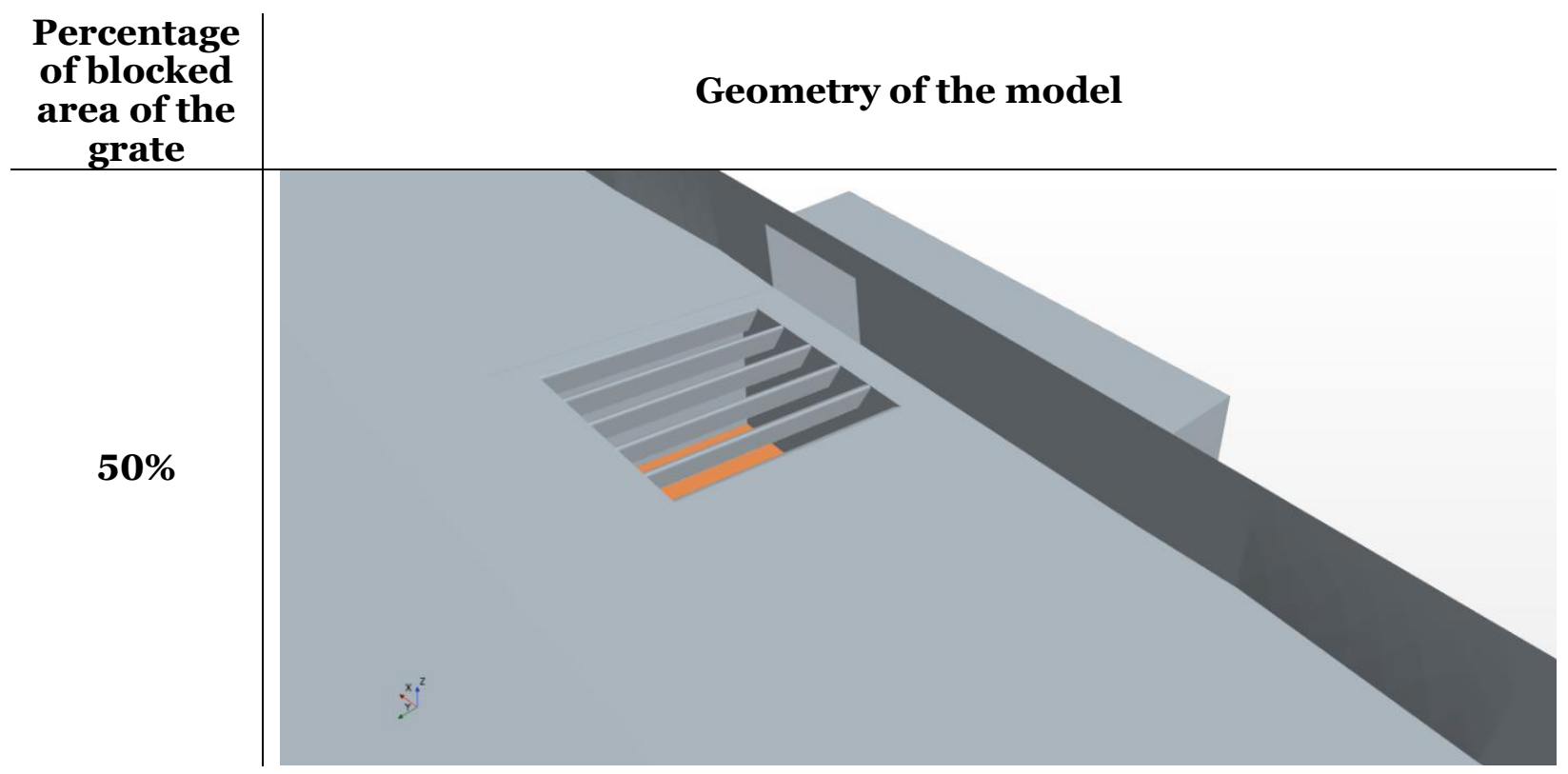

Figure 5.11 Geometry of the models with $0,10,30$, and $50 \%$ clogging of the grate.

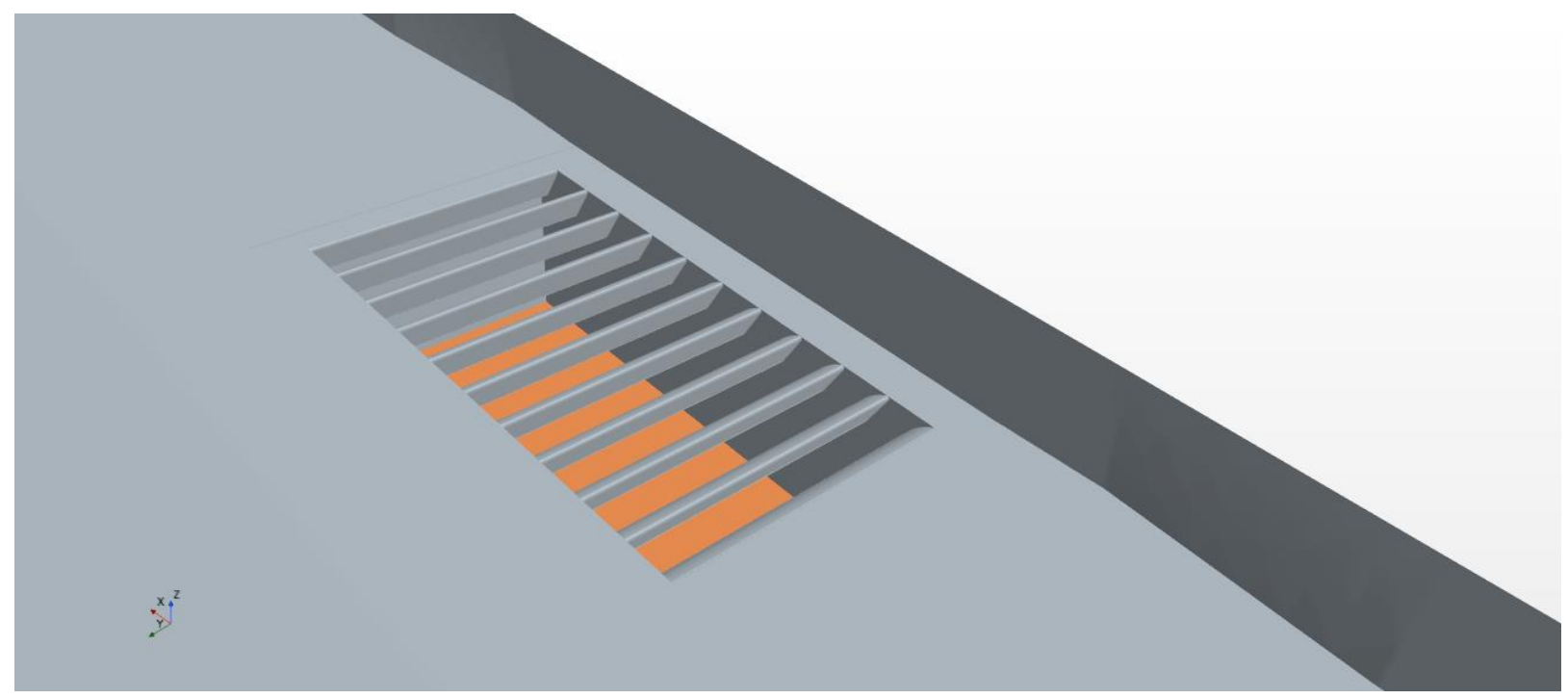

Figure 5.12 Model with entirely blocked curb opening.

Computational Analysis of Hydraulic Capacity of Ohio DOT Catch Basins On-Grade and in Sag Locations 


\section{Simulation Results}

The following section of the report presents the results of the three-dimensional computational fluid dynamics simulations of the flow capacity of catch basins CB3 and CB3A in on-grade and sag locations.

The influence of the roughness model on the flow on pavements for on-grade locations is analyzed based on two cases with different longitudinal grade and flow rate. Flow patterns and estimated catch basin efficiency are compared for (1) a smooth surface, (2) roughness modeled with roughness height, and (3) roughness modeled with a porous region. Examples of flow patterns observed in the simulations are presented. The hydraulic efficiency of the catch basin and the fractions of flow over the grate entering from the upstream edge and from the side of the grate, as well as through the curb opening, are studied as a function of various parameters. Modeling results are presented in the form of surface and line plots.

For catch basins in the sump condition, three scenarios were considered (1) unclogged grate and curb opening, (2) unclogged grate and fully clogged curb opening, and (3) fully clogged grate and unclogged curb opening. Dependence of the capacity of the drainage on various parameters was analyzed and the results are presented in form of data tables and graphs of water depth vs. discharge.

\subsection{On-Grade Locations}

\subsubsection{Influence of Pavement Roughness Model}

As described in Section 5.3, the roughness of the pavement was modeled in two ways: using wall roughness models available in STAR-CCM+ with a specified roughness height, and using an approach developed by the authors, where the rough surface of a pavement is represented with a porous layer with the thickness equal to the roughness height.

The spread of pooling on the pavement surface, which varies between cases and depends on the road geometry and inflow rate, is found in the simulations as an isoline of volume fraction of water equal to 0.5 on the road surface identifying the location of the water surface-air boundary (on the top of the asperities of the pavement). In the models with a porous region modeling the pavement, another isoline locating the position of the edge of the water can be found on the bottom surface of the porous layer, which represents the spread of the flow in the layer of aggregate.

Two cases considered in this part of the report are: a 2-foot composite curb and gutter with longitudinal grade $0.0025 \mathrm{ft} / \mathrm{ft}$, at flow rate of $0.187 \mathrm{cfs}$, and a 2 -foot composite curb and gutter with longitudinal grade of $0.08 \mathrm{ft} / \mathrm{ft}$, at flow rate $4.6 \mathrm{cfs}$. These two cases differ in the resulting spread as well as velocity of the flow and therefore are representative of the range of parameters tested in this study.

Figure 6.1 presents spreads for cases with a 2-ft-wide composite curb and gutter, and inlet water depth at curb $0.167 \mathrm{ft}$, and flow rate $0.187 \mathrm{cfs}$, and varying pavement roughness models. Figure 6.2 shows the top view of the model with a $4 \mathrm{~mm}$-thick, porous layer with water surface colored with elevation. Note that the elevation, Position[Z], equals zero at the lowest point of the gutter. Figure 6.3 presents pooling spread on the pavement for a 2-ft-wide composite curb and gutter

Computational Analysis of Hydraulic Capacity of Ohio DOT Catch Basins On-Grade and in Sag Locations

Page | 33 
with a longitudinal grade of $0.08 \mathrm{ft} / \mathrm{ft}$, at a flow rate of $4.6 \mathrm{cfs}$ and Figure 6.4 shows a corresponding top view of the water surface. The curves in Figure 6.1 and Figure 6.3 represent the extent of water on the pavement upstream of the grate. The left side of the plot is the location of the inlet boundary condition, and the right side is the location of the upstream edge of the grate. Table 6-1 provides a description of the data plotted in these figures.

In both cases, all models yield a similar extent of the pool of water. Differences are of the order of a fraction of a foot. As expected, the smooth wall model underestimates the spread. With no roughness on the surface, the fluid experiences less surface resistance, and therefore flows faster and covers a smaller portion of the pavement than when the roughness is modeled in the simulation. Rough surface models give result that falls in between the two spreads estimated by the porous region model: the spread on the pavement (top of the asperities) and spread in between the aggregate (bottom of the asperities). Models with $4 \mathrm{~mm}$ roughness height are characterized with slightly bigger spreads than the models with a $3 \mathrm{~mm}$ roughness height.

Table 6-1 Explanation of the Legend in Figure 6.1 and Figure 6.3

\begin{tabular}{|c|c|c|c|}
\hline $\begin{array}{l}\text { Line } \\
\text { type }\end{array}$ & $\begin{array}{l}\text { Pavement rough- } \\
\text { ness model }\end{array}$ & Location of isoline & $\begin{array}{c}\text { Roughness } \\
\text { height [mm] }\end{array}$ \\
\hline - & \multirow{2}{*}{ porous region } & surface of the pavement & \multirow{2}{*}{4.0} \\
\hline$-2-$ & & bottom surface of the porous layer & \\
\hline 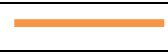 & \multirow{2}{*}{ porous region } & surface of the pavement & \multirow{2}{*}{3.0} \\
\hline$=-2=$ & & bottom surface of the porous layer & \\
\hline & \multirow{2}{*}{ rough wall } & surface of the pavement & 3.0 \\
\hline & & surface of the pavement & 4.0 \\
\hline - & smooth wall & surface of the pavement & n.a. \\
\hline
\end{tabular}

Computational Analysis of Hydraulic Capacity of Ohio DOT Catch Basins On-Grade and in Sag Locations 


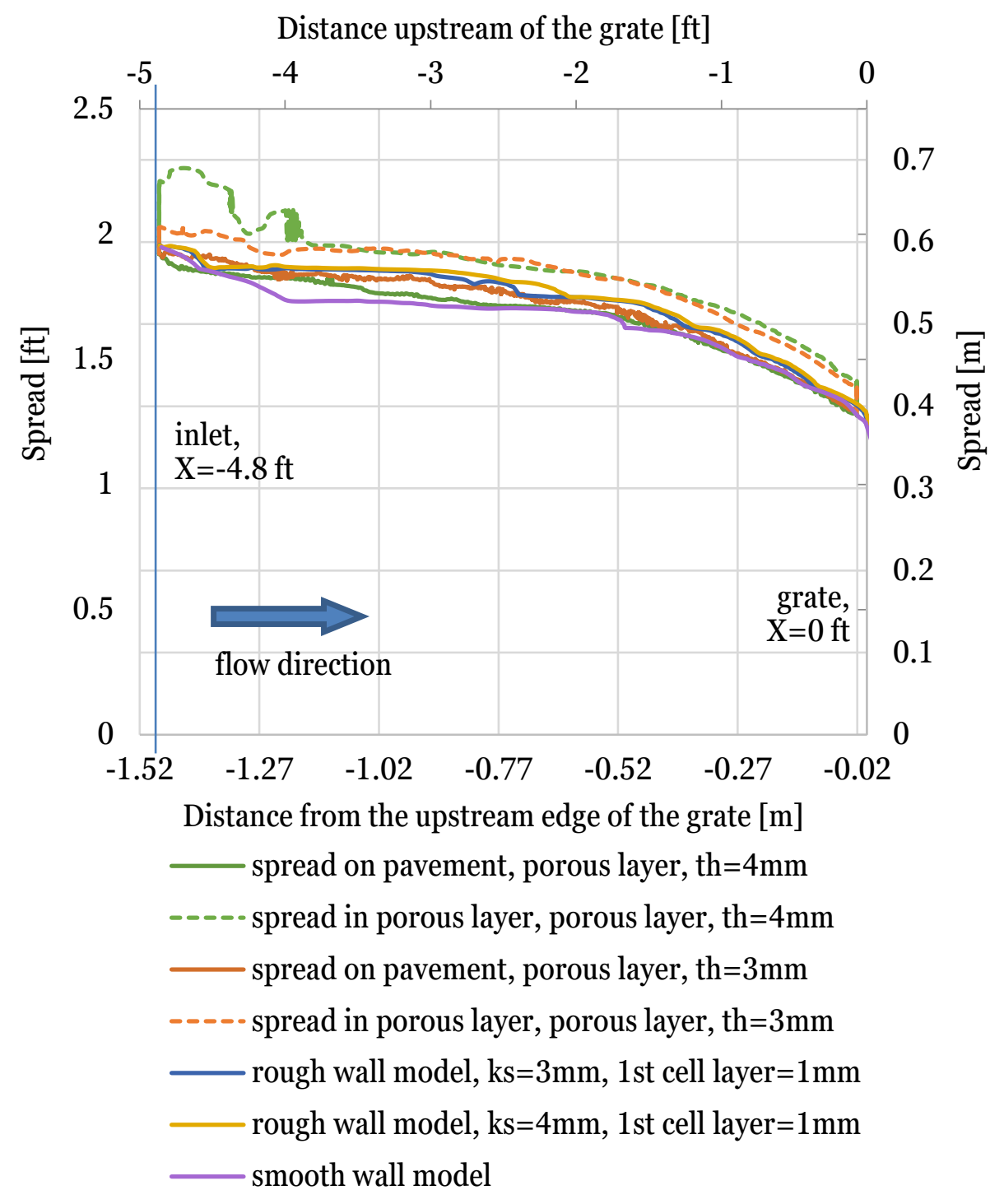

Figure 6.1 Pooling spread on a pavement for a 2-ft-wide composite curb and gutter with a longitudinal grade of $0.0025 \mathrm{ft} / \mathrm{ft}$, at a flow rate of $0.187 \mathrm{cfs}$.

Computational Analysis of Hydraulic Capacity of Ohio DOT Catch Basins On-Grade and in Sag Locations

Page | 35 


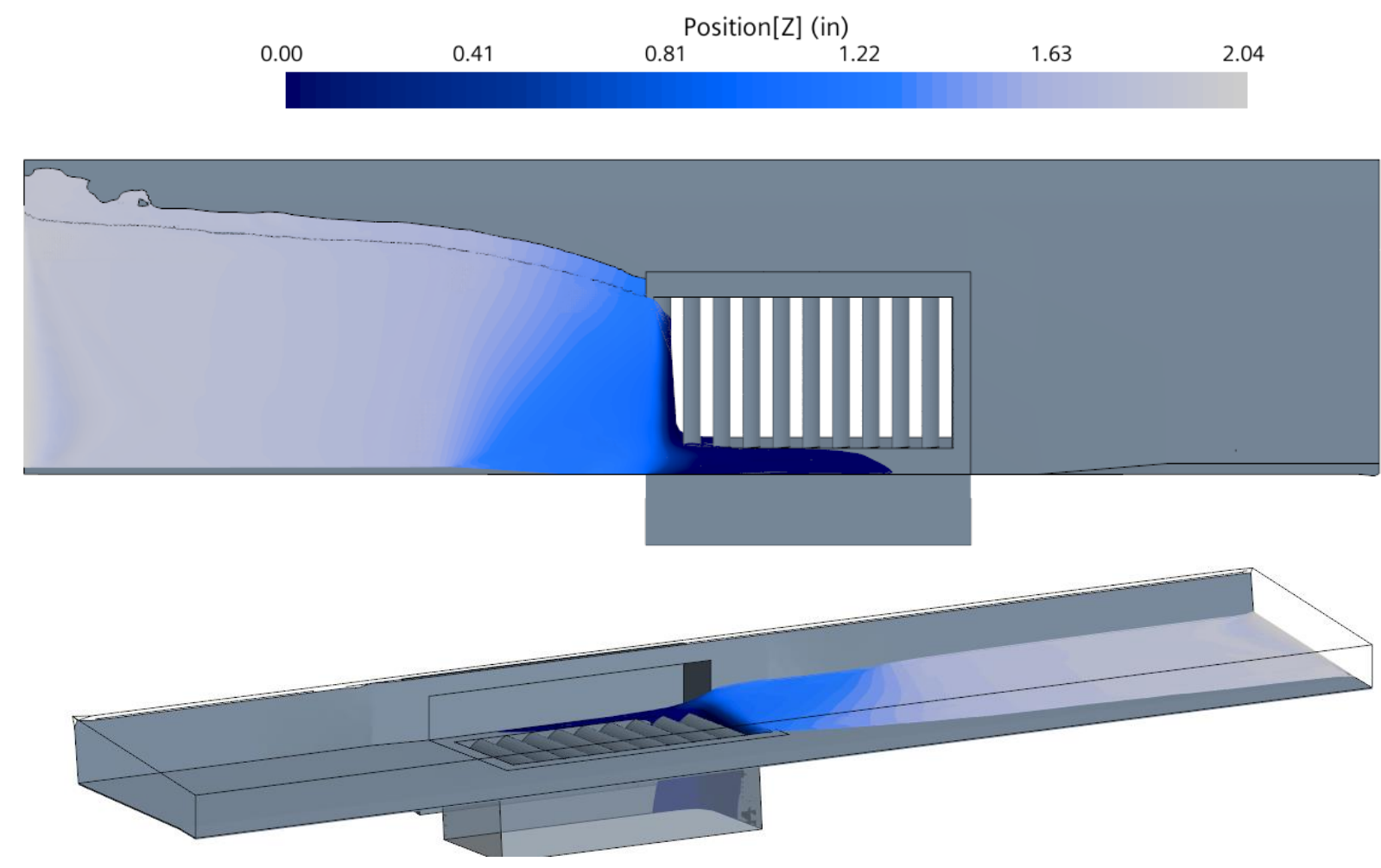

Figure 6.2 Top view of the model with a 4-mm-thick, porous layer with water surface colored with elevation. Water flow on a 2-ft-wide composite curb and gutter with a $0.0025 \mathrm{ft} / \mathrm{ft}$ longitudinal grade. 


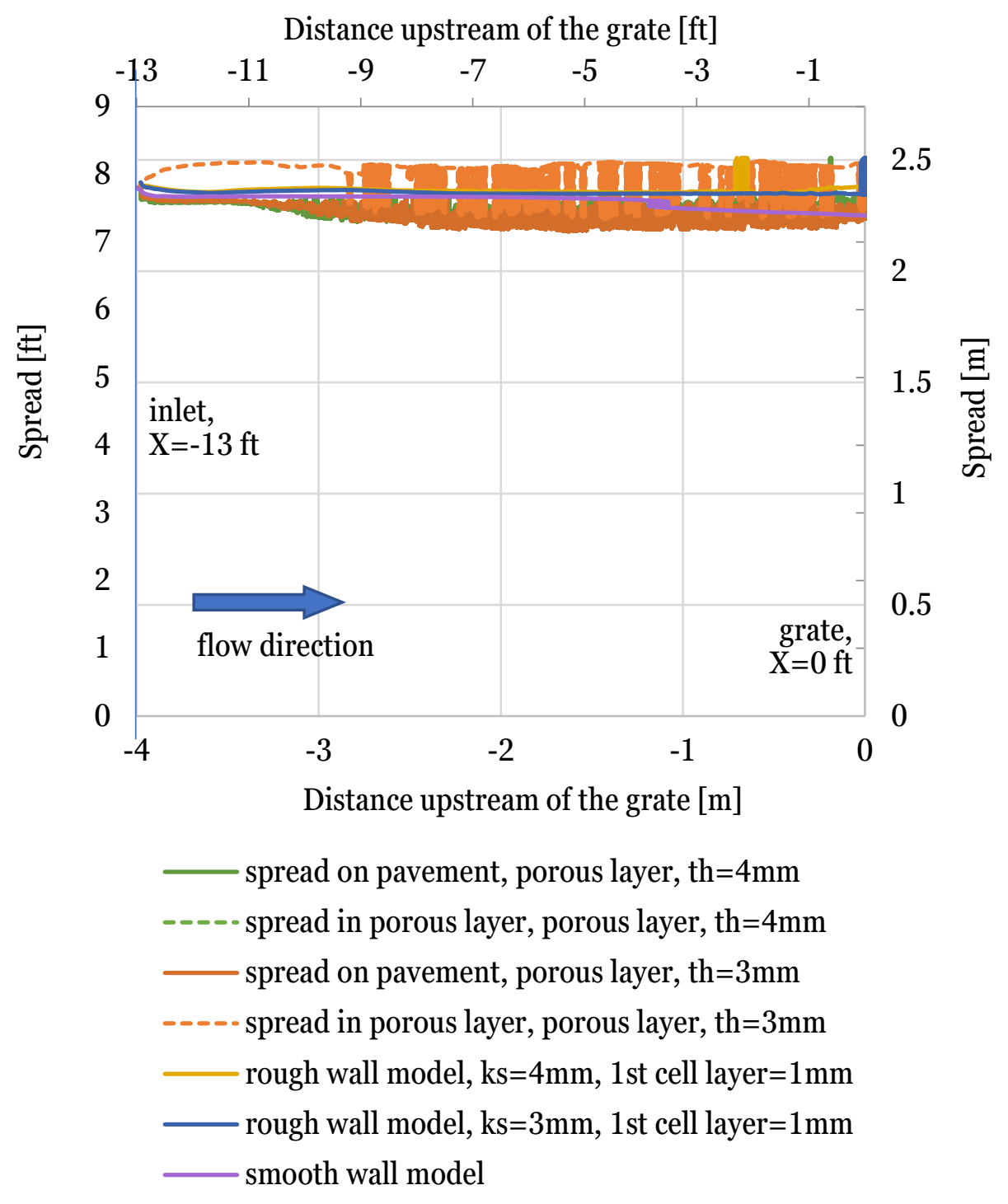

Figure 6.3 Pooling spread on a pavement for a 2-ft-wide composite curb and gutter with a longitudinal grade of $0.08 \mathrm{ft} / \mathrm{ft}$, at a flow rate of $4.6 \mathrm{cfs}$.

Computational Analysis of Hydraulic Capacity of Ohio DOT Catch Basins On-Grade and in Sag Locations 

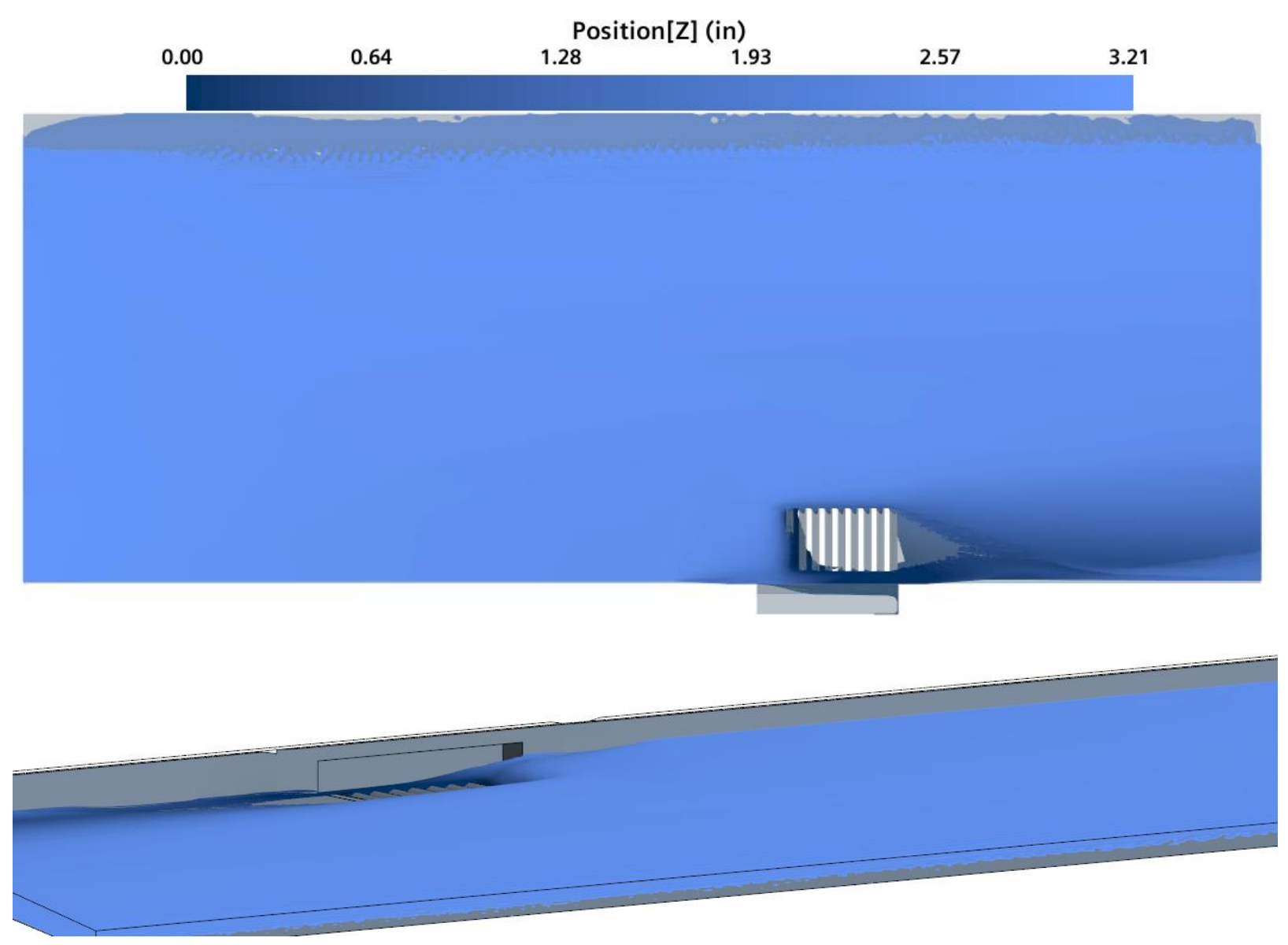

Figure 6.4 Top view of the model with a 4-mm-thick, porous layer with water surface colored with elevation. Water flow on a 2-ft-wide composite curb and gutter with a longitudinal grade of 0.08 $\mathrm{ft} / \mathrm{ft}$, at a flow rate of $4.6 \mathrm{cfs}$.

Flow interception was calculated for the two cases and divided into the grate and curb opening portion. Figure 6.5 and Figure 6.6 present a comparison of the flow intercepted by the grate and the curb opening for various models of the pavement surface. The differences are very small of order of $1 \%$. The model with pavement roughness modeled as a 4-mm-thick, porous layer was used in the modeling. 


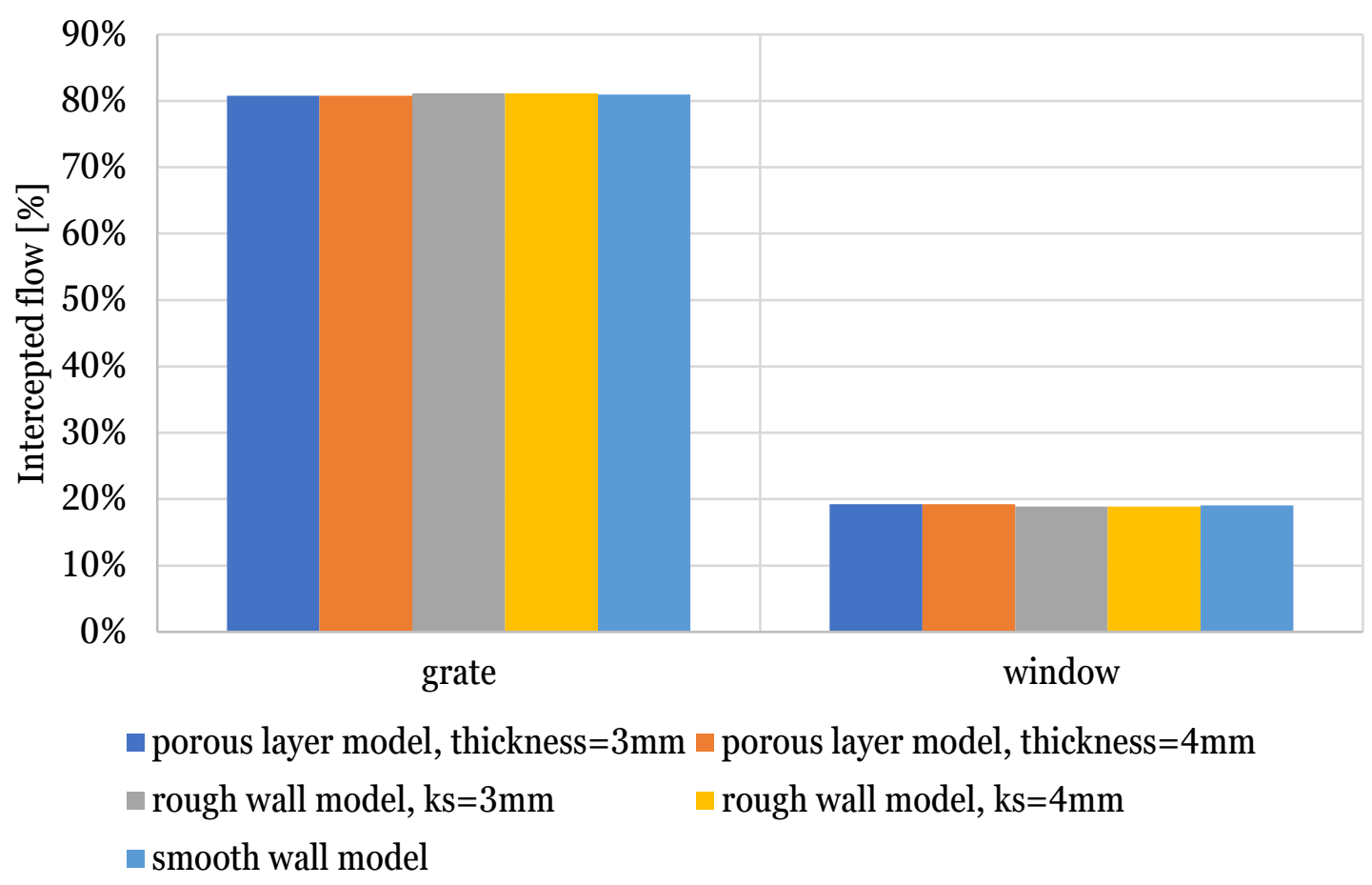

Figure 6.5 Flow intercepted by the grate and window for various models of the pavement surface for a 2 -foot composite curb and gutter with $0.0025 \mathrm{ft} / \mathrm{ft}$ longitudinal grade with $2 \mathrm{ft}$ spread.

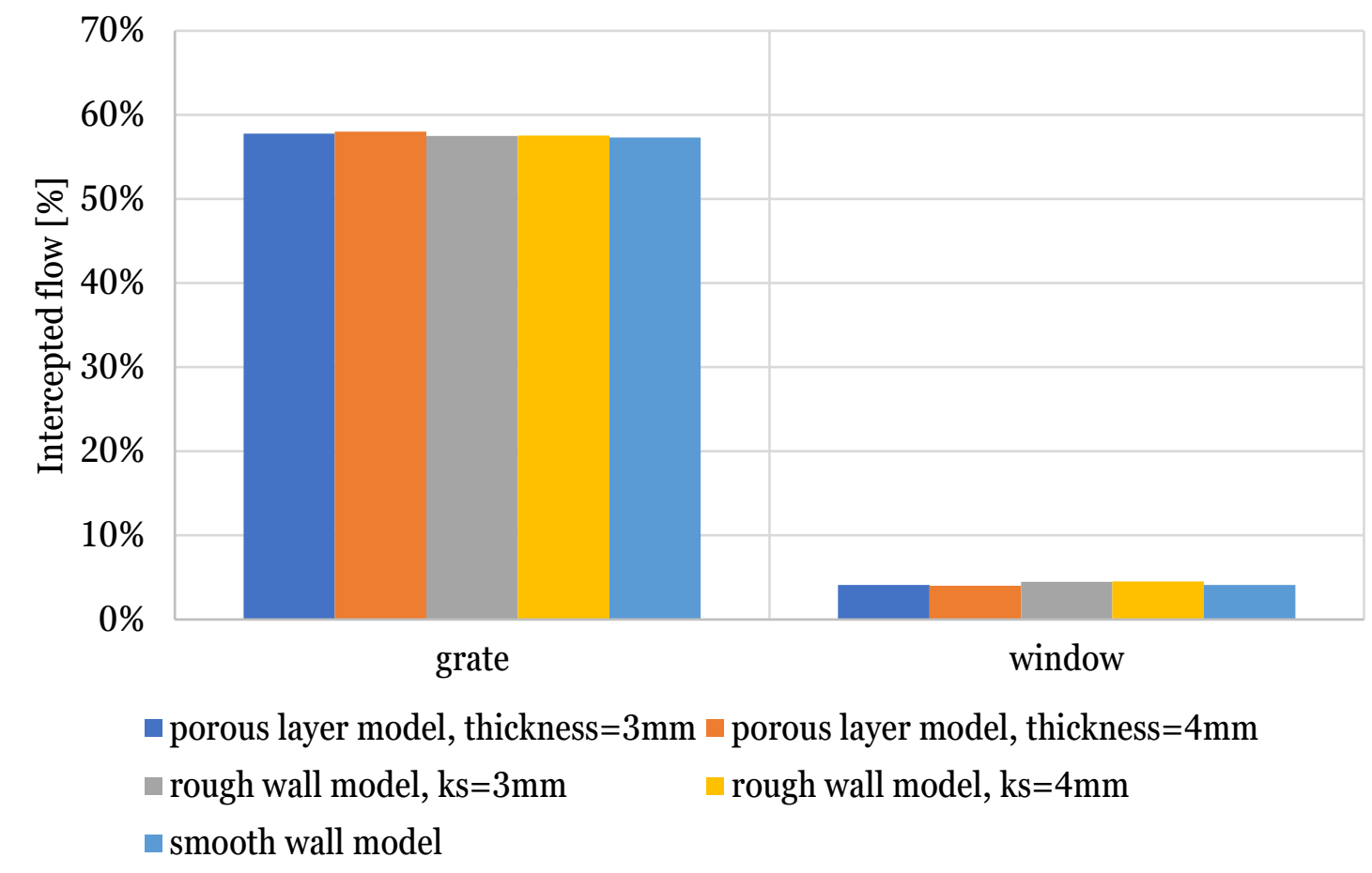

Figure 6.6 Flow intercepted by the grate and window for various models of the pavement surface for a 2-foot composite curb and gutter with $0.08 \mathrm{ft} / \mathrm{ft}$ longitudinal grade with $8 \mathrm{ft}$ spread.

Computational Analysis of Hydraulic Capacity of Ohio DOT Catch Basins On-Grade and in Sag Locations 


\subsubsection{Example Flow Patterns}

Additional flow patterns are shown in Figure 6.7, Figure 6.8, and Figure 6.9. Even for the biggest analyzed pool spread, overtopping of the grate does not occur for the simulated conditions.

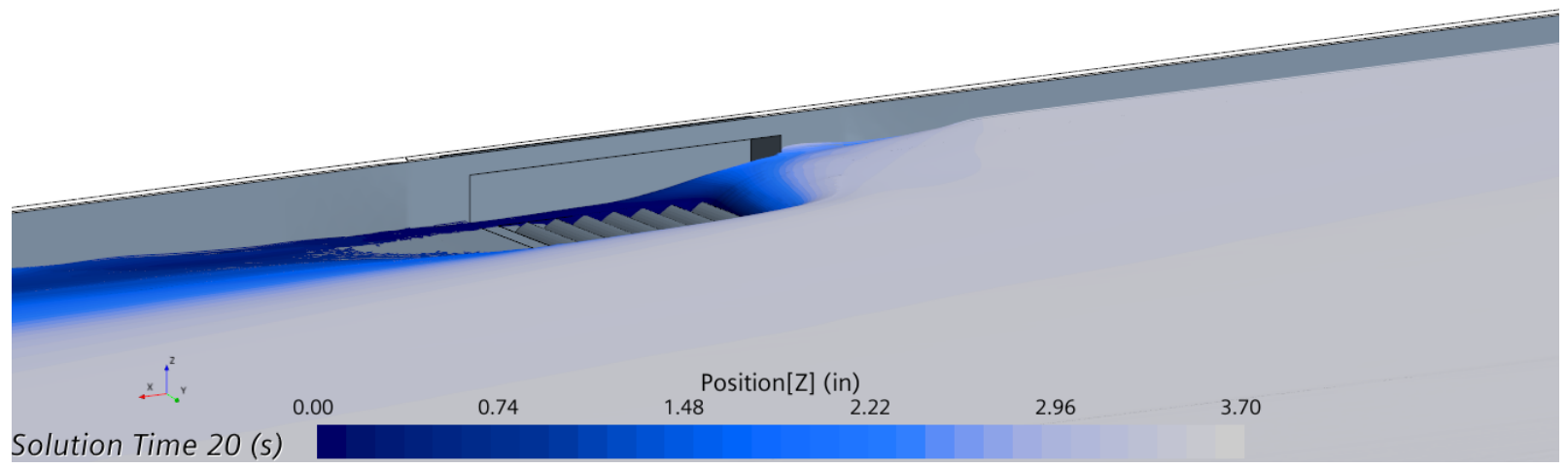

Figure 6.7 Water flow on a 2-foot composite curb and gutter with $0.08 \mathrm{ft} / \mathrm{ft}$ longitudinal grade. Pool spread is $10 \mathrm{ft}$.

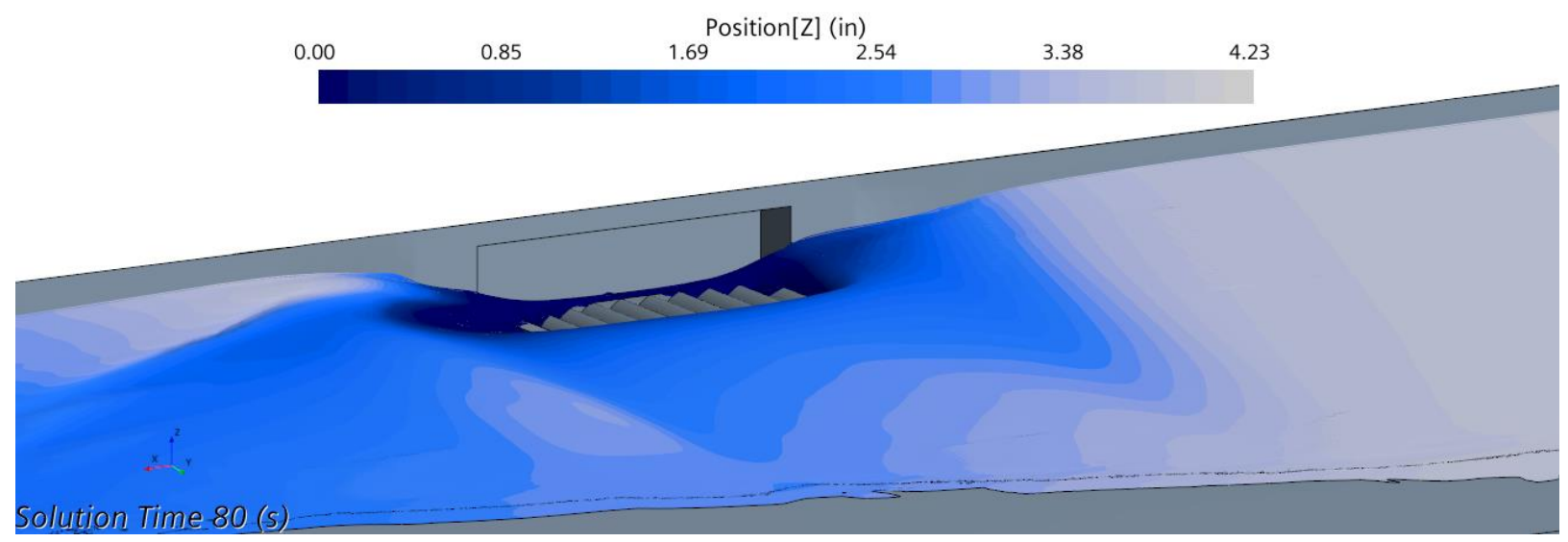

Figure 6.8 Water flow on a road with an 8-foot shoulder with $0.0025 \mathrm{ft} / \mathrm{ft}$ longitudinal grade. Pool spread is $10 \mathrm{ft}$.

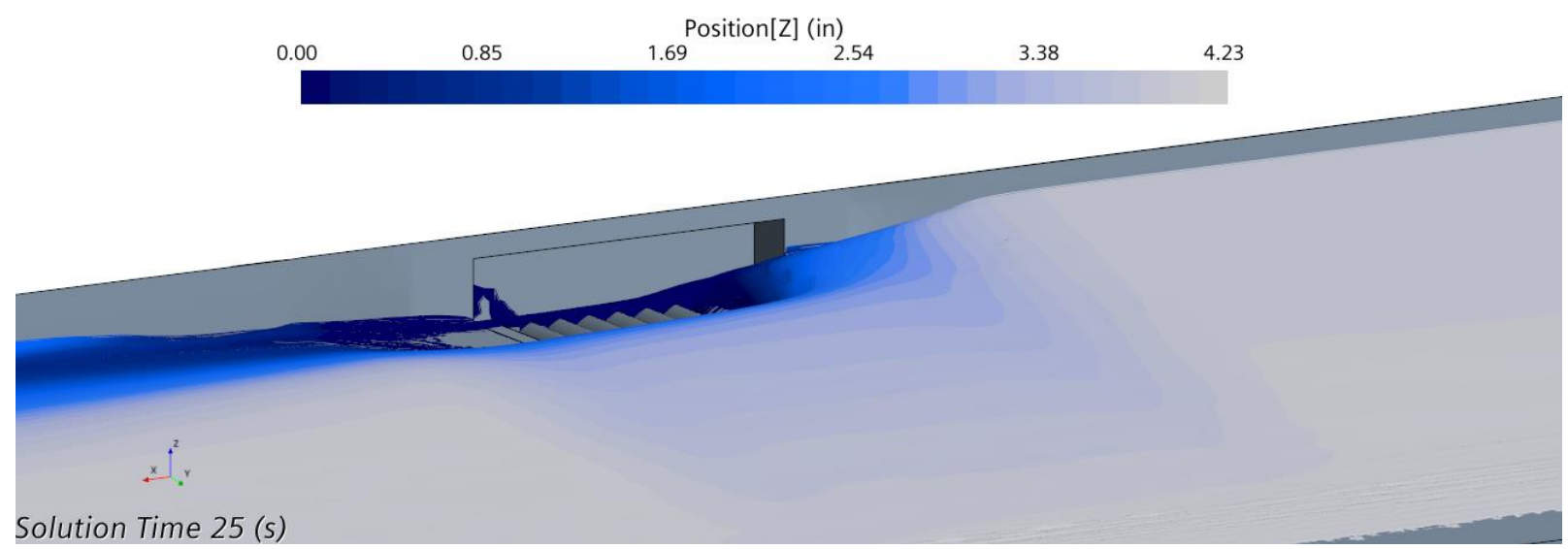

Figure 6.9 Water flow on a road with an 8 -foot shoulder with $0.08 \mathrm{ft} / \mathrm{ft}$ longitudinal grade. Pool spread is $10 \mathrm{ft}$.

Computational Analysis of Hydraulic Capacity of Ohio DOT Catch Basins On-Grade and in Sag Locations 


\subsubsection{CB 3A Catch Basin Efficiency}

Three cross-sections of the CFD models are considered: (1) a 2-ft-wide composite curb and gutter at $0.0833 \mathrm{ft} / \mathrm{ft}$ cross slope and a section of the rightmost lane at $0.016 \mathrm{ft} / \mathrm{ft}$ cross slope, (2) a 4-ftwide shoulder at $0.04 \mathrm{ft} / \mathrm{ft}$ cross slope and a section of the rightmost lane at $0.016 \mathrm{ft} / \mathrm{ft}$ cross slope, and (3) an 8-ft-wide shoulder at $0.04 \mathrm{ft} / \mathrm{ft}$ cross slope and a section of the rightmost lane at 0.016 $\mathrm{ft} / \mathrm{ft}$ cross slope. The design flow spread is in the range from 2 feet to 10 feet and the longitudinal slope differs from $0.0025 \mathrm{ft} / \mathrm{ft}$ to $0.08 \mathrm{ft} / \mathrm{ft}$. For each case from the run matrix the results of the most interest are the total intercepted flow and the catch basin efficiency, intercepted front flow, side flow, and the amount of the flow that bypasses the drain, as a function of the longitudinal grade and pool spread. This dependency is shown in the form of surface plots in figures from Figure 6.10 to Figure 6.13.

Figure 6.10 shows the catch basin efficiency calculated from eq. (54) as a function of spread and longitudinal grade for the three road geometries. Note that the range of pool spread was reversed on the chart for better readability. In all cases, the efficiency clearly drops for increasing longitudinal grade and spread. For a curb and gutter configuration with a 2 -ft-wide spread, the influence of the longitudinal grade is small, as over $90 \%$ of the flow is intercepted by the catch basin. With an increase of the spread, the influence of the longitudinal grade on efficiency also increases, and for a 10 -ft-wide spread, the efficiency drops by $50 \%$ with increasing slope. If the longitudinal grade is constant, and the spread varies, the dependence is similar. For the case of a road with 4-foot and 8-foot-wide shoulder at $0.04 \mathrm{ft} / \mathrm{ft}$ cross slope, the dependence is the same, with the difference that the efficiency is lower for the 10 -foot spread at $0.08 \mathrm{ft} / \mathrm{ft}$ longitudinal grade. Nevertheless, most of the flow is contained within the width of the shoulder, and rightmost travel lane experiences less flooding than for the 2-ft-wide curb and gutter case.

The percentage of flow intercepted through the upstream edge of the inlet (i.e., front flow), presented in Figure 6.11, has a similar dependency on the longitudinal grade and spread as the total interception with the difference that it is decreased by the amount of flow intercepted by the roadside edge of the grate inlet. Surface plots are presented in Figure 6.11 (a) $2 \mathrm{ft}$ curb and gutter, (b) $4 \mathrm{ft}$ shoulder, (c) $8 \mathrm{ft}$ shoulder. Note that the range of pool spread on Figure 6.11 was reversed for better readability. The percentage of flow intercepted through the roadside edge of the grate for different geometries of the road is presented in Figure 6.12 (a) $2 \mathrm{ft}$ curb and gutter, (b) $4 \mathrm{ft}$ shoulder, (c) $8 \mathrm{ft}$ shoulder. It is the highest for the largest spread in combination with a small longitudinal grade. It decreases significantly with decreasing spread, as most of the flow is intercepted by the upstream edge of the drain and curb opening. The percentage of bypass flow calculated from Equation (55), as a function of spread and longitudinal grade was plotted in Figure 6.13 (a) $2 \mathrm{ft}$ curb and gutter, (b) $4 \mathrm{ft}$ shoulder, (c) $8 \mathrm{ft}$ shoulder. The dependence of the flow bypassing the catch basin on the two variables is inverted with respect to the intercepted flow: it is zero for the smallest longitudinal grade and spread and increases for the largest spread and grade.

The surface plots allow for a general overview of the dependencies between the intercepted flow and road geometry and approach flow conditions. Additional plots are collected in the Appendix in Figure 10.1, Figure 10.2, Figure 10.3. They cover plots of total, front, side, and bypass flow as a function of longitudinal slope separately for each of the road geometries. The flow rate values are also collected in Table 10.1 in the Appendix.

Computational Analysis of Hydraulic Capacity of Ohio DOT Catch Basins On-Grade and in Sag Locations

Page | 41 
(a)

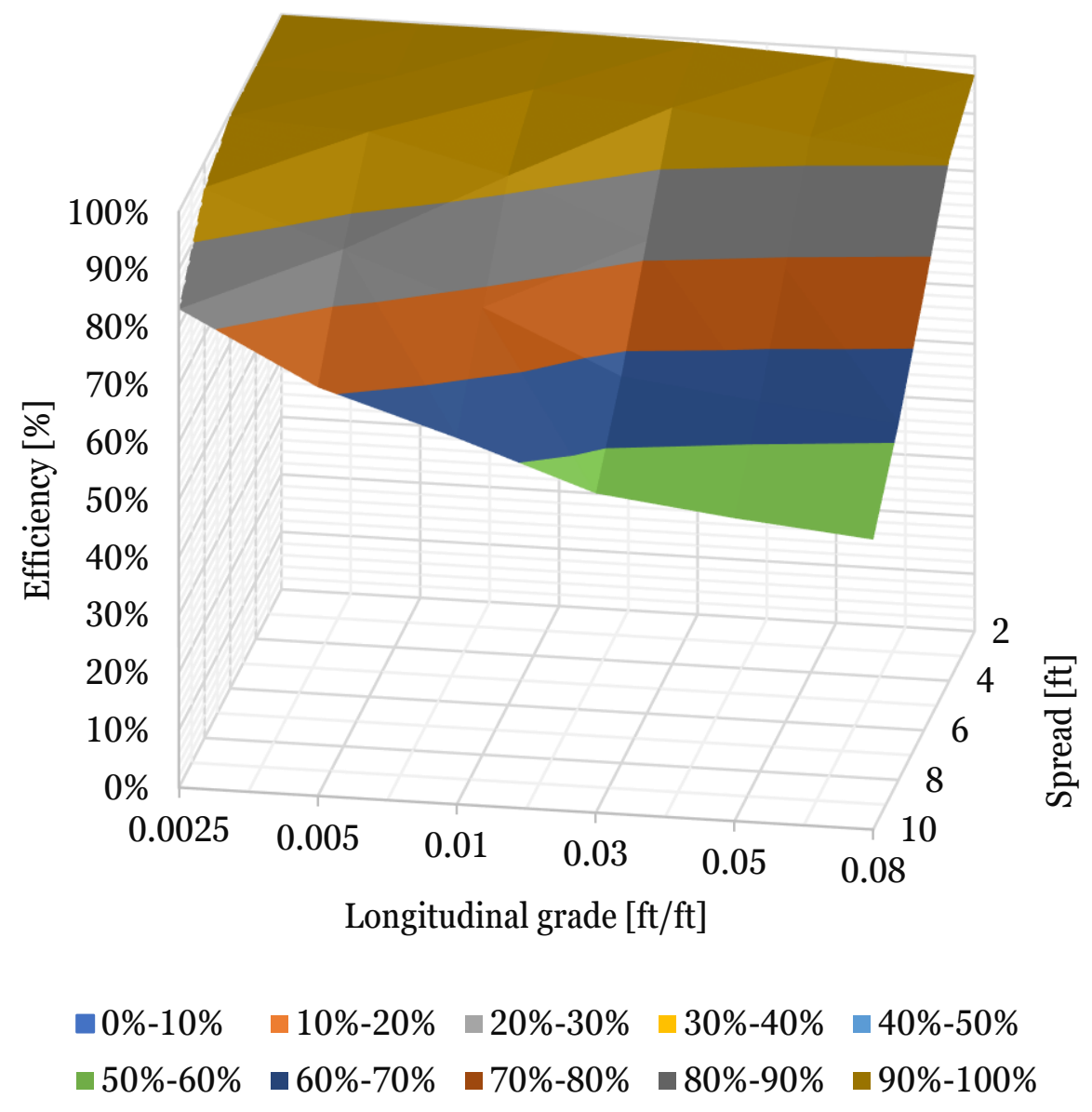

Computational Analysis of Hydraulic Capacity of Ohio DOT Catch Basins On-Grade and in Sag Locations Page | 42 
(b)

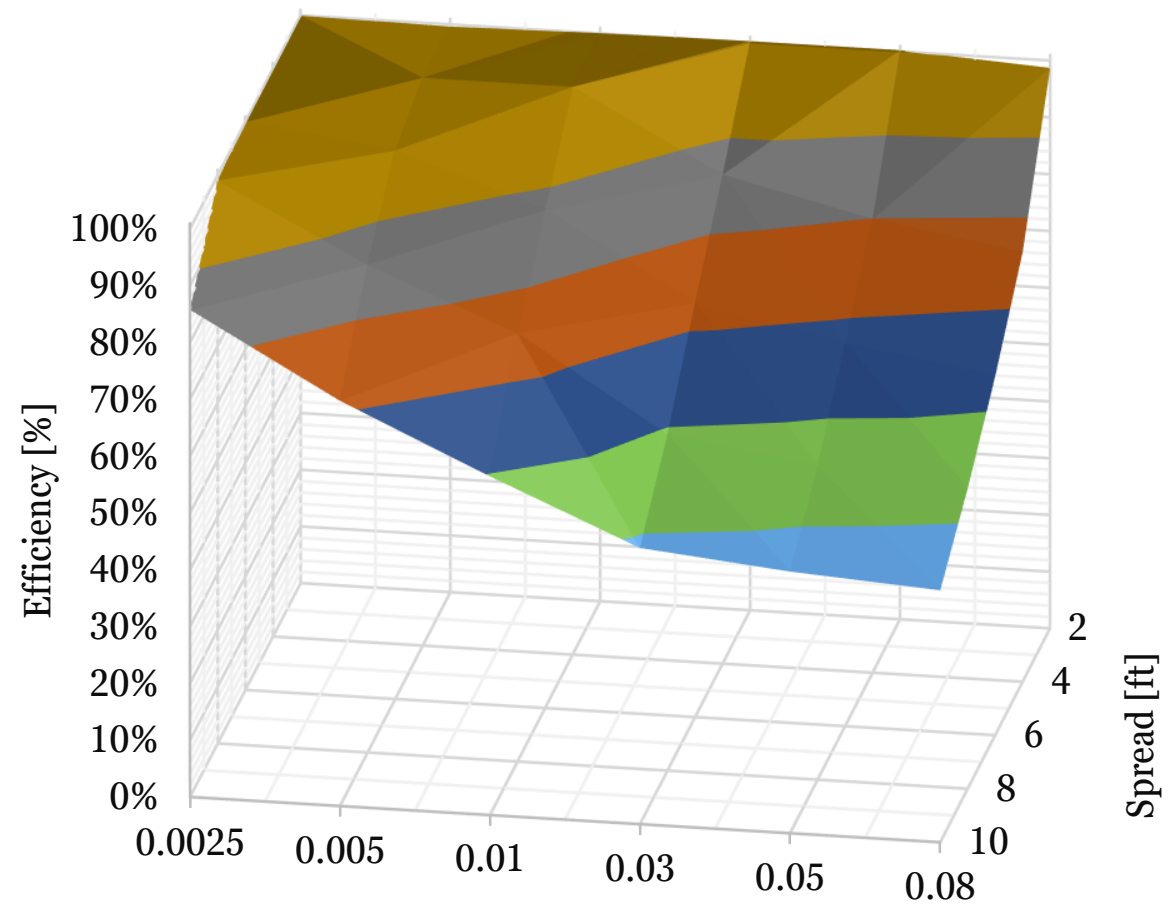

Longitudinal grade $[\mathrm{ft} / \mathrm{ft}]$

$$
\begin{array}{llll}
\square 0 \%-10 \% & \square 10 \%-20 \% & -20 \%-30 \% & \square 30 \%-40 \% \\
-40 \%-50 \% & \square 50 \%-60 \% & -60 \%-70 \% & -70 \%-80 \% \\
-80 \%-90 \% & \square 90 \%-100 \% & =100 \%-101 \%
\end{array}
$$


(c)

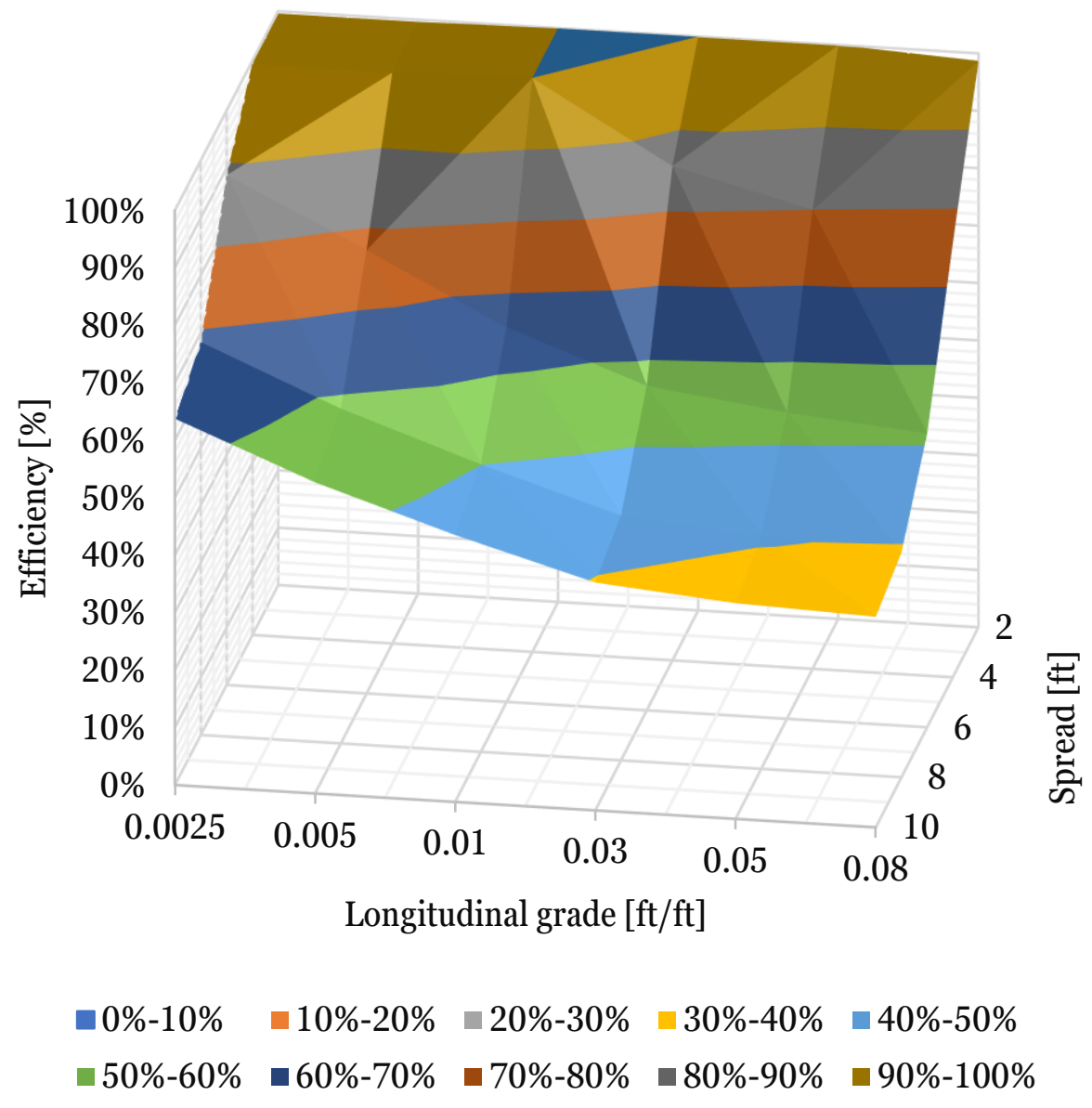

Figure 6.10 Catch basin efficiency as a function of spread and longitudinal grade for (a) a 2-ft-wide curb and gutter, (b) a 4-ft-wide shoulder, (c) an 8-ft-wide shoulder. Note: the range of pool spread was reversed for better readability of the chart.

Computational Analysis of Hydraulic Capacity of Ohio DOT Catch Basins On-Grade and in Sag Locations 
(a)

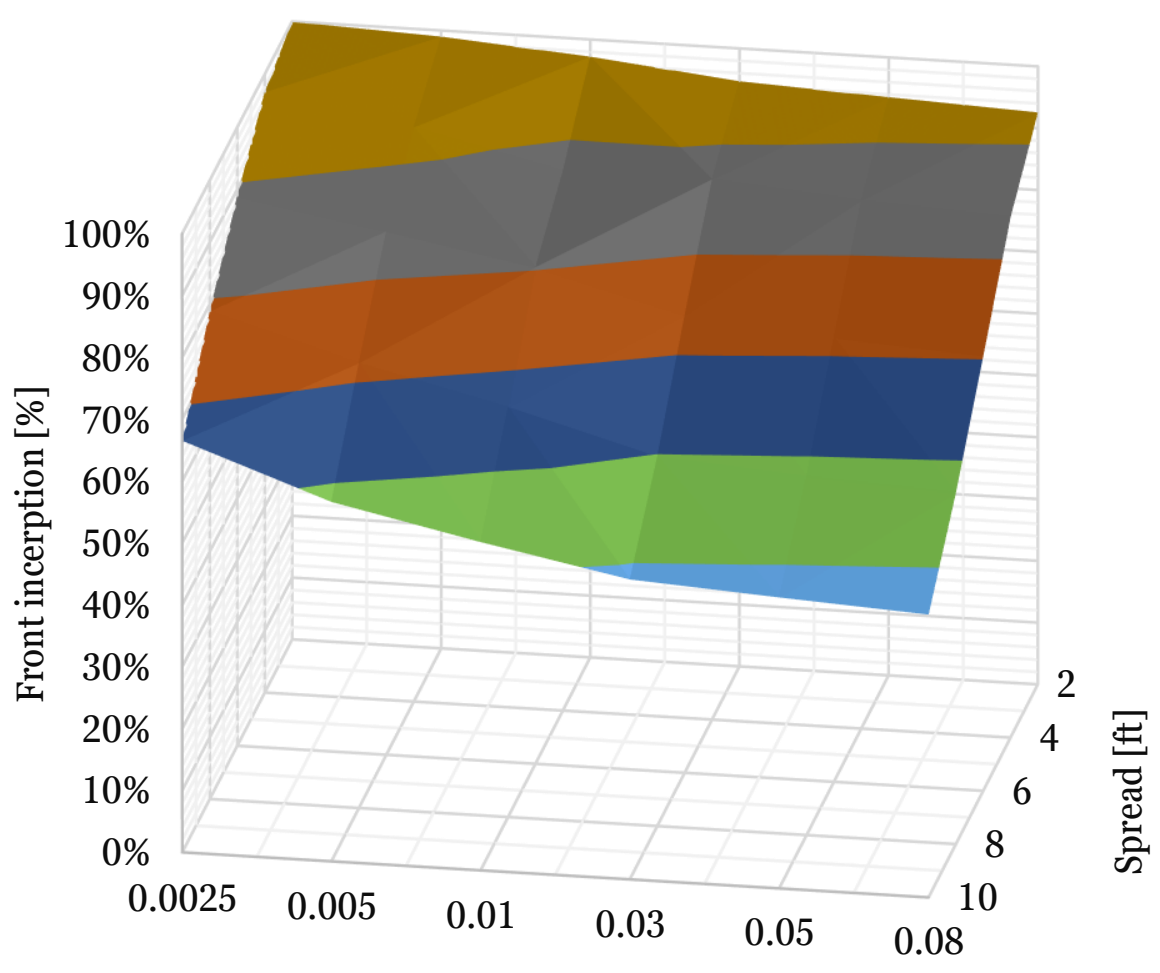

Longitudinal grade $[\mathrm{ft} / \mathrm{ft}]$

$$
\begin{array}{lllll}
\square 0 \%-10 \% & -10 \%-20 \% & -20 \%-30 \% & -30 \%-40 \% & \square-40 \%-50 \% \\
-50 \%-60 \% & -60 \%-70 \% & -70 \%-80 \% & -80 \%-90 \% & \square 90 \%-100 \%
\end{array}
$$


(b)

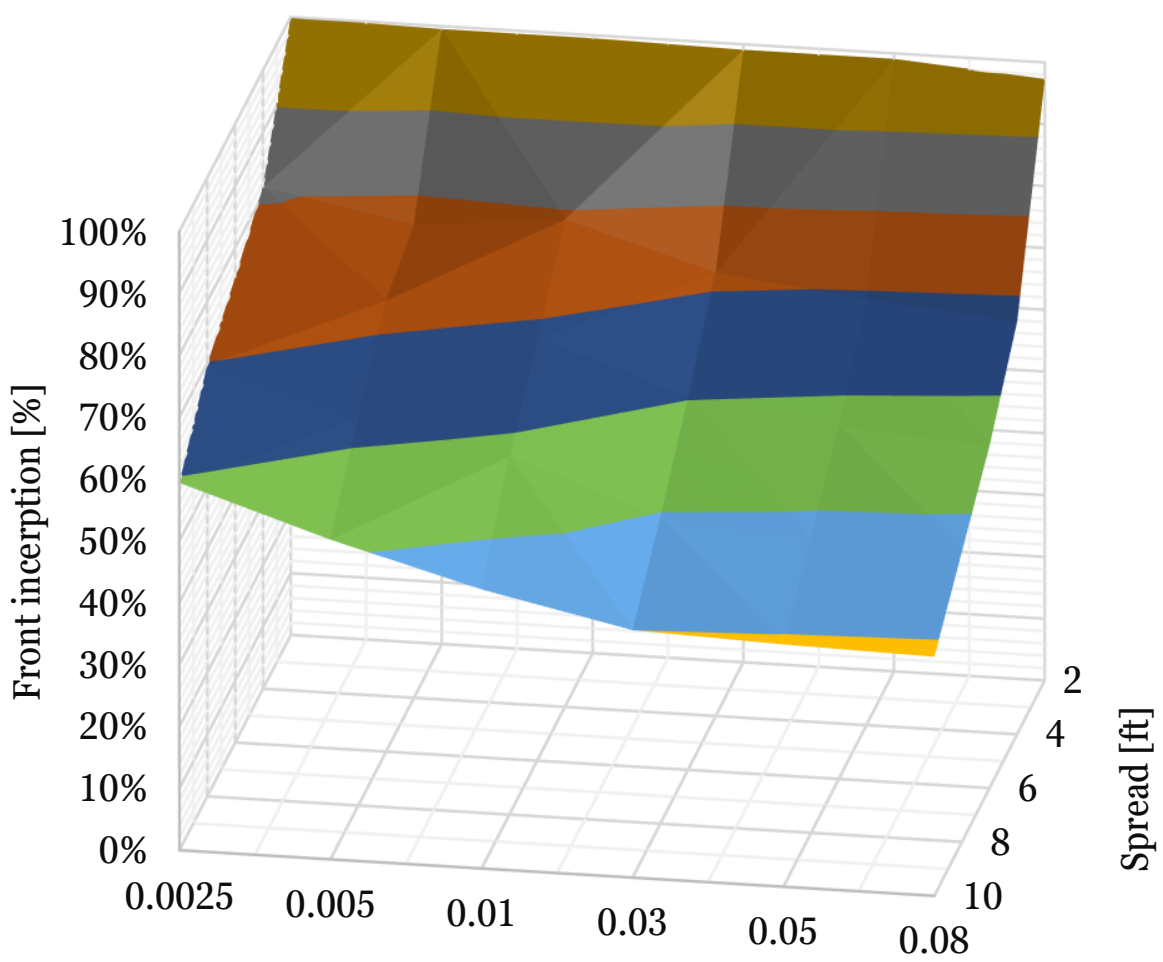

Longitudinal grade $[\mathrm{ft} / \mathrm{ft}]$

$$
\begin{array}{lllll}
\square 0 \%-10 \% & \square 10 \%-20 \% & \square 20 \%-30 \% & \square 30 \%-40 \% & \square-40 \%-50 \% \\
\square 50 \%-60 \% & \square 60 \%-70 \% & \square 70 \%-80 \% & \square 80 \%-90 \% & \square 90 \%-100 \%
\end{array}
$$


(c)

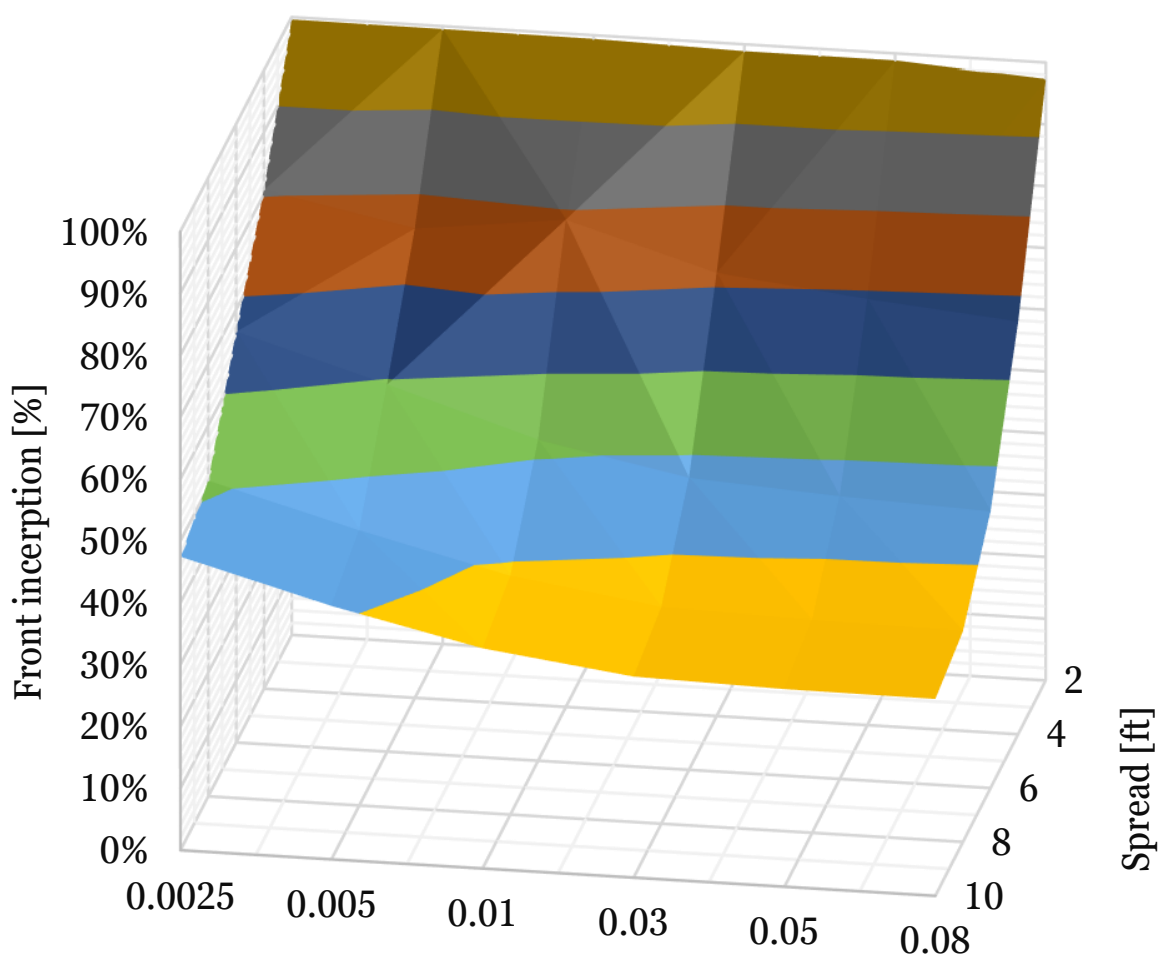

Longitudinal grade $[\mathrm{ft} / \mathrm{ft}]$

$$
\begin{array}{lllll}
\square 0 \%-10 \% & \square 10 \%-20 \% & \square 20 \%-30 \% & \square 30 \%-40 \% & \square-40 \%-50 \% \\
\square 50 \%-60 \% & \square 60 \%-70 \% & \square 70 \%-80 \% & \square 80 \%-90 \% & \square 90 \%-100 \%
\end{array}
$$

Figure 6.11 Front flow interception as a function of spread and longitudinal grade for (a) a 2-ftwide curb and gutter, (b) a 4-ft-wide shoulder, (c) an 8-ft-wide shoulder. Note: the range of pool spread was reversed for better readability of the chart.

Computational Analysis of Hydraulic Capacity of Ohio DOT Catch Basins On-Grade and in Sag Locations 
(a)

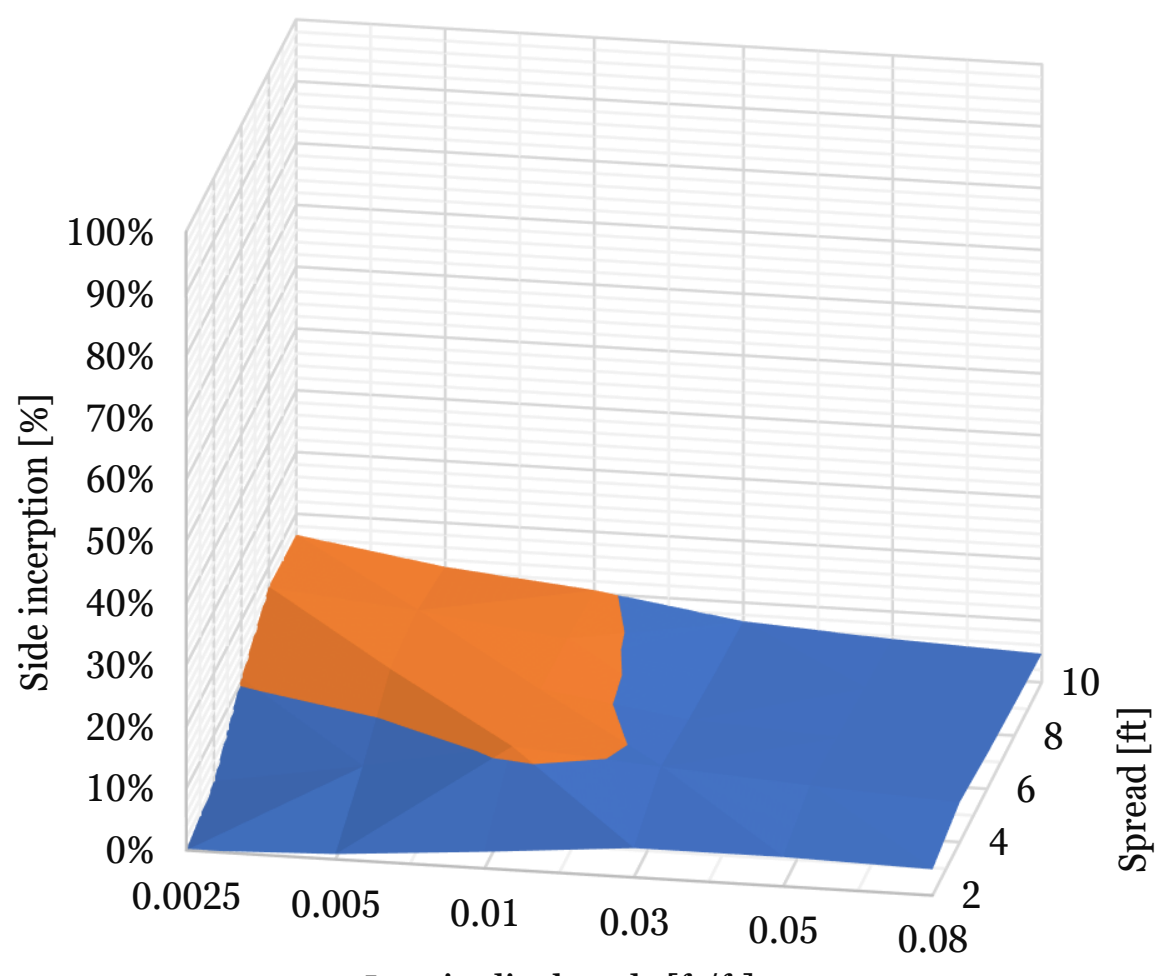

Longitudinal grade $[\mathrm{ft} / \mathrm{ft}]$

$$
\begin{aligned}
& \square 0 \%-10 \% \quad \square 10 \%-20 \% \quad \square 20 \%-30 \% \quad \square 30 \%-40 \% \quad \square 40 \%-50 \% \\
& \square 50 \%-60 \% \quad \square 60 \%-70 \% \quad \square 70 \%-80 \% \quad \square 80 \%-90 \% \quad \square 90 \%-100 \%
\end{aligned}
$$


(b)

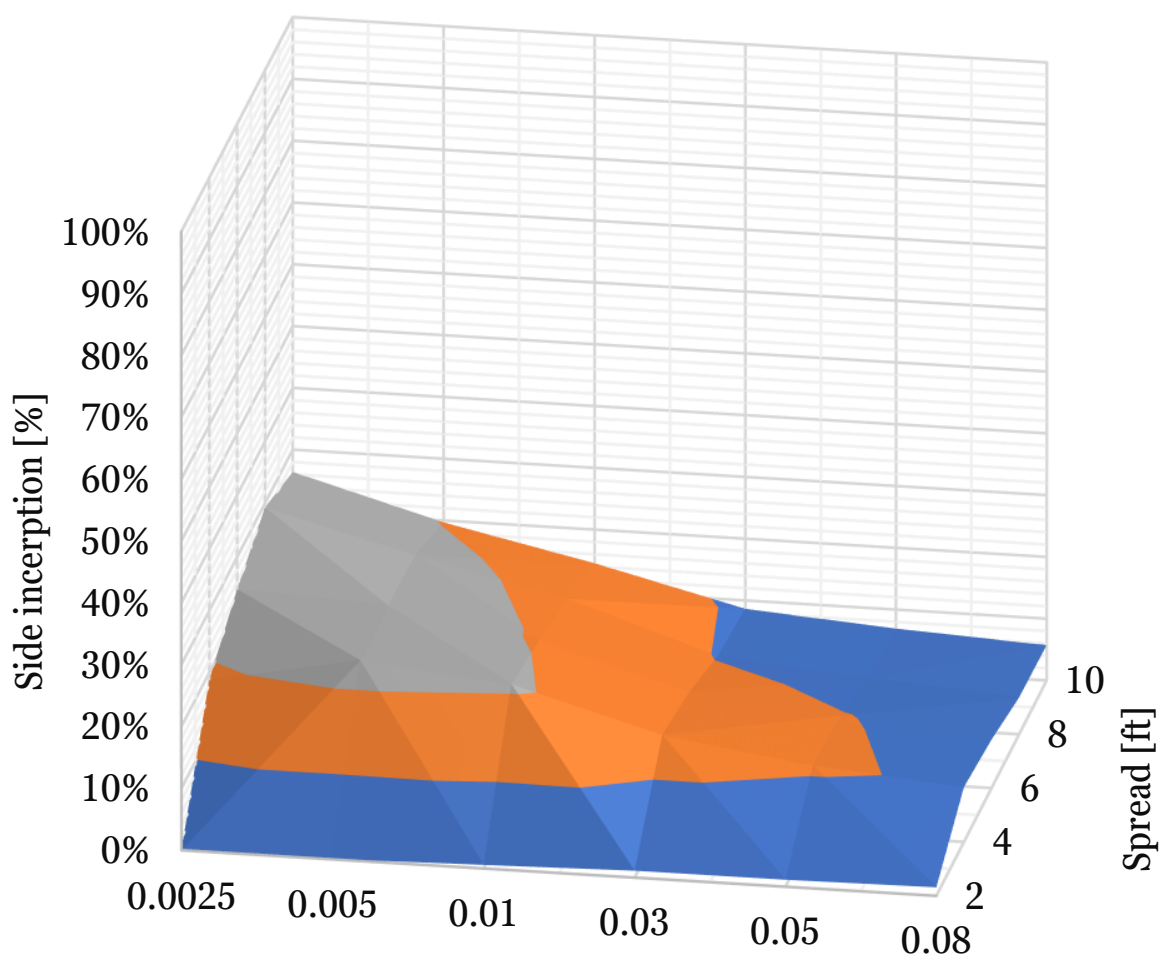

Longitudinal grade $[\mathrm{ft} / \mathrm{ft}]$

$$
\begin{array}{lllll}
\square 0 \%-10 \% & \square 10 \%-20 \% & \square 20 \%-30 \% & \square 30 \%-40 \% & \square-40 \%-50 \% \\
\square 50 \%-60 \% & \square 60 \%-70 \% & \square 70 \%-80 \% & \square 80 \%-90 \% & \square 90 \%-100 \%
\end{array}
$$


(c)

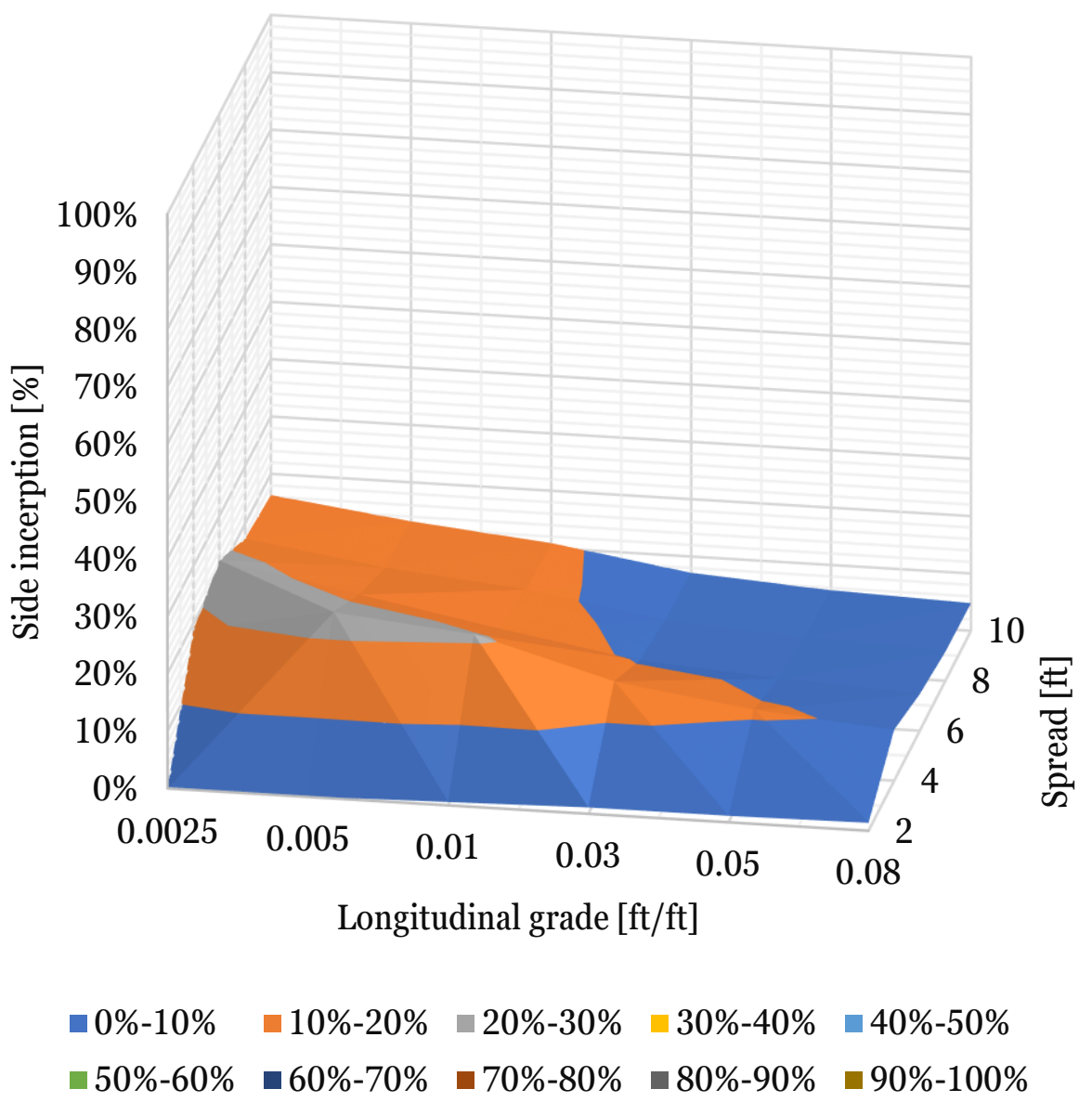

Figure 6.12 Side flow interception in function of spread and longitudinal grade for (a) $2 \mathrm{ft}$ curb and gutter, (b) $4 \mathrm{ft}$ shoulder, (c) $8 \mathrm{ft}$ shoulder.

Computational Analysis of Hydraulic Capacity of Ohio DOT Catch Basins On-Grade and in Sag Locations 
(a)

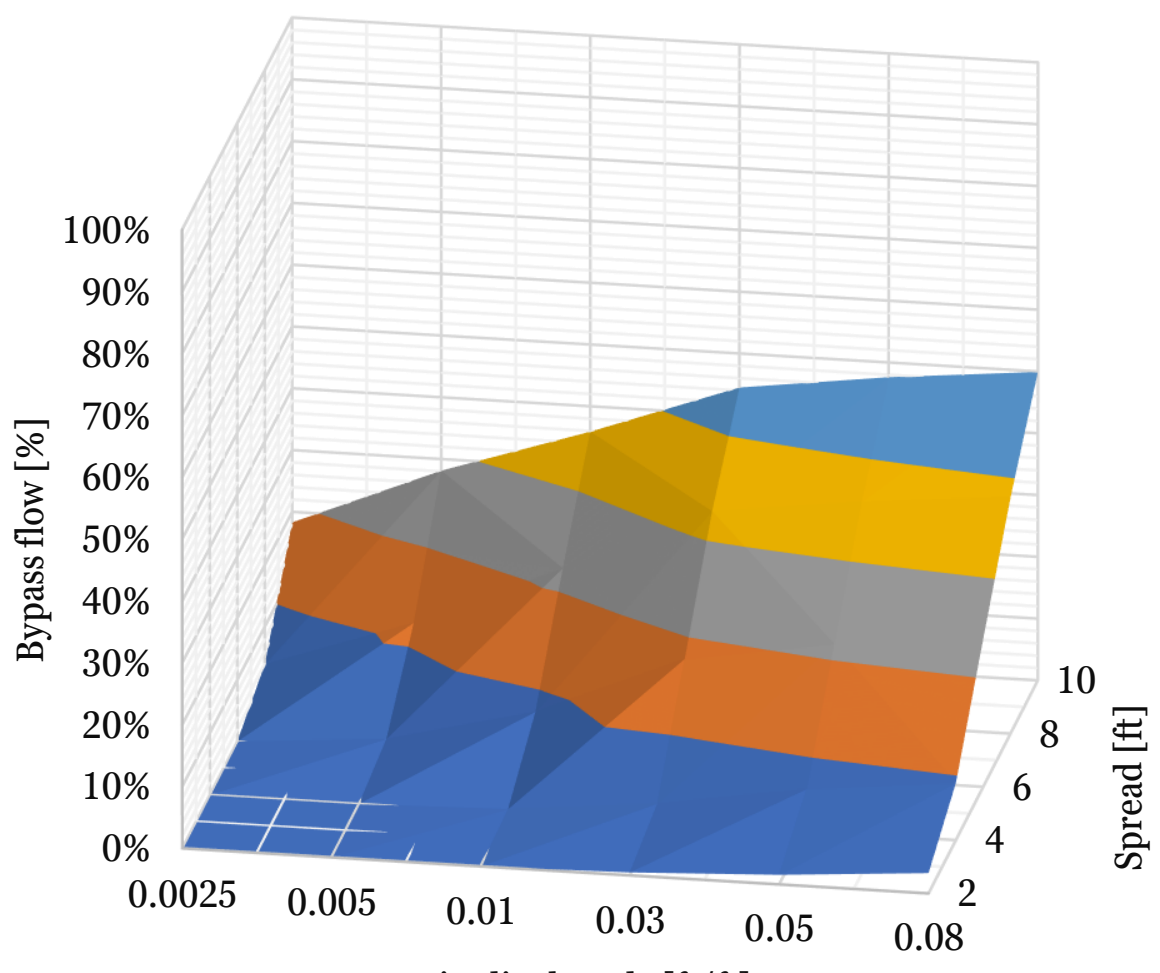

Longitudinal grade $[\mathrm{ft} / \mathrm{ft}]$

$$
\begin{array}{lllll}
\square 0 \%-10 \% & \square 10 \%-20 \% & -20 \%-30 \% & -30 \%-40 \% & \square-40 \%-50 \% \\
\square 50 \%-60 \% & -60 \%-70 \% & -70 \%-80 \% & \square 80 \%-90 \% & \square 90 \%-100 \%
\end{array}
$$


(b)

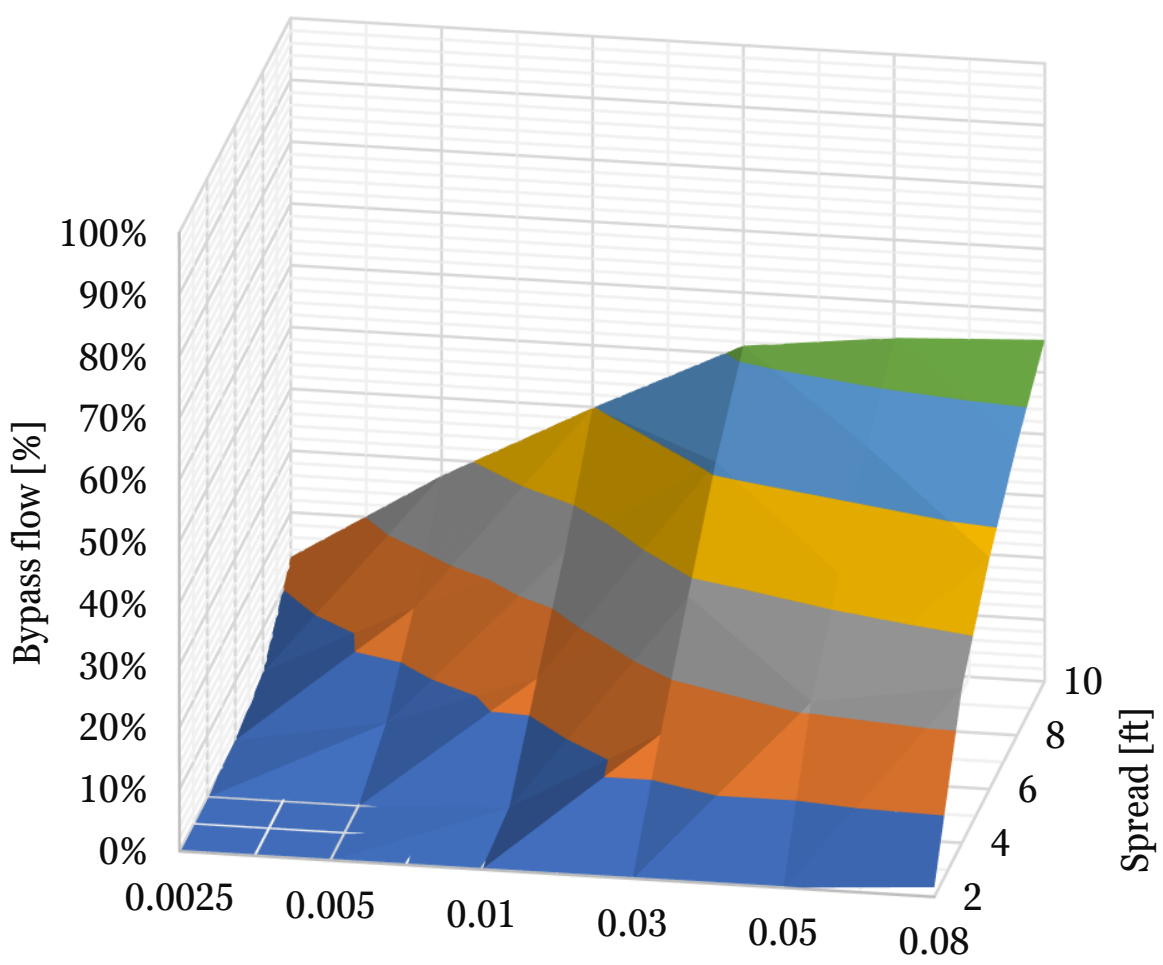

Longitudinal grade $[\mathrm{ft} / \mathrm{ft}]$

$$
\begin{array}{lllll}
\square 0 \%-10 \% & \square 10 \%-20 \% & \square 20 \%-30 \% & \square 30 \%-40 \% & \square-40 \%-50 \% \\
\square 50 \%-60 \% & \square 60 \%-70 \% & \square 70 \%-80 \% & \square 80 \%-90 \% & \square 90 \%-100 \%
\end{array}
$$


(c)

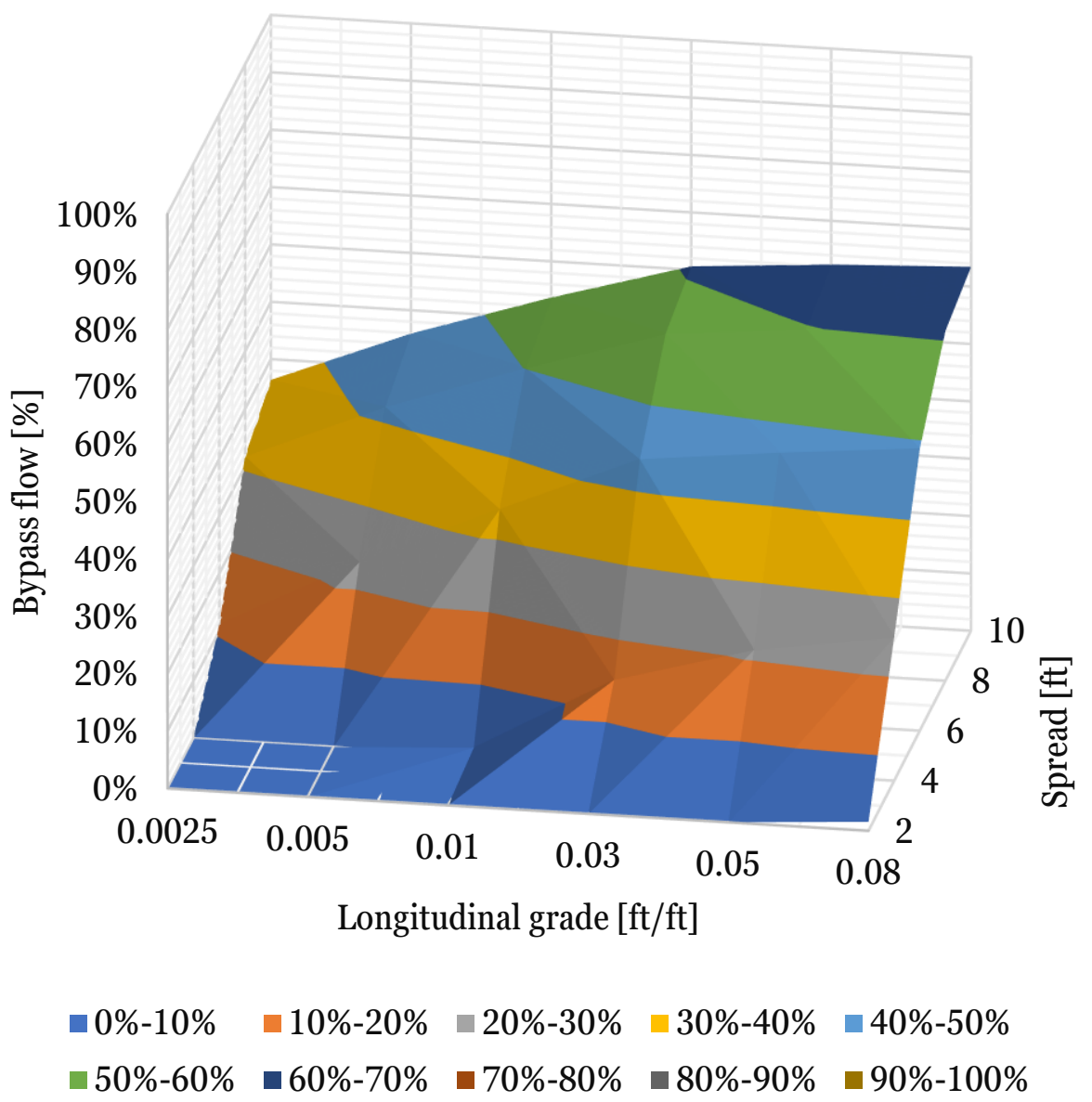

Figure 6.13 Bypass flow as a function of spread and longitudinal grade for (a) a 2-ft-wide curb and gutter, (b) a 4-ft-wide shoulder, (c) an 8-ft-wide shoulder.

The CFD results were compared with the results obtained by following the HEC 22 and ODOT design procedures, which assume that the catch basin intercepts total flow volume above the grate and a fraction of the side flow. The algorithm and the equations used in the process are presented in Section 4.1.6.

Water flowing on the pavement can be intercepted by the catch basin through the front (upstream) edge of the grate, the roadway side of the grate, the curb opening, and part of the flow can, although rarely, be intercepted by the back (downstream) edge of the grate when bypass flow splits at the stagnation point and part of it flows back into the grate. The condition where bypass flow enters the grate from the downstream end of the grate only occurs for small longitudinal grades.

The ODOT design procedure assumes that the roadside discharge is calculated as if it was a weir with the length of the grate. The calculation also assumes that the flow entering over the grate from the upstream edge has the same spread as it does at a distance upstream where the spread is not yet affected by the presence of the grate. The CFD calculations showed that this is not the case for flows with upstream Froude number less than one, when flow is subcritical. Then, any change in the downstream flow conditions, such as presence of a drain, affects the flow upstream. The spread of the pool decreases as the flow approaches the inlet and reduces the flow on the side

Computational Analysis of Hydraulic Capacity of Ohio DOT Catch Basins On-Grade and in Sag Locations 
of the grate. This assumption results in an underestimated total intercepted flow and overestimated roadside interception, and overall leads to a more conservative result. The side flow rate, $Q_{\text {out }}$, into the catch basin as a function of the flow spread and longitudinal grade for various road geometries is presented in Figure 6.14.

Computational Analysis of Hydraulic Capacity of Ohio DOT Catch Basins On-Grade and in Sag Locations 
(a)

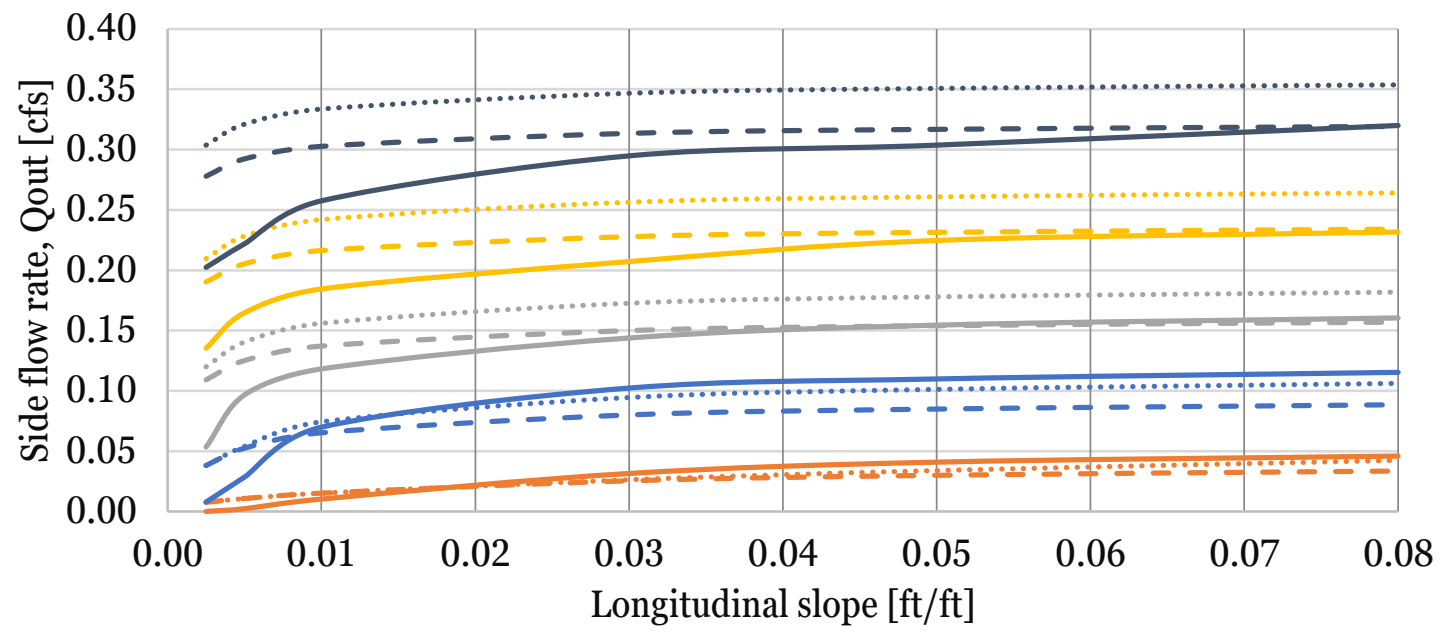

\begin{tabular}{|c|c|c|}
\hline$-\mathrm{CFD}, \mathrm{T}=2 \mathrm{ft}$ & --- ODOT, $\mathrm{T}=2 \mathrm{ft}$ & $\cdots \cdot \mathrm{HEC} 22, \mathrm{~T}=2 \mathrm{ft}$ \\
\hline $\mathrm{CFD}, \mathrm{T}=4 \mathrm{ft}$ & $---\mathrm{ODOT}, \mathrm{T}=4 \mathrm{ft}$ & $\cdots \cdot \mathrm{HEC} 22, \mathrm{~T}=4 \mathrm{ft}$ \\
\hline $\mathrm{CFD}, \mathrm{T}=6 \mathrm{ft}$ & --- ODOT, $\mathrm{T}=6 \mathrm{ft}$ & $\cdots \cdot$ HEC22, $\mathrm{T}=6 \mathrm{ft}$ \\
\hline CFD & $---\mathrm{ODOT}, \mathrm{T}=8 \mathrm{ft}$ & $\cdots \cdot \mathrm{HEC} 22, \mathrm{~T}=8 \mathrm{ft}$ \\
\hline$C F D$ & --- ODOT, $\mathrm{T}=10 \mathrm{ft}$ & … HEC22, $\mathrm{T}=1 \mathrm{C}$ \\
\hline
\end{tabular}

(b)

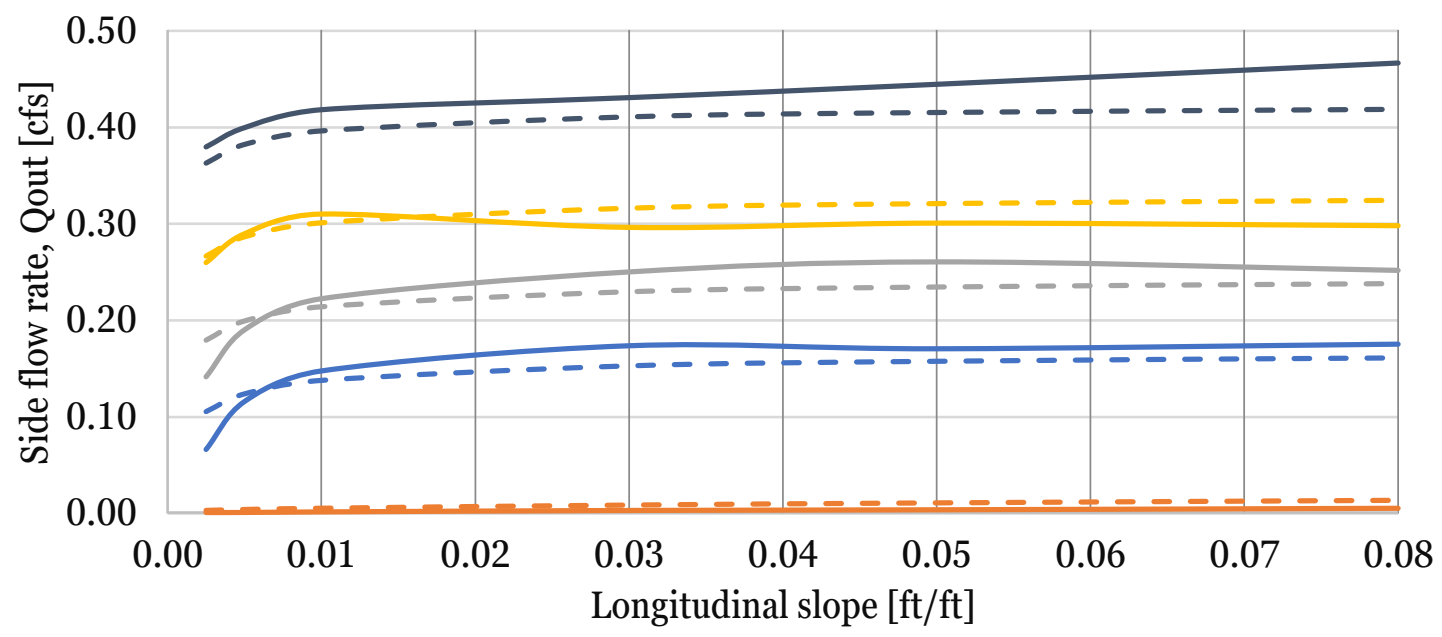

\begin{tabular}{|c|c|}
\hline$-\mathrm{CFD}, \mathrm{T}=2 \mathrm{ft}$ & --- ODOT/HEC22, $\mathrm{T}=2 \mathrm{ft}$ \\
\hline$-\mathrm{CFD}, \mathrm{T}=4 \mathrm{ft}$ & --- ODOT $/ \mathrm{HEC} 22, \mathrm{~T}=4 \mathrm{ft}$ \\
\hline $\mathrm{CFD}, \mathrm{T}=6 \mathrm{ft}$ & --- ODOT/HEC22, T=6ft \\
\hline $\mathrm{CFD}, \mathrm{T}=8 \mathrm{ft}$ & $--{ }^{-} \mathrm{ODOT} / \mathrm{HEC} 22, \mathrm{~T}=8 \mathrm{ft}$ \\
\hline $\mathrm{CFD}, \mathrm{T}=10 \mathrm{ft}$ & - - - ODOT/HEC22, T=10 \\
\hline
\end{tabular}

Computational Analysis of Hydraulic Capacity of Ohio DOT Catch Basins On-Grade and in Sag Locations

Page | 55 
(c)

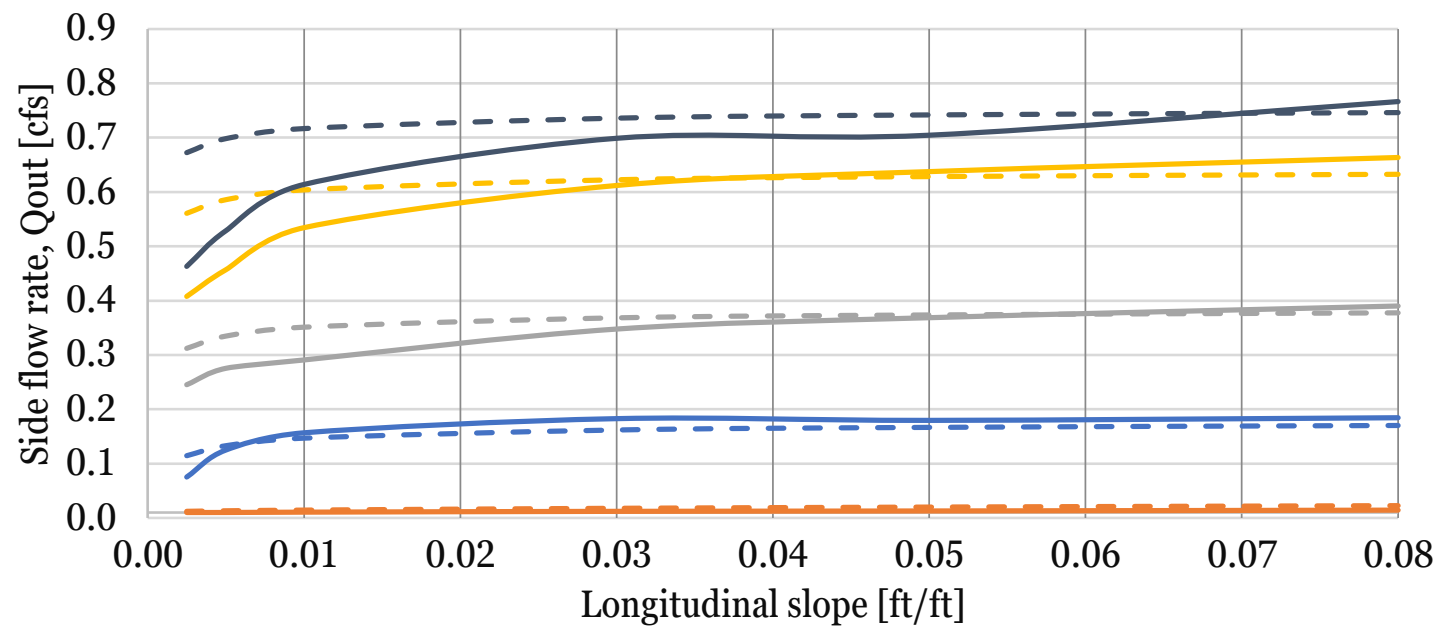

$$
\begin{aligned}
& \text { CFD, } \mathrm{T}=2 \mathrm{ft} \quad--{ }_{\mathrm{ODOT}} / \mathrm{HEC} 22, \mathrm{~T}=2 \mathrm{ft} \\
& \text { CFD, } \mathrm{T}=4 \mathrm{ft} \quad-- \text { ODOT } / \mathrm{HEC} 22, \mathrm{~T}=4 \mathrm{ft} \\
& -\mathrm{CFD}, \mathrm{T}=6 \mathrm{ft} \quad--\mathrm{ODOT} / \mathrm{HEC} 22, \mathrm{~T}=6 \mathrm{ft} \\
& -\mathrm{CFD}, \mathrm{T}=8 \mathrm{ft} \quad-- \text { ODOT/HEC22, } \mathrm{T}=8 \mathrm{ft} \\
& \text { CFD, T=10ft } \quad-- \text { ODOT/HEC22, T }=10 \mathrm{ft}
\end{aligned}
$$

Figure 6.14 Side flow into CB 3A catch basin vs. longitudinal profile grade for a road with (a) 2-ftwide composite curb and gutter, (b) 4-ft-wide shoulder, (c) 8-ft-wide shoulder.

The "grate flow", Qgrate, in the ODOT design procedure is calculated as the flow in the volume above the grate. In the computational analysis, it is calculated as the total intercepted approach flow decreased by the flow intercepted through the roadside edge of the grate. The "grate flow" is a sum of the flow going into the catch basin through the front, back and curbside edges of the grate, as well as the curb opening, which could be difficult to separate in a laboratory setting but can be established in a CFD simulation. The grate flow as a function of the flow spread and longitudinal grade for various road geometries is presented in Figure 6.15 for a road with (a) a 2-ft-wide composite curb and gutter, (b) a 4-ft-wide shoulder, (c) an 8-ft-wide shoulder. CFD simulations represent the shape of the design curves relatively well, for the majority of data points the difference between CFD computations and ODOT design equations is less than 10\%. Again, for small longitudinal grades, CFD gives a higher estimate of the intercepted discharge. 
(a)

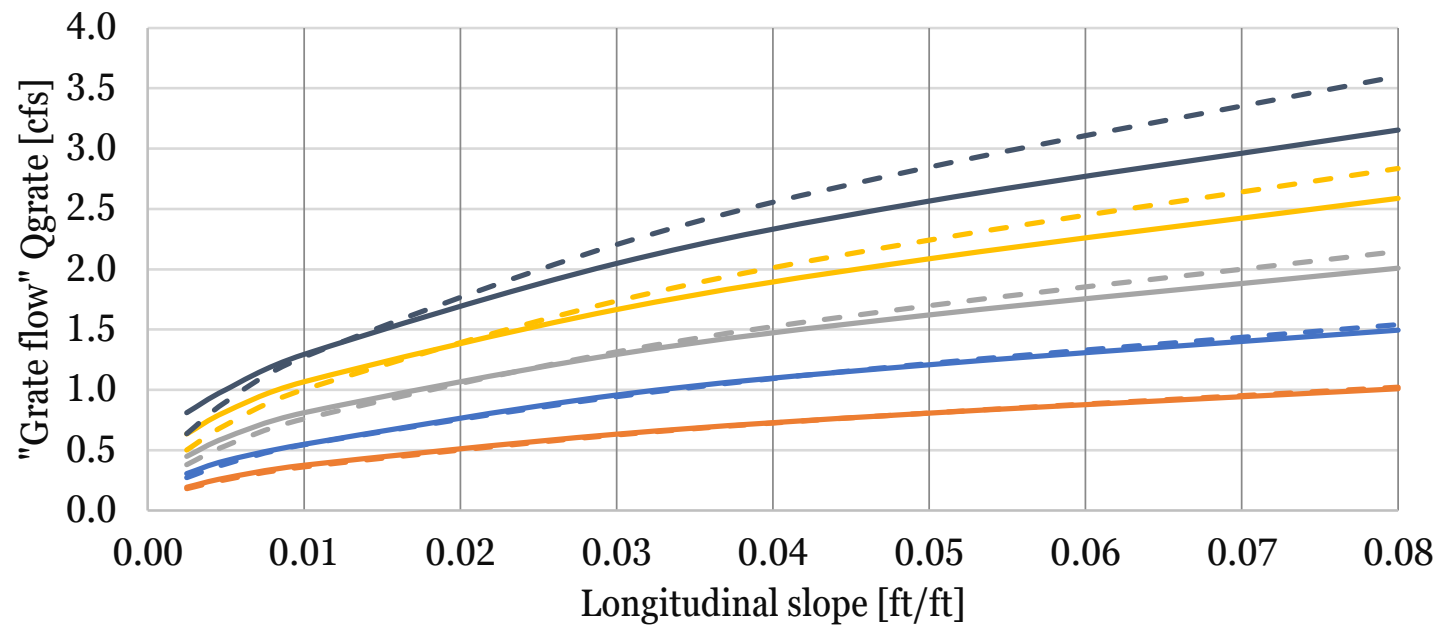
CFD, $\mathrm{T}=2 \mathrm{ft}$
- - ODOT/HEC22, $\mathrm{T}=2 \mathrm{ft}$
CFD, $\mathrm{T}=4 \mathrm{ft}$
- - - ODOT/HEC22, T=4ft
CFD, $\mathrm{T}=6 \mathrm{ft}$
- - ODOT/HEC22, T=6ft
$\mathrm{CFD}, \mathrm{T}=8 \mathrm{ft}$
- - ODOT/HEC22, $\mathrm{T}=8 \mathrm{ft}$
$\mathrm{CFD}, \mathrm{T}=10 \mathrm{ft}$
- - - ODOT/HEC22, T=10ft

(b)

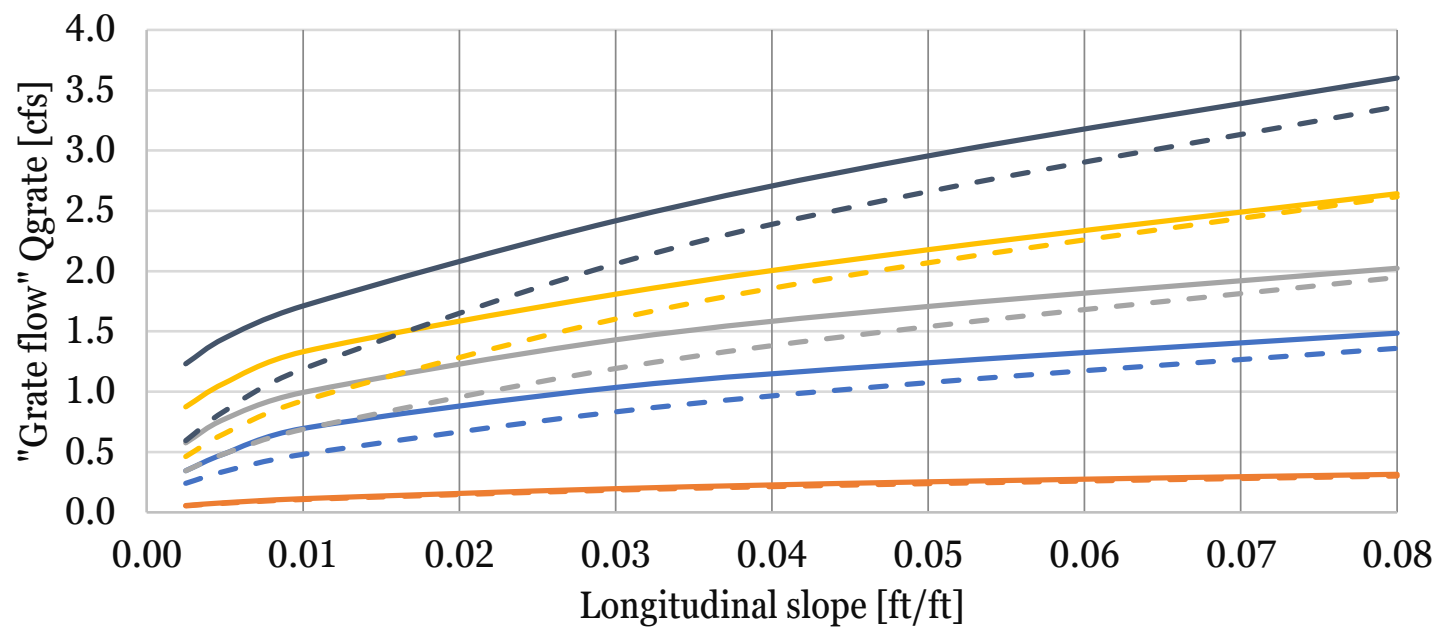

\begin{tabular}{|c|c|}
\hline $\mathrm{CFD}, \mathrm{T}=2 \mathrm{ft}$ & $---\mathrm{ODOT} / \mathrm{HEC} 22, \mathrm{~T}=2 \mathrm{ft}$ \\
\hline $\mathrm{CFD}, \mathrm{T}=4 \mathrm{ft}$ & $---\mathrm{ODOT} / \mathrm{HEC} 22, \mathrm{~T}=4 \mathrm{ft}$ \\
\hline $\mathrm{CFD}, \mathrm{T}=6 \mathrm{ft}$ & $---\mathrm{ODOT} / \mathrm{HEC} 22, \mathrm{~T}=6 \mathrm{ft}$ \\
\hline $\mathrm{CFD}, \mathrm{T}=8 \mathrm{ft}$ & --- ODOT/HEC22, T=8ft \\
\hline $\mathrm{CFD}, \mathrm{T}=10 \mathrm{ft}$ & - - - ODOT/HEC22, $\mathrm{T}=1$ \\
\hline
\end{tabular}

Computational Analysis of Hydraulic Capacity of Ohio DOT Catch Basins On-Grade and in Sag Locations

Page | 57 
(c)

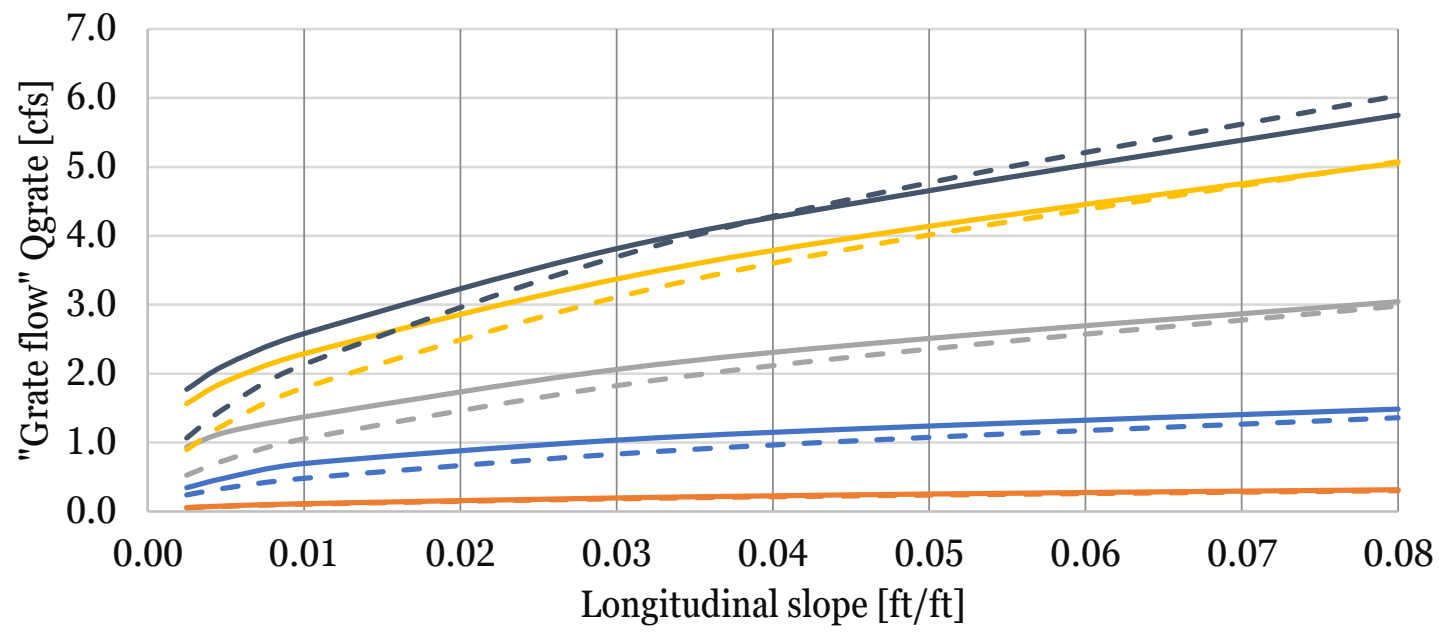

$$
\begin{aligned}
& \text { CFD, } \mathrm{T}=2 \mathrm{ft} \quad--- \text { ODOT/HEC22, } \mathrm{T}=2 \mathrm{ft} \\
& \text { CFD, } \mathrm{T}=4 \mathrm{ft} \quad-- \text { ODOT } / \mathrm{HEC} 22, \mathrm{~T}=4 \mathrm{ft} \\
& \text { CFD, } \mathrm{T}=6 \mathrm{ft} \quad--\mathrm{ODOT}_{\mathrm{H}} \mathrm{HEC} 22, \mathrm{~T}=6 \mathrm{ft} \\
& \text { CFD, } \mathrm{T}=8 \mathrm{ft} \quad--{ }_{-} \text {ODOT/HEC22, } \mathrm{T}=8 \mathrm{ft} \\
& \text { CFD, T=10ft } \quad-- \text { ODOT/HEC22, } \mathrm{T}=10 \mathrm{ft}
\end{aligned}
$$

Figure 6.15 "Grate flow" into CB 3A catch basin vs. longitudinal profile grade for a road with (a) a 2-ft-wide composite curb and gutter, (b) a 4-ft-wide shoulder, (c) an 8-ft-wide shoulder.

The flow bypassing the catch basin vs. longitudinal slope is plotted in Figure 6.16. The comparison shows that the CFD results are in good agreement with the ODOT equation results.

Computational Analysis of Hydraulic Capacity of Ohio DOT Catch Basins On-Grade and in Sag Locations 
(a)

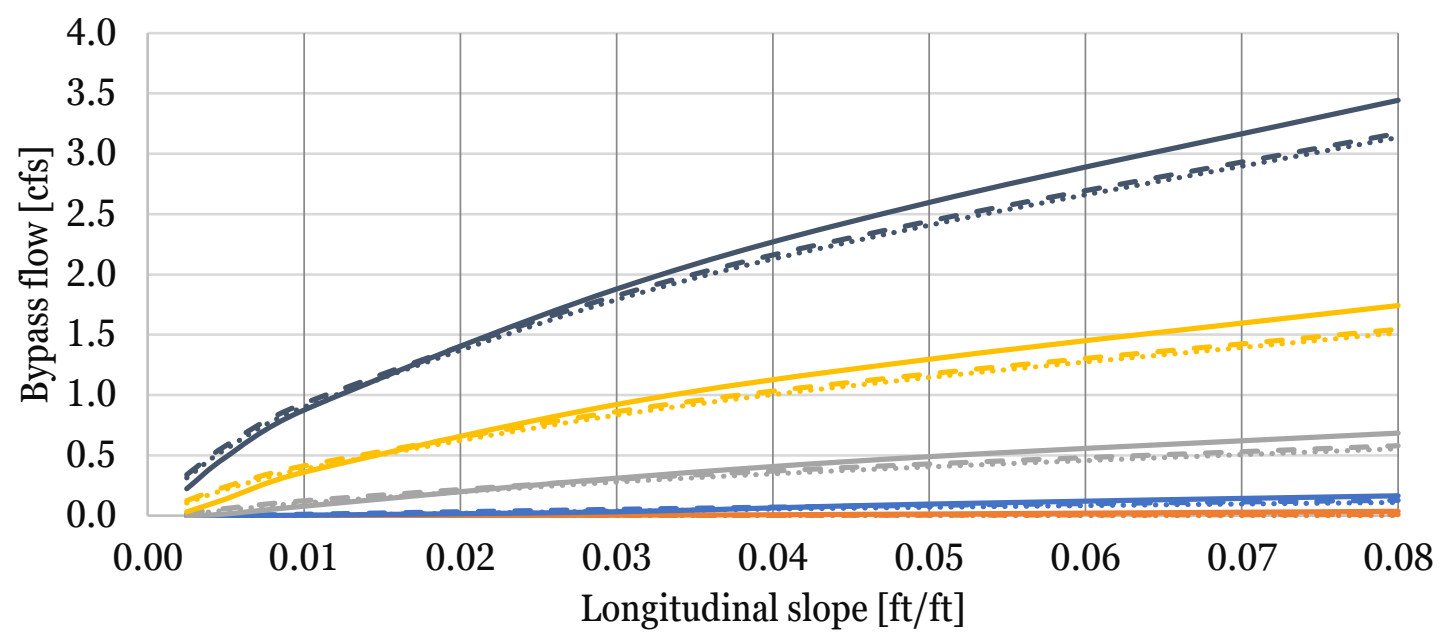

\begin{tabular}{|c|c|c|}
\hline$-\mathrm{CFD}, \mathrm{T}=2 \mathrm{ft}$ & --- ODOT, $\mathrm{T}=2 \mathrm{ft}$ & $\cdots \cdot \mathrm{HEC} 22, \mathrm{~T}=2 \mathrm{ft}$ \\
\hline $\mathrm{CFD}, \mathrm{T}=4 \mathrm{ft}$ & $---\mathrm{ODOT}, \mathrm{T}=4 \mathrm{ft}$ & $\cdots \mathrm{HEC} 22, \mathrm{~T}=4 \mathrm{ft}$ \\
\hline $\mathrm{CFD}, \mathrm{T}=6 \mathrm{ft}$ & --- ODOT, T=6ft & $\cdots \cdots \cdot \mathrm{HEC} 22, \mathrm{~T}=6 \mathrm{ft}$ \\
\hline & --- ODOT, T $=8 \mathrm{ft}$ & $\cdots \cdot \mathrm{HEC} 22, \mathrm{~T}=8 \mathrm{ft}$ \\
\hline CD & --- ODOT, $\mathrm{T}=10 \mathrm{ft}$ & $\cdot \mathrm{HEC} 22, \mathrm{~T}=1 \mathrm{C}$ \\
\hline
\end{tabular}

(b)

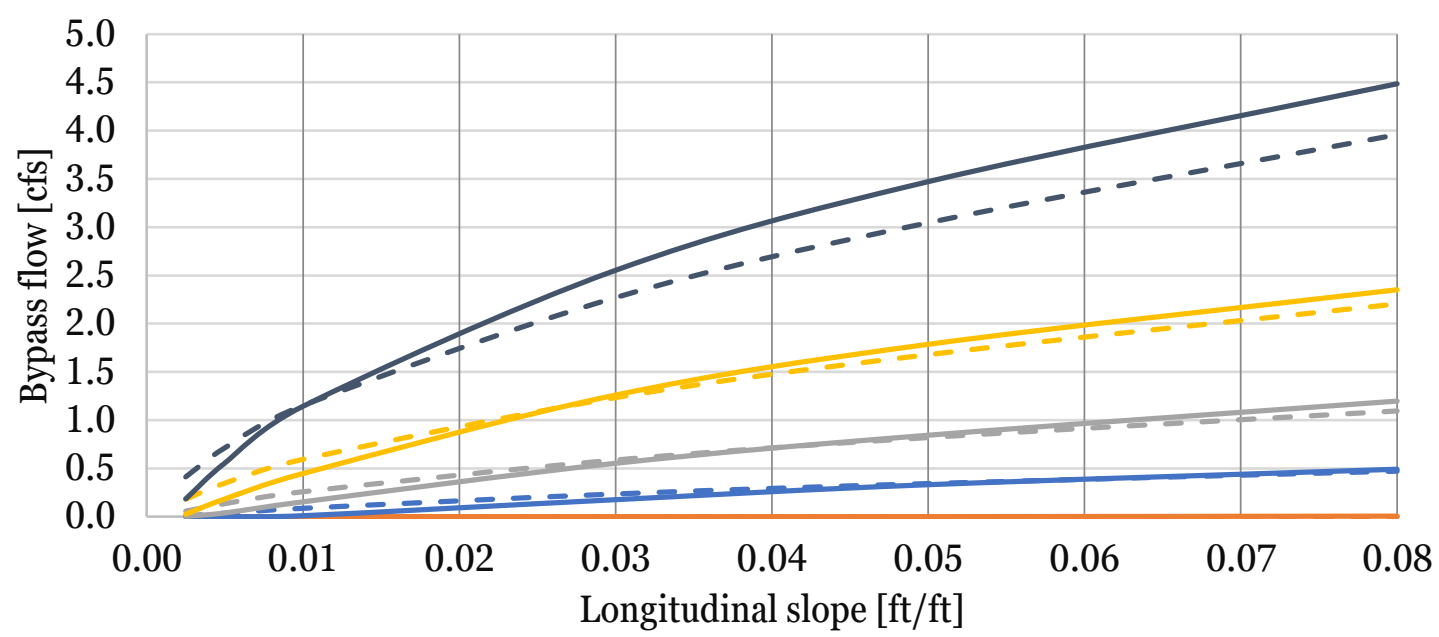

$$
\begin{aligned}
& -\mathrm{CFD}, \mathrm{T}=2 \mathrm{ft} \quad--- \text { ODOT/HEC22, } \mathrm{T}=2 \mathrm{ft} \\
& \text { CFD, } \mathrm{T}=4 \mathrm{ft} \quad-\quad-\text { ODOT/HEC22, } \mathrm{T}=4 \mathrm{ft} \\
& \text { CFD, } \mathrm{T}=6 \mathrm{ft} \quad--{ }_{-} \text {ODOT/HEC22, } \mathrm{T}=6 \mathrm{ft} \\
& \text { CFD, } \mathrm{T}=8 \mathrm{ft} \quad--{ }_{-} \text {ODOT/HEC22, } \mathrm{T}=8 \mathrm{ft} \\
& \text { CFD, T=10ft } \quad--- \text { ODOT/HEC22, T }=10 \mathrm{ft}
\end{aligned}
$$

Computational Analysis of Hydraulic Capacity of Ohio DOT Catch Basins On-Grade and in Sag Locations 
(c)

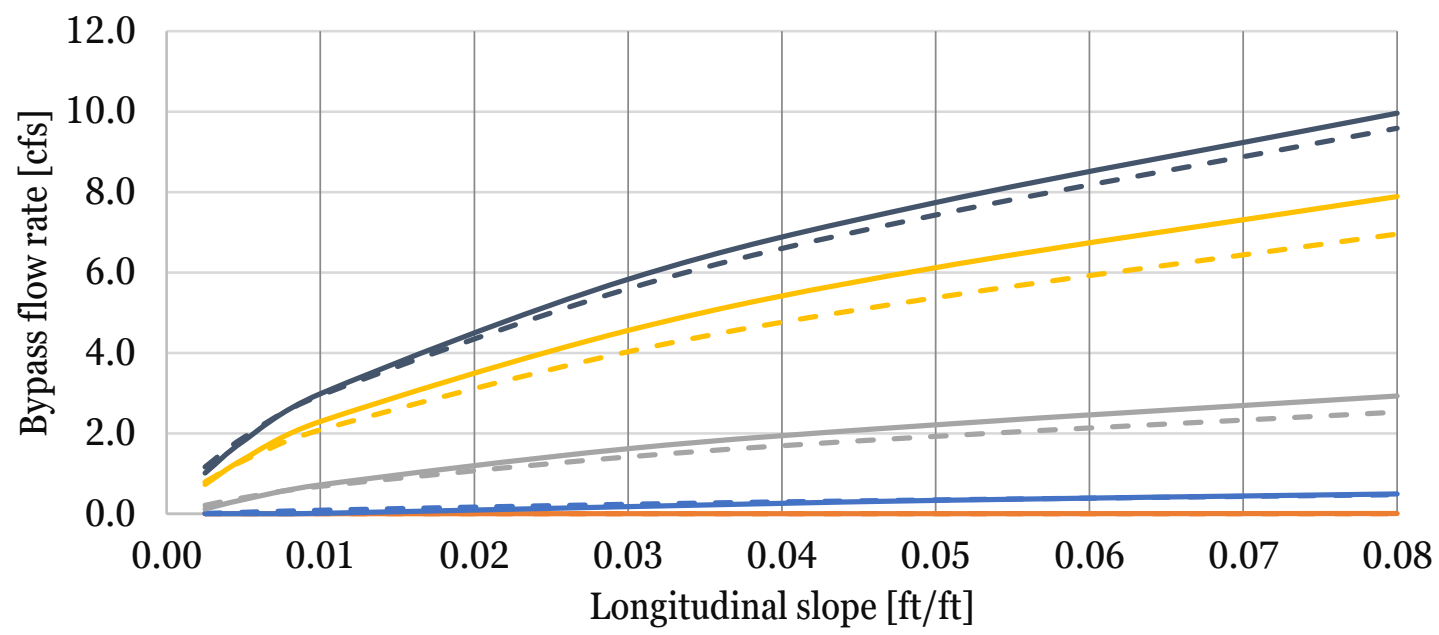

$$
\begin{aligned}
& \text { CFD, } \mathrm{T}=2 \mathrm{ft} \quad--- \text { ODOT/HEC22, } \mathrm{T}=2 \mathrm{ft} \\
& \text { CFD, } \mathrm{T}=4 \mathrm{ft} \quad-\quad-\text { ODOT/HEC22, } \mathrm{T}=4 \mathrm{ft} \\
& \text { CFD, } \mathrm{T}=6 \mathrm{ft} \quad--{ }_{\mathrm{ODOT}} / \mathrm{HEC} 22, \mathrm{~T}=6 \mathrm{ft} \\
& \text { CFD, } \mathrm{T}=8 \mathrm{ft} \quad--\mathrm{ODOT}_{\mathrm{H}} \mathrm{HEC} 22, \mathrm{~T}=8 \mathrm{ft} \\
& \text { - CFD, T=10ft } \quad-- \text { ODOT/HEC22, T=10ft }
\end{aligned}
$$

Figure 6.16 Bypass flow vs. longitudinal grade for a road with (a) a 2-ft-wide composite curb and gutter, (b) a 4-ft-wide shoulder, (c) an 8-ft-wide shoulder.

The efficiency of the combination inlet for varying pool spread and longitudinal grade obtained from computations compares well with the corresponding HEC 22 and ODOT estimates, as presented in Figure 6.17. Bigger differences occur for the 10-foot spread and minimum and maximum longitudinal grade when the spread is $8 \mathrm{ft}$, but even then, the differences exceed $\pm 20 \%$ in only 3 cases. Figure 6.18 shows a chart of $\mathrm{E}_{\mathrm{CFD}}$ vs. ЕОдот. Lines of $0 \%, 10 \%$, and $20 \%$ were plotted to improve the readability of the chart.

Computational Analysis of Hydraulic Capacity of Ohio DOT Catch Basins On-Grade and in Sag Locations 
(a)

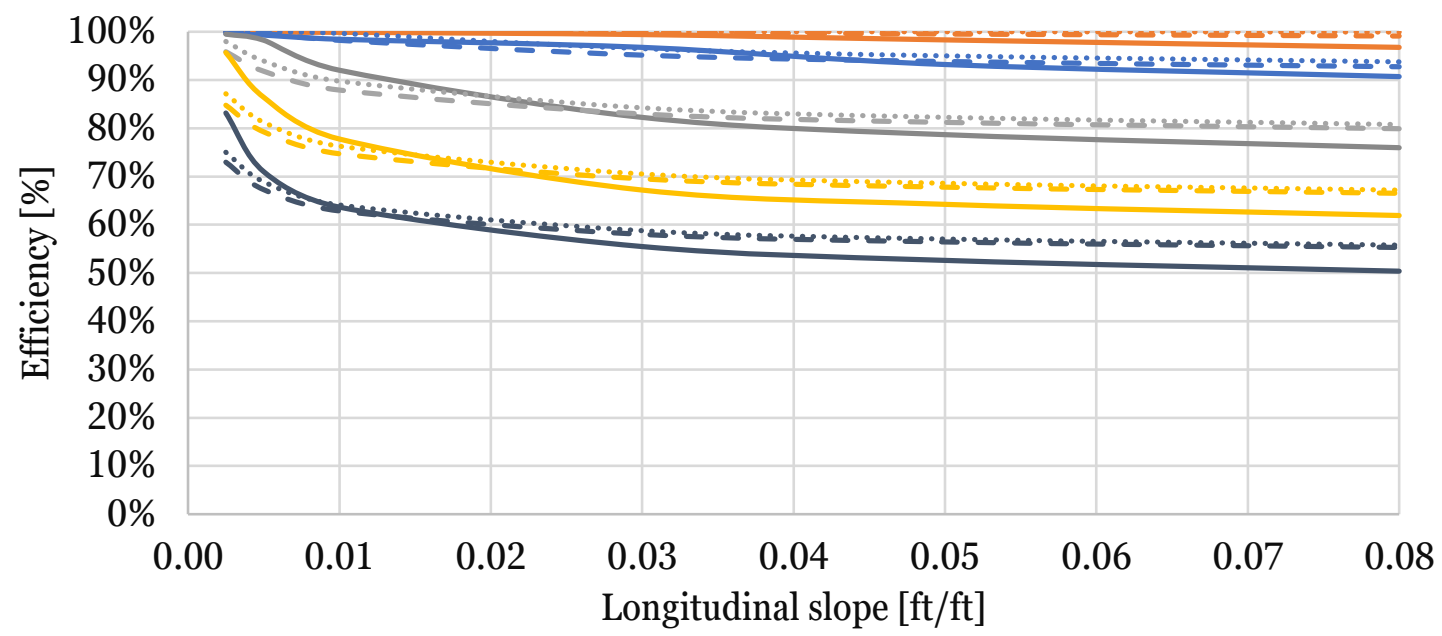

\begin{tabular}{|c|c|c|}
\hline $\mathrm{CFD}, \mathrm{T}=2 \mathrm{ft}$ & $---\mathrm{ODOT}, \mathrm{T}=2 \mathrm{ft}$ & $\cdots \cdot \mathrm{HEC} 22, \mathrm{~T}=2 \mathrm{ft}$ \\
\hline $\mathrm{CFD}, \mathrm{T}=4 \mathrm{ft}$ & --- ODOT, $\mathrm{T}=4 \mathrm{ft}$ & $\cdots \cdot \mathrm{HEC} 22, \mathrm{~T}=4 \mathrm{ft}$ \\
\hline $\mathrm{CFD}, \mathrm{T}=6 \mathrm{ft}$ & $---\mathrm{ODOT}, \mathrm{T}=6 \mathrm{ft}$ & $\cdots \cdot \mathrm{HEC} 22, \mathrm{~T}=6 \mathrm{ft}$ \\
\hline $\mathrm{CFl}$ & -- ODOT, $\mathrm{T}=8 \mathrm{ft}$ & $\cdots \cdot \mathrm{HEC} 22, \mathrm{~T}=8 \mathrm{ft}$ \\
\hline$C F D$ & --- ODOT, $\mathrm{T}=10 \mathrm{ft}$ & $\cdots \cdot$ HEC22, $\mathrm{T}=1 \mathrm{C}$ \\
\hline
\end{tabular}

(b)

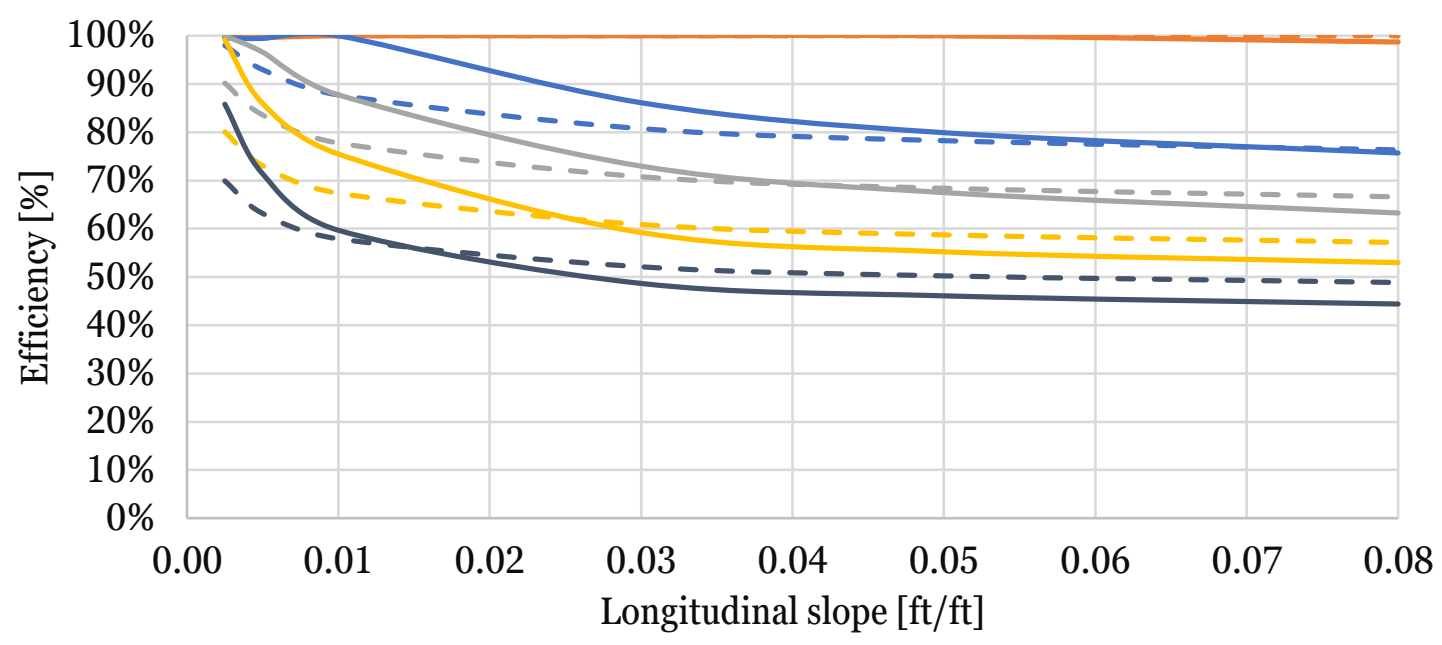

\begin{tabular}{|c|c|}
\hline$-\mathrm{CFD}, \mathrm{T}=2 \mathrm{ft}$ & --- ODOT/HEC22, $\mathrm{T}=2 \mathrm{ft}$ \\
\hline$-\mathrm{CFD}, \mathrm{T}=4 \mathrm{ft}$ & $---\mathrm{ODOT} / \mathrm{HEC} 22, \mathrm{~T}=4 \mathrm{ft}$ \\
\hline $\mathrm{CFD}, \mathrm{T}=6 \mathrm{ft}$ & --- ODOT/HEC22, $\mathrm{T}=6 \mathrm{ft}$ \\
\hline $\mathrm{CFD}, \mathrm{T}=8 \mathrm{ft}$ & $---\mathrm{ODOT} / \mathrm{HEC} 22, \mathrm{~T}=8 \mathrm{ft}$ \\
\hline $\mathrm{CFD}, \mathrm{T}=10 \mathrm{ft}$ & - - - ODOT/HEC $22, \mathrm{~T}=10$ \\
\hline
\end{tabular}

Computational Analysis of Hydraulic Capacity of Ohio DOT Catch Basins On-Grade and in Sag Locations

Page | 61 
(c)
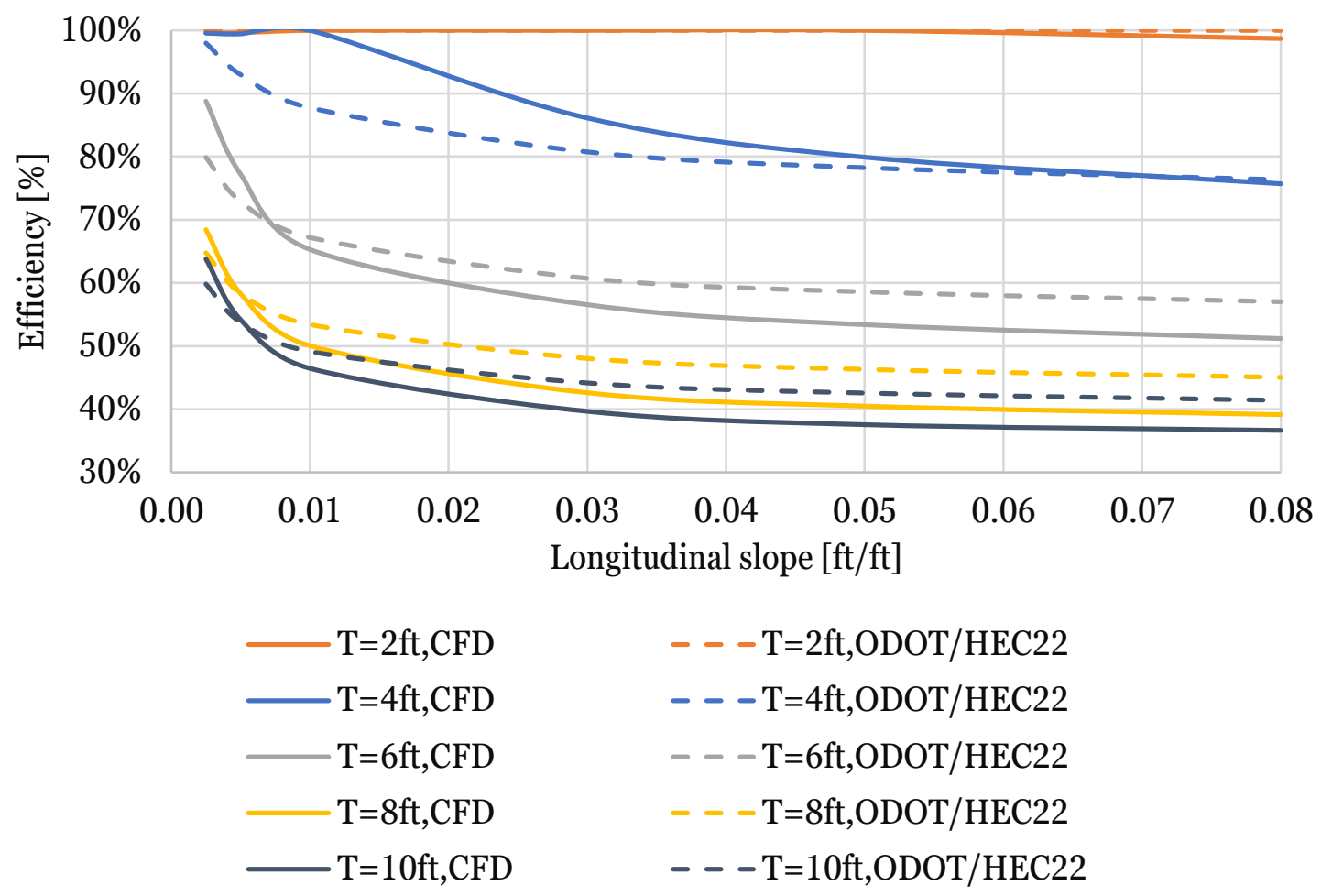

$$
\begin{aligned}
& \text { - - - T=2ft,ODOT/HEC22 } \\
& \text { - - - T=4ft,ODOT/HEC22 } \\
& \text { - - } \mathrm{T}=6 \mathrm{ft}, \mathrm{ODOT} / \mathrm{HEC} 22 \\
& \text { - - - T=8ft,ODOT/HEC22 } \\
& \text { - - - T=10ft,ODOT/HEC22 }
\end{aligned}
$$

Figure 6.17 Efficiency of CB3A catch basin vs. longitudinal grade for a road with (a) 2-ft-wide composite curb and gutter, (b) 4-ft-wide shoulder, (c) 8-ft-wide shoulder. 


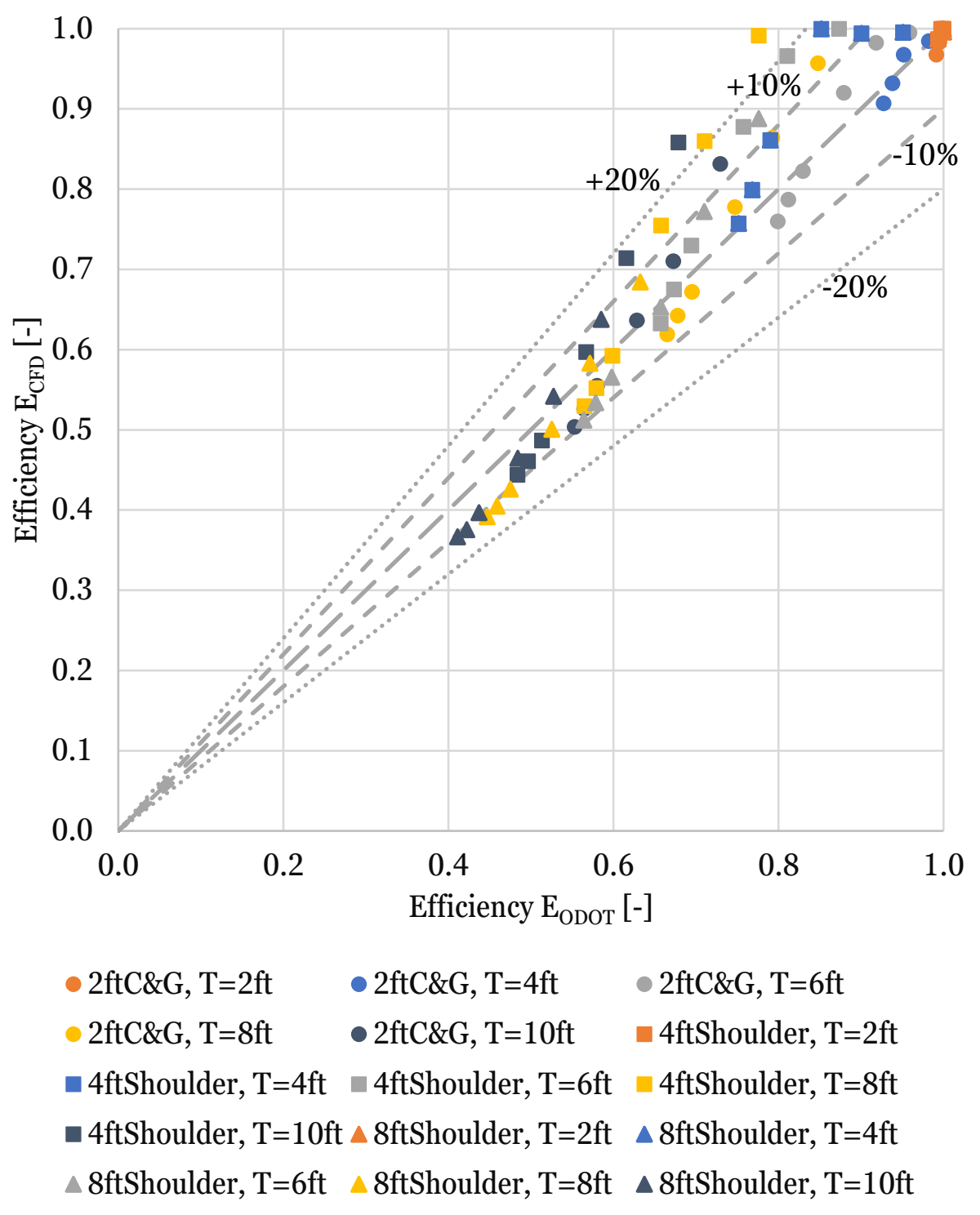

Figure 6.18 Comparison of CB3A efficiency obtained with CFD and ODOT design calculations. Dashed lines show a $\pm 10 \%$ difference, and dotted lines show a $\pm 20 \%$ difference (legend: $2 \mathrm{ftC} \& G$ stands for a road with a 2 -ft-wide composite curb and gutter, $4 \mathrm{ftShoulder} \mathrm{-} \mathrm{a} \mathrm{road} \mathrm{with} \mathrm{a} \mathrm{4-ft-wide}$ shoulder, $8 \mathrm{ftShoulder} \mathrm{-} \mathrm{a} \mathrm{road} \mathrm{with} \mathrm{an} 8$-ft-wide shoulder).

Figure 6.18 shows a summary chart that shows the difference between efficiency of the catch basin obtained with the use of CFD and from ODOT design procedure for all cases from the case set matrix. The plot shows a scatter of data points, with majority of them falling between the $\pm 10 \%$ lines. The remaining points, except for three of them, are within $\pm 20 \%$ range.

Computational Analysis of Hydraulic Capacity of Ohio DOT Catch Basins On-Grade and in Sag Locations 
Figure 6.19 presents the efficiency of the catch basin as a function of the design flow rate. All data points for all road geometries and flow conditions are combined on this plot. Two sections of the plot can be distinguished, marked with orange and blue colors in the figure. For flow rates lower than $\sim 1$ cfs the efficiency is almost constant and close to $100 \%$. When the flow rate is greater than $1 \mathrm{cfs}$, the efficiency drops from about $100 \%$ at $1 \mathrm{cfs}$ to $37 \%$ at the highest considered flow rate of $15.7 \mathrm{cfs}$. A best fit function was found for this subset of results, which is $y=0.93 x^{-0.35}$, with a coefficient of determination equal to $R^{2}=0.94$.

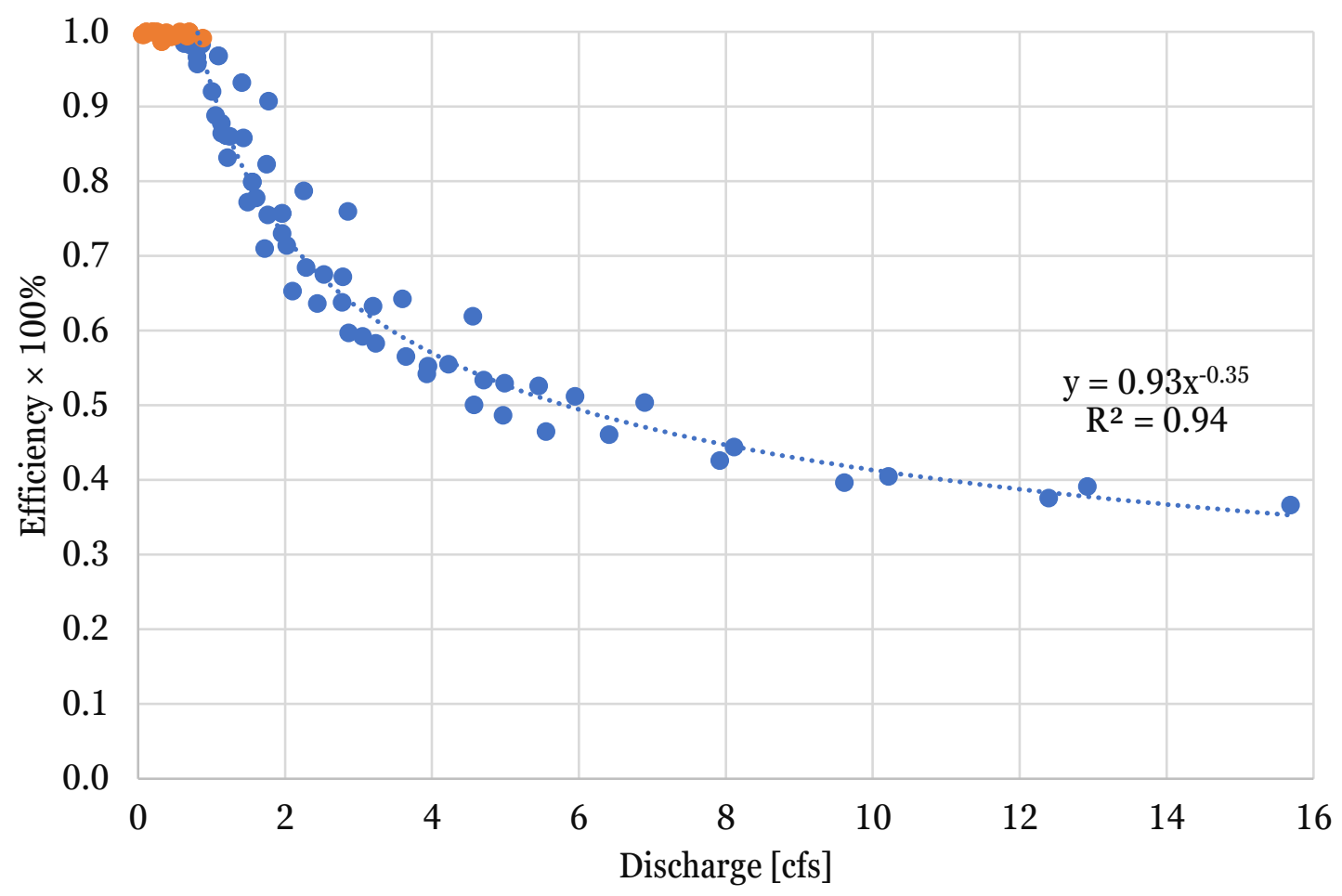

Figure 6.19 Efficiency vs. flow rate with varying longitudinal grade, and road geometry.

The differences in intercepted flow between CFD and design equations may be a result of the fact that HEC 22 equations, as well as ODOT design equations are based on experiments performed by Burgi et al.[10], [11]. Although the experiments encompass a wide range of parameters and their values, they do not account for:

- other grate shapes than the tested ones, out of which the curved vane grate is the most similar to ODOT's "V" grate,

- longitudinal slopes less than $0.5 \%$,

- composite pavement cross-sections and local depressions,

- flow rates over $5.6 \mathrm{cfs}$,

- Manning roughness coefficients other than 0.016 and 0.017 .

Each of these conditions is covered by the test case matrix in the present study:

- the smallest cross slope is $0.25 \%$,

- the pavement cross-section has a 2-ft-wide gutter at $8.3 \%$ cross slope and a travel lane at $1.6 \%$ cross slope, additionally there is a local depression at the inlet of 0.5 in,

- flow rates calculated from Manning's equation for the 10-ft spread, reach $16.3 \mathrm{cfs}$,

Computational Analysis of Hydraulic Capacity of Ohio DOT Catch Basins On-Grade and in Sag Locations 
- $\quad$ the pavement surface is assumed to be smoother, with roughness coefficient of 0.015 .

\subsubsection{Influence of Clogging on the Catch Basin Efficiency in On-Grade Locations}

The geometry of the model with a partially clogged inlet is described in Section 5.4. Figure 6.20 presents the flow pattern above the inlet for varying percentage of blocked grate area, starting with the base case of zero blockage, through $10 \%$ and $30 \%$, and ending at $50 \%$ of the area being blocked. This set of models aims at representing a scenario that can happen in reality when debris moving with the flow usually clogs the upstream openings of grate. Depending on the size, it may only block the flow into the grate, and/or the curb opening. If the curb opening is fully unobstructed, with increasing percentage of blocked area, more flow is intercepted by the curb opening. If, on the other hand the curb opening is fully blocked, then only the grate intercepts the flow. Figure 6.21 shows the geometry of a model with the curb opening closed.

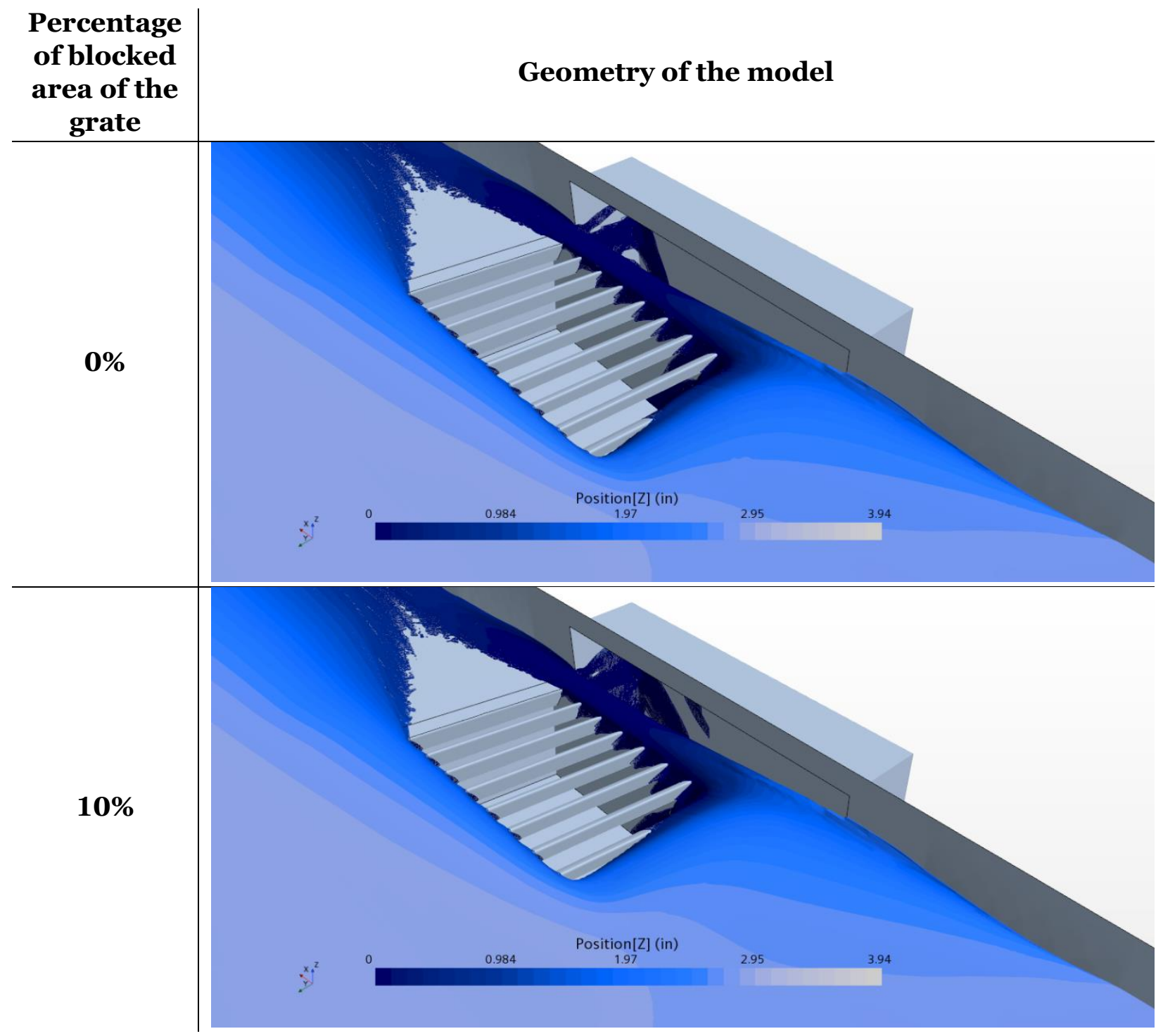

Computational Analysis of Hydraulic Capacity of Ohio DOT Catch Basins On-Grade and in Sag Locations 


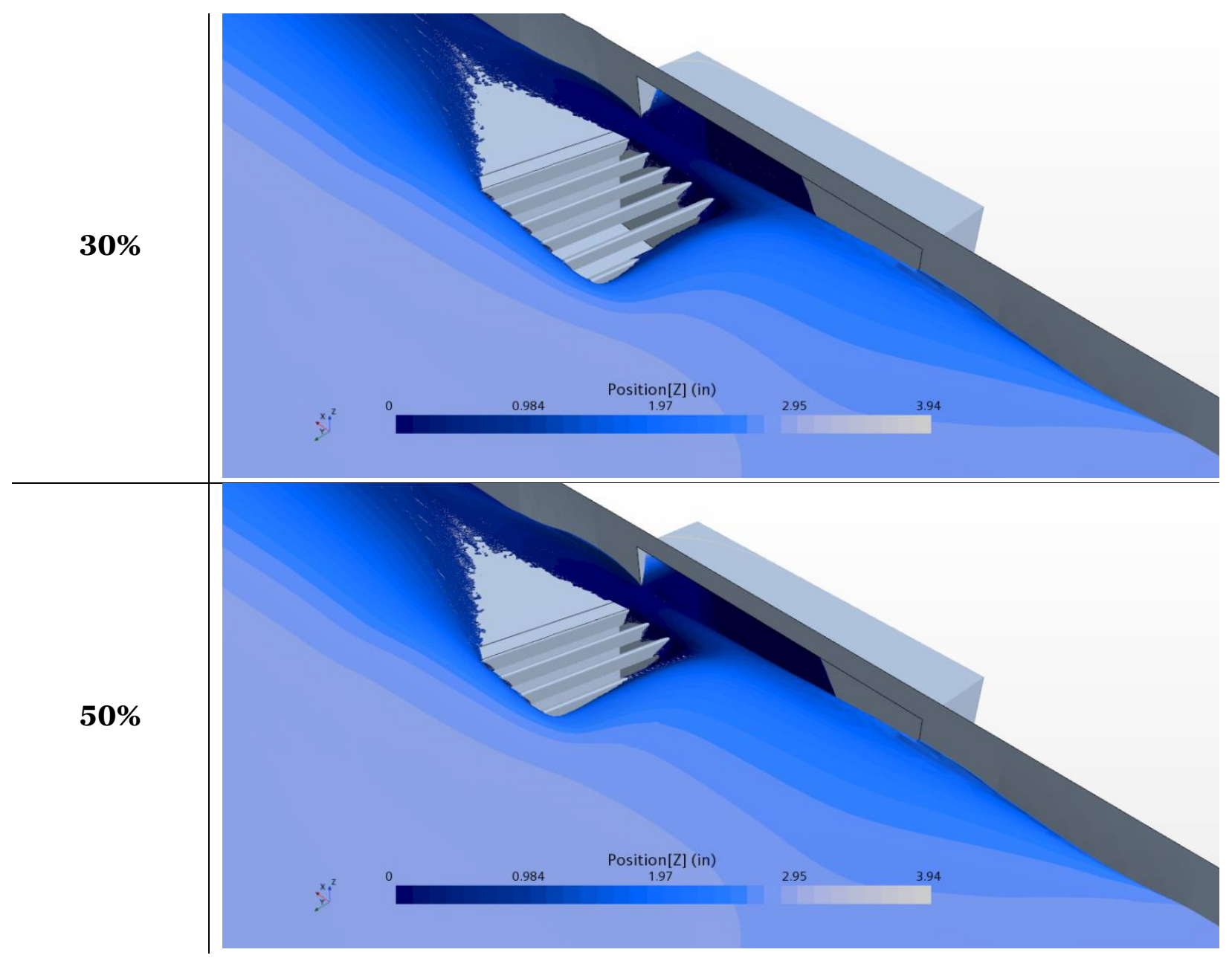

Figure 6.20 Flow patterns above a combination inlet for varying percentage of blocked area of the grate.

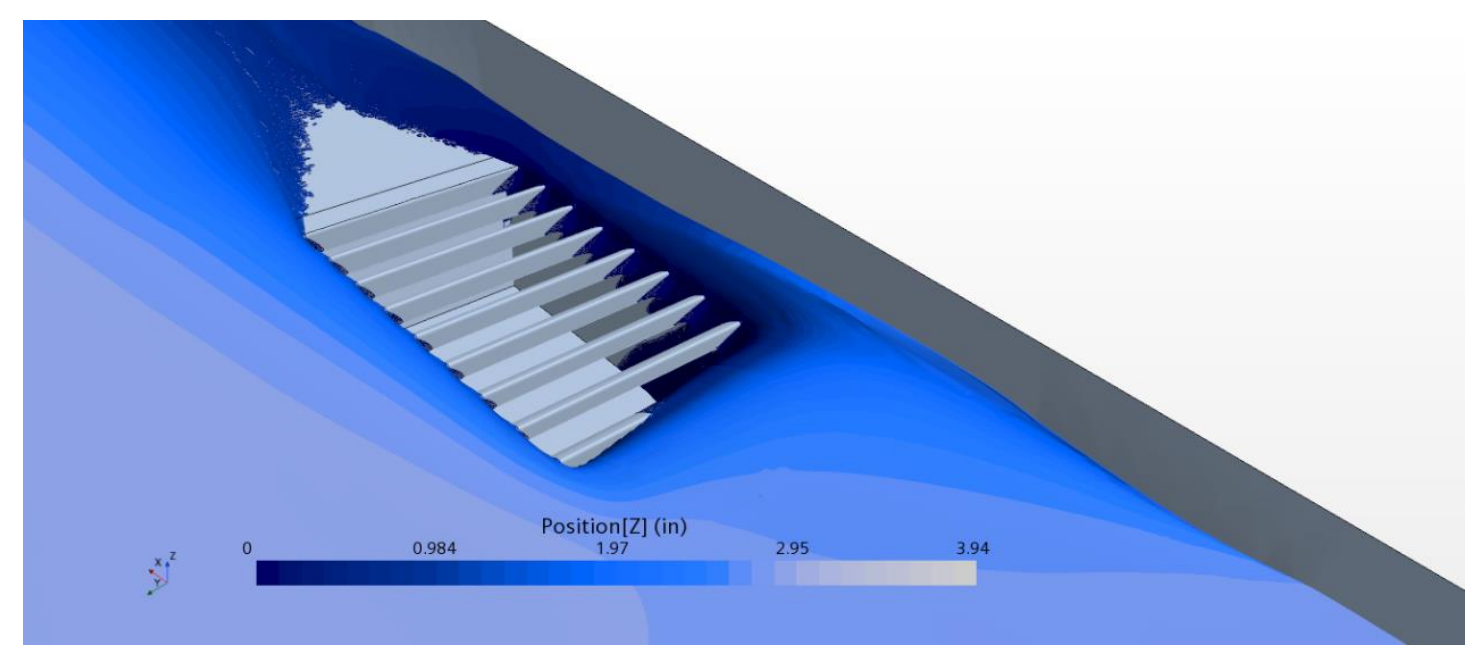

Figure 6.21 Flow pattern above a combination inlet with a blocked curb opening.

Computational Analysis of Hydraulic Capacity of Ohio DOT Catch Basins On-Grade and in Sag Locations 
Figure 6.22 presents a plot that combines two types of results: flow rates intercepted by the grate, curb opening, and total interception, as well as the resulting catch basin efficiency as a function of the percentage of the grate that is blocked. Also, efficiency of the catch basin in the scenario with a blocked curb opening and unobstructed grate was plotted for comparison.

When the open area of the grate decreases, its interception drops from $2.64 \mathrm{cfs}$ at $0 \%$ to $2.29 \mathrm{cfs}$ at $50 \%$, but simultaneously the interception of the curb opening increases from $0.18 \mathrm{cfs}$ at $0 \%$ to $0.41 \mathrm{cfs}$ at $50 \%$. This leads to only a small change in the overall efficiency from $62 \%$ to $59 \%$ (a 3 $\%$ drop). For comparison, the efficiency of the grate without the curb opening was added to the plot (dotted grey line) as a line of constant value of $61 \%$. In the considered case, if the grate is fully open, there is a negligible contribution from the curb opening, but if the grate is partially blocked, the window intercepts some of the flow that otherwise would bypass the catch basin. This finding confirms a recommendation provided by HEC 22 [2] and repeated in Section 4.1.5 to neglect the contribution of the curb opening when calculating the efficiency of a combination inlet in on-grade locations without clogging. It also shows the advantageous role of a curb opening when clogging occurs.

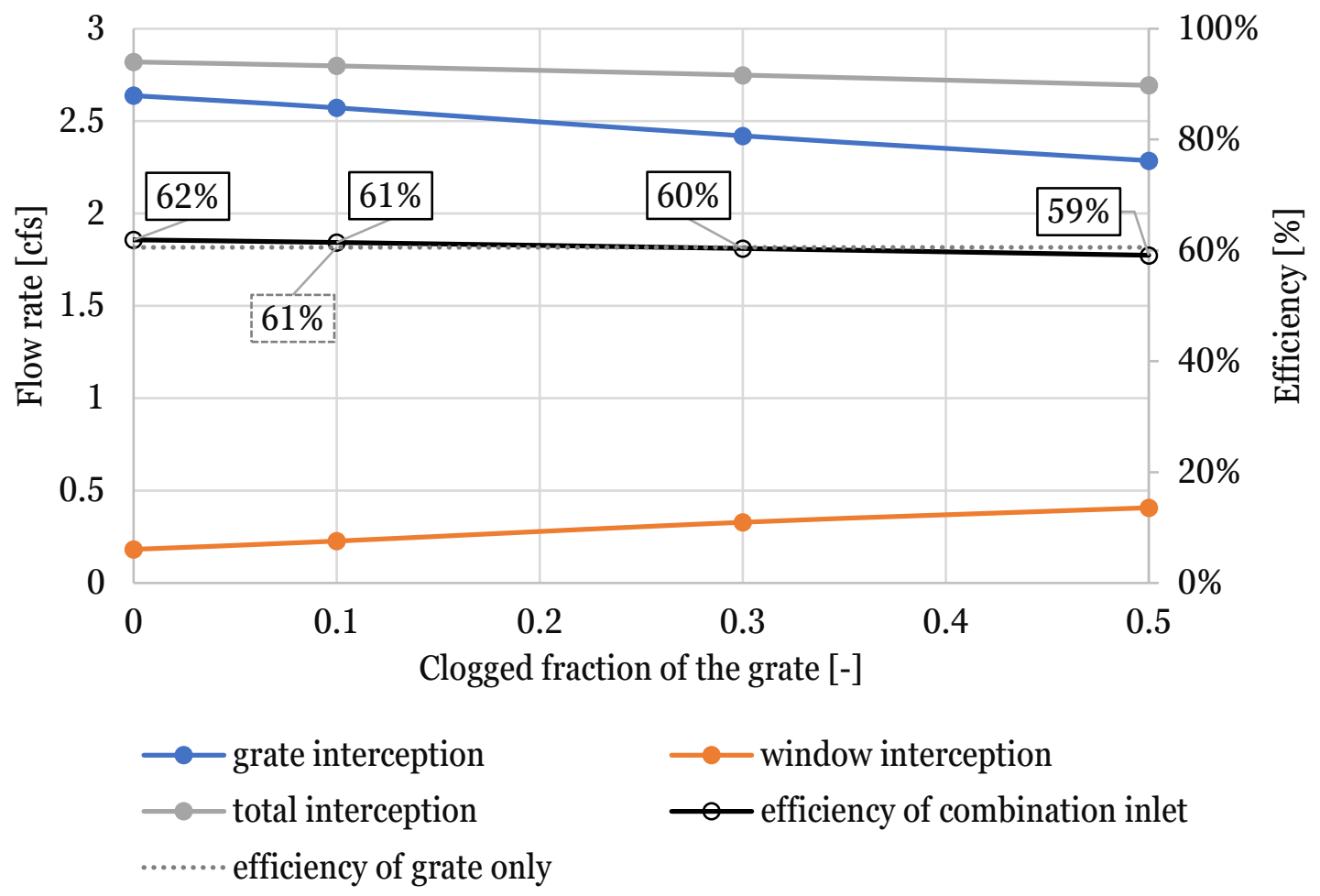

Figure 6.22 Flow interception by the grate (blue), window (orange), and total (grey) as a function of the percentage of clogged area of the grate. Efficiency of the catch basin with curb opening open (black solid line) and curb opening blocked (grey dashed line).

Computational Analysis of Hydraulic Capacity of Ohio DOT Catch Basins On-Grade and in Sag Locations 


\subsection{Sag Locations}

Three scenarios were considered for sump conditions:

(1) both the curb opening, and the grate contribute to the hydraulic capacity of the catch basin (both are unobstructed),

(2) the grate is unobstructed and there is no curb opening contribution, and

(3) the curb opening is unobstructed and there is no grate contribution.

ODOT CB3 catch basins are double inlets designed for sump conditions under the assumption that the "V" grates are positioned to collect flow from opposite directions i.e., the inlet is symmetric relative to the central axis. This condition makes it possible to assume that the flow through the catch basin is close to symmetrical, and therefore only half of the catch basin geometry needs to be included in the computational model, with a symmetry boundary condition on the symmetry plane. This approach reduces the computational resources needed to complete a simulation run.

Knowledge of the relationship between the design discharge and ponding depth is required to properly establish spacing between inlets in sag locations. Flow under sump conditions was represented with a model that contains the geometry of a section of a road with sufficient space above it for a deep pond with air layer above it, the grate and curb opening, and the catch basin. The entire extent of the pond above the grate is not included to reduce the computational cost of a simulation. The computational domain is initially filled with water from the road surface up to a selected height that is greater than the maximum design water depth. The simulation is unsteady and at time zero, water starts flowing through the grate and draining from the domain through the pressure outlet boundary condition surface on the bottom of the catch basin, with a set atmospheric pressure. Initially the catch basin below the grate contains only air. The start condition at time zero is as though a plate that was blocking flow through the grate is suddenly removed. During a simulation, the flow changes from an orifice flow regime, through a transition regime, to a weir flow regime. Simulations are usually ended when the water depth drops to $\sim 1$ inch, because at that time, the flow rate is very low, and the computations slow down drastically. Also, when the depth is so small, water is collected within the gutter in the vicinity of the grate, and its impact on the travel lanes is negligible. Every 5 to 10 timesteps, the average water depth away from the drain, and mass flow rate through the drain are saved, which allows for plotting the two quantities vs. simulated time. In the postprocessing phase, the plots are combined to show the ponding depth vs. design discharge relationship.

The flow conditions over inlets in sag locations can be of one of three types: weir flow, orifice flow, and the transition between them. When above the grate water surface is almost level and unbroken, flow is in the orifice type regime. In the weir flow regime, the grate is partially overtopped, and the surface is broken and dips down to the grate. When the flow is in an intermediate state, and the type of the flow is not clearly identifiable, it is said to be in a transition regime. HEC 22 provides orifice flow and weir flow equations to calculate the relation between flow rate and water depth. When the flow regime is not clear, HEC 22 recommends drawing a curve between the orifice flow and weir flow lines to obtain the depth versus flow rate values. ODOT design approach is to draw a linear function.

Computational Analysis of Hydraulic Capacity of Ohio DOT Catch Basins On-Grade and in Sag Locations

Page | 68 


\subsubsection{Curb Opening and Grate Contribution to Hydraulic Capacity of Catch Basin CB 3}

Figure 6.23, Figure 6.34, and Figure 6.39 show the depth of the ponding water as a function of discharge in sump conditions for a combination inlet, an inlet without the curb opening contribution and an inlet without the grate contribution, respectively. The figures include the results from CFD simulations, HEC 22, and ODOT equations for weir, transition, and orifice flow.

The curves representing the relationship between water depth and flow rate differ slightly depending on computational grid, timestep, as well as the in-plane size of the domain (or amount of street included), and initial water depth. Depending on the density of the computational grid and size of timestep, a different level of detail can be resolved. The in-plane size of the domain (size of the part of the pond reservoir that is modeled) must be big enough that the side surfaces have no influence on the flow through the grate and curb opening. When the domain is too small, the water depth is underestimated for a given discharge as compared to HEC 22 equations, while the water depth vs. discharge is not influenced under orifice flow conditions. The initial water depth is set so that the flow through the inlet is in orifice flow regime. Depending on the initial depth, the curves slightly differ, but despite these differences, when plotted on the same chart, all curves follow a similar trend.

Both, HEC 22 and ODOT design procedures, assume that the weir flow discharge for combination inlets is characterized by the same equation as that used for a grate inlet, (41) or (46), respectively, which means that the contribution of the curb opening is neglected. The discharge in orifice flow is a sum of the flow rate through the grate and curb opening, equations (43) and (50) or (47) and (52), respectively. ODOT procedure states that for depths between $0.4^{\prime} \leq d_{1} \leq 1.4^{\prime}$ a proportional transition should be used, the same way as for grates. HEC 22 does not specify the limits for transition flow, therefore the smaller discharge calculated from weir flow equation and orifice flow equation for a given water depth is selected, to obtain a more conservative result.

Figure 6.23 shows a combination of plots of water depth at curb away from the inlet vs. discharge through the combination inlet obtained from CFD, ODOT equations and HEC 22 equations. If the flow is in weir flow regime, the three estimates are in good agreement. A comparison between the computational results and calculations for orifice flow, shows that for a combination inlet CFD gives greater discharge for a given water depth than the design equations. ODOT design calculations for orifice flow given by equation (47) take a clear open area of a diagonal grate, equal to $1.45 \mathrm{ft}^{2}$ ("ODOT eqs." - solid blue line), which is smaller than the smallest open area of the vane grate, equal to $1.71 \mathrm{ft}^{2}$ ("ODOT eqs. (mod)" - dashed blue line). The modified ODOT eq. for orifice flow gives an estimate that is closer to the CFD results.

Standard drawings of a similar single and double " $\mathrm{V}$ " grates were obtained from the manufacturer [24], [25]. For a single grate, the free open area is stated to be equal to $1.77 \mathrm{ft}^{2}$, and for a double grate, free open area is equal to $2.8 \mathrm{ft}^{2}$, which is less than double area of a single grate. Note that the standard drawing shows the two grates in the double grate with the non-vertical bars pointing the same direction. The decreased free open area probably represents this configuration, which is less efficient than when the grates are installed symmetrically.

In a separate study [26], [27], the authors analyzed flow through three grates mentioned in HEC 22: P50 grate with vertical bars, a 45-degree tilt bar grate, and a curved vane grate, with the use of CFD modeling. The study showed that the computations give higher flow rates for a given depth

Computational Analysis of Hydraulic Capacity of Ohio DOT Catch Basins On-Grade and in Sag Locations

Page | 69 
in the case of grates with non-vertical bars than the HEC 22 estimates given by eq. (41)-(43). The conservative estimates provided by HEC 22 are a result of a comparative analysis performed by researchers [19] on two halves of a curved vane grate, placed "forward" i.e., with the vanes forward to the approach flow direction, and "backward" i.e., with the vanes in the opposite direction. The two half-grates had similar capacities under weir flow condition. Under orifice flow condition the grate positioned "backwards" had a lower capacity than a grate positioned "forward", which was accounted for in the design equations.

An experimental flume configuration is currently being developed at the Turner-Fairbank Highway Research Center, to test drainage discharge rates through one tenth-scale grates under sump conditions with a goal to validate the CFD computational findings.

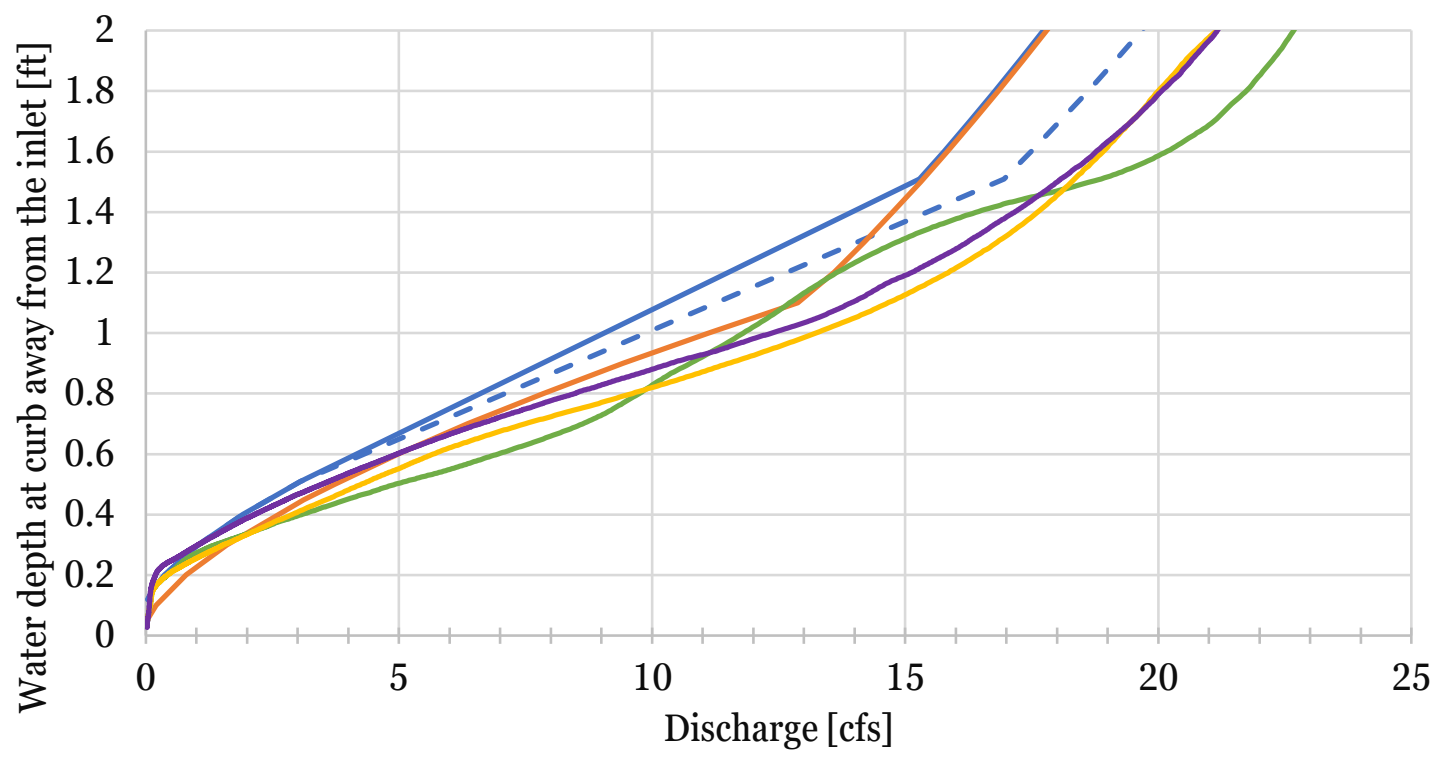

$\begin{array}{ll}- \text { ODOT eqs. } & -- \text { ODOT eqs. (mod) } \\ \text { HEC } 22 \text { eqs. } & - \text { CFD, Dinit }=1 \mathrm{~m}, \text { Wdom }=0.5 \mathrm{~m} \\ \text { CFD, Dinit }=2 \mathrm{~m}, \text { Wdom }=0.5 \mathrm{~m} & - \text { CFD, Dinit }=3 \mathrm{~m}, \text { Wdom }=3 \mathrm{~m}\end{array}$

Figure 6.23 Combination inlet. Depth of the ponding water vs. discharge in sump conditions (Dinit - initial water depth measured from the lowest point in the gutter, Wdom - domain width from the roadside edge of grate).

Figure 6.24 shows the change of discharge through a combination inlet and ponding water depth in time for a model with initial water depth Dinit=3 $\mathrm{m}$ and a bigger computational domain, Wdom $=3 \mathrm{~m}$. Water depth drops during the simulation from $3 \mathrm{~m}(\sim 10 \mathrm{ft})$ to almost zero. The curve is smooth and does not have any sudden changes in slope. The discharge through the curb opening has such a characteristic point, at $\sim 26$ seconds of simulated time, where the shape of the plot changes from almost linear to curved. The curve representing the discharge through the grate also changes slope, but the change is not so sudden; a transition phase occurs between 20 sec and 30 seconds of simulated time. Because total discharge is a sum of the two components, the curve has a smooth transition between time when the inlet is in an orifice flow condition, and weir flow condition. 
The ratio of the grate and curb opening contribution in the total intercepted flow is plotted in Figure 6.25. Up until $\sim 20$ seconds of simulated time, the grate and curb opening intercept an almost time-independent percentage of the flow, $73 \%$ and $27 \%$, respectively. Figure 6.26 shows a snapshot of the flow pattern when depth at curb is equal $\sim 2 \mathrm{ft}$. At approximately $20 \mathrm{sec}$, the contribution from the grate starts to decrease and reaches minimum of $70 \%$ at $25.7 \mathrm{sec}$. Next, it starts to rise again and reaches a maximum of $91 \%$ at $33.3 \mathrm{sec}$, after which slowly decreases. Figure 6.27 presents the water surface elevation at $25.7 \mathrm{sec}$. The surface reaches the top of the curb opening, which starts to operate as a weir. At the same time, the grate is still overtopped and operates as an orifice. As the water level at the curb reaches $\sim 0.8 \mathrm{ft}$, also the grate starts to operate as an orifice, as shown in Figure 6.28.

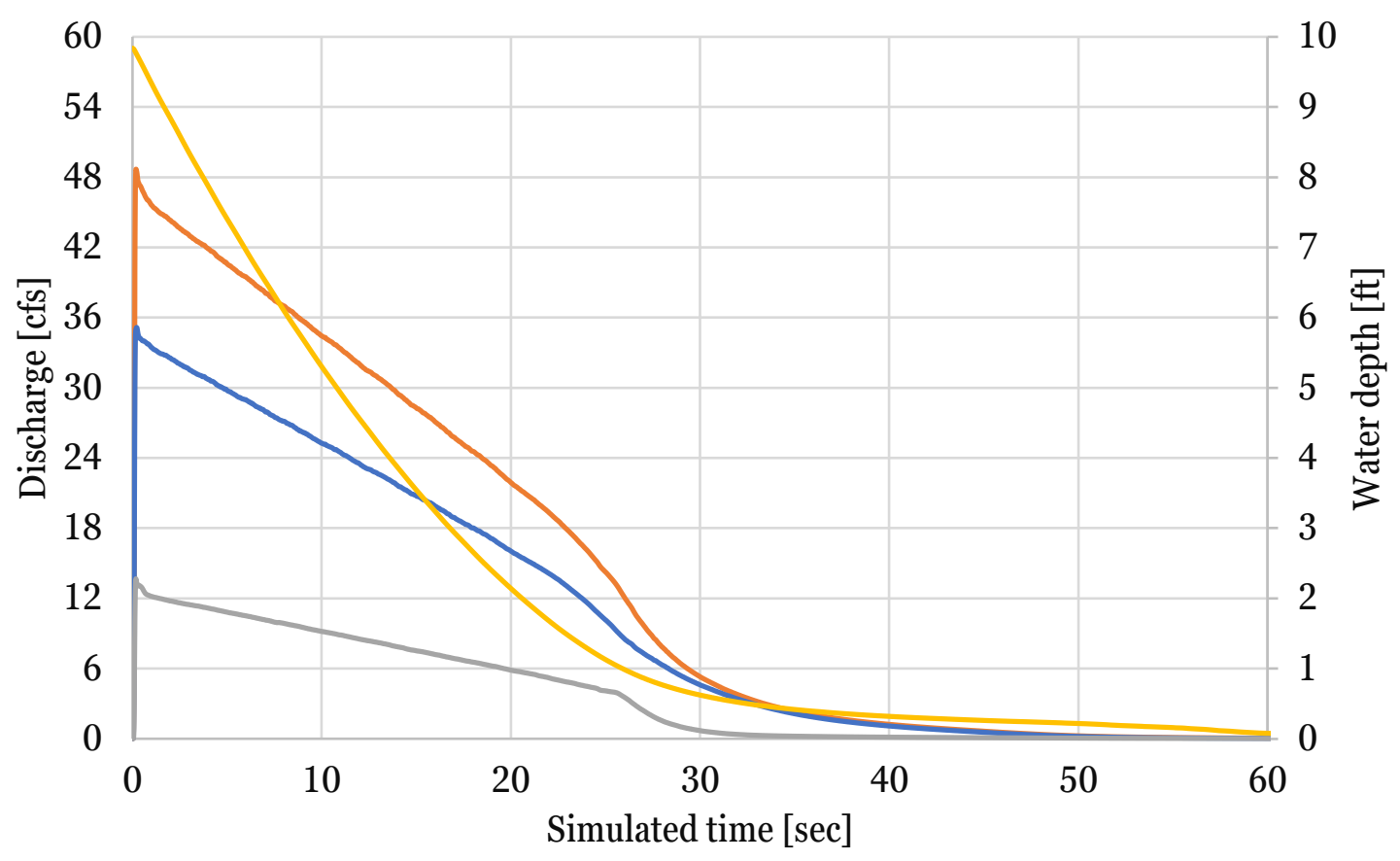

_ discharge, total — discharge, grate — discharge, window — water depth

Figure 6.24 Change of discharge through a combination inlet and ponding water depth in time for a model with Dinit $=3 \mathrm{~m}$ and a bigger computational domain, Wdom $=3 \mathrm{~m}$.

Computational Analysis of Hydraulic Capacity of Ohio DOT Catch Basins On-Grade and in Sag Locations 


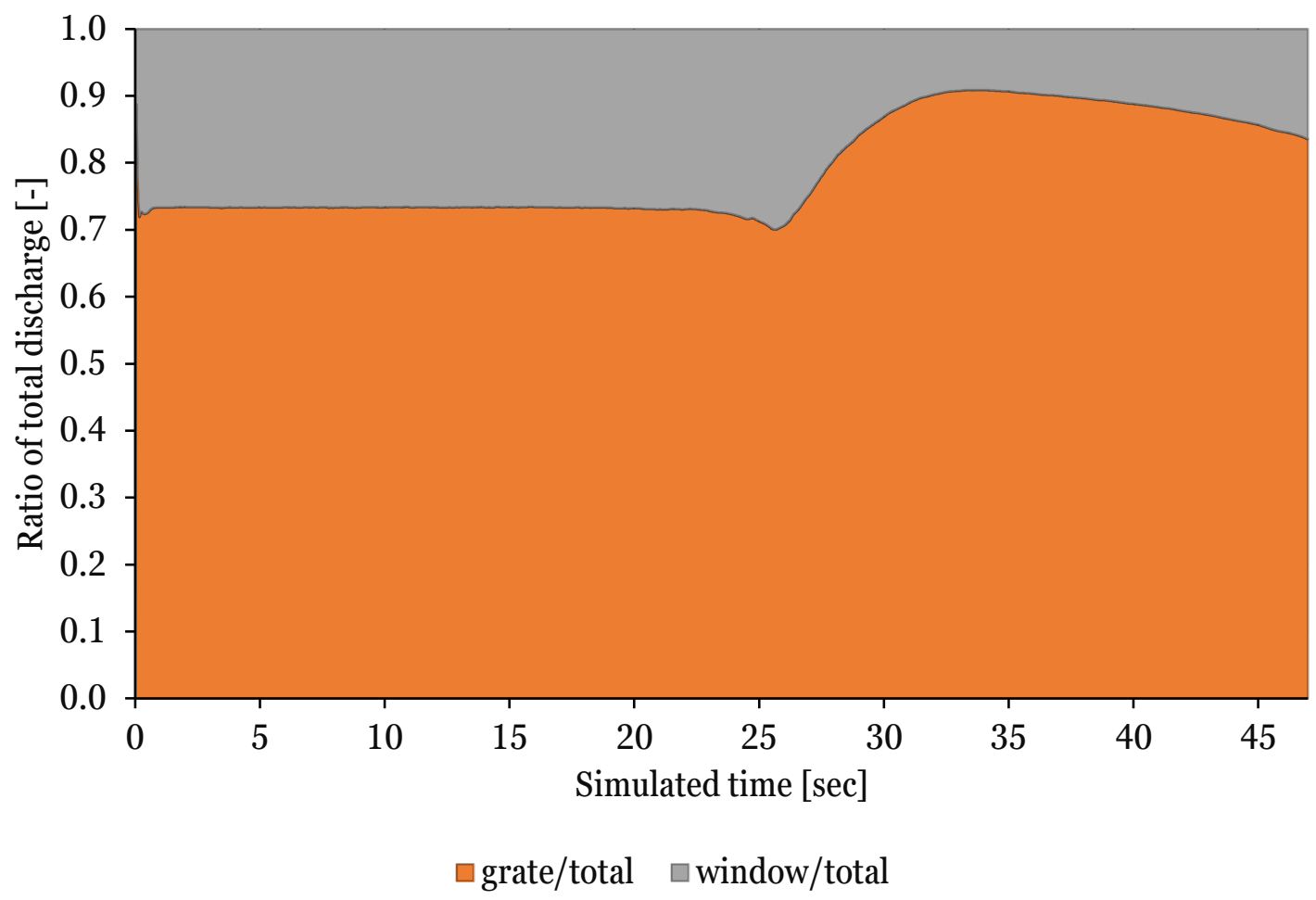

Figure 6.25 Ratio of grate and curb opening contribution in the total intercepted flow for a model with a combination inlet.

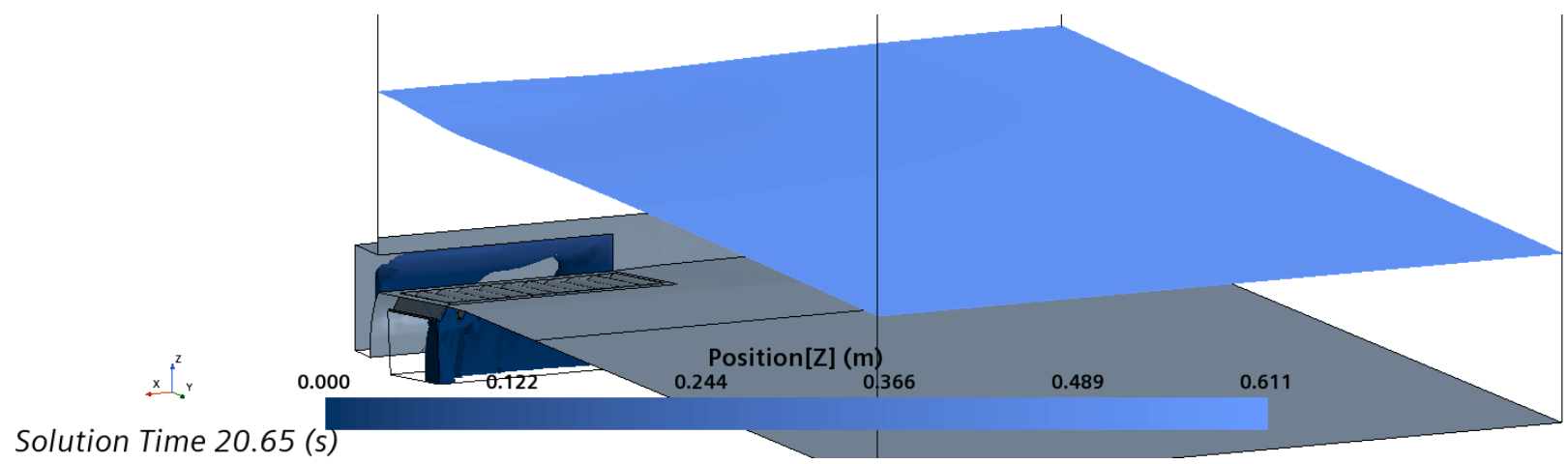

Figure 6.26 Water surface elevation for a model with a combination inlet. Water depth at curb away from the inlet is equal $0.611 \mathrm{~m}(\sim 2 \mathrm{ft})$. Orifice flow condition for both grate and window.

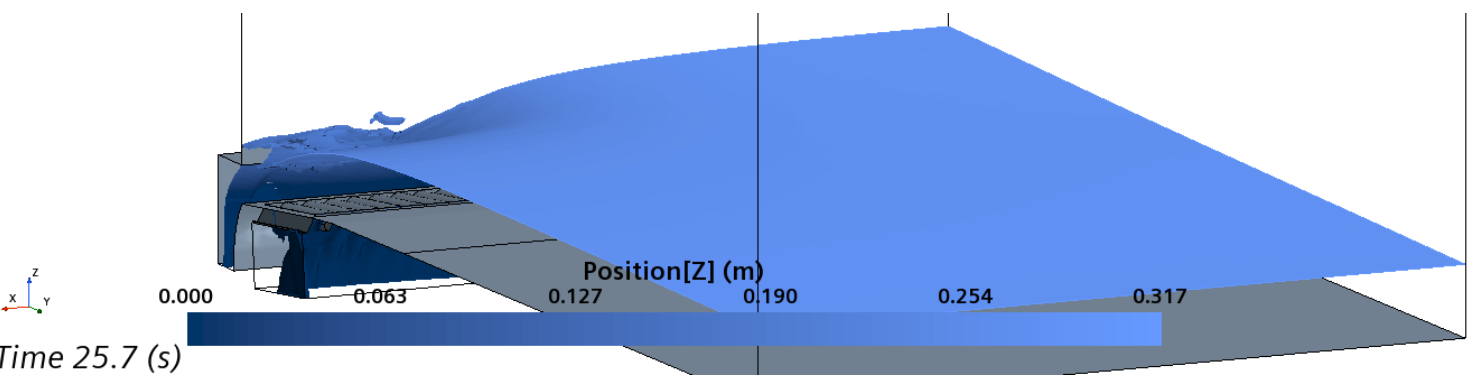

Solution Time 25.7 (s)

Figure 6.27 Water surface elevation at 25.7 seconds of simulated time for a model with a combination inlet. Water depth at curb away from the inlet is equal $0.317 \mathrm{~m}(\sim 1 \mathrm{ft})$.

Computational Analysis of Hydraulic Capacity of Ohio DOT Catch Basins On-Grade and in Sag Locations 
(a)

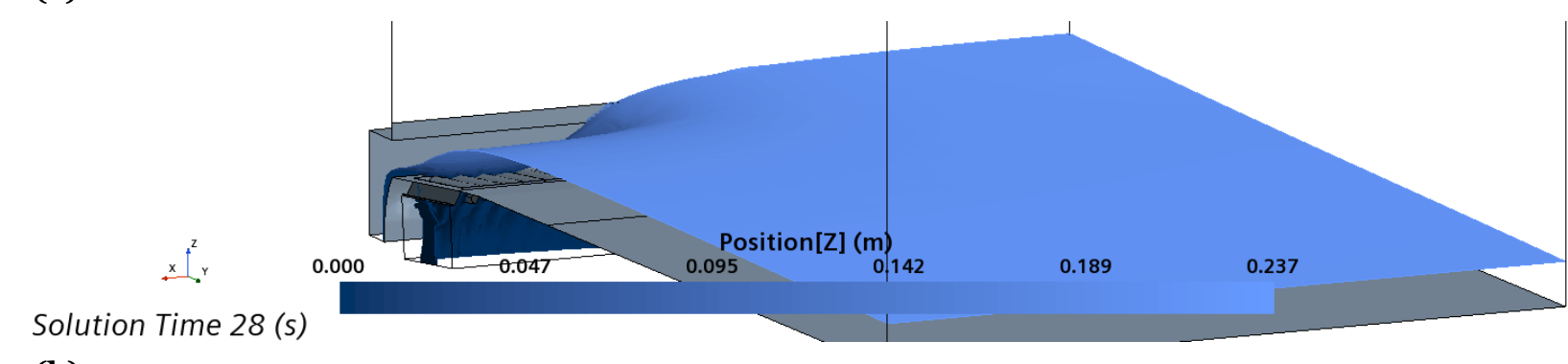

(b)

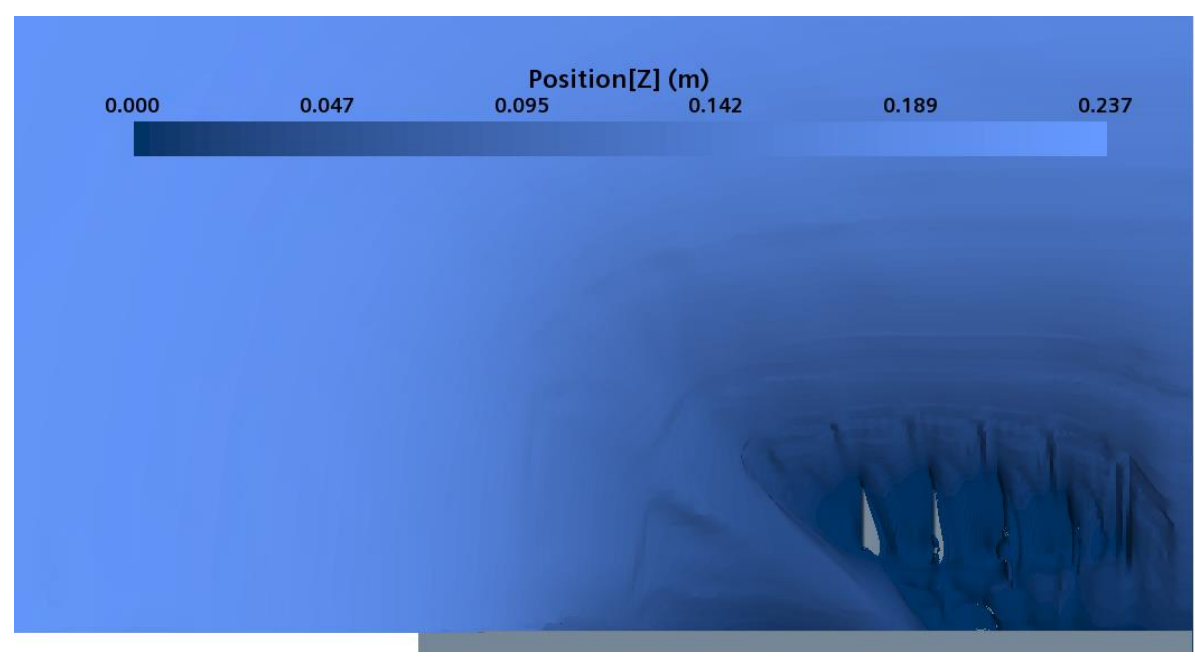

Figure 6.28 Views of the water surface elevation for a model with a combination inlet, (a) axisymmetric and (b) top view, at onset of weir flow condition for the grate. Water depth at curb away from the inlet is equal $0.237 \mathrm{~m}(\sim 9.3 \mathrm{in})$

Computational Analysis of Hydraulic Capacity of Ohio DOT Catch Basins On-Grade and in Sag Locations 


\subsubsection{No Contribution of Curb Opening to Hydraulic Capacity of Catch Basin CB 3}

In the next considered scenario, the curb opening is fully blocked and only the grate can intercept water pooling on the road. Figure 6.29 shows the change of discharge through a grate inlet and ponding water depth in time for a model with initial water depth $3 \mathrm{~m}$. The water depth decreases throughout the simulation, first faster, and then, around half of the simulated time it slows down. Even though this trend is clearly visible, there is no sudden change that could give insight into the flow condition. The discharge plot has a very similar shape to the one presented in Figure 6.24 for a combination inlet. It changes slope between 20 and 30 seconds of simulated time indicating a change in the flow conditions. Screenshots of the water surface at various times during the simulation are shown in figures. The water surface at 20 seconds of simulated time, when the flow is in the orifice regime is shown in Figure 6.30. The surface is very smooth, and the grate is overtopped.

Figure 6.31 shows the water surface at 25 seconds of simulated time. The surface starts to dip around the edges of the grate and the flow is in transition stage. Around 28.5 seconds the surface breaks over the grate and the flow condition changes into a weir flow. Figure 6.32 shows a top and a side view of the water surface over the grate where one can see that small sections of the vanes became visible. Water surface at 30 seconds in Figure 6.33 is in fully weir regime.

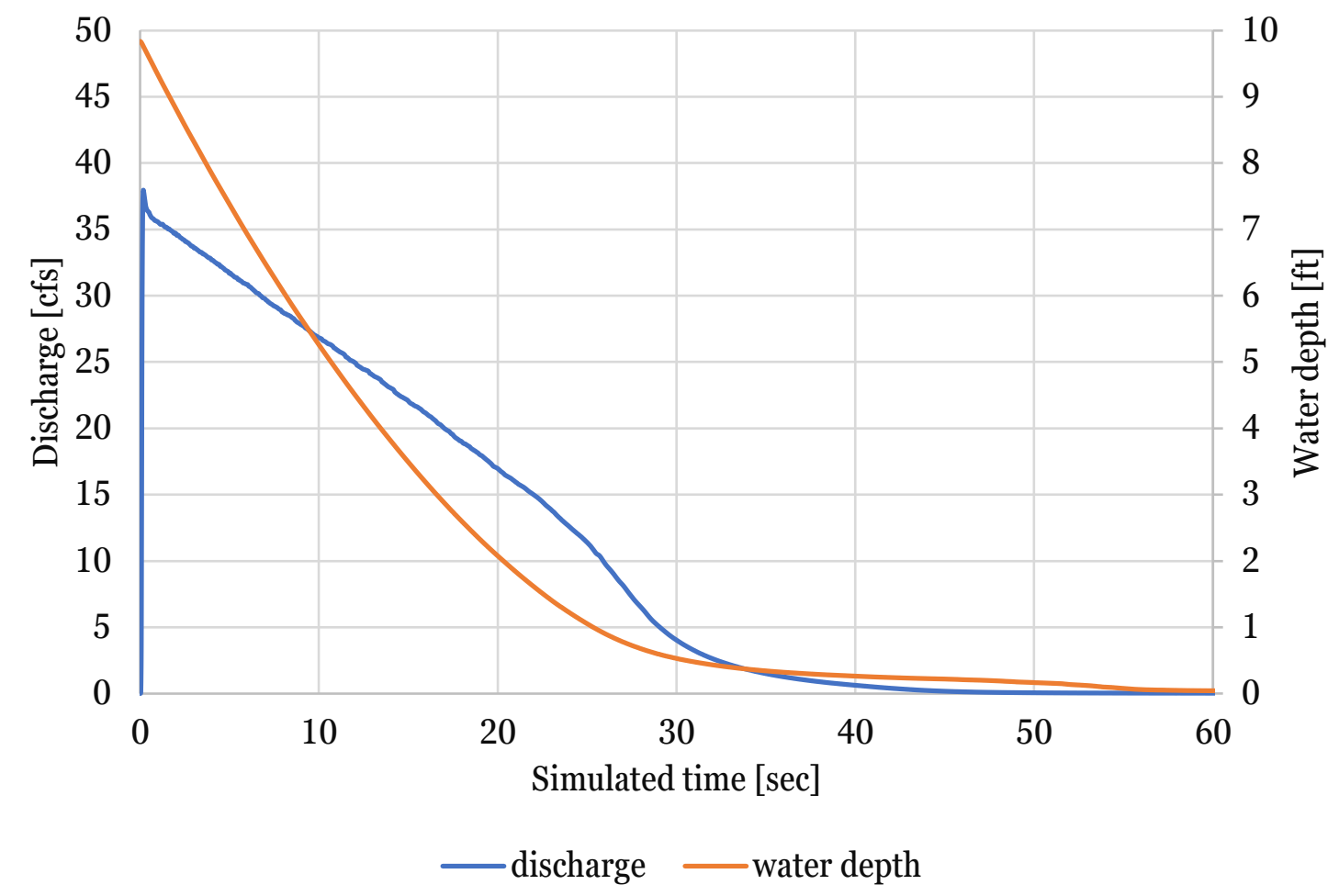

Figure 6.29 Change of discharge through a grate inlet and ponding water depth in time for a model with Dinit $=3 \mathrm{~m}$ and a bigger computational domain $\mathrm{Wdom}=3 \mathrm{~m}$.

Computational Analysis of Hydraulic Capacity of Ohio DOT Catch Basins On-Grade and in Sag Locations 


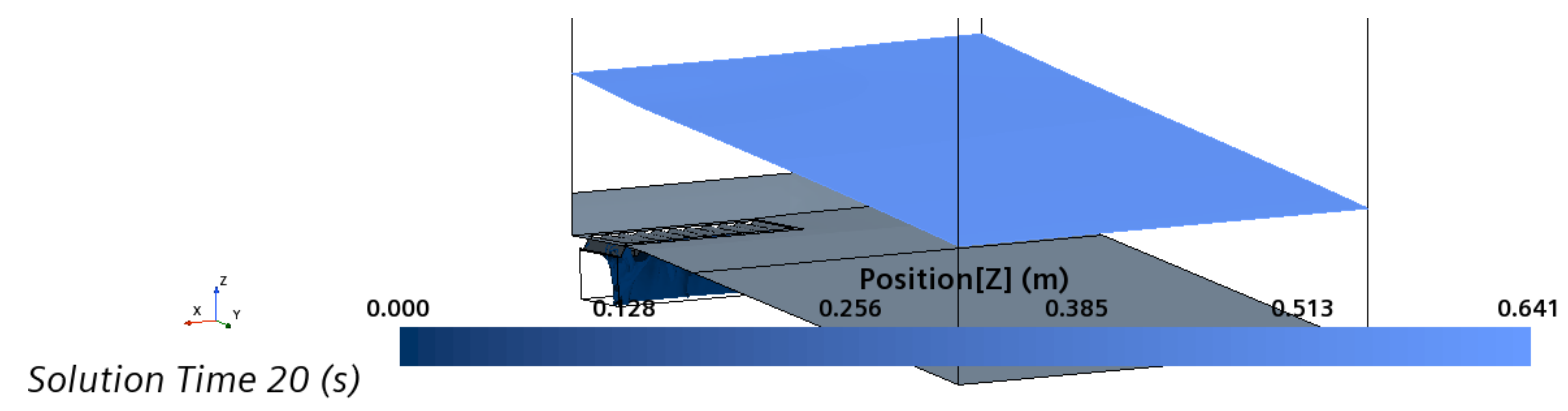

Figure 6.30 Water surface elevation at 20 seconds of simulated time for a model with a grate inlet. Orifice flow condition over the grate.

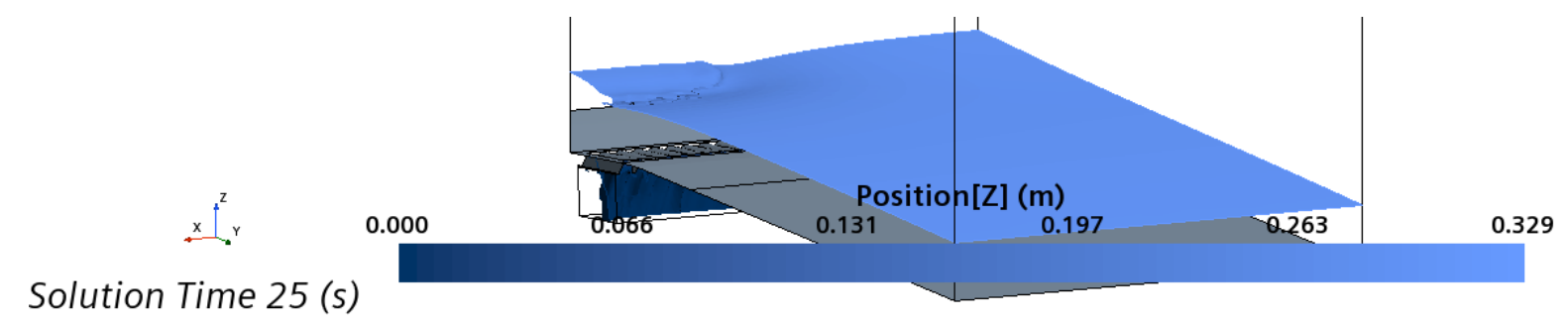

Figure 6.31 Water surface elevation at 25 seconds of simulated time for a model with a grate inlet. Transition flow condition over the grate.

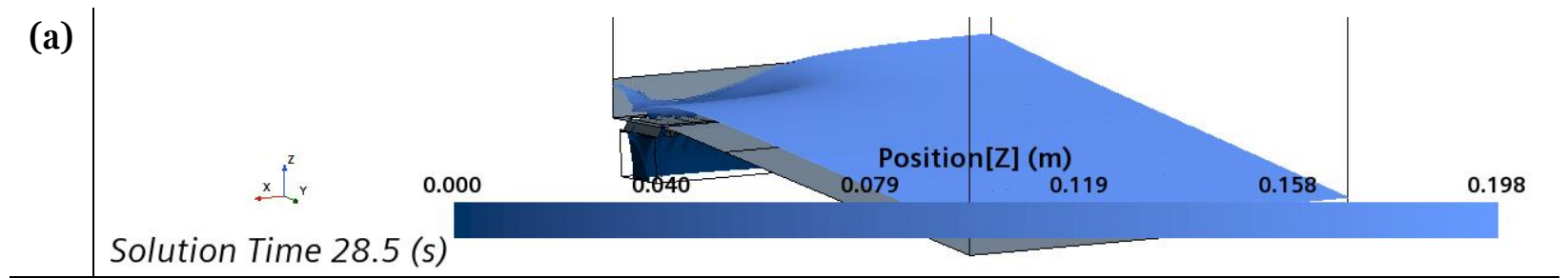

(b)

Solution Time 28.5 (s)

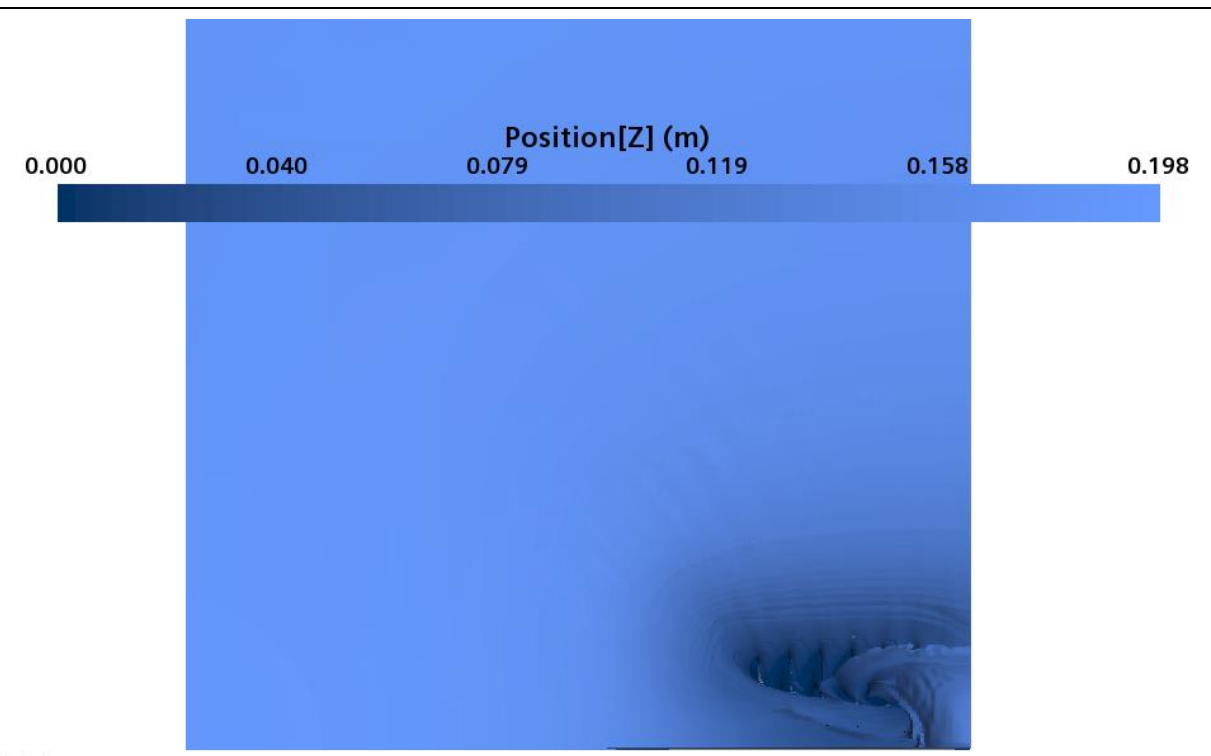

Figure 6.32 Water surface elevation at 28.5 seconds of simulated time for a model with a grate inlet, (a) top view, (b) side view. Onset of weir flow condition over the grate.

Computational Analysis of Hydraulic Capacity of Ohio DOT Catch Basins On-Grade and in Sag Locations 


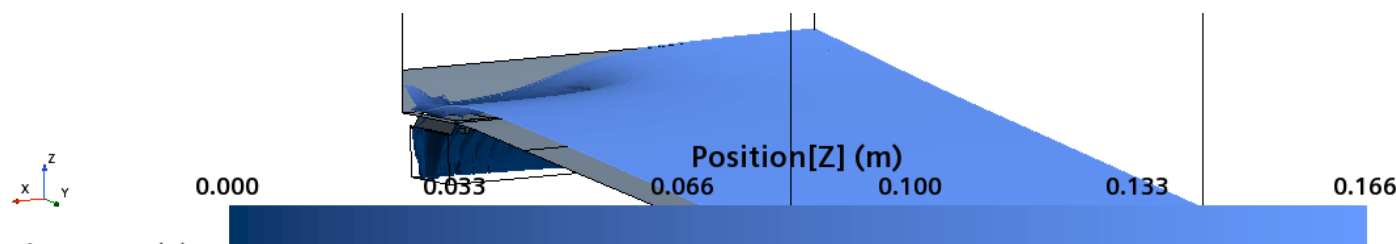

Solution Time 30 (s)

Figure 6.33 Water surface elevation at 30 seconds of simulated time for a model with a grate inlet. Weir flow condition over the grate.

Figure 6.34 presents a comparison of water depth vs. discharge plots obtained from CFD, as well as ODOT and HEC 22 design equations. ODOT design equations were used with the open area assumed by the engineers, $1.45 \mathrm{ft}^{2}$, and the minimum open area of the grate, $1.71 \mathrm{ft}^{2}$ (described as "ODOT eqs. (mod)" in the legend). The same as for a combination inlet, the CFD model compares well with the equation results when the flow is in the weir regime. There is a discrepancy between the computational and calculated results when flow is in the orifice flow regime. CFD predicts that for a given water depth, the flow rate is higher than both ODOT and HEC 22 equations. Three CFD curves are results of models that differ with initial water depth and domain width and their characteristics are the same as for the combination inlet: a bigger domain with a greater initial water depth allows for a more accurate representation of the depth vs. discharge relationship under weir conditions, and it does not influence the results in orifice flow.

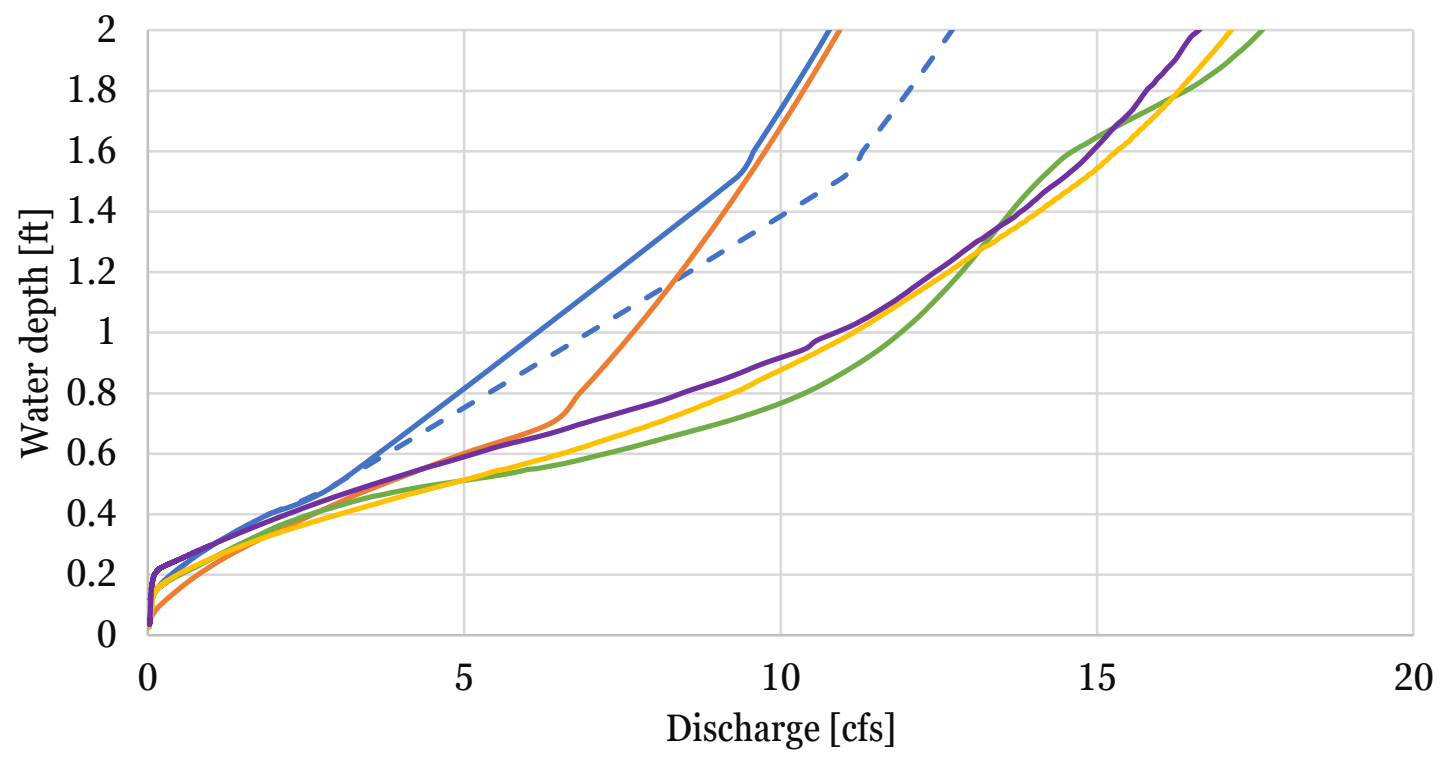

$\begin{array}{ll}- \text { ODOT eqs. } & -- \text { ODOT eqs. (mod) } \\ \text { HEC } 22 \text { eqs. } & - \text { CFD, Dinit }=1 \mathrm{~m}, \text { Wdom }=0.5 \mathrm{~m} \\ \text { CFD, Dinit }=2 \mathrm{~m}, \text { Wdom }=0.5 \mathrm{~m} & - \text { CFD, Dinit }=3 \mathrm{~m}, \text { Wdom }=3 \mathrm{~m}\end{array}$

Figure 6.34 Grate inlet without the curb opening contribution. Depth of the ponding water vs. discharge in sump conditions. 


\subsubsection{No Contribution of Grate to Hydraulic Capacity of Catch Basin CB 3}

Figure 6.35 shows a combined plot of two quantities: discharge through the curb opening and ponding water depth, as a function of a nondimensional simulated time, $\tau$, equal to the current simulated time divided by the time needed in a simulation for water surface to drop to 3 inches. This parameter was introduced because every simulation starts with a different initial water depth, $1 \mathrm{~m}(\sim 3 \mathrm{ft})$ and $2 \mathrm{~m} \mathrm{(} 6 \mathrm{ft})$, and therefore time needed to empty the computational domain differs as well; the simulation initialized with $1 \mathrm{~m}(\sim 3 \mathrm{ft})$ water depth was run for 22 seconds of computational time, and the simulation initialized with $2 \mathrm{~m}(\sim 6 \mathrm{ft})$ of water was run for 37 seconds of computational time. The non-dimensional time parameter allows for combining the curves on the same plot.

The water depth vs. time curves, plotted with solid lines, are quite smooth, and it is hard to distinguish any characteristic points. In contrast, the curves of discharge vs. time have a distinct change of slope at about $4 \mathrm{cfs}$ that corresponds to the moment when a break in the water surface starts to form, the curb opening is no longer fully overtopped, and the flow changes from the orifice regime to weir regime. As an example, two snapshots of the water surface elevation captured around the simulated time 12.42 seconds $(\tau=0.7)$ for the model with initial depth of $1 \mathrm{~m}$, are plotted in Figure 6.36. At this time in the simulation, the ponding water depth at curb away from the inlet is $\sim 7.2 \mathrm{in}(0.6 \mathrm{ft})$, water surface dips in the vicinity of the inlet and it reaches the opening height at the opening. Two other snapshots in time for $\tau=0.5$ and $\tau=1.0$ are presented in Figure 6.37 and Figure 6.38, that show orifice flow regime and weir flow regime, respectively.

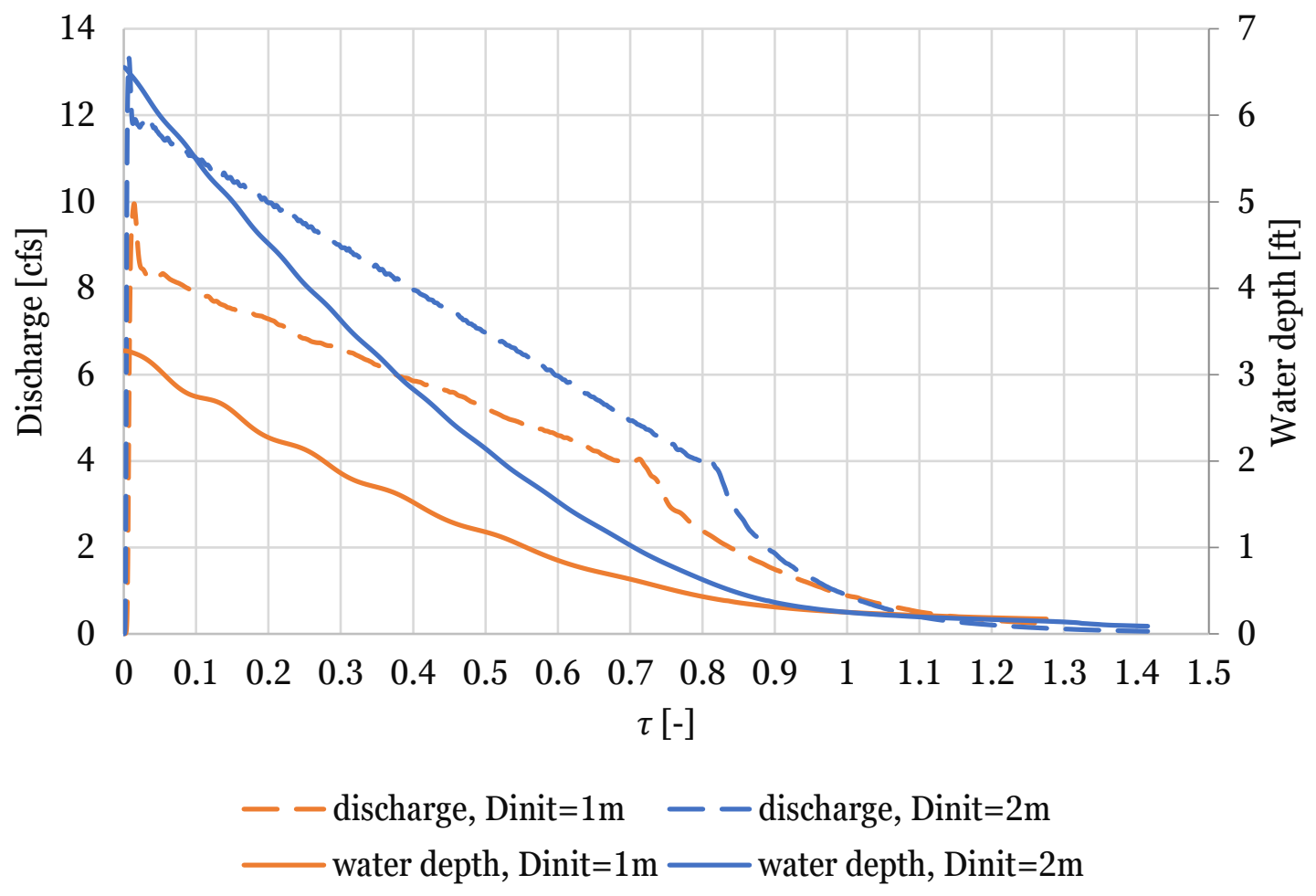

Figure 6.35 Discharge through the curb opening and ponding water depth vs. nondimensional simulated time, $\tau=\mathrm{t} / \mathrm{t}(\mathrm{d}=3 \mathrm{in})$.

Computational Analysis of Hydraulic Capacity of Ohio DOT Catch Basins On-Grade and in Sag Locations

Page | 77 


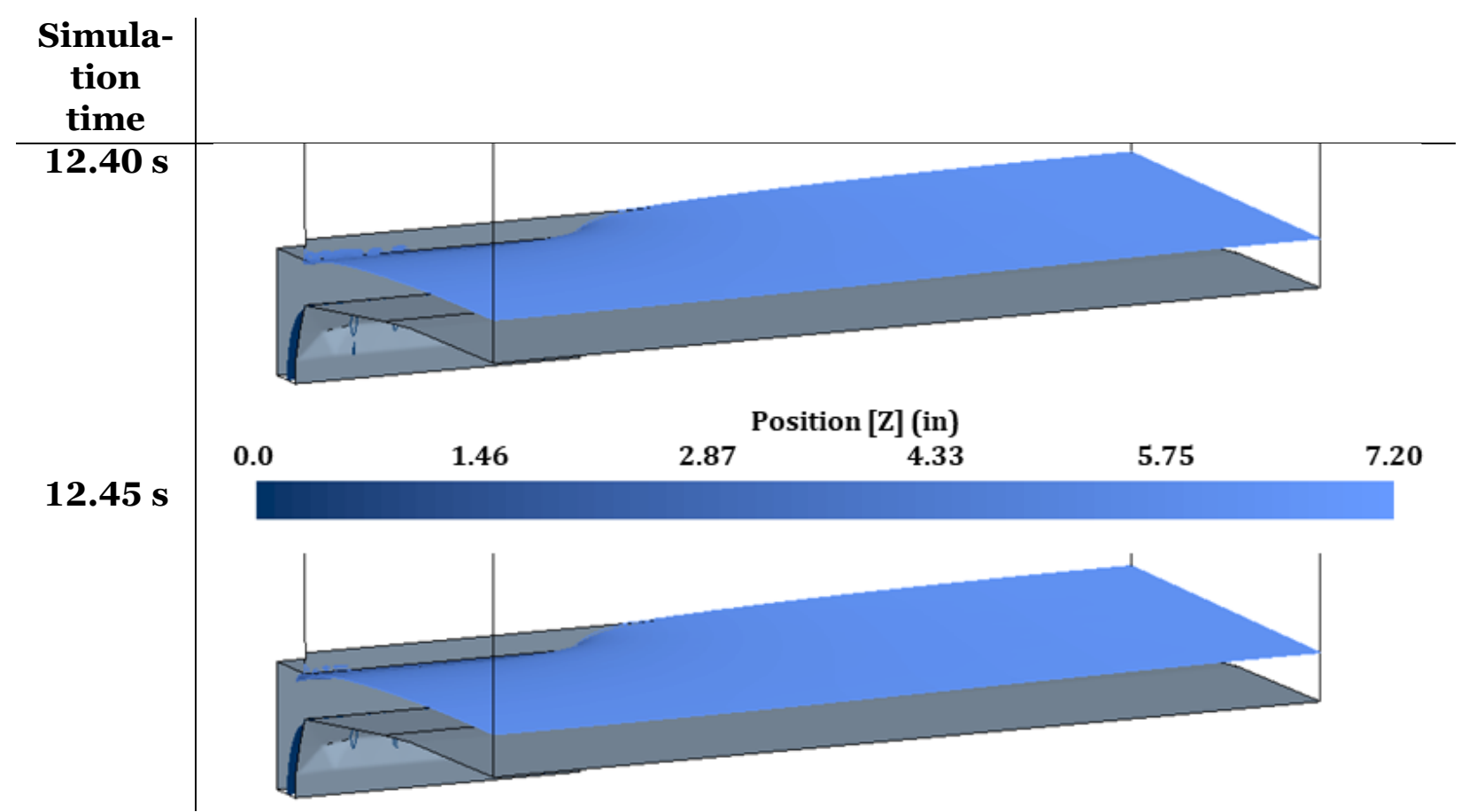

Figure 6.36 Snapshots of water surface elevation in a model with only curb opening unobstructed, initialized with $1 \mathrm{~m}(\sim 3.3 \mathrm{ft})$ of water depth, corresponding to $\tau=\sim 0.72$.

Solution Time 8.65 (s)

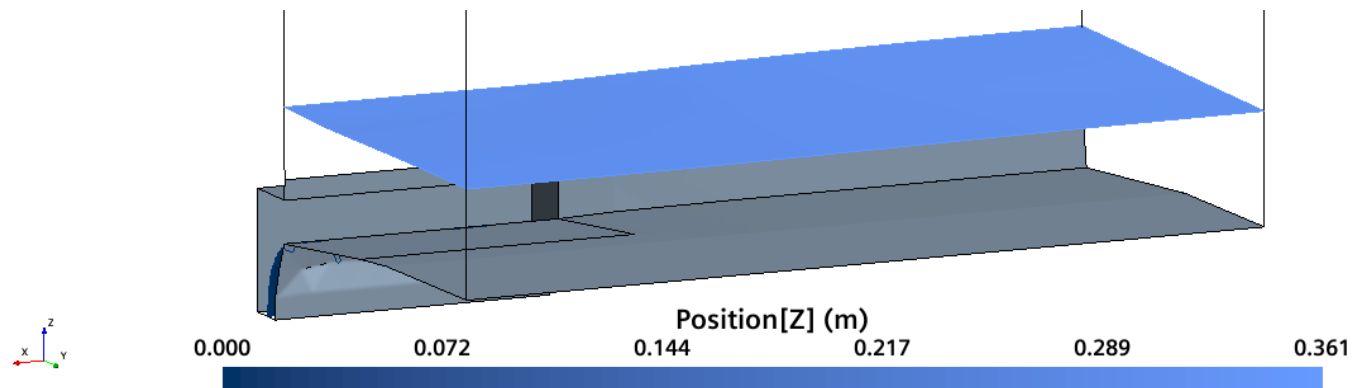

Figure 6.37 Snapshots of water surface elevation in a model with only curb opening unobstructed, initialized with $1 \mathrm{~m}(\sim 3.3 \mathrm{ft})$ of water depth, corresponding to $\tau=\sim 0.5$.

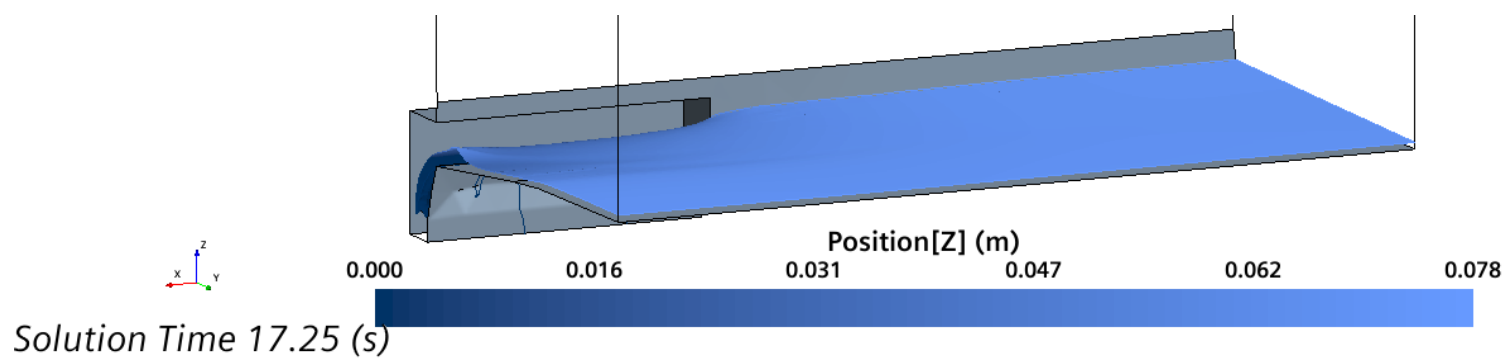

Figure 6.38 Snapshots of water surface elevation in a model with only curb opening unobstructed, initialized with $1 \mathrm{~m}(\sim 3.3 \mathrm{ft})$ of water depth, corresponding to $\tau=\sim 1$.

Computational Analysis of Hydraulic Capacity of Ohio DOT Catch Basins On-Grade and in Sag Locations 
Figure 6.39 shows the relation between the depth at the curb, $d_{c}$, away from the inlet and the discharge through a curb opening. It represents the scenario in which the grate is blocked, and the curb opening has to take over its function.

ODOT design manual states that a curb opening inlet is assumed to act as a weir for water depth at the opening up to its height. The height of the curb opening is $4.5 \mathrm{in}=0.375 \mathrm{ft}$. Taking into account a 0.5-inch $(0.041 \mathrm{ft})$ local depression, the limit water depth at curb away from the inlet is $\mathrm{d}_{2}=4$ in $(0.333 \mathrm{ft})$. The curb opening is assumed to act as an orifice for water depths equal to or greater than twice the height of the opening $2 h=9 \mathrm{in}$, which gives $d_{c}=8.5$ in $(0.71 \mathrm{ft})$. The weir flow condition is described with eq. (51) and the orifice flow type with eq. (52). The transition flow is represented with a linear function going through the two limit points. The depth vs. discharge curve was plotted with a solid blue line.

The HEC 22 design eq. (49) for weir flow is slightly different than the ODOT eq. (51) and accounts for the influence of the width of a local depression. There is also a difference in the depth limits of the transition flow: HEC 22 states that curb opening inlets with local depression operate as a weir for water depths at the opening up to the inlet height plus the local depression, $(h+a)$, and as orifices for depths equal or greater than $1.4 h=6.3 \mathrm{in}(0.53 \mathrm{ft})$. The depth vs. discharge curve was plotted with a solid orange line.

Compared calculations with the ODOT and HEC 22 equations, CFD gives the same estimate of water depth at the opening at the onset of weir flow namely, when the water depth at the opening is equal to its height.

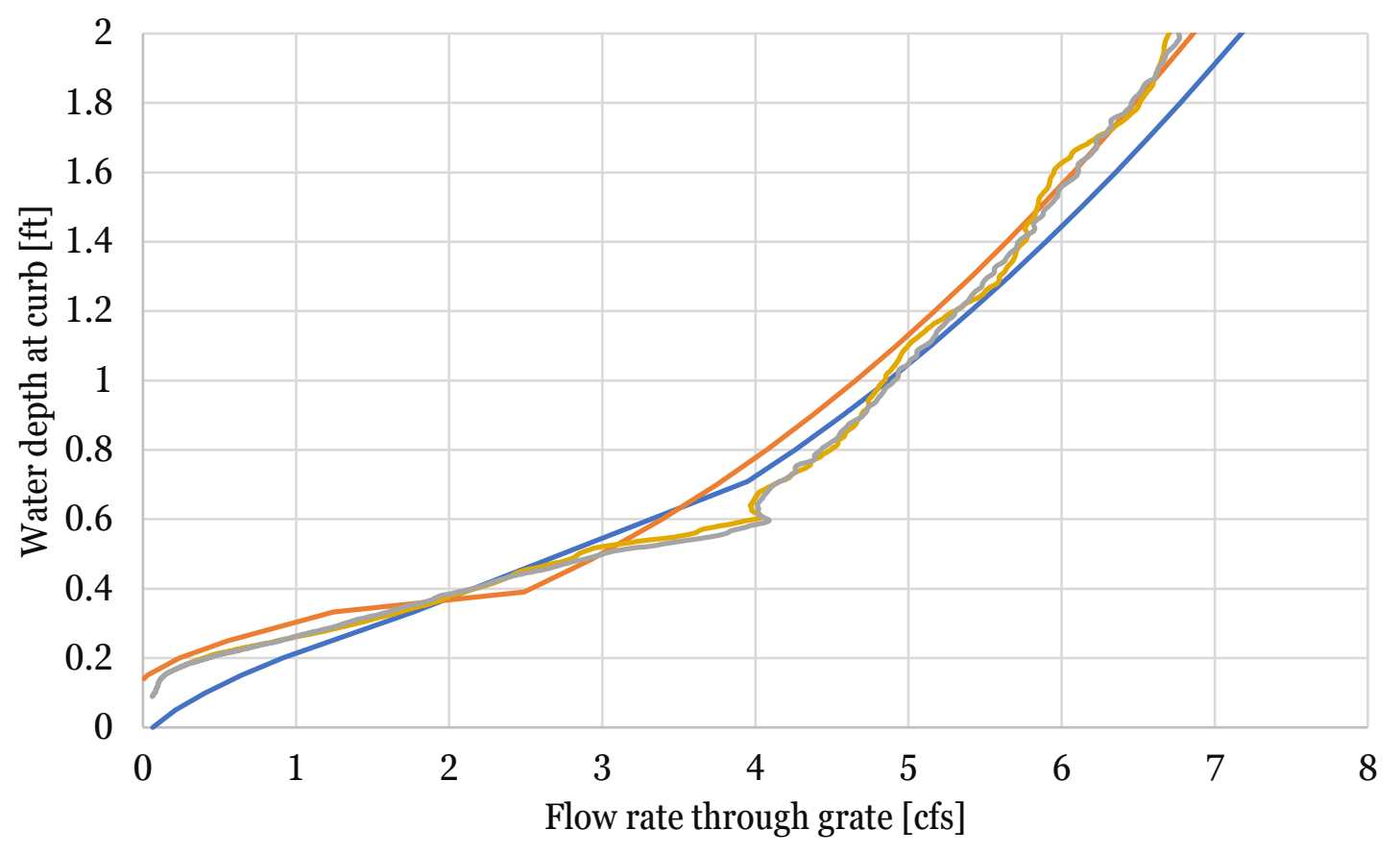

- ODOT eqs. $\quad-$ HEC 22 eqs. $\quad-$ CFD, Dinit $=1 \mathrm{~m} \quad-\mathrm{CFD}$, Dinit $=2 \mathrm{~m}$

Figure 6.39 Curb opening inlet without the grate contribution. Depth of the ponding water vs. discharge in sump conditions.

Computational Analysis of Hydraulic Capacity of Ohio DOT Catch Basins On-Grade and in Sag Locations

Page | 79 


\subsubsection{Influence of Clogging on Hydraulic Capacity of Inlets in Sag locations}

The influence of clogging of the drain can be observed in Figure 6.40, where the cases with either the curb opening, or the grate being blocked were plotted against the unobstructed catch basin. If the grate is clogged, the hydraulic capacity of the catch basin decreases significantly and the catch basin is in weir flow regime for much lower depth, approximately $0.6 \mathrm{ft}$ as compared to approximately $1 \mathrm{ft}$ for the other two scenarios of clogging. For example, for a flow rate of $5 \mathrm{cfs}$, the water depth in the gutter increases from $\sim 0.6 \mathrm{ft}$ to $\sim 1.0 \mathrm{ft}$, when the grate is fully clogged. On the other hand, if the curb opening gets clogged, then the water depth remains approximately the same for this flow rate. Clogging of a grate by debris is more probable than clogging of a curb opening. Grates are horizontal, or close to horizontal, which allows for accumulation of dead leaves or other debris on their surface. The openings in grates are smaller than the curb opening, which also makes it easier for blockages to form on the grate. Even though the interception of a curb opening is smaller than of a combination inlet or a grate, it does act as a last resort to avoid flooding of the pavement with no active drain.

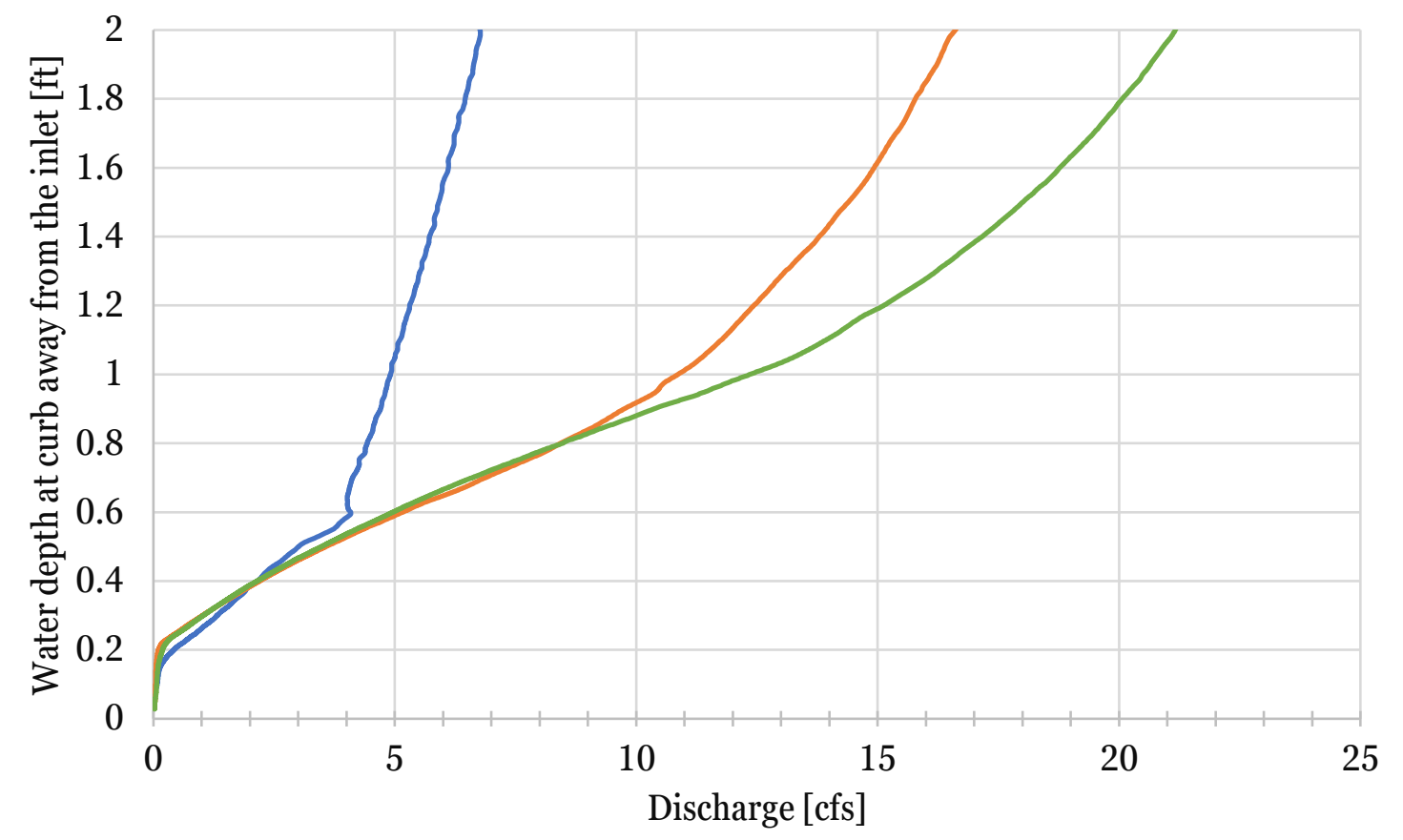

— curb opening inlet — grate inlet — combination inlet (grate + curb opening)

Figure 6.40 Influence of clogging on discharge capacity. Water depth vs. discharge for a combination inlet (grate and curb opening), only curb opening, and only grate.

Computational Analysis of Hydraulic Capacity of Ohio DOT Catch Basins On-Grade and in Sag Locations 


\section{Summary and Conclusions}

Proper design of drainage structures, such as curb opening inlets, grate inlets, or a combination of both, plays an important role in managing water runoff from roads with curbs or barriers. For on-grade locations, performance is measured in terms of hydraulic efficiency, which is equal to the ratio of the intercepted to the total flow rate on a pavement. In sag locations, performance is characterized by the relationship between the ponding depth and flow rate through the inlet.

The recently increasing intensity and frequency of rain events prompted Ohio DOT to revise their design methodology used to establish the performance of the drainage structures, as well as to perform a study that allows for a better understanding of the flow patterns over and around inlets and their interception capacity under various flow conditions.

The in-house Ohio DOT design procedure was reviewed and compared with the equations presented in FHWA Hydraulic Engineering Circular 22 "Urban Drainage Design Manual” (HEC 22). The calculation of the design flow rate was performed with the use of the Manning's gutter flow equation, which was discussed for triangular and trapezoidal (composite) gutter cross-sections.

Two catch basins with a combination inlet, single CB 3A and double CB 3, were analyzed in the study in on-grade and sag locations. The analysis of the on-grade locations covered various road geometries, including a 2 -ft-wide curb and gutter at $8.3 \%$ cross-slope, a 4 -ft-wide shoulder at $4 \%$ cross-slope and a 8 -ft-wide shoulder at $4 \%$ cross-slope with a $1.6 \%$ cross-slope on the travel lanes, longitudinal grade from $0.25 \%$ to $8 \%$, and flow spreads from $2 \mathrm{ft}$ to $10 \mathrm{ft}$. The analysis of the performance in sag locations was performed on the 2-ft-wide curb and gutter at $8.3 \%$ cross-slope section, with $0 \%$ longitudinal grade and varying ponding depth up to 18 inches. Several scenarios of clogging of the inlets were modeled to assess its impact on the interception capabilities. The selected parameter values encompass a wide range of real-life conditions that can be found in Ohio.

The STAR-CCM+ CFD software was chosen to perform the analysis of the hydraulic performance of the inlets. The computations were performed on an high-performance computing (HPC) cluster with the Unsteady Reynolds Averaged Navier-Stokes Solver using a k-epsilon turbulence model in combination with the Eulerian two-phase model using the Volume of Fluid model to calculate the free surface interface between air and water phases. The computational domain was discretized with a hexahedral mesh with cell size transitioning from a millimeter at the road and grate surfaces to a few centimeters away from solid boundaries, and a volumetric mesh control was used to decrease the mesh size in the vertical direction as compared to the horizontal dimensions, in order to better resolve the water free surface. The total number of computational cells varied from a few to over 20 million, depending on the case. The large number of computational cells resulted in runs that took up to $\sim 40$ hours on 10 computational nodes, each with 16 cores (for comparison, the same simulation took $\sim 2.25$ times longer i.e., 90 hours, to run on 4 nodes).

Two separate models were developed for the two flow conditions that occur on-grade and in sag locations. The geometry of the model of a catch basin on a continuous grade covers a section of a road with a longer fraction of the road upstream and shorter fraction downstream of the catch basin. Simulations were initialized with the computational domain filled with air and water was introduced at the upstream end of the model domain with a constant flow rate throughout the simulation. Each simulation from the case matrix was run until a steady state was reached and a flow split between three outlets: grate, curb opening, and street, was obtained. The flow through

Computational Analysis of Hydraulic Capacity of Ohio DOT Catch Basins On-Grade and in Sag Locations

Page | 81 
the curb opening and the grate were recorded at the end of a simulation and the results were used to calculate the efficiency of the catch basin as a function of the geometry and flow conditions.

The geometry of the computational model built to analyze the performance of the CB 3 catch basin in sump condition covers a section of a road upstream of the catch basin and half of the catch basin. The height of the domain was increased to capture the orifice flow condition that occurs at higher flow depths. The model was transient with the domain initially filled with water up to a depth sufficient to produce an orifice flow condition. During the simulation, the water drains through the grate and/or curb opening until all water leaves the domain. The discharge versus pooling water depth was recorded and used to evaluate the inlet.

The influence of pavement roughness on the pool spread and efficiency of the catch basin was also analyzed. A roughness height model, a porous region model, and a smooth wall boundary condition were investigated.

In all on-grade cases, the total intercepted flow decreases for increasing longitudinal grade and increasing spread. With an increase of the spread, the influence of the longitudinal grade on the interception also rises. The percentage of the flow intercepted through the upstream side of the inlet (i.e., front flow), has a similar dependency on the longitudinal grade and spread as the total interception with the difference that it is decreased by the amount of flow intercepted by the roadside edge of the grate inlet. The percentage of the flow intercepted through the roadside edge of the grate is the highest for the largest spread in combination with a small longitudinal grade. It decreases significantly with decreasing spread, as most of the flow is intercepted by the upstream edge of the drain and the curb opening. The dependence of the flow bypassing the catch basin on spread and longitudinal grade is the opposite: it is zero for the smallest longitudinal grade and spread and increases for the largest spread and grade.

The HEC 22 and ODOT design procedures assume that the catch basin intercepts total flow volume above the grate and a fraction of the side flow. The design procedure assumes that the roadside discharge is calculated as if it was a weir with the length of the grate. The calculation also assumes that the flow entering over the grate from the upstream edge has the same spread as it does at a distance upstream where the spread is not yet affected by the presence of the grate. The CFD calculations showed that is not valid for subcritical flow, when a change in the downstream flow conditions, such as presence of a drain, may affect the flow upstream. The presence of the drain intercepting much of the flow results in the spread decreasing as the flow approaches the inlet and reduces the flow on the side of the grate. The uniform spread assumption in the design procedure calculations results in an underestimated total intercepted flow and overestimated roadside interception, and overall leads to a more conservative result. The flow bypassing the catch basin obtained with the use of CFD, is, however, in good agreement with the ODOT equation results over nearly all of the parameter range analyzed. The efficiency of the combination inlet for varying pool spread and longitudinal grade obtained from computations compares well with the corresponding HEC 22 and ODOT estimates. The majority of CFD data points falls within $\pm 10 \%$ range from the calculated values. The remaining points, except for three of them, are within $\pm 20 \%$ range.

A limited analysis of the influence of clogging on the inlet efficiency on-grade and in sump condition was performed. On-grade clogging of the grate was modeled by blocking $10 \%, 30 \%$, and $50 \%$ of the upstream area of the grate, as well as blocking $100 \%$ of the curb opening. For sag locations 
three scenarios were considered, in which both the curb opening, and the grate were unobstructed, the grate was unobstructed and there was no curb opening contribution, and the curb opening was unobstructed and there was no grate contribution.

In on-grade locations, when the open area of the grate decreases, the interception of the grate drops, but at the same time the interception of the curb opening increases, which leads to a small change in the overall efficiency of the catch basin. In the considered case, if the grate is fully open, there is a negligible contribution from the curb opening, but if the grate is partially blocked, the curb opening intercepts some of the flow that otherwise would bypass the catch basin. This finding confirms the HEC 22 recommendation to neglect the contribution of the curb opening when calculating the efficiency of a combination inlet in on-grade locations without clogging. It also shows the advantageous role of a curb opening when clogging occurs.

For catch basins in sump conditions, HEC 22 and ODOT design procedures assume that the weir flow discharge for combination inlets is the same as for a grate inlet. The discharge in orifice flow is a sum of the flow rate through the grate and curb opening. The ODOT procedure states that for depths between $0.4 \mathrm{ft}$ and $1.4 \mathrm{ft}$ a proportional transition should be used, the same way as for grates. HEC 22 does not specify the depth limits for transition flow.

In the weir flow regime CFD analysis results compare very closely with ODOT and HEC 22 equations calculation results for the grate inlet and combination inlet. A comparison between the computational results and calculations for orifice flow, shows that for a combination inlet, CFD gives greater discharge for a given water depth than the design equations. The reason is that the ODOT design calculations for orifice flow take a clear open area of a diagonal grate to be equal to 1.45 $\mathrm{ft}^{2}$, which is smaller than the smallest open area of the vane grate, equal to $1.71 \mathrm{ft}^{2}$. If the latter is used in the ODOT eq. for orifice flow, the estimate is closer to the CFD results.

The ODOT design manual states that a curb opening inlet is assumed to act as a weir for water depth at the opening up to its height. The curb opening is assumed to act as an orifice for water depths equal to or greater than twice the height of the opening. The HEC 22 design equation is slightly different as it accounts for the influence of the width of a local depression. It is assumed that a curb opening inlet with a local depression operates as a weir for water depths at the opening up to the inlet height plus the local depression and as orifice for depths equal or greater than 1.4 times height. The CFD results indicate that using either the ODOT or HEC 22 procedure is adequate for design.

The influence of clogging in sump conditions is more pronounced than on-grade. When the grate is clogged, the hydraulic capacity of the catch basin decreases significantly. On the other hand, if the curb opening gets clogged, then the water depth for a given discharge remains approximately the same for weir flow but increases in the orifice flow regime.

The study and CFD results indicate that the ODOT design procedure and HEC 22 procedures are adequate for more extreme events at on-grade locations. CFD results under high flow conditions are more conservative by up to 10\% percent than the ODOT and HEC 22 procedures. Under sump conditions at sag locations the CFD results indicate that the ODOT and HEC 22 procedures are conservative by a significant margin under orifice flow conditions that are likely with more extreme rain events.

Computational Analysis of Hydraulic Capacity of Ohio DOT Catch Basins On-Grade and in Sag Locations

Page | 83 


\section{Acknowledgements}

The funding for this project came from the Transportation Pooled Fund Program TPF-5(446), managed by the Turner-Fairbank Highway Research Center through the Interagency Agreement Number DTFH61-14-X-300002 between DOT and DOE, and the work was performed under DOE's contract with UChicago Argonne, LLC, contract no. DE-AC02-06-CH11357. 


\section{References}

[1] F. L. Johnson and F. F. M. Chang, "Hydraulic Engineering Circular No. 12, HEC-12, Drainage of Highway Pavements," Federal Highway Administration, U.S. Department of Transportation, Washington D.C., FHWA-TS-84-202, Mar. 1984.

[2] S. A. Brown, J. D. Schall, J. L. Morris, C. L. Doherty, S. M. Stein, and J. C. Warner, "Urban Drainage Design Manual, Hydraulic Engineering Circular 22, Third Edition," FHWA-NHI10-009 HEC-22, Sep. 2009.

[3] M. A. Sitek, S. A. Lottes, and N. Sinha, "Hydraulic Study of the South Carolina DOT Catch Basin Type 25,” Argonne National Lab. (ANL), Argonne, IL (United States), ANL-19/20, May 2019. doi: 10.2172/1561115.

[4] S. Nuccitelli, "Assessment of HEC-22 Equations for the Design of Curb Inlets," in 2018 National Hydraulic Engineering Conference Abstracts and Biographies, Columbus, Ohio, Aug. 2018, p. 23. [Online]. Available: https://static.tti.tamu.edu/conferences/tsc18/presentations/structures-hydraulics/nuccitelli.pdf

[5] B. C. Comport and C. I. Thornton, "Hydraulic Efficiency of Grate and Curb Inlets for Urban Storm Drainage," Journal of Hydraulic Engineering, vol. 138, no. 10, pp. 878-884, Oct. 2012, doi: 10.1061/(ASCE)HY.1943-7900.0000552.

[6] S. Sarikelle and G. L. French, "Hydraulic Characteristics of Directional Grate Inlet," University of Akron, Akron, Ohio, Jun. 1976.

[7] "Manning's Formula for Gravity Flow," The Engineering Tool Box. https://www.engineeringtoolbox.com/mannings-formula-gravity-flow-d_800.html (accessed Apr. 10, 2021).

[8] G. J. Arcement and V. R. Schneider, "Guide for selecting Manning's roughness coefficients for natural channels and flood plains," Report 2339, 1989. doi: 10.3133/wsp2339.

[9] R. Lang, "Drainage Manual Part1. Hydrology, Pavement Drainage and Storm Sewer Design.” Ohio Department of Transportation internal correspondence.

[10] P. H. Burgi and D. E. Gober, "Bicycle-Safe Grate Inlets Study, Volume 1 - Hydraulic and Safety Characteristics of Se-lected Grate Inlets on Continuous Grades," Federal Highway Administration, Washington, D.C., FHWA-RD-77-24, Jun. 1977.

[11] P. H. Burgi and D. E. Gober, "Bicycle-Safe Grate Inlets Study, Volume 2 - Hydraulic Characteristics of Three Selected Grate Inlets on Continuous Grades," Federal Highway Administration, Washington, D.C., FHWA-RD-78-4, May 1978.

[12] W. J. Bauer, "Hydraulic Design of Depressed Curb-Opening Inlets," Washington, D.C., 1964, vol. Highway Research Board, Highway Research Record No. 58.

[13] C. F. Izzard, "Simplified Method for Design of Curb-Opening Inlets," presented at the Annual Meeting of the National Transportation Board, 1977.

[14] C. F. Izzard, "Tentative Results on Capacity of Curb Opening Inlets," Washington, D.C., Dec. 1950, no. 11B. [Online]. Available: https://trid.trb.org/view/104005

[15] S. S. Karaki and R. M. Haynie, "Depressed Curb-Opening Inlets-Experimental Data," Civil Engineering Section, Colorado State Univ., Fort Collins, CO, CER61SSK34, 1961.

[16] M. A. Muhammad, "Interception capacity of curb opening inlets," University of Texas at Austin, 2018.

[17] N. W. Conner, "Design and Capacity of Gutter Inlets," Highway Research Board Proceedings, vol. 25, 1946, Accessed: May 21, 2021. [Online]. Available: https://trid.trb.org/view/ 103972

[18] U. S. Army Corps of Engineers, "Airfield Drainage Structure Investigations," U.S. Army Corps of Engineers, St. Paul District Sub-Office, Hydraulic Laboratory, 54, 1949.

[19] P. H. Burgi, "Bicycle-Safe Grate Inlets Study, Volume 3 - Hydraulic Characteristics of Three Selected Grate Inlets in a Sump Condition," Federal Highway Administration, Washington, D.C., FHWA-RD-78-4, Sep. 1978.

[20] SIEMENS, "Simcenter STAR-CCM+ Documentation Version 2020.2.” 2020.

[21] S. A. Lottes, M. A. Sitek, and N. Sinha, "Computational Analysis of Water Film Thickness During Rain Events for Assessing Hydroplaning Risk, Part 1: Nearly Smooth Road Surfaces,”

Computational Analysis of Hydraulic Capacity of Ohio DOT Catch Basins On-Grade and in Sag Locations

Page | 85 
https://doi.org/10.2172/1674976, Jul. 2020. [Online]. Available: https://www.osti.gov/biblio/1674976-computational-analysis-water-film-thickness-during-rain-events-assessing-hydroplaning-risk-part-nearly-smooth-road-surfaces

[22] M. A. Sitek and S. A. Lottes, "Computational Analysis of Water Film Thickness During Rain Events for Assessing Hydroplaning Risk Part 2: Rough Road Surfaces,” https://doi.org/ 10.2172/1677647, Jul. 2020. [Online]. Available: https://www.osti.gov/biblio/1677647computational-analysis-water-film-thickness-during-rain-events-assessing-hydroplaningrisk-part-rough-road-surfaces

[23] C. McGahey and P. G. Samuels, "River Roughness - the Integration of Diverse Knowledge," presented at the River Flow 2004: The Second International Conference on Fluvial Hydraulics, Napoli, Italy, Jun. 2004. Accessed: May 21, 2021. [Online]. Available: https:/ /www.routledge.com/River-Flow-2004-Proceedings-of-the-Second-International-Conference-on-Fluvial/Greco-Carravetta-Morte/p/book/9789058096586

[24] "Neenah Foundry Curb Box R-3288-E2," May 2021, [Online]. Available: https:// www.nfco.com/products/inlets-catch-basins/combination-inlets/with-curb-box/r-3288-e2/

[25] "Neenah Foundry Curb Box R-3289," May 2021, [Online]. Available: https:// www.nfco.com/products/inlets-catch-basins/combination-inlets/with-curb-box/r-3289-c/

[26] M. A. Sitek, S. A. Lottes, and H. Ley, "Transportation Pooled Fund Program TPF 5(446) Quarterly Progress Report," Quarter 1, January-March 2021, Mar. 2021.

[27] M. A. Sitek and S. A. Lottes, "Transition flow for road drainage in sag locations," Federal Highway Administration, Mar. 2021.

Computational Analysis of Hydraulic Capacity of Ohio DOT Catch Basins On-Grade and in Sag Locations 


\section{Appendix}

Results obtained for the catch basin 3A in the CFD simulations are presented in this section in the form of the following plots and tables:

Figure 10.1 Two-foot-wide curb and gutter. Total, grate, window, and bypass discharge vs. longitudinal profile grade for flow spread: (a) $2 \mathrm{ft}$, (b) $4 \mathrm{ft}$, (c) $6 \mathrm{ft}$, (d) $8 \mathrm{ft}$, (e) $10 \mathrm{ft}$

Figure 10.2 Four-foot-wide shoulder. Total, grate, window, and bypass discharge vs. longitudinal profile grade for flow spread: (a) $2 \mathrm{ft}$, (b) $4 \mathrm{ft}$, (c) $6 \mathrm{ft}$, (d) $8 \mathrm{ft}$, (e) $10 \mathrm{ft}$

Figure 10.3 Eight-foot-wide shoulder. Total, grate, window, and bypass discharge vs. longitudinal profile grade for flow spread: (a) $2 \mathrm{ft}$, (b) $4 \mathrm{ft}$, (c) $6 \mathrm{ft}$, (d) $8 \mathrm{ft}$, (e) $10 \mathrm{ft}$

Table 10-1 Efficiency, Front, Side and Bypass Flow Rates for Catch Basin No. 3A in on-Grade Locations.

Table 10-2 Catch Basin No. 3 - Sump Hydraulic Capacity for Varying Ponding Depth. The type of flow was marked with a letter: (o) for orifice flow, (t) for transition flow, or (w) for weir flow. 
(a)

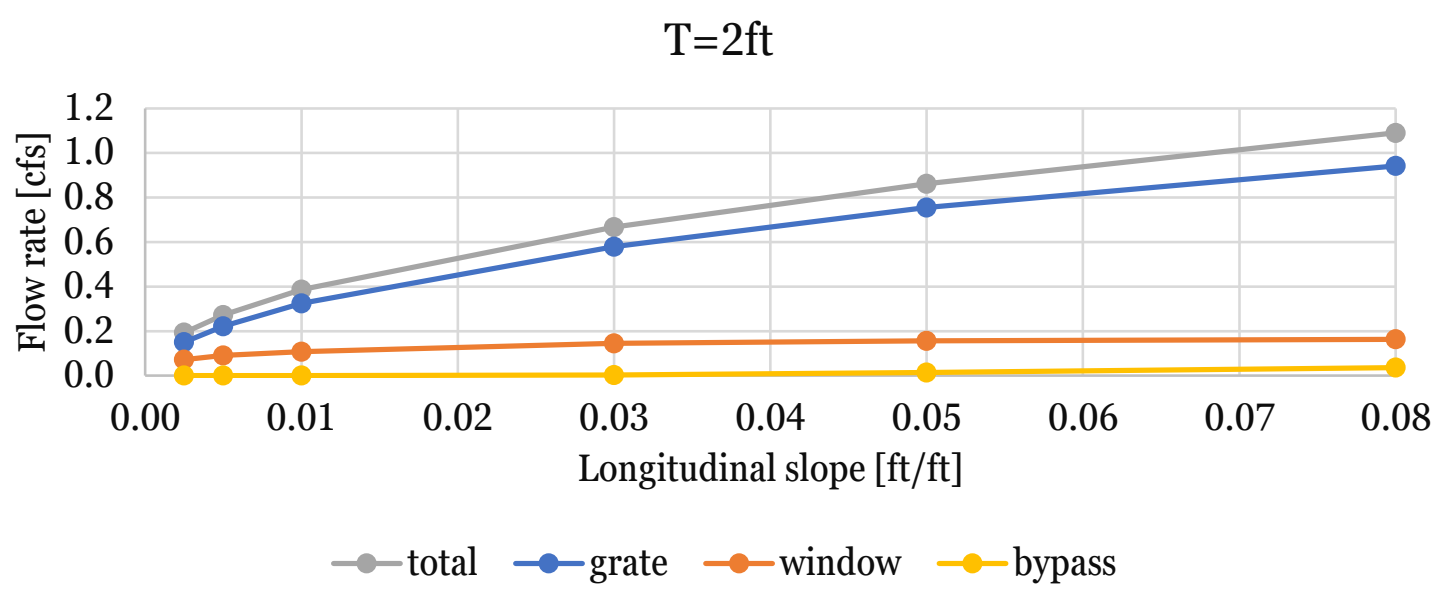

(b)

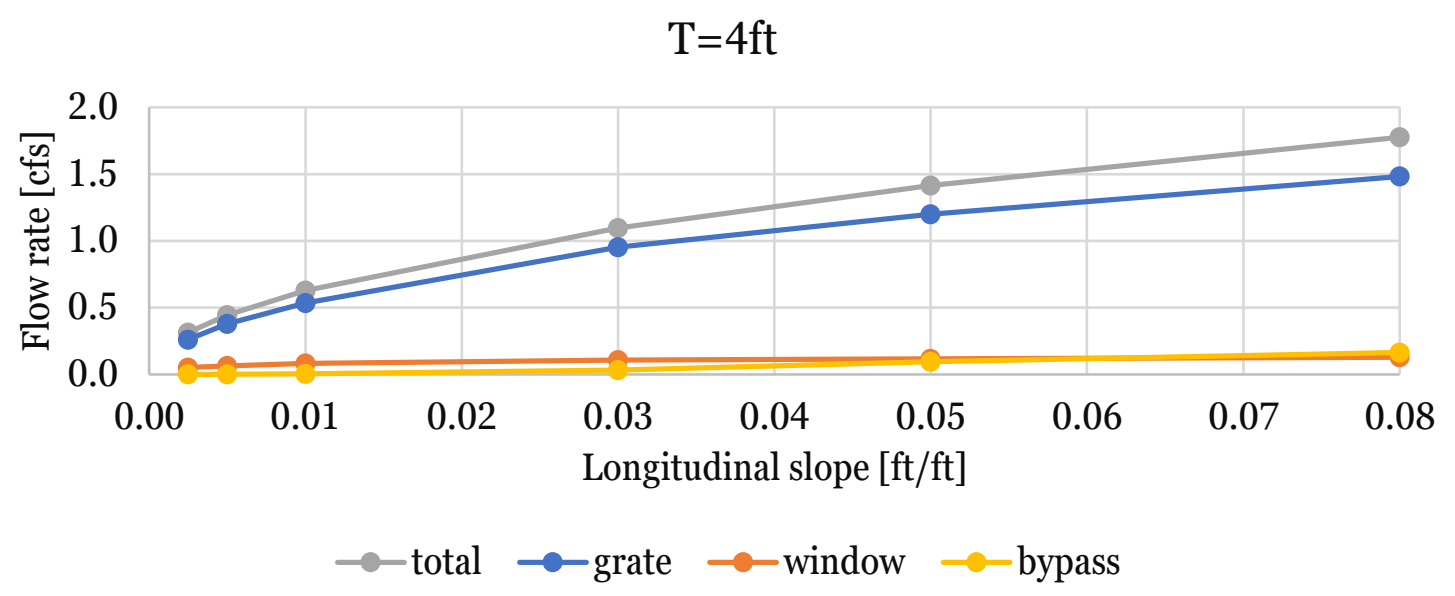

(c)

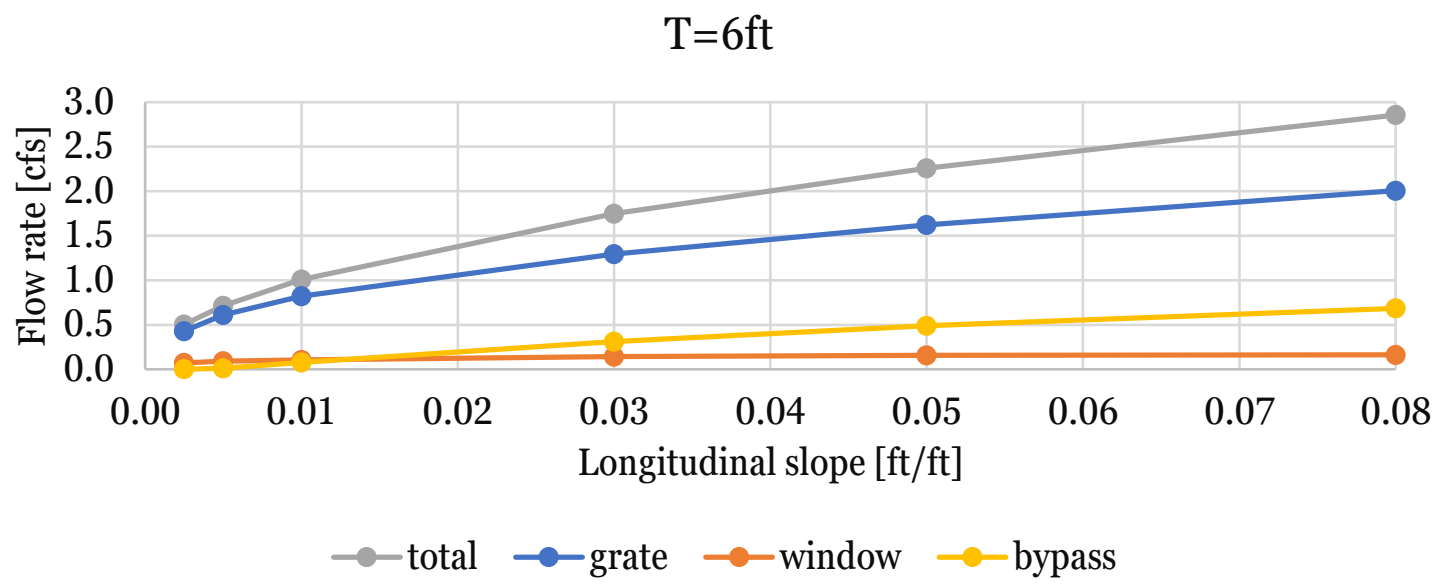

Computational Analysis of Hydraulic Capacity of Ohio DOT Catch Basins On-Grade and in Sag Locations

Page | 88 
(d)

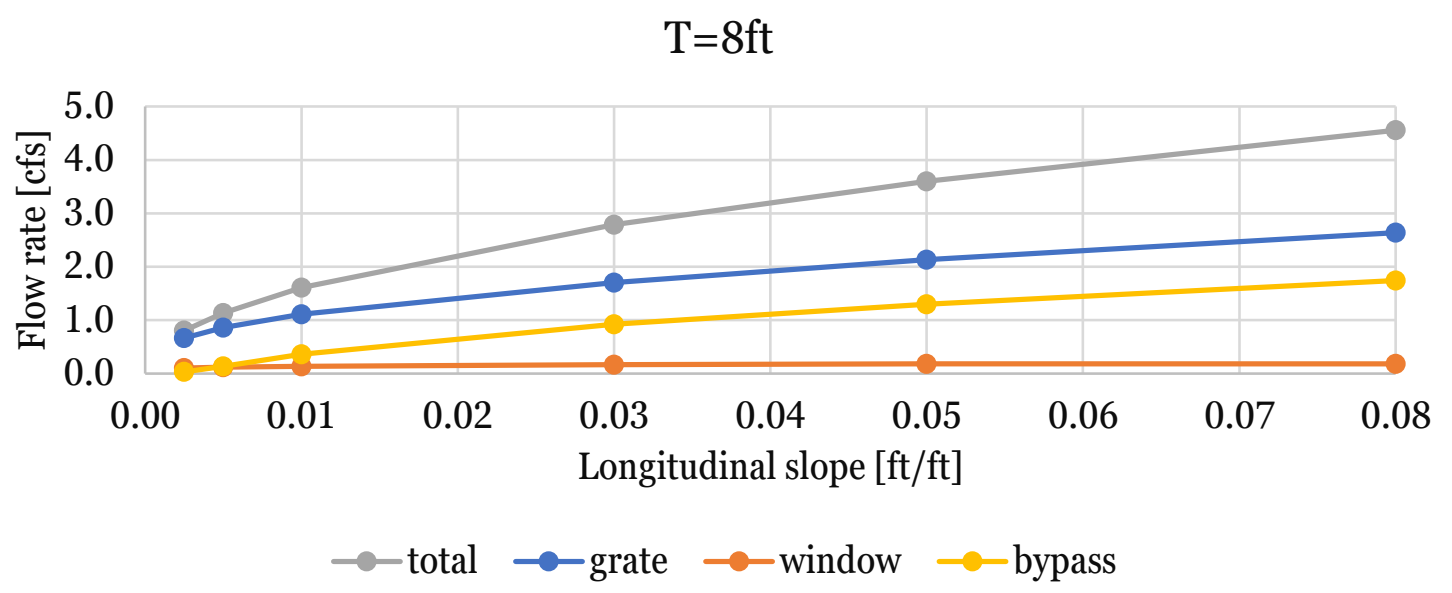

(e)

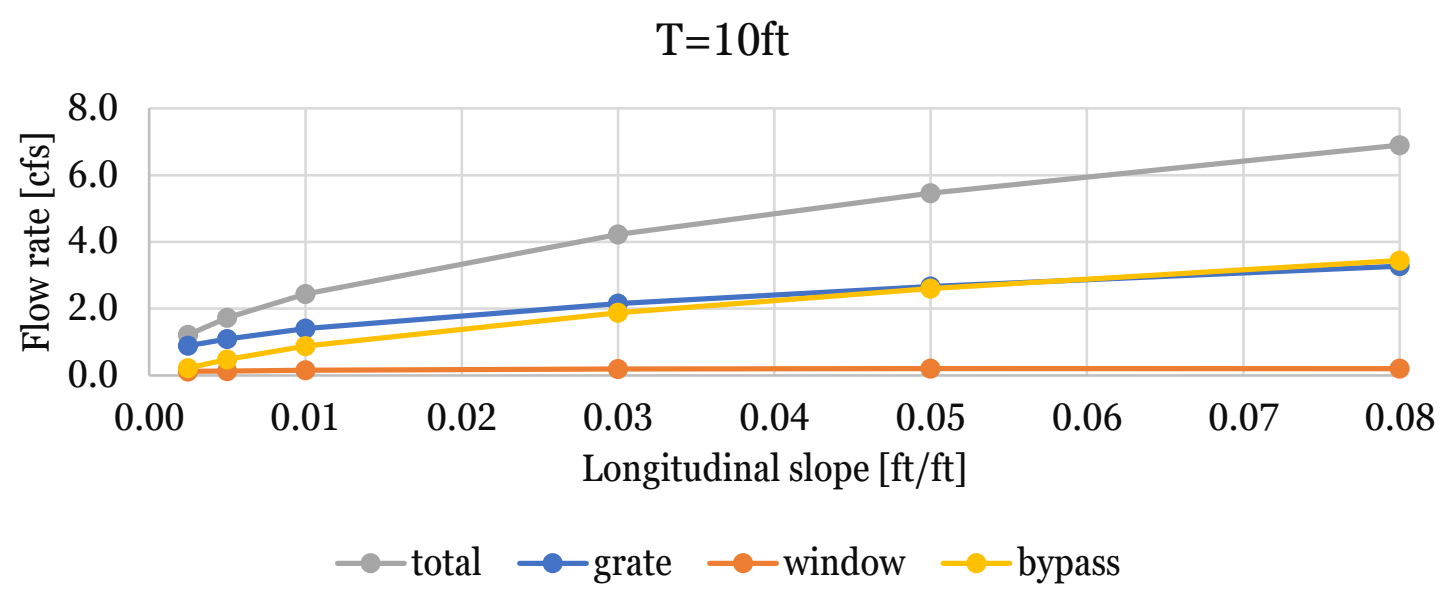

Figure 10.1 Two-foot-wide curb and gutter. Total, grate, window, and bypass discharge vs. longitudinal profile grade for flow spread: (a) $2 \mathrm{ft}$, (b) $4 \mathrm{ft}$, (c) $6 \mathrm{ft}$, (d) $8 \mathrm{ft}$, (e) $10 \mathrm{ft}$.

(a)

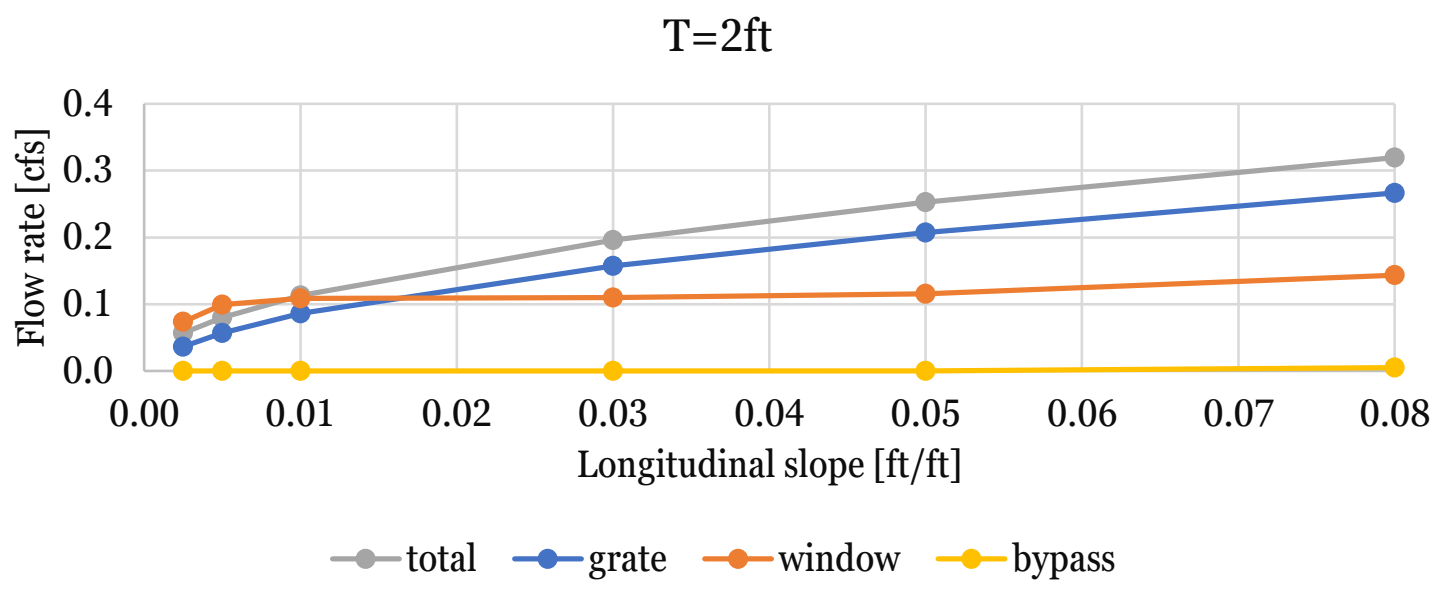

Computational Analysis of Hydraulic Capacity of Ohio DOT Catch Basins On-Grade and in Sag Locations

Page | 89 
(b)

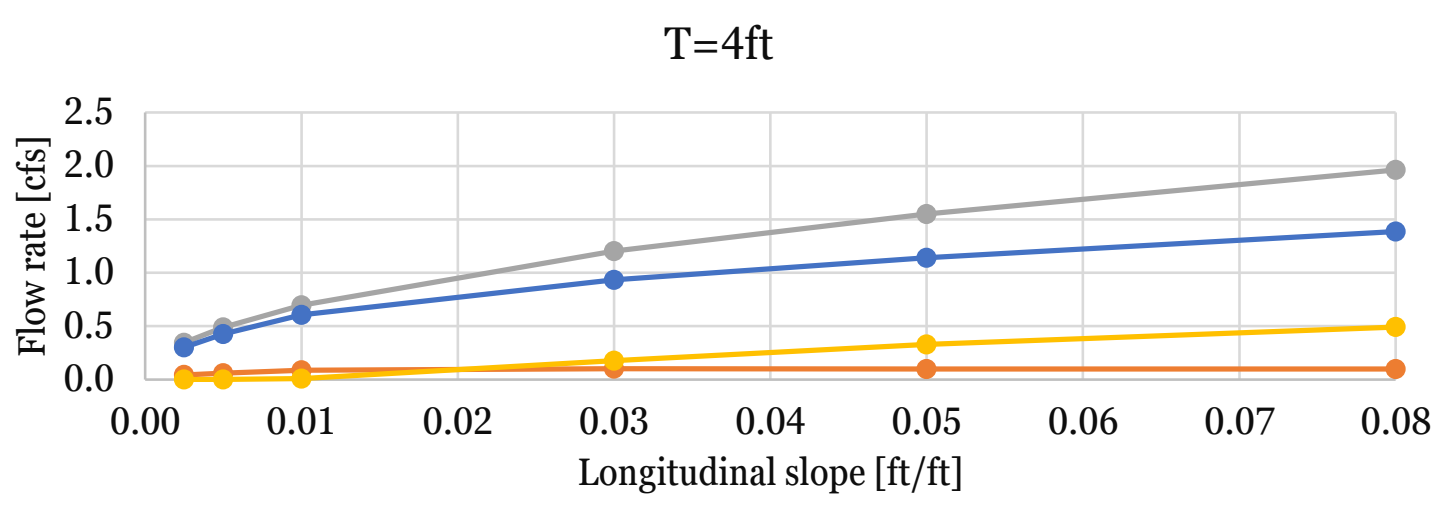

$\multimap$ total $\rightarrow$ grate $\rightarrow$-window $\multimap-$ bypass

(c)

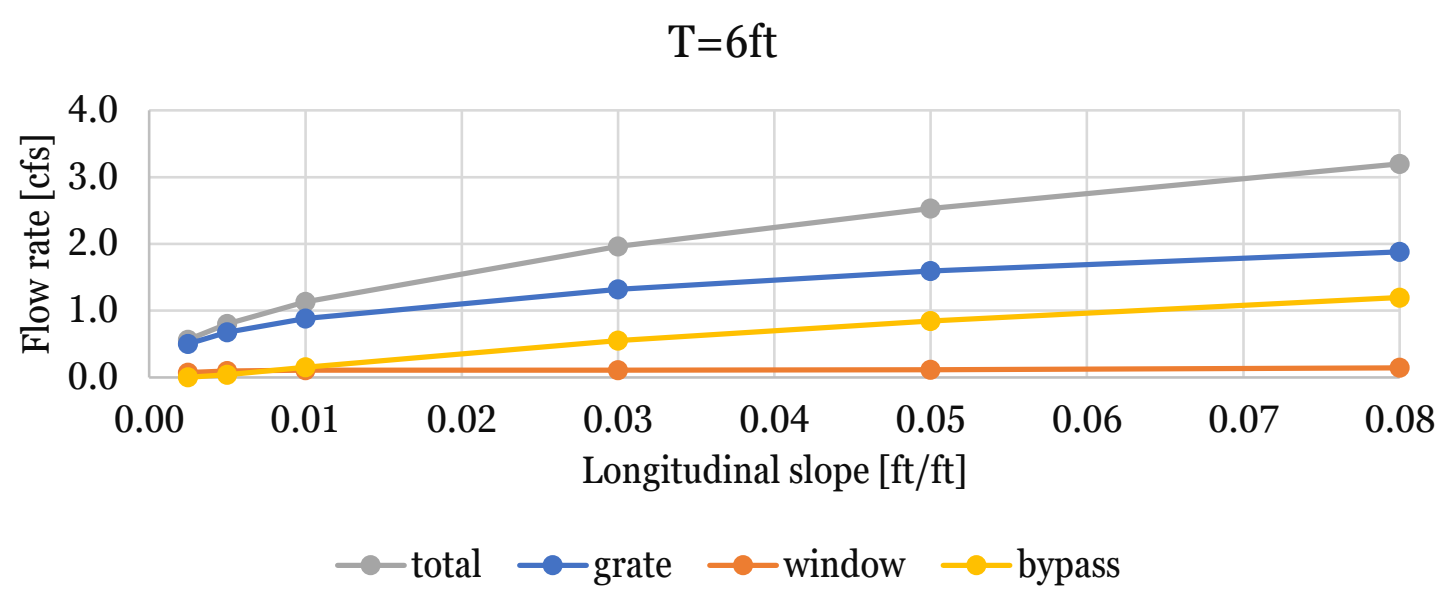

(d)

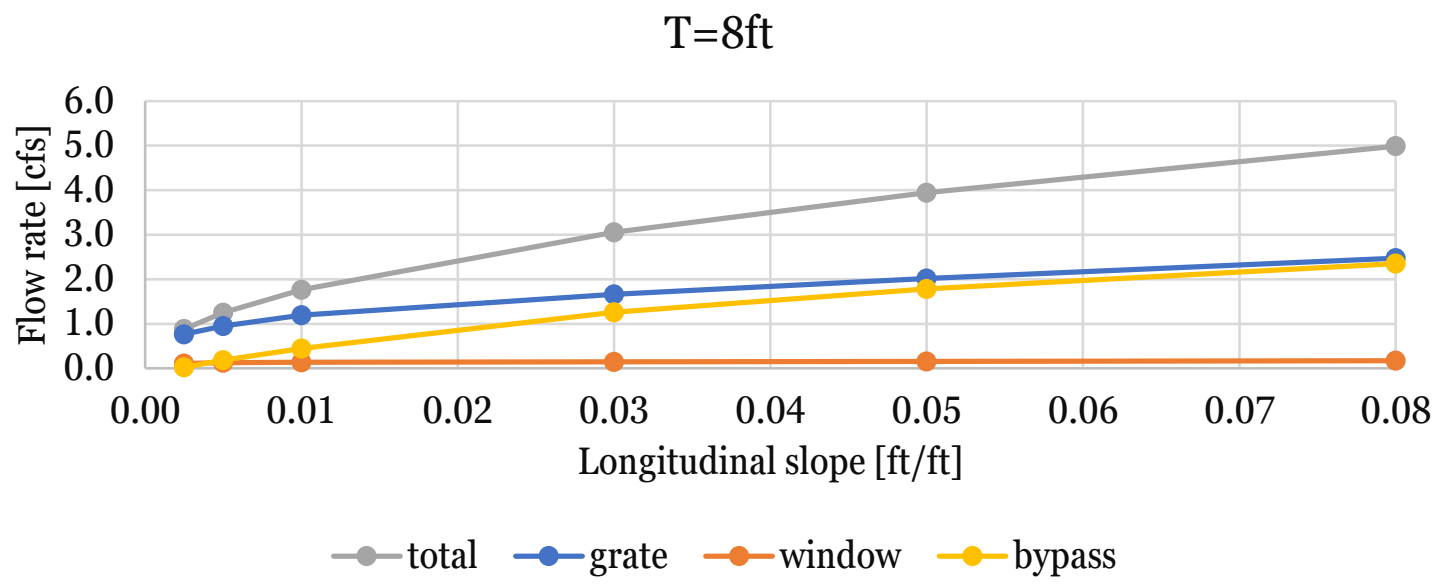

Computational Analysis of Hydraulic Capacity of Ohio DOT Catch Basins On-Grade and in Sag Locations 
(e)

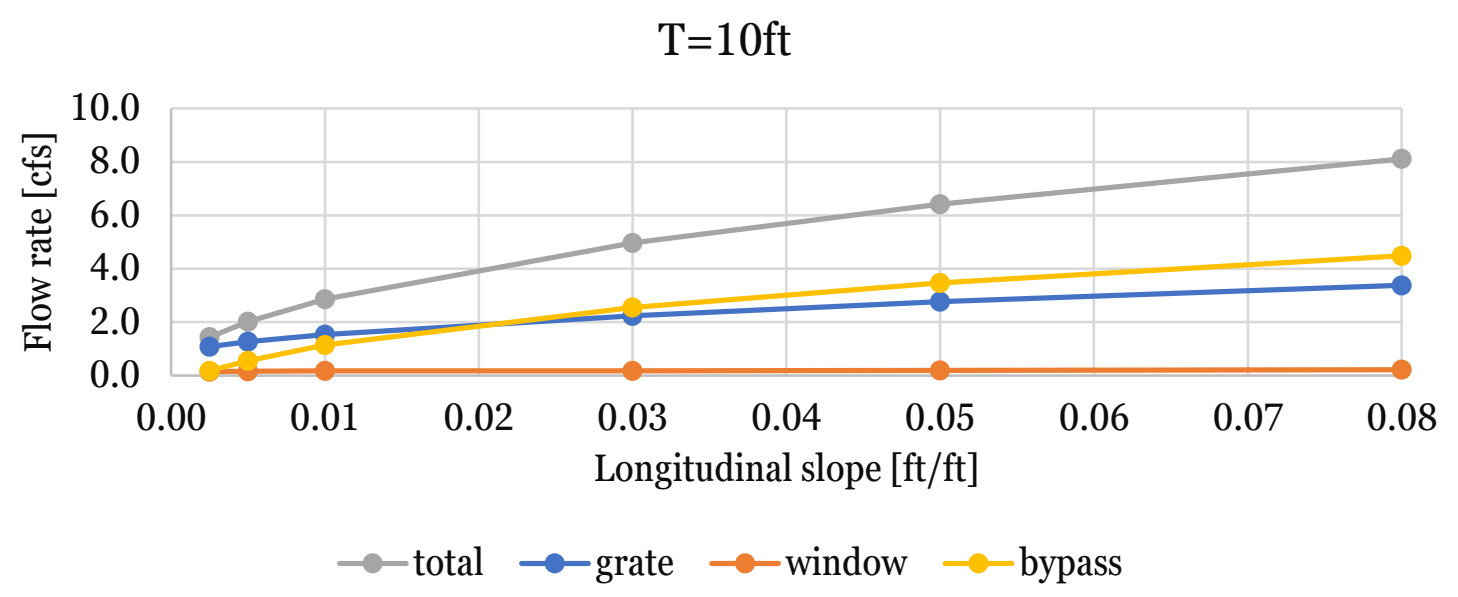

Figure 10.2 Four-foot-wide shoulder. Total, grate, window, and bypass discharge vs. longitudinal profile grade for flow spread: (a) $2 \mathrm{ft}$, (b) $4 \mathrm{ft}$, (c) $6 \mathrm{ft}$, (d) $8 \mathrm{ft}$, (e) $10 \mathrm{ft}$.

(a)

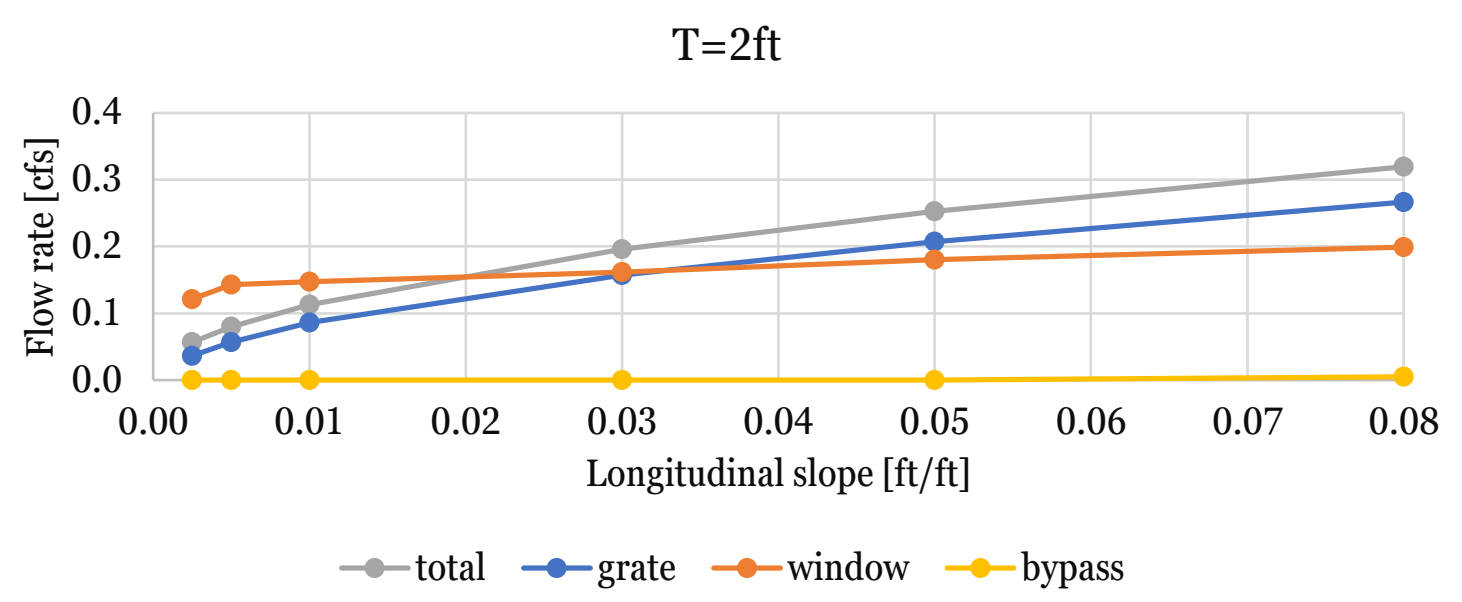

(b)

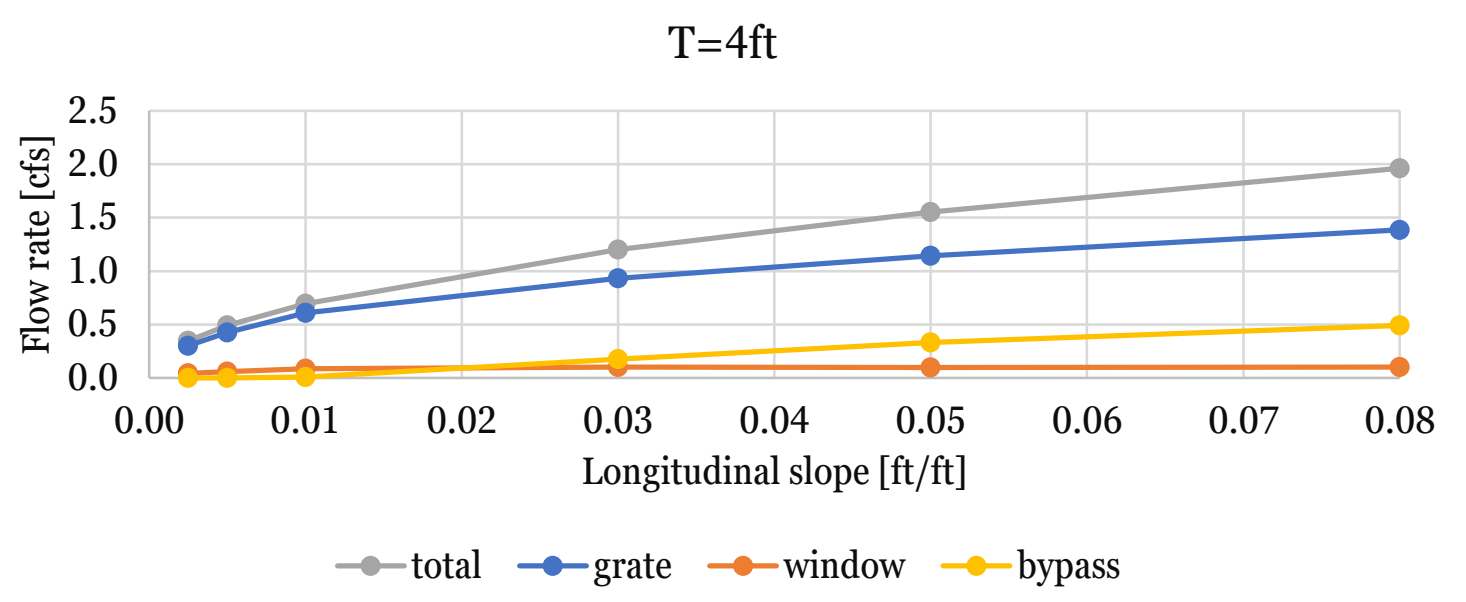

Computational Analysis of Hydraulic Capacity of Ohio DOT Catch Basins On-Grade and in Sag Locations

Page | 91 
(c)

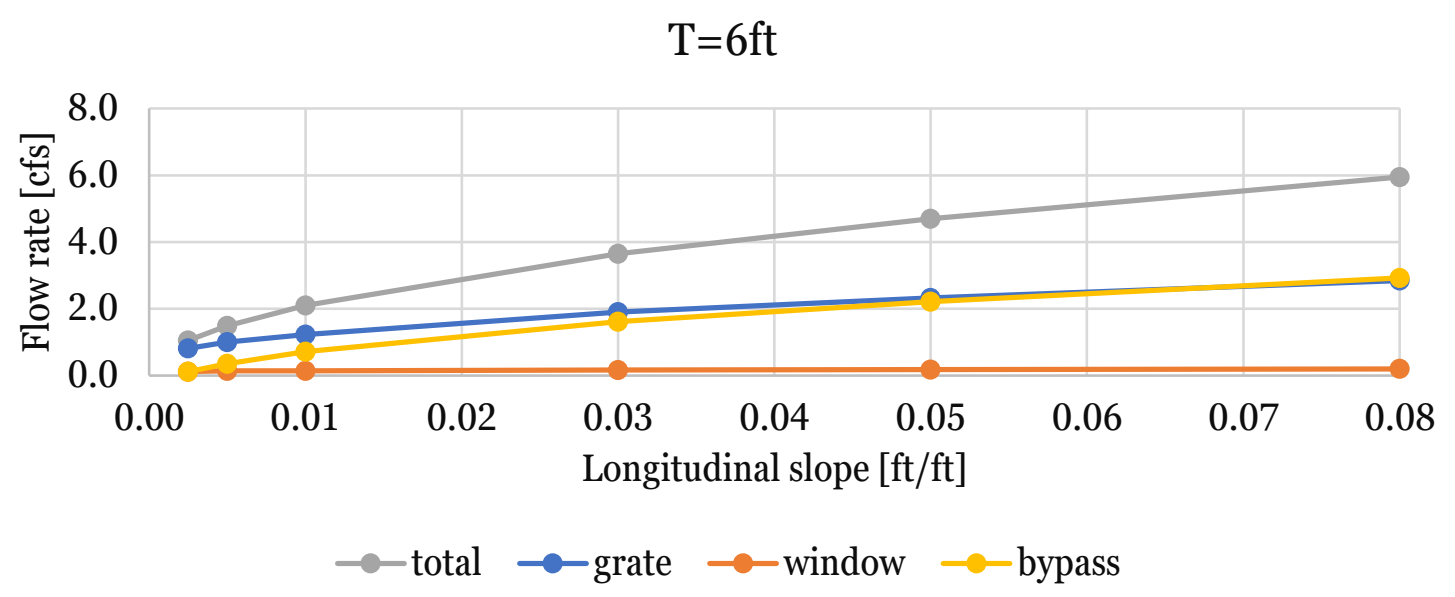

(d)

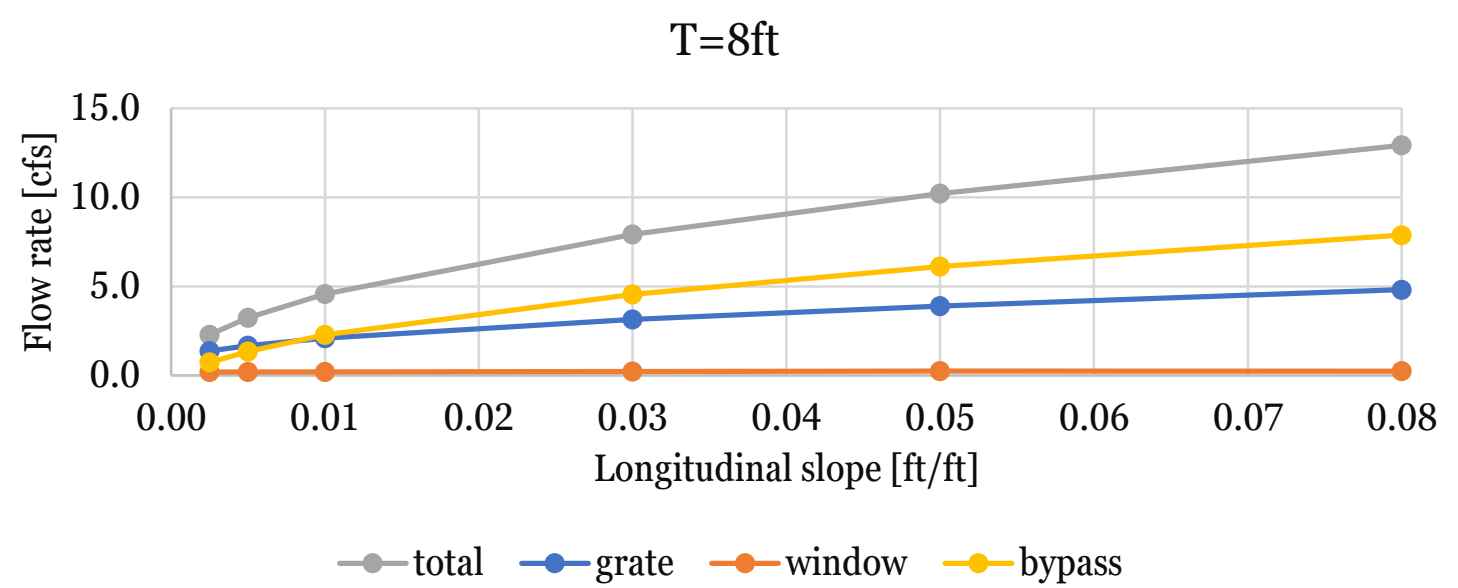

(e)

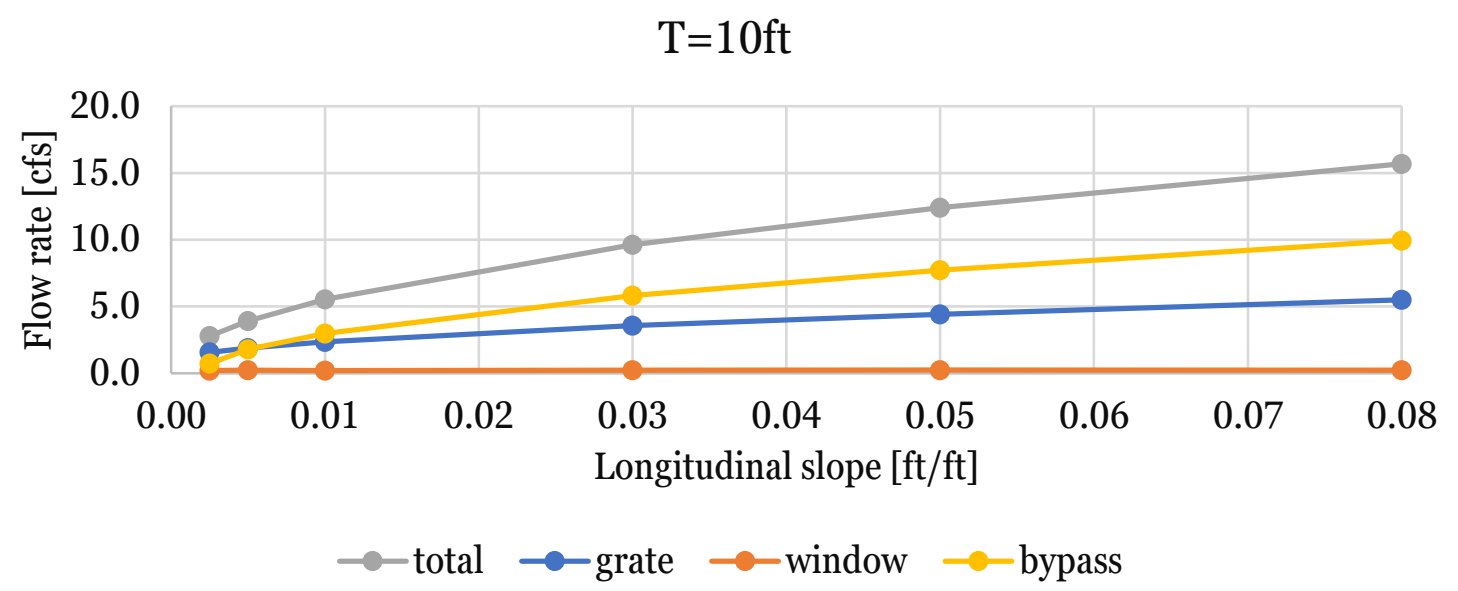

Figure 10.3 Eight-foot-wide shoulder. Total, grate, window, and bypass discharge vs. longitudinal profile grade for flow spread: (a) $2 \mathrm{ft}$, (b) $4 \mathrm{ft}$, (c) $6 \mathrm{ft}$, (d) $8 \mathrm{ft}$, (e) $10 \mathrm{ft}$.

Computational Analysis of Hydraulic Capacity of Ohio DOT Catch Basins On-Grade and in Sag Locations 
Table 10-1 Efficiency, Front, Side and Bypass Flow Rates for Catch Basin No. 3A in on-Grade Locations

\begin{tabular}{|c|c|c|c|c|c|c|c|c|c|c|c|c|c|c|c|c|c|c|c|c|}
\hline \multicolumn{21}{|c|}{2 Foot Composite Curb and Gutter at $8.33 \%$ \& Pavement at $1.6 \%$} \\
\hline \multicolumn{21}{|c|}{ Discharge (cfs) } \\
\hline \begin{tabular}{|l|} 
Long. \\
slope
\end{tabular} & Bypass & Frontal & Side & Eff \% & Bypass & Frontal & Side & Eff \% & Bypass & Frontal & Side & Eff \% & Bypass & Frontal & Side & Eff \% & Bypass & Frontal & Side & Eff \% \\
\hline 0.25 & 0.00 & 0.19 & 0.00 & $100 \%$ & 0.00 & 0.31 & 0.01 & $100 \%$ & 0.00 & 0.45 & 0.05 & $100 \%$ & 0.03 & 0.63 & 0.14 & $96 \%$ & 0.22 & 0.81 & 0.20 & $96 \%$ \\
\hline 0.50 & 0.00 & 0.27 & 0.00 & $100 \%$ & 0.00 & 0.41 & 0.03 & $99 \%$ & 0.01 & 0.60 & 0.10 & $98 \%$ & 0.14 & 0.82 & 0.16 & $86 \%$ & 0.48 & 1.00 & 0.22 & $86 \%$ \\
\hline 1.00 & 0.00 & 0.38 & 0.01 & $100 \%$ & 0.00 & 0.55 & 0.07 & $98 \%$ & 0.08 & 0.81 & 0.12 & $92 \%$ & 0.36 & 1.07 & 0.18 & $78 \%$ & 0.87 & 1.29 & 0.26 & $78 \%$ \\
\hline 3.00 & 0.00 & 0.63 & 0.03 & $99 \%$ & 0.03 & 0.96 & 0.10 & $97 \%$ & 0.31 & 1.29 & 0.14 & $82 \%$ & 0.92 & 1.67 & 0.21 & $67 \%$ & 1.88 & 2.05 & 0.29 & $67 \%$ \\
\hline 5.00 & 0.01 & 0.81 & 0.04 & $98 \%$ & 0.10 & 1.21 & 0.11 & $93 \%$ & 0.49 & 1.62 & 0.15 & $79 \%$ & 1.30 & 2.09 & 0.22 & $64 \%$ & 2.60 & 2.57 & 0.30 & $64 \%$ \\
\hline 8.00 & 0.04 & 1.01 & 0.05 & $97 \%$ & 0.16 & 1.50 & 0.12 & $91 \%$ & 0.68 & 2.01 & 0.16 & $76 \%$ & 1.74 & 2.59 & 0.23 & $62 \%$ & 3.44 & 3.15 & 0.32 & $62 \%$ \\
\hline & \multicolumn{4}{|c|}{2} & \multicolumn{4}{|c|}{4} & \multicolumn{4}{|c|}{6} & \multicolumn{4}{|c|}{8} & \multicolumn{4}{|c|}{10} \\
\hline \multicolumn{21}{|c|}{ Pavement Spread (ft) } \\
\hline \multicolumn{21}{|c|}{4 Foot Shoulder at $4 \%$ \& Pavement at $1.6 \%$} \\
\hline \multicolumn{21}{|c|}{ Discharge (cfs) } \\
\hline $\begin{array}{l}\text { Long. } \\
\text { slope }\end{array}$ & Bypass & Frontal & Side & Eff \% & Bypass & Frontal & Side & Eff \% & Bypass & Frontal & Side & Eff \% & Bypass & Frontal & Side & Eff \% & Bypass & Frontal & Side & Eff \% \\
\hline 0.25 & 0.00 & 0.06 & 0.00 & $100 \%$ & 0.00 & 0.28 & 0.07 & $100 \%$ & 0.00 & 0.44 & 0.14 & $100 \%$ & 0.03 & 0.62 & 0.26 & $99 \%$ & 0.18 & 0.85 & 0.38 & $86 \%$ \\
\hline 0.50 & 0.00 & 0.08 & 0.00 & $100 \%$ & 0.00 & 0.37 & 0.11 & $100 \%$ & 0.04 & 0.58 & 0.19 & $97 \%$ & 0.18 & 0.78 & 0.29 & $86 \%$ & 0.56 & 1.05 & 0.40 & $71 \%$ \\
\hline 1.00 & 0.00 & 0.11 & 0.00 & $100 \%$ & 0.01 & 0.55 & 0.15 & $100 \%$ & 0.15 & 0.77 & 0.22 & $88 \%$ & 0.45 & 1.02 & 0.31 & $75 \%$ & 1.14 & 1.29 & 0.42 & $60 \%$ \\
\hline 3.00 & 0.00 & 0.19 & 0.00 & $100 \%$ & 0.18 & 0.86 & 0.17 & $86 \%$ & 0.55 & 1.18 & 0.25 & $73 \%$ & 1.26 & 1.51 & 0.30 & $59 \%$ & 2.55 & 1.99 & 0.43 & $49 \%$ \\
\hline 5.00 & 0.00 & 0.25 & 0.00 & $100 \%$ & 0.33 & 1.07 & 0.17 & $80 \%$ & 0.84 & 1.45 & 0.26 & $67 \%$ & 1.79 & 1.88 & 0.30 & $55 \%$ & 3.47 & 2.51 & 0.44 & $46 \%$ \\
\hline 8.00 & 0.00 & 0.31 & 0.00 & $99 \%$ & 0.49 & 1.31 & 0.17 & $76 \%$ & 1.20 & 1.77 & 0.25 & $63 \%$ & 2.35 & 2.35 & 0.30 & $53 \%$ & 4.49 & 3.14 & 0.47 & $44 \%$ \\
\hline & \multicolumn{4}{|c|}{2} & \multicolumn{4}{|c|}{4} & \multicolumn{4}{|c|}{6} & \multicolumn{4}{|c|}{8} & \multicolumn{4}{|c|}{10} \\
\hline \multicolumn{21}{|c|}{ Pavement Spread (ft) } \\
\hline
\end{tabular}




\begin{tabular}{|c|c|c|c|c|c|c|c|c|c|c|c|c|c|c|c|c|c|c|c|c|}
\hline \multicolumn{21}{|c|}{8 Foot Shoulder at 4\% \&Pavement at $1.6 \%$} \\
\hline \multicolumn{21}{|c|}{ Discharge (cfs) } \\
\hline \begin{tabular}{|l|} 
Long. \\
slope
\end{tabular} & Bypass & Frontal & Side & Eff \% & Bypass & Frontal & Side & Eff \% & Bypass & Frontal & Side & 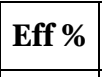 & Bypass & Frontal & Side & Eff \% & Bypass & Frontal & Side & Eff \% \\
\hline 0.25 & 0.00 & 0.06 & 0.00 & $100 \%$ & 0.00 & 0.28 & 0.07 & $100 \%$ & 0.12 & 0.70 & 0.24 & $89 \%$ & 0.73 & 1.17 & 0.40 & $68 \%$ & 1.01 & 1.32 & 0.45 & $64 \%$ \\
\hline 0.50 & 0.00 & 0.08 & 0.00 & $100 \%$ & 0.00 & 0.37 & 0.11 & $99 \%$ & 0.35 & 0.88 & 0.27 & $77 \%$ & 1.35 & 1.44 & 0.45 & $58 \%$ & 1.80 & 1.61 & 0.52 & $54 \%$ \\
\hline 1.00 & 0.00 & 0.11 & 0.00 & $100 \%$ & 0.01 & 0.55 & 0.15 & $100 \%$ & 0.72 & 1.09 & 0.28 & $65 \%$ & 2.29 & 1.76 & 0.52 & $50 \%$ & 2.98 & 1.98 & 0.60 & $46 \%$ \\
\hline 3.00 & 0.00 & 0.19 & 0.00 & $100 \%$ & 0.18 & 0.86 & 0.17 & $86 \%$ & 1.62 & 1.72 & 0.34 & $57 \%$ & 4.55 & 2.77 & 0.60 & $43 \%$ & 5.82 & 3.12 & 0.69 & $40 \%$ \\
\hline 5.00 & 0.00 & 0.25 & 0.00 & $100 \%$ & 0.33 & 1.07 & 0.17 & $80 \%$ & 2.21 & 2.15 & 0.36 & $53 \%$ & 6.11 & 3.51 & 0.63 & $40 \%$ & 7.73 & 3.96 & 0.69 & $38 \%$ \\
\hline \multirow[t]{2}{*}{8.00} & 0.00 & 0.31 & 0.00 & $99 \%$ & 0.49 & 1.31 & 0.17 & $76 \%$ & 2.93 & 2.66 & 0.38 & $51 \%$ & 7.88 & 4.40 & 0.65 & $39 \%$ & 9.95 & 4.99 & 0.76 & $37 \%$ \\
\hline & \multicolumn{4}{|c|}{2} & \multicolumn{4}{|c|}{4} & \multicolumn{4}{|c|}{6} & \multicolumn{4}{|c|}{8} & \multicolumn{4}{|c|}{10} \\
\hline \multicolumn{21}{|c|}{ Pavement Spread (ft) } \\
\hline
\end{tabular}


Table 10-2 Catch Basin No. 3 - Sump Hydraulic Capacity for Varying Ponding Depth. The type of flow was marked with a letter: (o) for orifice flow, (t) for transition flow, or (w) for weir flow.

\begin{tabular}{|c|c|c|c|}
\hline & \multicolumn{3}{|c|}{ Hydraulic capacity (cfs) } \\
\hline $\begin{array}{c}\text { Ponding depth } \\
{[i n]([\mathrm{ft}])}\end{array}$ & $\begin{array}{c}\text { Grate and } \\
\text { curb opening }\end{array}$ & Grate only & $\begin{array}{c}\text { Curb opening } \\
\text { only }\end{array}$ \\
\hline $\mathbf{1 8 ( 1 . 5 )}$ & $18.0(\mathrm{o})$ & $14.4(\mathrm{o})$ & $5.9(\mathrm{o})$ \\
\hline $\mathbf{1 2 ( 1 . 0 )}$ & $12.4(\mathrm{t})$ & $10.9(\mathrm{t})$ & $4.9(\mathrm{o})$ \\
\hline $\mathbf{6 ( 0 . 5 )}$ & $3.5(\mathrm{w})$ & $3.6(\mathrm{w})$ & $3.0(\mathrm{w})$ \\
\hline $\mathbf{4 ( 0 . 3 3 )}$ & $1.4(\mathrm{w})$ & $1.4(\mathrm{w})$ & $1.6(\mathrm{w})$ \\
\hline $\mathbf{2 ( 0 . 1 6 7 )}$ & $0.1(\mathrm{w})$ & $0.06(\mathrm{w})$ & $0.2(\mathrm{w})$ \\
\hline
\end{tabular}

Computational Analysis of Hydraulic Capacity of Ohio DOT Catch Basins On-Grade and in Sag Locations 


\section{Argonne}

Nuclear Science and Engineering Division

Argonne National Laboratory

9700 South Cass Avenue, Bldg. 208

Argonne, IL 60439-4815

www.anl.gov

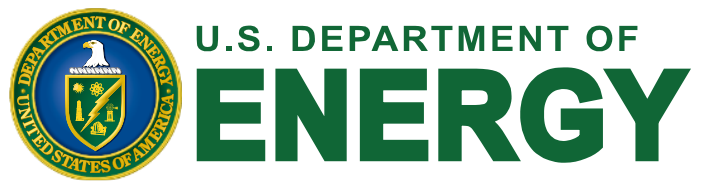

Argonne National Laboratory is a U.S. Department of Energy laboratory managed by UChicago Argonne, LLC

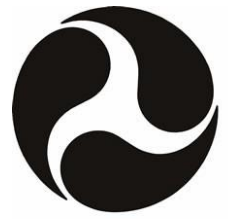

U.S. Department of Transportation

\section{Federal Highway Administration}

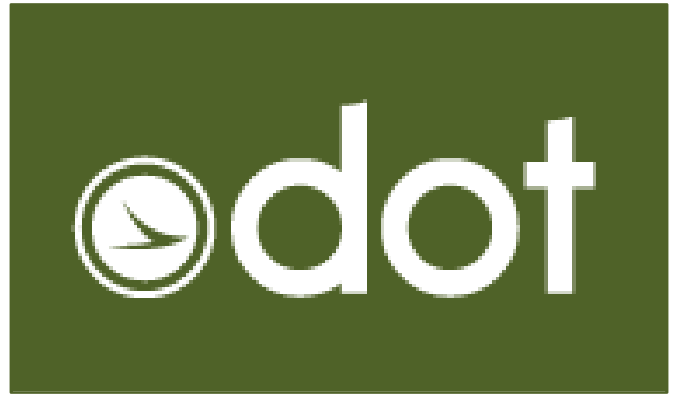

